UNIVERSIDADE DE SÃO PAULO

FACULDADE DE ECONOMIA, ADMINISTRAÇÃO E CONTABILIDADE DEPARTAMENTO DE CONTABILIDADE E ATUÁRIA

PROGRAMA DE PÓS-GRADUAÇÃO EM CONTROLADORIA E CONTABILIDADE

CUSTEIO ALVO À LUZ DA TEORIA DA CONTINGÊNCIA E DA NOVA SOCIOLOGIA INSTITUCIONAL: ESTUDO DE CASO SOBRE SUA ADOÇÃO, IMPLEMENTAÇÃO E USO

Kelly Cristina Mucio Marques

Orientador: Prof. Dr. Welington Rocha

SÃO PAULO 
Prof. Dr. João Grandino Rodas

Reitor da Universidade de São Paulo

Prof. Dr. Reinaldo Guerreiro

Diretor da Faculdade de Economia, Administração e Contabilidade

Prof. Dr. Edgard Bruno Cornacchione Júnior Chefe do Departamento de Contabilidade e Atuária

Profa. Dra. Silvia Pereira de Castro Casa Nova

Coordenadora do Programa de Pós-Graduação em Controladoria e Contabilidade 


\section{CUSTEIO ALVO À LUZ DA TEORIA DA CONTINGÊNCIA E DA NOVA SOCIOLOGIA INSTITUCIONAL: ESTUDO DE CASO SOBRE SUA ADOÇÃO, IMPLEMENTAÇÃO E USO}

Tese apresentada ao Departamento de Contabilidade e Atuária da Faculdade de Economia, Administração e Contabilidade da Universidade de São Paulo, como requisito para obtenção do título de Doutora em Ciências.

Orientador: Prof. Dr. Welington Rocha

\section{Versão Corrigida}

(versão original disponível na Faculdade de Economia, Administração e Contabilidade)

\section{SÃO PAULO}


Marques, Kelly Cristina Mucio

Custeio alvo à luz da teoria da contingência e da nova sociologia institucional: estudo de caso sobre sua adoção, implementação e uso / Kelly Cristina Mucio Marques. -- São Paulo, 2012. $286 \mathrm{p}$.

Tese (Doutorado) - Universidade de São Paulo, 2012.

Orientador: Welington Rocha.

1. Contabilidade gerencial 2. Administração estratégica de custo 3. Sociologia organizacional 4. Estudo de caso I. Universidade de São Paulo. Faculdade de Economia, Administração e Contabilidade. II. Título.

CDD -658.151 
Aos meus pais Maria e Adauto e ao meu marido Claudio, pela compreensão e apoio. 
À DEUS acima de tudo e por tudo...

À toda minha família que sempre me apoiou e incentivou. Pai, mãe, Sandro, Claudio, vocês são meu porto seguro.

Aos meus amigos de longa data e de todas as horas, Alice, Fátima, Hamilton, Massakazu, Marcelo, Moribe, Márcio, pela amizade, pelo incentivo.

Às minhas amigas Suliani e Tatyana agradeço em especial pelos momentos que tivemos de alegrias, descobertas e sofrimento, afinal...não há aprendizado sem dor! Mas, valeu a pena.

Aos meus amigos Rodrigo, Josedilton, Gabriel, Simone, Aládio, Manoel, Kelly, Josué, Luis Paulo, Sheizi, Eric, juntos descobrimos que o caminho para o conhecimento não é fácil, mas que é muito bom ter companhia nessa jornada.

Aos meus novíssimos amigos, Rose, Júlio, Lara, Isabel, Kleber, Humberto, Anderson, Marilu, pena ter conhecido vocês no final do meu percurso.

Ao meu orientador Welington Rocha, por ter acreditado em minha ideia desde o início e por ter permitido o desafio de desenvolver a tese com as abordagens escolhidas. Agradeço também pela disponibilidade e apoio em todas as horas.

Aos professores do EAC, especialmente ao Ari, Gilberto, Frezatti e Edgard, com quem tive maior convívio e que sempre me atenderam prontamente, obrigada.

Ao professor Rafael Alcadipani da FGV-SP, pela experiência e pelas dicas sobre pesquisas qualitativas.

Ao professor David Carter da Roehampton University-Londres pela disponibilidade e interesse em me ajudar e pelo auxílio relativo às abordagens qualitativas, em especial o interpretativismo e a fenomenologia. Embora não tenha usado esta última na tese ficam suas dicas para os trabalhos futuros.

Ao professor João Marcelo Crubellate pela atenção e ideias trocadas.

Ao Carlos Bertucci pelas ideias e discussões.

À todos os meus colegas e amigos de departamento da Universidade Estadual de Maringá, sempre prestativos.

Aos professores da banca de qualificação (Fábio Frezatti e Miguel Juan Bacic) pelas valiosas contribuições, assim como aos professores da banca de defesa.

Aos funcionários da empresa Alfa, em especial o chefe do controle de custos, pela compreensão, pela oportunidade, pela abertura que proporcionou para que as informações necessárias ao andamento da minha pesquisa fossem conseguidas. Agradeço também ao presidente da Alfa pela atenção e disponibilidade. 
Aos funcionários da FEA/EAC, pelo apoio e disponibilidade de sempre.

Agradeço pela oportunidade e pelos momentos de discussões filosóficas, didáticas, científicas e epistemológicas, sejam nas aulas ou outros momentos. Isso ajudou em muito na elaboração e desenvolvimento do meu trabalho. 
"Human action is purposeful behavior." Ludwig von Mises 


\section{RESUMO}

A pesquisa teve como objetivo investigar as deduções e inferências que podem ser extraídas acerca da adoção, implementação e uso do Custeio Alvo à luz da Teoria da Contingência e da Nova Sociologia Institucional. Como estratégia de pesquisa utilizou-se estudo de caso interpretativo em uma subsidiária denominada Alfa, usando técnicas de pesquisa documental e entrevista semi-estruturada, sendo o discurso tratado via análise de conteúdo. Em relação à Teoria da Contingência os achados evidenciaram que o processo do Custeio Alvo é aplicado em todos os projetos de desenvolvimento de produtos, que é uma atividade chave para a Alfa de acordo com suas estratégias, para controlar os custos variáveis considerando o preço de mercado e a margem objetivada pela organização. Quando o produto começa a ser fabricado é feito o acompanhamento entre o esperado e o realizado (com rígido controle de custos via custo padrão, integrado com a avaliação de desempenho e o sistema de compensação), fornecendo evidências da integração e coordenação entre planos, ações e resultados. Poucos dos fatores contingentes presentes na Alfa apresentaram diferença em relação ao que a literatura trata como adequado (estes envolveram a baixa incerteza ambiental, a padronização de produtos e a combinação de estratégias encontrada) e nenhum deles foi considerado inadequado ou com possibilidade de inibir a utilização do Custeio Alvo. Foi verificado o uso do tipo interativo, a satisfação com o Custeio Alvo e a percepção de sua utilidade. As Conclusões foram: o Custeio Alvo é uma prática gerencial compatível com posturas estratégicas conservadoras, como defensora e mantenedora, e que essa opção não conflita com a postura de diferenciação; é difícil senão impossível estabelecer, a priori, correlações, biunívocas ou não, entre o uso de determinadas práticas de Controle Gerencial e determinadas posturas estratégicas; necessidade de analisar o fator incerteza ambiental juntamente com outros fatores. Em relação à Nova Sociologia Institucional as análises indicaram que o mecanismo coercitivo foi o responsável pela adoção do Custeio Alvo na Alfa e as evidências mostraram uma associação entre a estrutura e as ações (resposta do tipo coupling) ressaltando o perfil cognitivo, indicando uma estreita relação entre meios e fins e uma consistência da prática com os valores e crenças da organização. As evidências apontaram que o aspecto econômico embasou a forma de interpretação resultando na crença sobre a validade técnica do Custeio Alvo. Uma das conclusões relacionadas à investigação do processo de institucionalização foi que nos casos em que a difusão se apresenta eminentemente da forma coercitiva, os mitos, as regras e as normas institucionais podem determinar a estrutura, mas não necessariamente as rotinas. As evidências apontaram que a mudança nas rotinas depende da interpretação que os atores fazem das mesmas, construindo as respostas de modo a acomodar as conveniências e interesses tanto do ambiente externo quanto interno. Esta conclusão difere dos estudos de Nor-Aziah e Scapens (2007) e Siti-Nabiha e Scapens (2005). Os resultados na Alfa sugerem que a rotina (e não a estrutura) parece ser alvo de mudança quando a interpretação da instituição levar ao entendimento e à significação com base em sua validade técnica e não em sua validade simbólica. Por isso, o significado das instituições em contextos específicos depende da interpretação e da agência dos atores envolvendo os interesses e pressões sofridas. Uma das implicações desse raciocínio é que mesmo tendo suas bases fundamentadas na obtenção de eficiência, as práticas da Contabilidade podem não ser entendidas e significadas dessa forma em todas as organizações e outros fatores como os institucionais e as características da organização podem influenciar essa interpretação. Em relação aos achados com base na Nova Sociologia Institucional, destaca-se a originalidade do uso da abordagem recursiva nos estudos sobre os Sistemas de Controle Gerenciais, e mais especificamente da Contabilidade Gerencial e do Custeio Alvo, tanto no Brasil quanto no exterior. 


\begin{abstract}
The objective of the research was to investigate the assumptions and inferences that can be made regarding the adoption, implementation and use of Target Costing in light of the Contingency Theory and New Institutional Sociology. The research strategy consisted of an interpretive case study at a subsidiary named Alfa, using document research techniques and semi-structured interviews; discourse was treated using content analysis. With regard to Contingency Theory, the findings evidenced that the process of Target Costing is applied in all product development projects, which are a key activity for Alfa according to its strategies, in order to control variable costs considering market price and the margin desired by the organization. As product manufacture begins, there is monitoring of expected and actually realized results (with strict cost control through standard cost, integrated with performance evaluation and the compensation system), thus evidencing the integration and coordination between plans, actions and results. Few of the contingency factors present in Alfa showed differences from what the literature regards as adequate (they involved low environmental uncertainty, product standardization, and the combination of strategies found herein) and none were considered inadequate or capable of inhibiting the use of Target Costing. The study assessed the use of interactive typing, satisfaction with Target Costing and the perception of its usefulness. As conclusions: Target Costing is a management practice consistent with conservative strategic postures as defender and hold, and this option does not conflict with the posture of differentiation; it is difficult if not impossible to establish a priori correlations, biunivocal or not, between the use of certain Management Control practices and certain strategic postures; it's necessary to analyze the environmental uncertainty factor along with other factors. With regard to New Institutional Sociology, the analyses indicated that the coercive mechanism was responsible for the adoption of Target Costing at Alfa, and evidence showed an association between structure and actions (coupling-like response), highlighting the cognitive profile, indicating a close relationship between means and ends, as well as a consistency of practice with the values and beliefs of the organization. Evidence indicated that the economic aspect was the basis for the manner of interpretation, resulting in belief towards the technical validity of Target Costing. One of the conclusions related to the investigation into the institutionalization process was that in the cases in which diffusion is presented eminently in a coercive fashion, institutional myths, rules and norms can determine the structure but not necessarily the routines. Evidence showed that changes in routine depend on the interpretation the actors make about them, building their responses so as to accommodate the conveniences and interests of both inner and outer environments. This conclusion differs from the studies by Nor-Aziah \& Scapens (2007) and Siti-Nabiha \& Scapens (2005). The results obtained at Alfa suggest that the routine (and not the structure) seems to be the target for change whenever the interpretation by the institution leads to understanding and signification based on technical rather than symbolic validity. Therefore, the meaning of institutions within specific contexts depends on the interpretation and agency of the actors involving the interests and pressures they withstand. One of the implications of this reasoning is that even though Accounting practices are based on achieving efficiency, they may not be understood and signified as such in all organizations, and that other factors (such as institutional ones and characteristics of each organization) can influence that interpretation. With regard to the findings based on New Institutional Sociology, highlight is given to the originality of using the recursive approach in studies on Management Control Systems, and more specifically in Managerial Accounting and Target Costing, both in Brazil and overseas.
\end{abstract}




\section{SUMÁRIO}

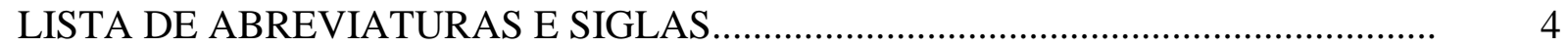

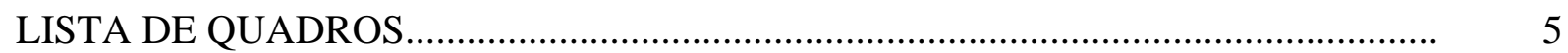

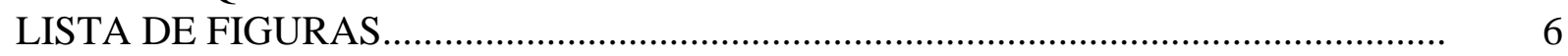

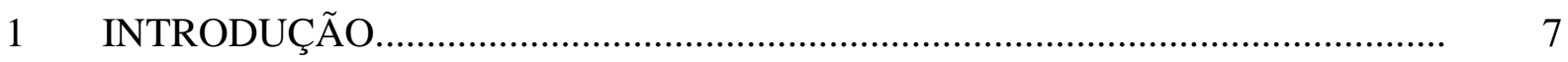

1.1 Contextualização e Caracterização do Problema............................................... 7

1.2 Formulação das Questões de Pesquisa........................................................... $\quad 10$

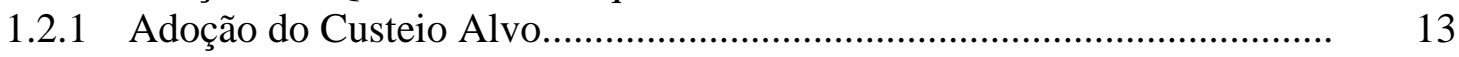

1.2.2 Implementação do Custeio Alvo............................................................. 15

1.2.3 Uso do Custeio Alvo........................................................................... 16

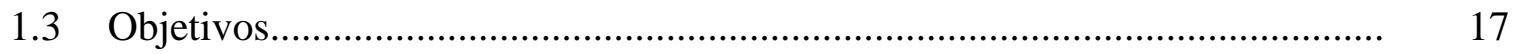

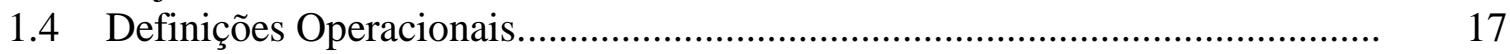

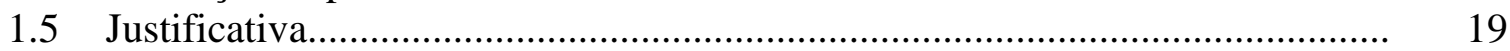

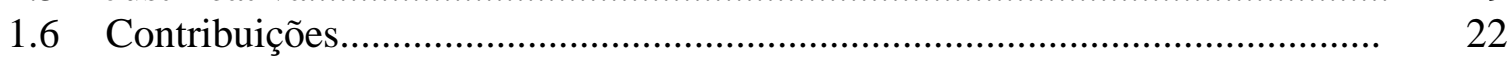

1.7 Delimitações do Estudo Empírico.................................................................. 23

1.8 Estrutura do Trabalho.............................................................................. 25

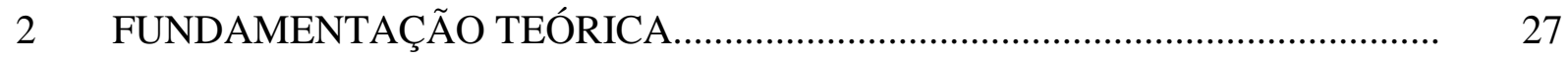

2.1 Teoria da Contingência Estrutural................................................................. 27

2.1.1 Teoria da Contingência e a Contabilidade Gerencial.............................. 29

2.1.2 Aspectos Epistemológicos da Teoria da Contingência............................ 30

2.1.3 O Custeio Alvo e a Teoria da Contingência............................................ 33

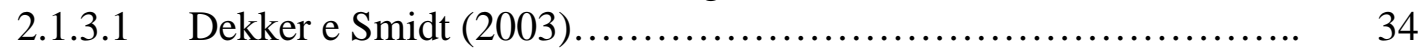

2.1.3.2 Hibbets et al. (2003)...................................... 34

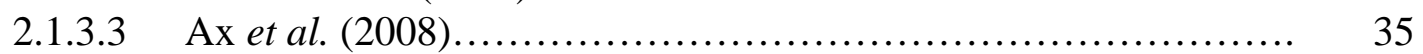

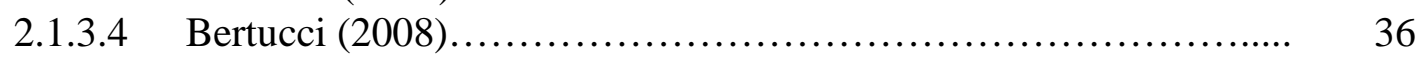

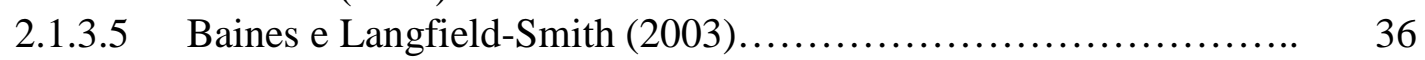

2.1.3.6 Cadez e Guilding (2008).......................................................... 37

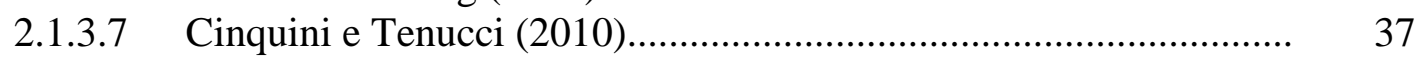

2.1.4 Análise dos Fatores Contingentes e sua Adequação em Relação ao
Custeio Alvo..................................................................................... 39

2.1.4.1 Ambiente............................................................................ 42

2.1.4.2 Estratégia................................................................................ 45

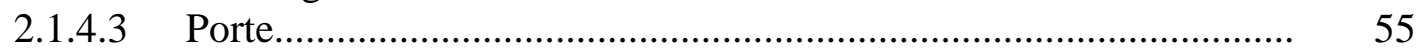

2.1.4.4 Estrutura.................................................................. 56

2.1.4.5 Tecnologia............................................................................... 59

2.1.5 Definições e Medidas dos Fatores Contingentes Avaliados...................... 63

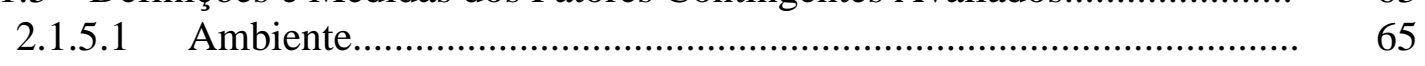

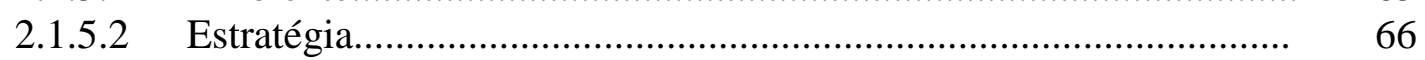

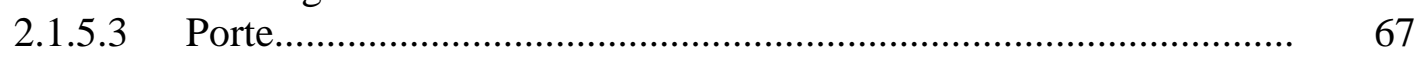

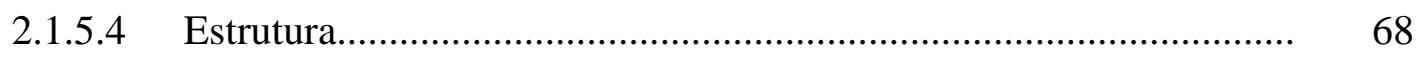

2.1.5.5 Tecnologia............................................................................ 69

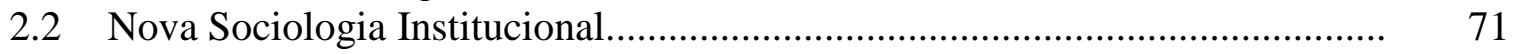

2.2.1 Aspectos Epistemológicos da NSI...................................................... 74

2.2.2 Fundamentos da Nova Sociologia Institucional..................................... 79

2.2.2.1 Instituição e Institucionalização................................................... $\quad 79$

2.2.2.2 Legitimidade........................................................................ 81

2.2.2.3 Decoupling e Loose Coupling...................................................... 83

2.2.2.4 Ambiente Econômico e Ambiente Institucional.............................. 86

2.2.2.5 Mecanismos de Isomorfismo Institucional................................... 88 
2.2.2.6 Nível de Análise.......................................................................... $\quad 90$

2.2.3 Estágios do Processo de Institucionalização................................................ 91

2.2.4 Nova Sociologia Institucional e a Contabilidade Gerencial...................... 98

2.2.5 Conteúdo da Pesquisa Empírica em Relação à NSI................................... 104

3 SISTEMAS DE CONTROLES GERENCIAIS.................................................... 107

3.1 Sistema de Controle Gerencial....................................................................... 107

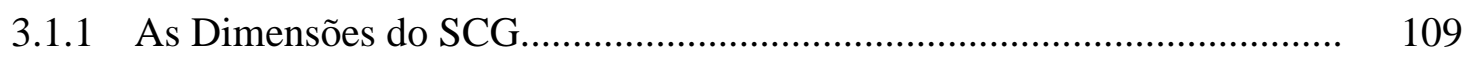

3.1.1.1 Desenho do SCG.......................................................................... 110

3.1.1.2 Uso do Sistema de Controle Gerencial........................................... 112

3.1.1.3 Desempenho em relação ao SCG.................................................. 115

3.1.2 Medidas da Pesquisa quanto às Dimensões Avaliadas............................. 116

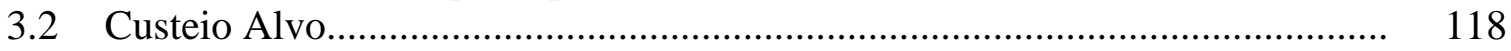

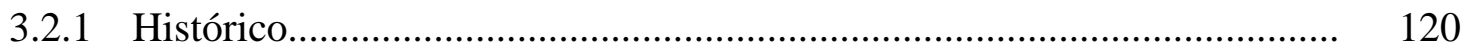

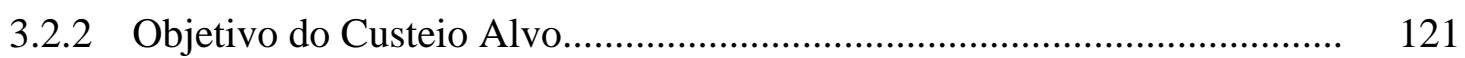

3.2.3 Fundamentos e Características do Custeio Alvo......................................... 123

3.2.4 Definição do Custeio Alvo.................................................................... 127

3.2.5 Processo do Custeio Alvo.................................................................. 130

3.2.6 Características das Informações Extraídas do Processo do Custeio Alvo. 133

3.2.7 Utilização do Custeio Alvo na Prática....................................................... 137

3.2.8 Conteúdo da Pesquisa Empírica em Relação ao Custeio Alvo.................. 139

4 TRAJETÓRIA METODOLÓGICA................................................................. 143

4.1 Delineamento Geral da Pesquisa................................................................. 143

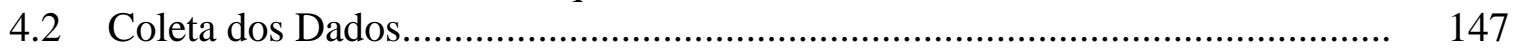

4.2.1 Instrumento de Coleta de Dados............................................................... 151

4.3 Tratamento dos Dados............................................................................... 155

4.4 Aspectos Metodológicos Específicos............................................................. 156

4.4.1 Aspectos Metodológicos Relativos ao Uso da Teoria da Contingência..... 157

4.4.2 Aspectos Metodológicos Relativos ao Uso da NSI.................................. 162

4.5 Análise dos Dados e Resultados da Pesquisa Empírica................................... 166

4.6 Delimitação Temporal e Limitação do Estudo de Caso...................................... 167

5 APRESENTAÇC̃̃O E ANÁLISE DOS RESULTADOS DO ESTUDO DE

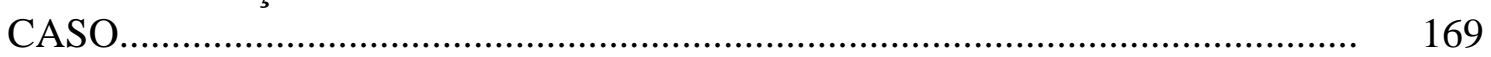

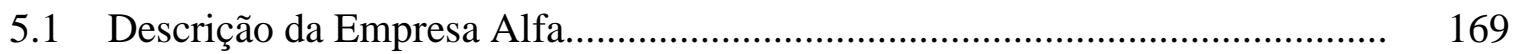

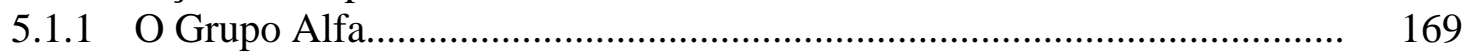

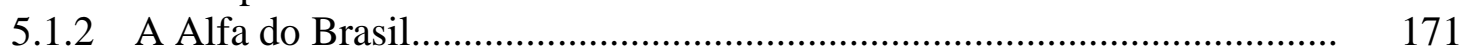

5.2 O Custeio Alvo na Alfa............................................................................ 173

5.3 Análise das Categorias Investigadas à Luz da Teoria da Contingência............ 178

5.3.1 Fatores Contingentes....................................................................... 179

5.3.1.1 Fator Ambiente......................................................................... 179

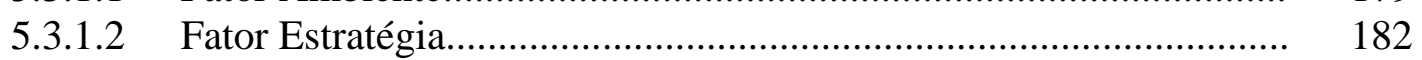

5.3.1.3 Fator Porte ............................................................................ 189

5.3.1.4 Fator Estrutura...................................................................... 189

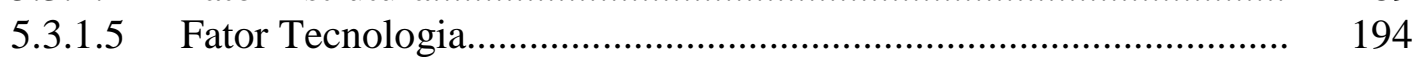

5.3.1.6 Outros Aspectos.......................................................................... 197

5.3.2 Dimensão Uso do Custeio Alvo................................................................ 199

5.3.3 Desempenho do Custeio Alvo................................................................. 202

5.4 Análise das Categorias Investigadas à Luz da NSI...................................... 203

5.4.1 Fatores Institucionais Relacionados à Adoção........................................ 204

5.4.1.1 Mecanismo de Mudança Isomórfica............................................... 204

5.4.1.2 Legitimidade.................................................................. 206 
5.4.2 Fatores Econômicos Relacionados à Adoção.............................................. 208

5.4.3 Implementação do Custeio Alvo.............................................................. 210

5.4.3.1 Estágios do Processo de Institucionalização.................................... 210

5.4.3.2 Influência dos Fatores Institucionais e Econômicos sobre a Resposta Estratégica............................................................. 228

5.4.3.3 Resposta Estratégica................................................................. 232

5.5 Discussões e Análises Gerais do Caso........................................................... 236

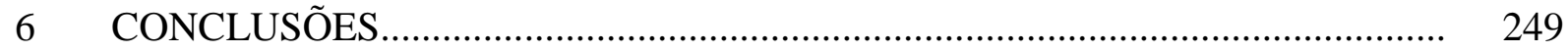

6.1 Conclusões Referentes aos Achados Baseados na Teoria da Contingência. $\quad 249$

6.2 Conclusões Referentes aos Achados Baseados na NSI.................................... 251

6.3 Recomendações para Futuras Pesquisas e para as Organizações...................... 254

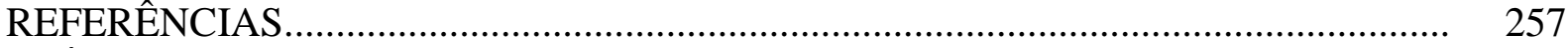

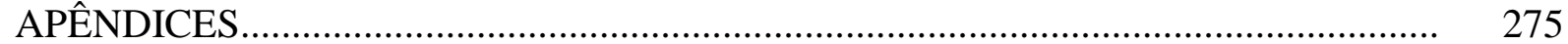




\section{LISTA DE ABREVIATURAS E SIGLAS}

BNDES: Banco Nacional do Desenvolvimento

CAD: Desenho Auxiliado por Computador

CAM: Produção Auxiliada por Computador

CAM-I: Consortium for Advanced Manufacturing-International

CIM: Manufatura Integrada por Computador

ERP: Enterprise Resource Planning

JIT: Just in Time

MAC: Modelo de Alavancas de Controle

NSI: Nova Sociologia Institucional

PCP: Planejamento e Controle da Produção

SCG: Sistema de Controle Gerencial

VE0: Value Engineering Zero

VT1: Value Table One 


\section{LISTA DE QUADROS}

Quadro 1: Resumo das principais pesquisas que relacionam fatores contingentes e 38

Custeio Alvo

Quadro 2: Adequação dos fatores contingentes ao Custeio Alvo.................................. 63

Quadro 3: Classificação de porte de empresa.............................................................. 68

Quadro 4: Matriz de classificação das categorias investigadas.................................... 160

Quadro 5: Resumo da análise dos fatores contingentes............................................... 199

Quadro 6: Resumo dos achados sobre o estágio de objetificação do processo de 225 institucionalização.

Quadro 7: Resumo dos Achados.... 


\section{LISTA DE FIGURAS}

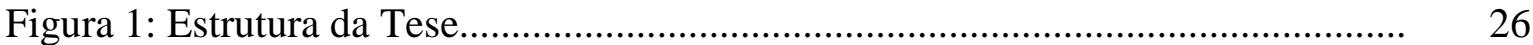

Figura 2: Fatores contingentes investigados........................................................ 41

Figura 3: Estados sociais e formas de objetificação................................................. 92

Figura 4: Estágios do processo de institucionalização................................................ 96

Figura 5: Dimensões avaliadas em relação ao SCG................................................... 117

Figura 6: Processo do Custeio Alvo...................................................................... 132

Figura 7: Modelo Teórico Proposto.......................................................................... 164

Figura 8: Nível hierárquico dos setores dos entrevistados........................................ 173 


\section{INTRODUÇÃO}

\subsection{Contextualização e Caracterização do Problema}

Muitas empresas têm passado por significantes mudanças em seus modelos organizacionais, no ambiente competitivo, nas tecnologias de informação e, devido a esse contexto, alguns especialistas alertaram que para a Contabilidade Gerencial manter sua relevância seria preciso uma adaptação em direção às necessidades dos gestores (CHENHALL; LANGFIELDSMITH, 1998b, KAPLAN, 1984, JOHNSON; KAPLAN, 1987), levando ao entendimento de que tais mudanças implicam na necessidade de mudar a Contabilidade Gerencial (BURNS e VAIVIO, 2001).

Diversas práticas ligadas à Contabilidade Gerencial, focadas em promover a criação de valor (ITTNER; LARCKER, 2001), vêm sendo desenvolvidas com o intuito de tentar adequar suas informações a esse ambiente em constante mudança. Esse desenvolvimento é comumente conhecido como mudança da Contabilidade Gerencial (WICKRAMASINGHE, ALAWATTAGE, 2007). Exemplos dessas práticas são o Custeio Baseado em Atividades, o Balanced Scorecard, o Custeio Alvo, dentre muitas outras. Esses fatos suscitaram o aparecimento de pesquisas interessadas em investigar a mudança de práticas de Contabilidade Gerencial, ou seja, sua introdução nas organizações, como os trabalhos de Scapens (2006); Scapens e Roberts (1993); Lukka (2007); Ma e Tayles (2009); Järvinen (2006); Siti-Nabiha e Scapens (2005); Dillard et al. (2004); Tsamenyi et al. (2006); Nor-Aziah e Scapens (2007); Abrahamsson e Gerdin (2006); Quatrone e Hopper (2001); Ribeiro e Scapens (2006); Soin et al. (2002); Baines e Langfield-Smith, 2003; Abdel-Kader e Luther, 2008; Chong e Chong, 1997; Gerdin, 2005; Cadez e Guilding (2008).

No entanto, ainda existem dúvidas sobre em que circunstâncias essas práticas são adotadas e como são implementadas e usadas pelas organizações em seus sistemas de controle, em especial pelo fato de que a introdução das mesmas não segue um padrão, sendo modeladas de acordo com as características individuais da organização. Nesse sentido, Otley (2001) comenta que empresas que atuam no mesmo ramo de atividade possuindo características semelhantes respondem de formas muito distintas ao uso de tais práticas. Järvinen (2006) pesquisou a adoção e a implementação de um sistema de custeio em duas empresas e os resultados mostraram que somente o nome do custeio era o mesmo; sua estrutura e conteúdo 
eram diferentes em cada empresa. Anderson e Young (1999) relataram a existência de falhas na implementação dessas práticas e mencionaram que, em relação ao Custeio Baseado em Atividades, por exemplo, apenas $10 \%$ das empresas que o adotaram continuavam a utilizá-lo posteriormente.

Os resultados dessas pesquisas mencionadas evidenciam que o processo de mudança relacionado à adoção de uma prática pelas organizações é complexo e envolve inúmeros aspectos que podem dificultar seu entendimento por completo. Scapens (2006) comenta que para entender a diversidade das práticas de Contabilidade Gerencial é necessário compreender a complexa miscelânea de influências inter-relacionadas que modelam as mesmas nas organizações individuais.

Para Baxter e Chua (2003) as práticas de Contabilidade Gerencial emergem como um fenômeno altamente situacional limitado por condições históricas específicas a determinado tempo e lugar, por significados e valores locais, pela racionalidade local encontrada em configurações organizacionais particulares e pelos hábitos individuais dos participantes organizacionais ligados à condução da Contabilidade Gerencial.

Essas limitações atuam de forma a modelar as respostas organizacionais. Com isso, os motivos que influenciaram a adoção dessas práticas em determinada organização podem não ser os mesmos em outra e, ainda, a inter-relação dos fatores envolvidos faz com que existam as diferenças. Desse modo, não basta uma organização adotar tais práticas para atingir os resultados a que as mesmas se propõem; a forma como essas novas ideias são introduzidas e como passam a ser usadas interfere no seu resultado. Granlund (2001) argumenta que apesar da influência das mudanças do mercado e outras que exercem uma enorme pressão para a mudança dos sistemas da contabilidade, estes são difíceis de mudar.

Esse panorama indica a necessidade de entendimento acerca de questões que esclareçam para que finalidade as práticas são adotadas e utilizadas e qual o resultado para a organização. Por que quando as organizações adotam essas práticas as formas de utilização são tão diversas? Qual seria a percepção das organizações em relação à importância dessas práticas? Ma e Tayles (2009) assinalaram que existe uma falta de evidência sobre como essas práticas de Contabilidade Gerencial são adotadas pelas organizações bem como sobre os processos dessas adoções, reforçam ainda que teorizações sobre o processo de adoção dessas práticas são relativamente escassas. 
Por isso, Langfield-Smith (2008) argumenta que entender como essas práticas ganham a atenção dos atores organizacionais e como elas são implementadas e desenvolvidas continua a ser uma fonte interessante de pesquisa. Malmi e Granlund (2009) reforçam que um dos propósitos da pesquisa em Contabilidade Gerencial deveria ser a determinação de quais práticas funcionam e em que circunstâncias e como mudar as práticas nas organizações.

Desta forma, apesar de muitas pesquisas terem investigado a introdução de práticas da Contabilidade Gerencial (conforme mencionado nos parágrafos anteriores) dúvidas sobre como se dá sua adoção e seu funcionamento ainda existem. Decorrente disso, o problema que se apresenta nessa pesquisa é a constatação da necessidade de entendimentos adicionais acerca dos aspectos ligados às motivações para a adoção de práticas da Contabilidade Gerencial pelas organizações e como isso se reflete em seu funcionamento. Isso leva à necessidade de se investigar não somente as razões da adoção, ou seja, quais fatores a influenciaram, mas também os aspectos que permearam sua implementação e como se dá seu uso, ou seja, a forma como a organização lida com a prática. Por isso, seguindo um caminho distinto dos trabalhos referenciados anteriormente, tanto em relação às perspectivas teóricas usadas quanto à consideração de três etapas do processo que envolve a introdução dessas práticas, essa pesquisa pretende contribuir com informações adicionais acerca do problema levantado, investigando na organização objeto do estudo de caso, fatores que podem ter influenciado a adoção, a implementação e como isso se reflete no uso de uma dessas práticas, o Custeio Alvo.

É importante destacar nesse momento que embora o Custeio Alvo esteja sendo relacionado à Contabilidade Gerencial, a proposta dessa pesquisa, conforme apresentada na sequência, é estudá-lo enquanto prática do Sistema de Controle Gerencial (SCG). Isso porque se compartilha da ideia de Chenhall (2007) e Frezatti et al. (2009) de que o SCG se constitui em uma área mais ampla que engloba a Contabilidade Gerencial e ainda outros tipos de controles gerenciais. O SCG é modelado para ajudar uma organização a se adaptar ao ambiente em que atua e atingir os resultados esperados pelos interessados, geralmente os sócios e/ou acionistas (MERCHANT; OTLEY, 2007); e é neste sentido que o Custeio Alvo está sendo considerado, permitindo que o corpo de conhecimento relativo ao SCG possa auxiliar no delineamento e nas análises do presente trabalho. 


\subsection{Formulação das Questões de Pesquisa}

Conforme evidenciado na contextualização, ainda existem lacunas acerca do entendimento da adoção, implementação e uso de práticas de Contabilidade Gerencial e uma das dificuldades apontadas pela literatura é que esse processo é complexo e envolve inúmeros fatores. Para tentar envolver parte dessa complexidade na investigação, essa pesquisa buscou apoio nos comentários de Covaleski et al. (1996), Lukka (2010) e Malmi (2010) sobre a necessidade do uso de diferentes paradigmas nas pesquisas em Contabilidade Gerencial. Isso porque o uso de diferentes abordagens podem suscitar novos e interessantes caminhos para a investigação e para o estudo da prática da Contabilidade Gerencial (BAXTER; CHUA, 2003).

Dessa forma, esse trabalho se apoiou em duas abordagens teóricas situadas em diferentes paradigmas para investigar o mesmo fenômeno, o Custeio Alvo e seu funcionamento. Devido às diferenças subjacentes a cada teoria foi necessária uma separação entre questão orientadora e questões secundárias da pesquisa de forma a acomodar cada dimensão investigada (adoção, implementação e uso) em suas devidas perspectivas.

Berry et al. (2009) argumentam que parece haver três características principais dos sistemas de controle que têm influenciado fortemente o modo com que o tema vem se desenvolvendo. A primeira se refere ao reconhecimento de que o controle gerencial é um processo em que um grupo de pessoas tenta impor controles sobre subgrupos inerentemente auto controlados; na segunda, os SCG são artefatos socialmente construídos que criam um contexto social real para aqueles a quem são impostos podendo afetar fundamentalmente o comportamento; na terceira, uma ampla gama de fatores contextuais condiciona as consequências das atividades de controle (BERRY et al., 2009).

Essas três características evidenciam a complexidade da natureza do SCG principalmente pelo fato de estarem ligadas a perspectivas tão distintas. A primeira reflete questões ligadas à política e ao poder, a segunda se refere aos aspectos culturais e sociais que permeiam a atividade organizacional e a terceira está ligada aos fatores contextuais que afetam a estrutura e o desempenho da organização. Essas peculiaridades evidenciam que o desenvolvimento de um quadro referencial global para entender o SCG seria útil, mas improvável de ser satisfatório (BERRY et al., 2009).

Por outro lado, a tentativa de entender o modelo e o funcionamento do SCG por apenas um ângulo também não se mostra alternativa muito frutífera. Por isso, de acordo com as 
características mencionadas, esta pesquisa focou a influência dos fatores contextuais e dos aspectos culturais e sociais como ponto de partida para investigar, em uma organização, a adoção, a implementação e o uso de uma prática do SCG, o Custeio Alvo.

Quanto aos fatores contextuais, Espejo (2008) menciona que as organizações possuem dinâmicas próprias e são afetadas por variáveis que conduzem a comportamentos distintos no que se refere aos controles gerenciais. Assim, esses fatores impactam de alguma forma o desenho e o uso desses sistemas e as organizações respondem de maneira particular a essas influências. Para Berry et al. (2009), devido ao fato de que uma ampla gama de fatores condicionam as consequências das atividades de controle, a Teoria da Contingência tem sido usada para analisar esses efeitos contextuais. Por isso, a Teoria da Contingência se mostra útil para o estudo desses fatores (CHENHALL, 2007; LANGFIELD-SMITH, 2007; TILLEMA, 2005), sendo empregada nesta pesquisa para verificar se as condições ou características técnicas (espelhadas pelos fatores contingentes) encontradas na organização investigada favorecem ou não a utilização do Custeio Alvo.

Donaldson (2007) argumenta que na Teoria da Contingência não existe uma estrutura única que seja altamente efetiva para todas as organizações e que a organização ótima é aquela contingente aos fatores contextuais. Então, o sistema de controle deve estar adequado aos fatores contingentes presentes na organização de forma a obter eficiência. O mercado é regido em grande parte pela lógica da eficiência; por isso, as organizações buscam meios de reduzir as incertezas de forma a aplicar os recursos e conseguir vantagem competitiva. Para Donaldson (2007), a adequação entre os fatores contextuais e a estrutura da organização é fator indispensável para obtenção de eficiência. Por isso, identificar, analisar e interpretar os fatores contingentes que podem ter influência na adoção e utilização do Custeio Alvo é importante para verificar essa adequação.

Quanto aos aspectos culturais e sociais, considerar o SCG como uma realidade socialmente construída requer o entendimento de como essa realidade emergiu no ambiente organizacional e como as pessoas envolvidas lidam com a mesma. Nesse sentido, a Teoria Institucional, principalmente em sua vertente sociológica denominada Nova Sociologia Institucional (NSI), vem sendo usada para pesquisar aspectos sociais e culturais dos SCG e da Contabilidade Gerencial (como nos trabalhos de DAMBRIN et al., 2007; TSAMENYI et al., 2006; JÄRVINEN, 2006; KHOLEIF et al., 2007; MA; TAYLES, 2009; HUSSAIN; HOQUE, 
2002), tratando esses sistemas como elementos institucionais, mostrando-se útil para os propósitos da presente pesquisa.

A NSI considera que o indivíduo se comporta como ator social ao formular ações estratégicas com base nos significados atribuídos às regras de funcionamento das organizações, institucionalizadas na sociedade (FONSECA; MACHADO-DA-SILVA, 2002). No processo de institucionalização é que esses significados são construídos, considerando os fatores institucionais da organização e da sociedade na qual está inserida. Na NSI o ambiente é visualizado como repositório de redes relacionais e de sistemas culturais, compostos por valores, crenças e regras, que transmitem conceitos sobre modos apropriados de fazer e de agir, e a conformação a tais fatores normativos garante suporte e legitimidade para a organização (FONSECA; MACHADO-DA-SILVA, 2002).

Nesse sentido, regras e normas sociais devem ser seguidas como forma de legitimar as ações organizacionais (MEYER; ROWAN, 1977; DIMAGGIO; POWELL, 1983; SCOTT, 2001). Então, a busca pela redução das incertezas e pela eficiência no ambiente competitivo deve estar pautada nessas regras e normas para que a organização seja aceita em seu meio, existindo também uma forma particular de responder a essas influências (MEYER; ROWAN, 1977; OLIVER, 1991; BECKERT, 1999, CRUBELLATE et al., 2004; MACHADO-DASILVA et al., 2005; CRUBELLATE, 2004). Por isso, verificar como os atores interpretaram o Custeio Alvo na organização e como o mesmo foi institucionalizado se torna um aspecto relevante para entender seu funcionamento naquele contexto.

Pelo exposto, a decisão de adotar uma prática de controle gerencial pode estar baseada tanto na busca de eficiência quanto de legitimidade, podendo variar o grau de influência de cada uma (POWELL, 1991). Além disso, em muitos casos essas duas lógicas podem se comportar como forças opostas causando tensões e dificuldades que também podem influenciar a implementação e a utilização de uma prática (MEYER; ROWAN, 1977). Desse modo, estudar o processo pelo qual o Custeio Alvo foi instituído é uma forma de tentar entender a ligação entre esses dois propósitos (eficiência e legitimação) e o tipo de resposta da organização.

Considerando que a introdução de práticas de controle gerencial pode ser influenciada tanto por fatores contingentes quanto institucionais, que isso se reflete na forma como a prática é 
entendida na organização e que a forma de resposta a essa influência afeta sua adoção, sua implementação e seu uso, a questão orientadora da pesquisa é:

\section{Quais deduções e inferências podem ser extraídas acerca da introdução do Custeio Alvo na empresa objeto do estudo de caso à luz da Teoria da Contingência e da NSI?}

Essa questão engloba vários aspectos de forma que para ser respondida torna-se essencial a sua separação em várias dimensões, sendo necessária a formulação de questões complementares, secundárias, relativas a cada aspecto que emergiu da problemática identificada. Para tanto, as questões secundárias foram separadas em três perspectivas: (1) se refere à adoção do Custeio Alvo podendo ser influenciado por fatores contingentes (Teoria da Contingência) e por fatores institucionais (NSI); (2) se refere à implementação do Custeio Alvo focando a forma como ele foi construído socialmente e como está atrelado ao sistema de controle, com base na NSI; (3) se refere ao modo pelo qual o Custeio Alvo vem sendo usado pela organização e o desempenho percebido em relação ao mesmo, com base na Teoria da Contingência.

Ressalta-se que a adoção, a implementação e o uso fazem parte de um continuum no processo de introdução de práticas gerenciais, não se tratando de categorias estanques, no entanto, com a finalidade de delimitar os estágios analisados em cada teoria foi feita essa separação. É relevante mencionar também que em função do objetivo da pesquisa o estudo empírico foi empreendido em uma organização que adotou, implementou e vem usando o Custeio Alvo, a qual passa a ser designada com o nome fictício de Alfa. Na sequência foram estabelecidas as questões secundárias referentes a cada perspectiva.

\subsubsection{Adoção do Custeio Alvo}

A adoção do Custeio Alvo foi investigada tendo por base a Teoria da Contingência e a NSI, envolvendo respectivamente fatores contingentes e institucionais ligados à busca por eficiência e por legitimidade. Como englobam teorias distintas foram formuladas duas questões conforme o desenvolvimento a seguir.

Em relação à busca por eficiência, Tillema (2005) argumenta que o uso bem sucedido de práticas da Contabilidade Gerencial pode estar relacionado às características mais gerais das organizações e de seus ambientes; então, as circunstâncias que envolvem seu uso podem 
afetar a adequação das mesmas. Por isso, não existe uma única melhor forma de se organizar e sim várias, de acordo com o contexto de cada empresa.

Disso depreende-se que uma prática como o Custeio Alvo pode ser adequada apenas em determinados contextos, que consideram tanto as características da organização quanto as do ambiente em que a mesma esteja inserida. Por isso, busca-se, com o emprego da Teoria da Contingência, mapear os fatores contingentes, tanto organizacionais quanto do ambiente, que estavam presentes e que podem ter influenciado a decisão pela adoção desta prática e, ainda, verificar se a adoção do Custeio Alvo está adequada em relação aos fatores encontrados. Para isso, a seguinte questão foi levantada:

\section{Q1.1 Dos fatores contingentes descritos na literatura como relacionados à adoção do Custeio Alvo, quais estavam presentes na Alfa inibindo ou favorecendo sua utilização?}

As organizações lidam com diferentes pressões e os atores podem interpretá-las de formas totalmente distintas, considerando outros objetivos que não apenas a busca pela eficiência. Nascimento et al. (2010) mencionam que vários estudos têm comprovado que a adoção de práticas de Contabilidade Gerencial pode ser motivada por vários fatores, não necessariamente pela busca de melhor desempenho.

Segundo a NSI as organizações podem adotar determinadas práticas gerenciais por pressões institucionais para obter legitimidade perante os stakeholders e não necessariamente para aumentar sua eficiência (MEYER; ROWAN, 1977; DIMAGGIO; POWELL, 1983). No entanto, por atuarem concomitantemente em ambientes institucionais e econômicos (SCOTT; MEYER, 1991) as organizações podem considerar também os fatores econômicos na decisão de adoção de uma prática. Nesse sentido, a seguinte questão foi levantada:

Q1.2 Quais fatores institucionais, dentre os elencados na literatura, estavam presentes por ocasião da adoção do Custeio Alvo na Alfa inibindo ou favorecendo sua adoção? Quais os fatores econômicos presentes nesse contexto? 


\subsubsection{Implementação do Custeio Alvo}

Tão importante quanto entender os fatores contingentes e institucionais que podem ser, de algum modo, influentes ou responsáveis pela adoção de determinada prática gerencial é o entendimento de como a organização respondeu à sua adoção. Quando a motivação está respaldada na busca pela legitimação e existe conflito com a busca pela eficiência, é até possível que haja a adoção; no entanto, pela percepção de não haver utilidade técnica ou por outros fatores envolvidos no processo de institucionalização, a mesma pode não ser efetivamente considerada nas atividades de controle e decisão (MEYER; ROWAN, 1977). Por isso, é relevante verificar e entender como o Custeio Alvo está atrelado ao SCG e de que forma isso acontece.

A implementação do Custeio Alvo foi avaliada tendo por base seu processo de institucionalização, através de estágios (HASSELBLADH; KALLINIKOS, 2000), considerando o modo como ele foi interpretado e a resposta estratégica da organização. Além disso, também foi avaliado se pressões institucionais e econômicas estavam presentes nesse processo e se podem ter influenciado a forma como a organização implementou a prática. Como resultado, buscou-se verificar se o Custeio Alvo foi implementado de forma acoplada (coupling) ao SCG sendo utilizado seu potencial técnico ou se foi adotado de forma cerimonial (decoupling ${ }^{l}$ ), servindo apenas para amortecer algum tipo de pressão para conferir algum tipo de legitimidade, tendo um caráter simbólico. Para tanto, as seguintes questões foram elaboradas:

Q1.3 De acordo com o modelo de estágios do processo de institucionalização de Hasselbladh e Kallinikos (2000), em qual estágio o Custeio Alvo encontra-se institucionalizado na Alfa?

Q1.4 Considerando-se a influência dos fatores institucionais e econômicos encontrados nesse processo, qual foi o tipo de motivação predominante (busca de eficiência ou de legitimidade) em relação à institucionalização do Custeio Alvo?

\section{Q1.5 De que forma o Custeio Alvo encontra-se institucionalizado, coupled ou decoupled?}

\footnotetext{
${ }^{1}$ Embora existam traduções para esse termo como, por exemplo, "dissociado", optou-se por não traduzi-lo sob pena de perder o significado dessa expressão em relação à NSI. Este termo, nessa pesquisa, foi empregado mais no sentido de conceito do que de palavra, e indica uma desconexão entre a estrutura e a rotina da organização.
} 


\subsubsection{Uso do Custeio Alvo}

Quanto à dimensão uso, foi considerada a tipologia de uso diagnóstico, interativo e disfuncional, englobados no Modelo de Alavancas de Controle (MAC) de Simons (1995). Para Simons (1987), o uso diagnóstico está relacionado à implementação e ao monitoramento dos resultados em relação às estratégias adotadas e o interativo foca as incertezas estratégicas em que a alta gestão direciona maior atenção aos sistemas de controle usando-os de forma mais ativa para intervir no processo de tomada de decisão organizacional. O uso disfuncional ocorre quando da existência de efeitos colaterais do uso diagnóstico (SIMONS, 1995), sendo direcionado para outras finalidades que não as do uso diagnóstico ou do interativo (FERREIRA; OTLEY, 2006).

Ferreira e Otley (2006) mencionam que a literatura sobre SCG sugere que a eficácia do sistema de controle é dependente tanto de sua sofisticação técnica quanto do uso das informações geradas. Enquanto o uso interativo encoraja o comportamento inovador, o diagnóstico serve para verificar se as pessoas se comportam de acordo com regras e planos pré-estabelecidos (SIMONS, 1995). Em função da importância de se investigar o tipo de uso, foi elaborada a seguinte questão:

\section{Q1.6 Que tipo de uso - diagnóstico, interativo ou disfuncional - a Alfa vem fazendo em relação ao Custeio Alvo?}

Resta ainda a questão da avaliação do desempenho. Foi verificado anteriormente que a adequação do SCG aos fatores contingentes pode resultar em aumento de desempenho organizacional. Otley (2001) argumenta que as práticas de controle estão presentes nas organizações através de uma ampla variedade de atividades e que seria insensato assumir que uma prática em particular possa ser facilmente associada ao desempenho organizacional. Nesse sentido, Ferreira e Otley (2009) argumentam que é mais adequado avaliar o desempenho do sistema e não o da organização. Pelo exposto, em relação ao desempenho do Custeio Alvo parece ser viável a sua análise em termos de utilidade, ou seja, de desempenho do sistema, ao invés do desempenho organizacional. Nessa perspectiva a seguinte questão foi elaborada:

\section{Q1.7 O desempenho do Custeio Alvo quanto à satisfação dos usuários e ao impacto} individual, na Alfa, inibe ou favorece sua utilização? 
Na sequência foram estabelecidos os objetivos da pesquisa.

\subsection{Objetivos}

O objetivo geral da pesquisa foi investigar e identificar as deduções e inferências que podem ser extraídas acerca da adoção, implementação e uso do Custeio Alvo na Alfa à luz da Teoria da Contingência e da NSI. Para tanto, os seguintes objetivos específicos foram estabelecidos:

1) Verificar, dentre os fatores contingentes descritos na literatura como relacionados ao Custeio Alvo, quais estão presentes na Alfa inibindo ou favorecendo sua adoção e utilização, à luz da Teoria da Contingência;

2) Verificar, dentre os fatores institucionais e econômicos contemplados na literatura, quais estavam presentes por ocasião da adoção do Custeio Alvo na Alfa, inibindo ou favorecendo sua a adoção à luz da NSI;

3) Verificar em qual estágio do processo de institucionalização o Custeio Alvo se encontra na Alfa;

4) Verificar o tipo de interpretação predominante (busca de eficiência ou de legitimidade), considerando-se a influência dos fatores institucionais e econômicos investigados, em relação à institucionalização do Custeio Alvo;

5) Verificar se o Custeio Alvo foi institucionalizado de forma coupled ou decoupled em relação às rotinas da Alfa;

6) Verificar de que forma o Custeio Alvo vem sendo usado pela Alfa;

7) Verificar se o desempenho do Custeio Alvo quanto à satisfação do usuário e ao seu impacto individual vem favorecendo ou inibindo a prática na Alfa.

\subsection{Definições Operacionais}

De acordo com a problemática que embasa essa pesquisa foi verificado que fatores contingentes, institucionais e econômicos podem influenciar a adoção do Custeio Alvo e, 
posteriormente, sua implementação e uso. Para facilitar o entendimento acerca dos termos específicos usados nas questões de pesquisa, foram apresentadas suas definições operacionais.

a) Fatores Contingentes: são variáveis que caracterizam os ambientes interno e externo das organizações e que podem influenciar sua estrutura e desempenho. Na pesquisa foram investigados fatores externos à organização (intensidade da concorrência e incerteza ambiental) e internos (porte, estratégia, estrutura organizacional e tecnologia).

b) Fatores Institucionais: representam as pressões de ordem social e cultural que podem impactar a estrutura organizacional. Nessa pesquisa foram investigados de duas formas, sendo os mecanismos de mudança isomórfica e a legitimidade. Os mecanismos de mudança isomórfica são representados pelos tipos de pressões institucionais a que uma organização está sujeita podendo ser o coercitivo, o normativo e o mimético (DIMAGGIO; POWELL, 1983) e se referem à fase de adoção da prática. Quanto à legitimidade foram investigados indícios de sua presença no ambiente externo e interno nas fases de adoção e implementação.

c) Fatores econômicos: foram considerados os aspectos de natureza operacional, financeira e patrimonial que podem impactar o desempenho econômico e que podem influenciar as fases de adoção e implementação do Custeio Alvo. Esses aspectos foram considerados em relação à busca de eficiência por parte da organização. Foram representados por aspectos como redução de custos, obtenção de metas, aumento (redução) de resultado, aumento (redução) de participação no mercado, aumento (redução) de vendas etc.

d) Adoção do Custeio Alvo: refere-se à existência do processo do Custeio Alvo na organização. Dessa forma, não implica dizer que a adoção se refere ao momento (referente ao tempo) em que foi adotado e sim que a empresa o adotou e vem utilizando. A utilização se refere ao fato de a Alfa estar alimentando o processo do Custeio Alvo de modo a gerar informações; portanto, não diz respeito à forma de uso das informações (interativo, diagnóstico e/ou disfuncional), que se refere à outra categoria analisada no estudo.

e) Implementação do Custeio Alvo: modo como o Custeio Alvo foi levado à prática, ou seja, como ele foi operacionalizado pela Alfa. 
f) Institucionalização: processo através do qual o Custeio Alvo foi internalizado na Alfa.

g) Uso do Custeio Alvo: indica a forma de uso (interativo, diagnóstico e disfuncional) de acordo com o modelo de Simons (1995).

h) Desempenho do Custeio Alvo: se refere à utilidade percebida do Custeio Alvo quanto à satisfação do usuário e ao impacto individual.

\subsection{Justificativa}

Esta pesquisa pode ser justificada sob os seguintes aspectos: quanto ao interesse da comunidade acadêmica e das organizações a respeito do entendimento sobre o funcionamento de uma prática de controle gerencial, quanto à escolha pelo Custeio Alvo, quanto às lentes teóricas usadas para lidar com o problema, quanto à estratégia de pesquisa e quanto à organização investigada.

Quanto ao primeiro aspecto foi verificado que a decisão de adotar uma prática de controle gerencial requer análises de variada ordem devido aos muitos fatores que podem influenciar essa decisão, uma vez que podem afetar o modo como a mesma vai ser institucionalizada e utilizada. Portanto, investigar como uma organização lidou com esses fatores nas fases de adoção, implementação e uso pode evidenciar a inter-relação desses fatores e sua importância nesse tipo de tomada de decisão.

Merchant e Otley (2007) comentam que o objetivo da pesquisa em controle gerencial é desenvolver um melhor entendimento de como e por que os sistemas de controle funcionam em várias situações e o que pode ser feito para melhorar os mesmos a partir da perspectiva do alcance dos objetivos organizacionais. Por isso, estudar, num contexto real de atuação, como uma prática de controle gerencial foi adotada e como isso se refletiu nas fases posteriores de implementação e uso de modo a auxiliar o entendimento de seu funcionamento e seu resultado para a organização é interessante e necessário. Isso é importante na medida em que esclarece os aspectos apontados por Nascimento (2011, p. 19) de que "A relevância da contabilidade ocorre, necessariamente, se ela é usada, como é usada, por que é usada e quando." (grifo do original) e adiciona-se neste rol o resultado obtido com esse tipo de funcionamento. 
Para Frezatti et al., (2009) cabe aos pesquisadores identificar problemas com a implantação de práticas de controle, apresentando propostas para o aperfeiçoamento das mesmas e avaliando suas reais potencialidades de utilidade para as organizações. Por isso, com base no exposto, o que foi proposto nessa pesquisa atende ao interesse tanto da comunidade acadêmica quanto das organizações uma vez que fornece esclarecimentos a respeito do funcionamento de uma prática de controle gerencial ajudando em seu entendimento, podendo auxiliar uma organização na obtenção de seus objetivos e mostrando alguns pontos que devem ser observados quando da decisão de adoção da mesma.

Quanto ao objeto analisado cabe ressaltar que devido à abrangência e à complexidade do que se pretendeu fazer, apenas uma das práticas de controle da Alfa fez parte deste estudo, o Custeio Alvo. Uma das razões dessa escolha se deve ao fato de que segundo Ansari et al. (2007) o mesmo vem sendo cada vez mais adotado por empresas ao redor do mundo e mencionam ainda que empresas como Chrysler e Caterpillar atribuem sua virada financeira ocorrida na metade da década de 1990 à sua adoção. Dessa forma, torna-se importante investigar uma prática que vem apresentando crescimento na taxa de adoção e, pelos relatos, vem auxiliando no gerenciamento dos custos e na obtenção de resultados.

Ansari et al. (2007) mencionam também que o Custeio Alvo nos últimos vinte anos tem chamado a atenção de pesquisadores japoneses e ocidentais e, mesmo assim, dúvidas ainda existem sobre como o mesmo vem sendo usado pelas organizações. Chenhall (2007) menciona que práticas como o Custeio Alvo são pouco estudadas e que seu entendimento pode auxiliar na gestão das organizações que atuam em ambientes caracterizados por mudanças como a redução do ciclo de vida dos produtos.

Nos levantamentos bibliográficos realizados para essa pesquisa, tanto no exterior quanto no Brasil, poucos estudos tiveram o objetivo de investigar os motivos que levam uma empresa a adotá-lo e como a mesma o utiliza para atingir os objetivos esperados. Embora essa prática venha sendo usada por muitas empresas há algumas décadas, ela tem sido fragmentada e mal entendida, carecendo de entendimento sobre como é usada (ANSARI et al., 2007). Essas declarações justificam o estudo de uma prática de interesse da academia e das organizações e que ainda necessita de entendimento sobre seu funcionamento.

Quanto às teorias usadas para lidar com o problema ressalta-se a intenção de abordar no estudo aspectos de variada ordem como os contingentes e os sociais e culturais como forma 
de conseguir captar nuances que podem auxiliar o entendimento acerca da adoção, implementação e uso de práticas de controle englobando a busca de eficiência e de legitimidade. Por isso, foram usadas duas teorias com diferentes paradigmas de forma separada: a Teoria da Contingência, focando os fatores contingentes relativos à adoção, e a NSI, focando os fatores institucionais bem como os econômicos envolvidos na adoção e implementação de uma prática de controle gerencial.

Essa escolha encontra respaldo na afirmativa de que a utilização de um pluralismo paradigmático é uma forma de melhorar o entendimento de questões nas ciências sociais (COVALESKI et al., 1996; LUKKA, 2010; VOLLMER, 2009; MODELL, 2010; BAXTER; CHUA, 2003). Covaleski et al. (1996) mencionam que a Contingência e as abordagens interpretativas como a Teoria Institucional fornecem múltiplos entendimentos da Contabilidade Gerencial que não são oferecidos por uma análise mais estreita, centrada em uma preferência individual. Ressalta-se que nenhum dos trabalhos encontrados na literatura e usados nessa pesquisa como base empregou a Teoria da Contingência e a NSI de forma complementar, como nesse caso; daí seu caráter de ineditismo. Além disso, Nascimento et al. (2010) concluíram em sua pesquisa que apenas $2 \%$ dos artigos acadêmicos sobre Contabilidade Gerencial publicados no Brasil seguiram paradigmas interpretativos. Essa constatação é um indício da carência do emprego desse tipo de paradigma em pesquisas na área gerencial no Brasil. Pelo exposto, essa escolha se justifica uma vez que pode trazer insights interessantes pelo fato de que se propõe analisar um mesmo fenômeno sob diferentes prismas teóricos.

Quanto à estratégia metodológica usada na pesquisa foi escolhido o estudo de caso como forma de aprofundar o conhecimento acerca das questões levantadas. Esta escolha se justifica por várias razões. Primeiro, por estar estudando uma prática do sistema de controle em seu contexto real de atuação (conforme recomendações de OTLEY, 2001; 2008 e BERRY et al., 2009). Segundo, por conseguir com isso ter acesso tanto ao sistema formal quanto ao informal, ou seja, o que está estabelecido nas regras e o que acontece, de fato, nas rotinas da organização (SCOTT, 2001; MEYER; ROWAN, 1977). Terceiro, a possibilidade de captar como os atores interpretaram e deram significado ao Custeio Alvo e como ele foi institucionalizado. A reunião de todos esses aspectos justifica a opção por essa estratégia de pesquisa. 
Quanto à empresa escolhida, a investigação na Alfa traz a oportunidade de pesquisar uma subsidiária pertencente a um grupo de classe mundial cuja matriz é citada na literatura especializada como referência no uso do Custeio Alvo. Isso vai ao encontro do que Malmi e Granlund (2009) mencionam a respeito de se devotar mais tempo e atenção dos pesquisadores sobre as práticas de controle e contabilidade em organizações de sucesso, pois parece haver um viés em direção ao estudo de problemas e deficiências da contabilidade, sendo que análises relativas aos casos bem sucedidos são raramente publicadas. Esses motivos justificam a escolha da organização investigada.

Todos os aspectos mencionados foram considerados importantes para a investigação proposta com o intuito de gerar resultados que auxiliem tanto a pesquisa quanto a aplicação da prática nas organizações. Na sequência foram apresentadas as contribuições esperadas com essa pesquisa.

\subsection{Contribuições}

De forma geral, os resultados dessa pesquisa podem auxiliar no entendimento de como fatores contingentes, institucionais e econômicos podem influenciar a adoção, implementação e uso do Custeio Alvo; evidenciando os pontos que merecem atenção quando da decisão de adotar este tipo de prática, bem como de seu funcionamento no SCG. Nesse sentido, as contribuições do trabalho podem ser separadas entre o que se espera com o estudo e o que o mesmo apresenta em termos de originalidade.

Em relação à primeira, a expectativa em torno desta pesquisa é que seus achados possam auxiliar tanto as futuras pesquisas da área quanto os gestores das organizações no que diz respeito a introdução de práticas de controle como o Custeio Alvo. No tocante à pesquisa, espera-se contribuir adicionando conhecimento sobre os assuntos englobados na investigação em relação à Teoria da Contingência e à NSI. Conforme a especificação de Keating (1995) é o que se pode denominar de refinamento da teoria. Espera-se ainda adicionar conhecimento em relação à literatura sobre Custeio Alvo e como o mesmo está acoplado ao SCG. Com isso, espera-se que os achados da pesquisa possam contribuir para o entendimento das dificuldades e tensões que as organizações enfrentam quando da adoção de uma prática do sistema de controle e sua relação com os fatores contingentes, institucionais e econômicos que podem afetar seu funcionamento e seus resultados. 
Quanto às organizações, espera-se contribuir com o fornecimento de subsídios para auxiliar os gestores nas decisões de adoção de práticas de controle, em especial relativos aos fatores que podem influenciar desde sua adoção até a utilização. Os achados dessa pesquisa são inerentes ao Custeio Alvo devido aos aspectos específicos considerados em relação ao mesmo, principalmente no tocante aos fatores contingentes. No entanto, os aspectos gerais (contingentes, institucionais e econômicos) que devem ser considerados quando da decisão de adotar ou não uma prática podem ser estendidos às demais práticas, podendo indicar quais são os pontos relevantes que devem ser observados quando desse tipo de decisão, tanto na etapa de adoção quanto na de implementação e uso. Isto é importante para auxiliar as organizações a atingirem seus objetivos.

Em relação à originalidade da pesquisa vários aspectos podem ser destacados: (1) tratar o objeto de estudo de forma não reducionista abrangendo as etapas de adoção, implementação e uso; (2) abordar o problema sob duas perspectivas com paradigmas diferentes, a Teoria da Contingência e a NSI, de forma que uma possa complementar a outra; (3) abordar os assuntos relativos à Teoria da Contingência em uma visão interpretativa e qualitativa, diferindo da maioria dos estudos que utilizaram essa abordagem, pois geralmente tais estudos são quantitativos; (4) abordar a NSI sob a vertente que considera a possibilidade de agência estratégica e a recursividade no processo de institucionalização (MEYER; ROWAN, 1977; OLIVER, 1991; BECKERT, 1999, CRUBELLATE et al., 2004, MACHADO-DA-SILVA et al., 2005, CRUBELLATE , 2004). A junção desses aspectos de originalidade diferencia a construção desta pesquisa em relação aos estudos usados como base, tanto da literatura acadêmica brasileira como da internacional, podendo oferecer como resultado diferentes insights acerca dos temas investigados.

A consideração das contribuições esperadas e dos aspectos de originalidade empregados na busca do objetivo, além dos vários outros fatores antes mencionados, qualifica este trabalho enquanto tese de doutorado.

\subsection{Delimitações do Estudo Empírico}

É importante em um trabalho desta natureza que o que se pretende fazer esteja claro e bem definido, por isso, algumas delimitações são necessárias. O principal objetivo de estabelecer 
seus limites é que o mesmo tenha condições de ser elaborado de acordo com o que se pretende. As delimitações podem ser separadas:

1) Quanto ao escopo: o Custeio Alvo foi a prática do SCG investigada na Alfa e os aspectos investigados abordam sua adoção, implementação e uso. Este último inclui a forma de uso (diagnóstico, interativo ou disfuncional) bem como sua utilidade para a Alfa.

2) Quanto às variáveis contingentes: as variáveis abordadas na pesquisa foram intensidade da concorrência, incerteza ambiental percebida (GORDON; NARAYANAN, 1984; AX et al., 2008), estratégia (PORTER, 1992; MILES; SNOW, 2003; GUPTA; GOVINDARAJAN, 1984), porte (ESPEJO, 2008; MERCHANT, 1984), estrutura (GORDON; NARAYANAN, 1984; HANSEN; VAN DER STEDE, 2004; JUNQUEIRA, 2010; BAINES; LANGFIEL-SMITH, 2003; ABERNETHY; LILLIS, 1995), tecnologia da informação (KRUMWIEDE, 1998; HYVÖNEN, 2007) e tecnologia da produção (KRUMWIEDE, 1998; BAINES; LANGFIEL-SMITH, 2003, GUERRA, 2007).

3) Quanto aos estágios do processo de institucionalização: foram investigados na etapa de implementação e a teoria de base foi a NSI. No entanto, existe uma limitação devido ao foco da NSI estar geralmente no nível de campo organizacional (DILLARD et al., 2004, CARRUTHERS, 1995; MA; TAYLES, 2009), ou seja, em nível macro, extra e inter-organizacional. Nesse sentido, Hasselbladh e Kallinikos (2000) fazem uma classificação em termos de estágios (quanto aos ideais, discurso e técnica de controle) para verificar o nível de institucionalização da mudança, tratando a institucionalização como um processo. Essa estrutura conceitual inspirada na NSI pode ser usada como um dispositivo para analisar como a mudança inter-organizacional (nova lógica institucional em um dado campo organizacional) pode resultar em mudança intraorganizacional (institucionalização de novas práticas coerentes com a nova lógica institucional em uma empresa específica) (DAMBRIN et al., 2007). Essa escolha se deve ao fato de a mesma ser capaz de descrever o processo de institucionalização em detalhes podendo ser ajustada para analisar as instituições no processo de formação e os mecanismos subjacentes a esse processo (nível micro), vindo ao encontro do objetivo desta pesquisa. 
4) Quanto à legitimidade: a busca por legitimidade, avaliada nas etapas de adoção e implementação, foi analisada enquanto estado/resultado do processo de institucionalização do Custeio Alvo. Para tanto, foi investigada a existência de indícios nas entrevistas e nos textos institucionais que pudessem confirmar a presença dessa categoria. Destaca-se que não fez parte do escopo dessa pesquisa avaliar o processo de legitimação, ou seja, a construção social da legitimidade, mas sim seu resultado.

5) Quanto aos fatores econômicos: no âmbito da NSI também foi investigada a pressão por eficiência referente aos fatores econômicos. Essa pressão se refere ao ambiente econômico e pode existir em conjunto com as pressões institucionais (MEYER; ROWAN, 1977; SCOTT; MEYER, 1991), uma se sobressaindo sobre a outra a depender do tipo de organização e do assunto avaliado, influenciando a estrutura organizacional. Foram investigados indícios de sua presença nas fases de adoção e implementação do Custeio Alvo, relacionados ao aumento (redução) de resultado, aumento (redução) de participação no mercado, aumento (redução) de vendas, obtenção de metas, redução de custos, dentre outros que possam ser caracterizados como econômicos e que estavam presentes nos discursos. Cabe ressaltar que a interpretação enquanto busca por eficiência relacionada aos fatores econômicos foi avaliada de acordo com os termos mencionados anteriormente presentes no conteúdo das entrevistas e nos textos institucionais, indicando a presença dessa categoria. No entanto, não fez parte do escopo dessa pesquisa investigar o que é eficiência do ponto de vista institucional enquanto construção do seu significado naquele contexto, ou seja, o que a mesma representa para a organização.

\subsection{Estrutura do Trabalho}

A estrutura do trabalho pode ser visualizada pela Figura 1 . No Capítulo 1 foi desenvolvida a introdução ao estudo, mostrando seu contexto, a problemática, as questões de pesquisa, os objetivos, a justificativa e as contribuições esperadas com seu empreendimento. 


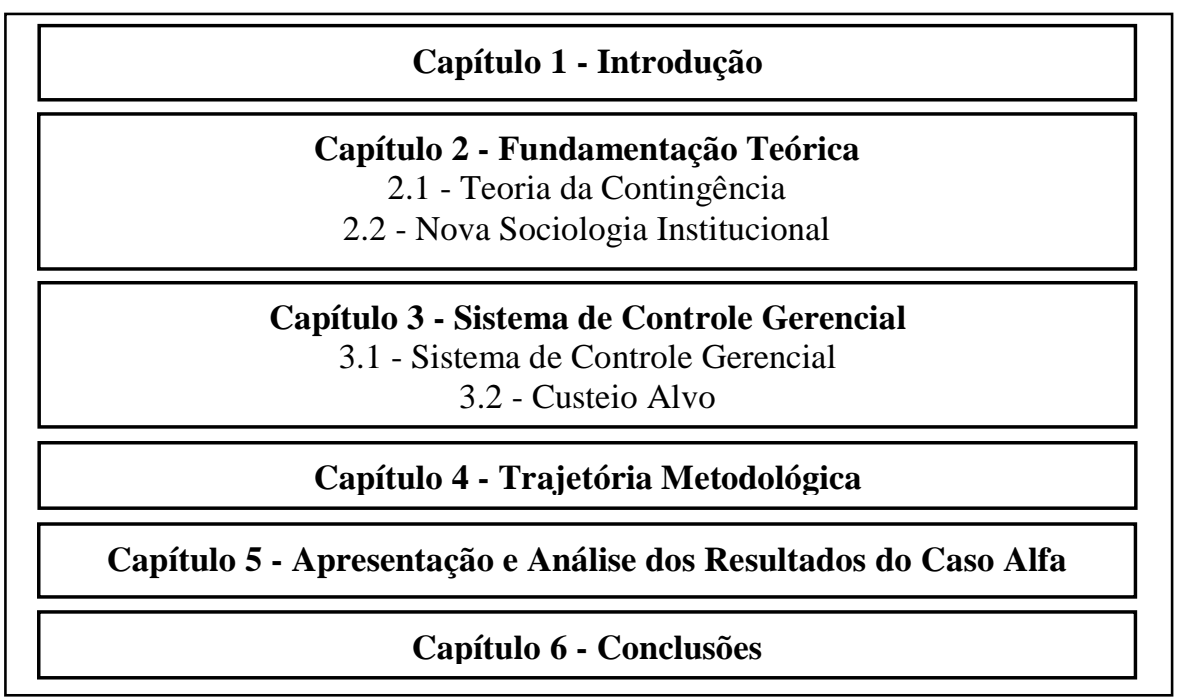

Figura 1 - Estrutura da tese

No Capítulo 2 foi desenvolvida a fundamentação teórica compreendendo as duas teorias de base.

No Capítulo 3 foi abordado o SCG e suas categorias analisadas na pesquisa, incluído o desenho do SCG, os tipos de uso e o desempenho do sistema. Neste capítulo também foi apresentado o Custeio Alvo, que foi a prática do SCG investigada.

O Capítulo 4 evidenciou a trajetória metodológica englobando aspectos como a ontologia e a epistemologia que serviram de base para o estudo empírico, a estratégia de pesquisa, as técnicas de coleta e tratamento dos dados, o instrumento de coleta de dados, a forma de análise e interpretação dos dados e as limitações da pesquisa.

O Capítulo 5 apresentou os dados e as análises do caso na Alfa, evidenciando os resultados da pesquisa de acordo com as questões levantadas, tendo como base as teorias empregadas.

O Capítulo 6 se refere às conclusões extraídas das análises e às recomendações para futuros trabalhos. Posteriormente foram apresentadas as referências que serviram de base para a pesquisa e os apêndices, que apresentam o instrumento de coleta de dados na integra e uma parte da matriz usada para a análise de conteúdo, a título de exemplo. 


\section{FUNDAMENTAÇÃO TEÓRICA}

Este capítulo tem o objetivo de apresentar os fundamentos teóricos que serviram de base para o desenvolvimento dessa pesquisa, sendo a Teoria da Contingência e a NSI. O uso de apenas uma das teorias iria restringir a fundamentação e a análise dos fatores ligados à adoção, à implementação e ao uso do Custeio Alvo somente à existência de fatores contingentes propícios à sua adoção ou somente aos aspectos culturais e sociais que propiciaram a interpretação e a significação da prática de modo a ser institucionalizada e usada da forma como está. Para que os dois focos fizessem parte do estudo as duas teorias foram aplicadas de forma separada, cada uma com suas características e pressupostos. Dessa forma, buscou-se investigar o mesmo fenômeno (Custeio Alvo), em seu contexto real de aplicação, sob perspectivas teóricas diferentes, de modo que isso pode resultar em achados não captados por outros estudos que trataram desse assunto. Ressalta-se que as duas teorias mencionadas podem ser intercambiáveis, no entanto, não fez parte dos objetivos dessa pesquisa entrar nesse mérito. As categorias investigadas não são estanques, todavia o foco da pesquisa considerou dois momentos distintos cada qual com uma lente, por isso, as duas teorias foram consideradas de forma separada.

Para esclarecer de que forma cada teoria foi usada para embasar a formulação das questões de pesquisa, as análises, interpretações e as conclusões, foram apresentados o modelo teórico, conceitos e aspectos epistemológicos, bem como alguns dos estudos que relacionam o controle gerencial e o Custeio Alvo a cada uma. Ainda, foram apresentadas as medidas das variáveis usadas na parte empírica da pesquisa.

\subsection{Teoria da Contingência Estrutural}

A Teoria da Contingência Estrutural é derivada do funcionalismo estrutural desenvolvido na Sociologia e foi incorporada aos estudos organizacionais que buscavam entender a lógica em que as organizações eram estruturadas. A Teoria da Contingência Estrutural, que neste trabalho foi denominada apenas de Teoria da Contingência, faz parte dos estudos organizacionais e tem fornecido um paradigma coerente para a análise da estrutura das 
organizações, sendo construída como um corpo de conhecimento científico (DONALDSON, 2007).

No início do desenvolvimento da Administração científica algumas teorias procuravam oferecer soluções universais para todos os problemas, definindo técnicas e estruturas que deveriam funcionar em todos os casos (MAXIMIANO, 2004). Contrariando essa escola clássica de Administração, para a qual existiria apenas uma única estrutura organizacional que seria altamente efetiva para organizações de todos os tipos (the best way), a Teoria da Contingência estabelece que não existe uma estrutura organizacional única que seja altamente efetiva para todas as organizações (DONALDSON, 2001).

Orientada por esta ideia principal, para a Teoria da Contingência a otimização de uma estrutura depende de fatores internos à organização, que por sua vez são influenciados pelo ambiente. Os estudos evidenciam vários fatores chamados de contingentes (estratégia, porte, incerteza com relação às tarefas, tecnologia, dentre outros) e para ser efetiva a organização precisa ajustar sua estrutura a seus fatores e, com isso, ao ambiente (DONALDSON, 2007). A adequação ou ajuste (fit) ocorre para evitar perda de desempenho, ou seja, quando uma contingência afeta a organização sua estrutura deve ser ajustada a essa contingência, caso contrário a mesma começa perder eficiência. Assim, a busca pela eficiência é a finalidade do ajuste da estrutura.

Os estudos iniciais desse campo tentavam encontrar padrões entre determinados fatores contingentes e a estrutura, bem como sua relação com o desempenho. Esses desenvolvimentos deram origem a duas teorias: a orgânica e a da burocracia, que constituem os componentes da Teoria da Contingência. Como no Brasil existem trabalhos como os de Guerra (2007), Espejo (2008) e Junqueira (2010), que apresentam as pesquisas iniciais da Teoria da Contingência e seus resultados em detalhes, optou-se por não fazer o mesmo aqui.

Atualmente, de acordo com suas pesquisas sobre a evolução da abordagem contingencial, Donaldson (2007) mostra que a mesma se desenvolveu formando um paradigma coerente para os estudos organizacionais e acrescenta que "A ciência normal que tem sido seguida dentro do paradigma contingencial é provavelmente a mais ampla corrente isolada de ciência normal no estudo da estrutura organizacional até o presente." (p. 105). 


\subsubsection{Teoria da Contingência e a Contabilidade Gerencial}

As pesquisas que usam a abordagem da contingência no campo dos estudos organizacionais desde o início de sua evolução geralmente relacionam os fatores contingentes à estrutura organizacional, tendo o objetivo amplo de explicar a forma da organização, ou seja, qual a estrutura adequada de acordo com determinados fatores contingentes presentes na organização. A partir daí, alguns pesquisadores ligados à Contabilidade passaram a relacionar os fatores contingentes com aspectos da Contabilidade Gerencial usando a mesma lógica, ou seja, a forma do sistema de Contabilidade Gerencial depende dos fatores contingentes.

Assim, simultaneamente ao desenvolvimento da Teoria da Contingência das Organizações, mas de forma totalmente independente, começou a se desenvolver a Teoria da Contingência da Contabilidade Gerencial, com a percepção de que o contexto organizacional de um sistema contábil era de fundamental importância para sua eficiência (OTLEY, 1980).

Os primeiros estudos deste tipo na Contabilidade investigaram a relação de fatores como o ambiente, a tecnologia, a estrutura e o porte com o modelo do SCG (CHENHALL, 2007). De acordo com Otley (1980), a abordagem da contingência da Contabilidade Gerencial é baseada na premissa de que não existe um sistema contábil universalmente apropriado que se aplique igualmente a todas as organizações em todas as circunstâncias. Ao invés disso, é sugerido que características particulares de um sistema contábil gerencial apropriado dependerão das circunstâncias específicas em que uma organização se encontra e a não existência do "the best way" passou a fazer parte da agenda dos pesquisadores.

Covaleski et al. (1996) mencionam que o tema básico elaborado pela Teoria da Contingência da Contabilidade Gerencial é que sistemas de controle apertados (tight) devem ser utilizados em organizações de administração centralizada, que lidam com tecnologia simples em ambiente de trabalho estável; já um sistema de controle frouxo (loose) deve ser utilizado em organizações descentralizadas, confrontadas com ambientes dinâmicos e tarefas complexas.

De acordo com Chenhall e Langfield-Smith (1998a) as estruturas conceituais da contingência têm sido empregadas extensivamente na literatura organizacional e contábil e, para Dent (1990), a Teoria da Contingência tem se tornado um dos paradigmas dominantes na pesquisa sobre os SCG. A preocupação com questões de coordenação e controle nos estudos baseados na Teoria da Contingência forneceu importantes contribuições para a pesquisa em Contabilidade Gerencial por auxiliar a compreensão de temas como a concepção de sistemas 
de informação e controle, orçamento e planejamento estratégico (COVALESKI et al., 1996). Além disso, devido ao fluxo contínuo de artigos empíricos nessa área de pesquisa pode se verificar sua importância e vitalidade (GERDIN; GREVE, 2004), sendo útil para as contínuas buscas por respostas para os problemas e dilemas organizacionais.

\subsubsection{Aspectos Epistemológicos da Teoria da Contingência}

As escolas de pensamento organizacional são várias, diferenciando-se nos aspectos ontológicos, epistemológicos, nos níveis de análise e na forma como enxergam a natureza humana. Conhecer as questões epistemológicas de uma teoria é importante para poder entender sua delimitação e para auxiliar seu emprego em uma pesquisa. Por isso, na sequência esses aspectos foram apresentados em relação à Teoria da Contingência.

O funcionalismo sociológico é a base da Teoria da Contingência evidenciando que as variações na estrutura das organizações são identificadas e explicadas por funcionarem eficazmente em determinada situação; assim, a estrutura se ajusta às contingências e por sua vez ao ambiente (DONALDSON, 2007). O paradigma da sociologia funcionalista, de acordo com seus pressupostos, abriga várias escolas de pensamento dentre elas a Teoria do Sistema Social, da qual fazem parte o funcionalismo estrutural e a Teoria dos Sistemas, que fundamentaram a origem da Teoria da Contingência Estrutural (BURRELL; MORGAN, 1979). Esse paradigma procura explicar as estruturas sociais através de suas funções. Merton (1968) menciona que a estrutura afeta a função e a função afeta a estrutura e que as funções sociais de uma organização ajudam a determinar a estrutura assim como a estrutura ajuda a determinar a eficácia com que as funções são realizadas.

As classificações dos aspectos relativos ao funcionalismo feitas na sequência foram baseadas em Burrel e Morgan (1979). Em relação à natureza humana o funcionalismo é determinista. Para Astley e Van de Ven (2005), na orientação determinista a origem absoluta das mudanças é o ambiente e o comportamento organizacional é moldado por uma série de mecanismos impessoais que atuam como restrições internas sobre os agentes. No debate determinista entram mais alguns pressupostos relativos ao funcionalismo estrutural como o comportamento adaptativo, a racionalidade e o papel reativo do gestor. Isto ocorre pelo fato de que, no determinismo, a organização deve se adaptar ao ambiente; assim, não resta alternativa para o 
gestor senão uma reação: a adaptação. Essa reação tem como consequência a tentativa de manter ou maximizar resultados, ou seja, a racionalidade econômica.

Quanto à questão da racionalidade na tomada de decisão, Astley e Van de Ven (2005) mencionam que nas abordagens estrutural-funcionais a tomada de decisão é predominantemente racional, pois apresenta um comportamento funcional orientado para resultados. E complementam afirmando que "A Teoria da Contingência presume que as restrições contextuais apresentam efeitos obrigatórios nas operações organizacionais. Em outras palavras, o contexto possui uma primazia causal; a gestão responde simplesmente de maneira tecnicamente adequada." (ASTLEY; VAN de VEN, 2005, p. 58).

O conceito chave do funcionalismo é o da organização como um sistema em que atingir metas explícitas por meio da tomada de decisão racional é funcionalmente eficaz (CLEGG; HARDY, 2007). Assim, a mudança ocorre de forma adaptativa, ou seja, o ambiente determina a mudança e de acordo com a racionalidade a empresa se adapta ao ambiente. Astley e Van de Ven (2005) mencionam que a visão de adaptação tem dominado historicamente a teoria organizacional e que os teóricos da contingência têm enfatizado essa característica no sentido de que as organizações respondem às mudanças de forma a elaborar ou modificar as estruturas internas para manter uma relação isomórfica com o ambiente.

O funcionalismo adota o objetivismo. De acordo com Caldas e Vergara (2005, p. 67) "Para os funcionalistas, as organizações são objetos tangíveis, concretos e objetivos." Para Abbagnano (2007, p. 841) o objetivismo representa "Qualquer doutrina que admita a existência de objetos (significados, conceitos, verdades, valores, normas etc.) válidos independentemente das crenças e das opiniões dos diferentes sujeitos."

O funcionalismo apresenta uma ontologia realista, ou seja, advém do realismo. De acordo com Abbagnano (2007) em relação à sua definição ontológica entende-se por realismo, na filosofia de orientação analítica, a crença em determinados tipos de entidades que implicam as seguintes teses: o descritivismo, o objetivismo e o objeto-centrismo. Essa acepção indica que o real é o objeto ou a coisa que pode ser descrita sem subjetividade, ou seja, não está nas ideias e sim no mundo sensorial, é o que existe e não o que deveria existir ou o que alguém imagina que deveria existir.

O funcionalismo é positivista. O positivismo, assim como o realismo, busca explicar as coisas sem envolver subjetivismo, dando atenção ao objeto na tentativa de descrevê-lo. Esse tipo de pesquisa busca identificar relações entre variáveis, estabelecendo hipóteses e fazendo seu 
teste, utiliza critérios probabilísticos para a definição de amostras, usa instrumentos estruturados para a coleta de dados e técnicas estatísticas para o seu tratamento, buscando a generalização (CALDAS; VERGARA, 2005). Para Burrell e Morgan (1979) o positivismo é caracterizado por epistemologias que procuram explicar e prever o que ocorre no mundo social pela busca de regularidades e relações causais entre os elementos que o constituem.

O nível de análise da Teoria da Contingência é o micro, representado por organizações individuais (ASTLEY; VAN de VEN, 2005). Nesse tipo de pesquisa as ações individuais dos gestores não são analisadas, não se levando em conta os atores individuais, mas sim a organização. Dadas as características do paradigma funcionalista, que é a base da Teoria da Contingência, pode-se a partir daí verificar como a mesma funciona.

A dinâmica da Teoria da Contingência geralmente envolve três categorias de análise sendo uma relacionada à estrutura, outra ao desempenho e outra ao fator contingente, que possui um efeito moderador sobre as outras duas. Como o que causa a mudança da estrutura é a contingência, é interessante verificar qual seu significado para a teoria. De acordo com Donaldson (2001, p. 7) "Uma contingência é qualquer variável que modera o efeito de uma característica organizacional sobre o desempenho organizacional"2. De forma mais específica, são fatores que podem afetar a relação entre as características do SCG e o desempenho (CHENHALL; CHAPMAN, 2006).

Esclarecido seu conceito pode-se verificar o modelo teórico contingente. De acordo com Donaldson (2001), a Teoria da Contingência contém três elementos essenciais que juntos formam seu paradigma central: primeiro, existe uma associação entre contingência e estrutura organizacional; segundo, a contingência determina a estrutura; terceiro, existe uma adequação/ajuste (fit) de algum nível da variável da estrutura organizacional a cada nível de contingência que conduz a um aumento de desempenho, enquanto um desajuste (misfit) conduz a uma redução no desempenho. A relação adequação-desempenho é o coração do paradigma da Teoria da Contingência, fornecendo explicação teórica para os dois primeiros elementos (DONALDSON, 2001).

Quando esse modelo é transportado para os estudos da Contabilidade Gerencial alguns ajustes são necessários, sempre observando os aspectos relativos ao seu paradigma teórico. Em primeiro lugar, na Contabilidade o elemento "estrutura organizacional" se refere aos tipos de

\footnotetext{
2 "A contingency is any variable that moderates the effect of an organizational characteristic on organizational performance.” Em inglês no original. Tradução livre da autora.
} 
sistemas gerenciais (por exemplo, sistema de controle e sistema de contabilidade gerencial) ou às práticas gerenciais (como o Balanced Scorecard, Custeio Alvo, Orçamento, dentre outras), uma vez que estes são o objeto de interesse da Contabilidade Gerencial.

Então, a avaliação recai sobre o tipo de sistema ou de prática que é mais adequado para promover o desempenho de acordo com as contingências presentes em uma organização. Nesse caso, primeiro existe uma associação entre contingência e sistemas ou práticas gerenciais; segundo, a contingência determina o sistema ou a prática; terceiro, existe uma adequação/ajuste (fit) de algum nível da variável do sistema ou da prática gerencial a cada nível de contingência que conduz a um aumento de desempenho, enquanto um desajuste (misfit) conduz a uma redução no desempenho.

É nessa linha de raciocínio que o presente trabalho utilizou a Teoria da Contingência, procurando identificar, dentre alguns fatores que podem estar relacionados à adoção do Custeio Alvo, quais estavam presentes na organização investigada. Vários trabalhos, analisados na sequência, estudaram fatores contingentes que são mais propícios para a adoção do Custeio Alvo; no entanto, alguns dos resultados são conflitantes, havendo a necessidade de pesquisas adicionais. Dessa forma, o objetivo foi verificar a adequação do Custeio Alvo em relação aos fatores contingentes presentes na empresa Alfa.

A avaliação de desempenho em relação ao sistema ou às práticas também foi considerada. Devido à dificuldade em se isolar o efeito dos sistemas de controle ou das práticas em relação ao resultado organizacional, conforme evidenciado no Capítulo 3 item 3.1.1.3, nessa pesquisa o desempenho foi avaliado em relação à utilidade do Custeio Alvo para a Alfa. Assim, uma vez que o mesmo esteja adequado às contingências enfrentadas pela organização, a tendência é haver uma percepção favorável acerca da sua utilidade.

\subsubsection{O Custeio Alvo e a Teoria da Contingência}

O objetivo desse tópico foi verificar o que os trabalhos que abordaram o Custeio Alvo no âmbito da Teoria da Contingência puderam auxiliar no desenvolvimento da presente pesquisa. Por isso, foi feita uma busca em periódicos internacionais e nacionais como: Accounting Horizons, Accounting, Organizations and Society, Management Accounting Research, 
Revista de Administração Contemporânea, Revista de Administração de Empresas, Revista de Administração da USP e Revista Contabilidade e Finanças, referentes aos últimos vinte anos.

Essa análise permitiu que fossem encontrados diversos artigos envolvendo os temas mencionados, inclusive em outros periódicos. Foi encontrada também uma dissertação de mestrado apresentada no Brasil. A análise não pretendeu esgotar o assunto nem ser exaustiva; apenas teve o objetivo de mostrar o que as pesquisas encontradas desenvolveram em termos de medidas e resultados que puderam auxiliar as questões envolvendo a adequação entre os fatores contingentes e o Custeio Alvo.

\subsubsection{Dekker e Smidt (2003)}

O trabalho buscou verificar se as empresas adotaram ou não o Custeio Alvo ou ainda se usam técnicas similares sem estarem familiarizadas com seu conceito. Os setores que tiveram a maior incidência do uso foram o eletrônico, têxtil, de equipamentos de precisão e química. Somente uma das empresas respondeu que o sistema usado se chamava Custeio Alvo; nas demais os nomes eram variados como "preço básico líquido", "redução de custos", "redução de custo de manufatura", "maximização da margem de contribuição" dentre outros.

O estudo investigou ainda os fatores contingentes (concorrência, incerteza ambiental e foco no custo) relacionados à adoção. A concorrência foi mensurada usando-se dois indicadores: o número de concorrentes e a intensidade da concorrência percebida. A incerteza ambiental percebida foi mensurada pela imprevisibilidade do ambiente e o último fator mensurou a importância do foco em custo. Os testes estatísticos mostraram que um ambiente mais imprevisível e uma concorrência mais intensa estavam significativamente relacionados ao uso destas práticas. $\mathrm{O}$ número de concorrentes e o foco em custo não foram significativamente relacionados com a adoção.

\subsubsection{Hibbets et al. (2003)}

O objetivo do trabalho foi avaliar o ambiente competitivo e a estratégia das empresas que têm sido identificadas como implementadoras do Custeio Alvo para determinar se forças ambientais específicas acopladas à estratégia da empresa poderiam ser ligadas à decisão de 
adotar o mesmo. A estratégia foi avaliada de acordo com a tipologia de Porter, liderança de custos e diferenciação de produtos, e também a estratégia de confronto (confrontational) de Cooper, pela qual a empresa produz itens de alta qualidade ao menor custo possível.

O ambiente competitivo foi avaliado pelo modelo das cinco forças de Porter, que são: intensidade ou rivalidade entre os vendedores concorrentes, a ameaça de novos entrantes potenciais, a ameaça dos substitutos, o poder dos fornecedores chave e o poder dos compradores chave. A pesquisa investigou a pressão competitiva coletivamente, verificando se as mesmas eram fortes entre as empresas que adotaram e, individualmente, verificando se cada força competitiva teve efeito importante sobre a escolha. Também foi investigado se as empresas que adotaram o Custeio Alvo possuíam combinações de forças competitivas individuais e estratégia.

Em relação à estratégia a maioria utilizava a diferenciação de produtos. Quanto ao ambiente competitivo os resultados mostraram que as forças competitivas foram altas para todas as empresas, especialmente em relação à rivalidade e poder dos compradores. O último item analisado se refere à investigação sobre combinações de forças competitivas individuais e estratégia entre as empresas analisadas e os achados mostraram que quando um ambiente competitivo caracterizado por intensa rivalidade e alto poder dos fornecedores e cujas empresas seguem a estratégia de diferenciação de produto os gestores deveriam considerar a adoção do Custeio Alvo.

\subsubsection{Ax et al. (2008)}

O trabalho teve como objetivo verificar a influência de fatores contingentes (intensidade da concorrência e incerteza ambiental percebida) na adoção do Custeio Alvo. Para medir a intensidade da concorrência e a incerteza ambiental os autores fizeram uma adaptação do instrumento de Gordon e Narayanan (1984). O porte da empresa foi medido pelo número de empregados e foi usado como variável de controle no modelo de regressão logística.

Foi encontrada uma correlação positiva entre a intensidade da concorrência e a adoção, conforme estudos anteriores. Os testes estatísticos relacionados à incerteza ambiental e à adoção não foram significantes; no entanto, mostraram indícios de uma relação negativa, contrariando estudos anteriores que acharam uma relação positiva. A pesquisa também 
verificou que um aumento na incerteza ambiental reduz o impacto positivo da intensidade da concorrência sobre a probabilidade de adotar o Custeio Alvo, ou seja, a incerteza ambiental modera o efeito da concorrência sobre a adoção da prática.

\subsubsection{Bertucci (2008)}

Trata-se de uma dissertação de mestrado, sendo o único trabalho brasileiro encontrado envolvendo o Custeio Alvo e fatores contingentes. Os achados do trabalho não foram conclusivos em relação às empresas que adotaram ou não o Custeio Alvo, embora haja uma forte tendência de que o mesmo não fosse utilizado. Por isso, seus resultados não puderam ser usados para comparações com os demais trabalhos analisados, mas é interessante verificar quais fatores foram analisados e como foram medidos. Os fatores analisados foram a estratégia, concorrência, porte e tempo de estabelecimento da empresa. O porte foi avaliado de acordo com o faturamento bruto. $\mathrm{O}$ fator estratégia foi medido baseado na tipologia de Porter (liderança de custos e diferenciação de produtos). A concorrência foi mensurada através de duas questões não relacionadas diretamente a algum construto usado em trabalhos anteriores.

Além das pesquisas apresentadas relacionadas apenas ao Custeio Alvo, alguns trabalhos relativos ao assunto buscaram analisar várias práticas gerenciais. Alguns destes estudos são igualmente importantes pelo fato de o Custeio Alvo estar presente entre as práticas analisadas. Na sequência estes estudos são abordados não em sua totalidade, mas unicamente quanto aos pontos que se referem à prática em questão.

\subsubsection{Baines e Langfield-Smith (2003)}

O trabalho teve como objetivo investigar as relações entre as mudanças no ambiente competitivo e uma série de variáveis organizacionais como sendo fatores antecedentes à mudança na Contabilidade Gerencial. Os resultados indicaram que um aumento no ambiente competitivo tem resultado em um maior enfoque nas estratégias de diferenciação que, por sua vez, tem influenciado mudanças no modelo organizacional, em tecnologias avançadas de produção e em práticas avançadas de Contabilidade Gerencial. Embora não apareça 
claramente no texto quais são as práticas avançadas, o Custeio Alvo é citado quando da elaboração da hipótese mencionada anteriormente.

\subsubsection{Cadez e Guilding (2008)}

O objetivo do estudo foi examinar o efeito das escolhas estratégicas, da orientação de mercado e do porte da empresa sobre duas dimensões da Contabilidade Gerencial Estratégica e, ainda, o efeito mediador desta última sobre o desempenho da companhia. A estratégia foi avaliada pelo construto de Miles e Snow (prospectores e defensores). Os achados indicaram que o uso das práticas analisadas (dentre elas o Custeio Alvo) foi positivamente associado com a estratégia de negócios relativa aos prospectores e ainda com o porte. Foram encontradas evidências de que o uso das práticas afetou positivamente o desempenho da companhia. Para a maioria dos entrevistados o fator que mais afeta o uso das práticas analisadas é a estratégia do negócio e o segundo é a intensidade da concorrência. A orientação de mercado não teve significância estatística em relação ao uso das práticas.

\subsubsection{Cinquini e Tenucci (2010)}

O estudo teve como objetivo investigar se a estratégia de negócio influenciava o uso de práticas da Contabilidade Gerencial Estratégica. Para avaliar a estratégia foram usados três construtos: o de Miles e Snow (prospectores e defensores); o de Gupta e Govindarajan (construir e colher) e o de Porter (diferenciação e liderança de custo). Foram analisadas 11 práticas de Contabilidade Gerencial Estratégica, dentre elas o Custeio Alvo. O porte da companhia foi usado como variável de controle. As evidências mostraram que na estratégia do tipo defensores existia uma maior incidência do uso das práticas classificadas como custeio, incluindo o Custeio Alvo. Não foram encontradas relações entre as estratégias construir e colher com práticas como o Custeio Alvo. A estratégia de liderança de custo foi relacionada com as práticas de custeio, dentre elas o Custeio Alvo.

Um resumo com os principais aspectos avaliados nos trabalhos expostos podem ser visualizados no Quadro 1 na sequência. 
Quadro 1: Resumo das principais pesquisas que relacionam fatores contingentes e Custeio Alvo

\begin{tabular}{|c|c|c|c|c|}
\hline Trabalho & Objetivo & $\begin{array}{c}\text { Fatores } \\
\text { Contingentes }\end{array}$ & Construtos & Principais Achados \\
\hline $\begin{array}{l}\text { Dekker e } \\
\text { Smidt } \\
(2003)\end{array}$ & $\begin{array}{lr}\text { Investigar } & \text { a } \\
\text { adoção e uso de } \\
\text { práticas } & \text { de } \\
\text { custeio que } & \text { se } \\
\text { assemelham } & \text { com } \\
\text { o conceito de } \\
\text { Custeio } \\
\text { japonês. Alvo }\end{array}$ & $\begin{array}{c}\text { Setor, } \\
\text { concorrência, } \\
\text { incerteza } \\
\text { ambiental e o } \\
\text { foco no custo }\end{array}$ & $\begin{array}{l}\text { A concorrência foi } \\
\text { mensurada usando: o } \\
\text { número de concorrentes e } \\
\text { a intensidade da } \\
\text { concorrência percebida. A } \\
\text { incerteza ambiental } \\
\text { percebida foi mensurada } \\
\text { pela imprevisibilidade do } \\
\text { ambiente. }\end{array}$ & $\begin{array}{l}\text { - Um ambiente mais } \\
\text { imprevisível e uma } \\
\text { concorrência mais intensa } \\
\text { são significativamente } \\
\text { relacionados ao uso do } \\
\text { Custeio Alvo; } \\
\text { O número de } \\
\text { concorrentes e o foco em } \\
\text { custo não foram } \\
\text { significativamente } \\
\text { relacionados com a } \\
\text { adoção. }\end{array}$ \\
\hline $\begin{array}{l}\text { Hibbets } \\
\text { et al. } \\
(2003)\end{array}$ & $\begin{array}{l}\text { Avaliar } 0 \\
\text { ambiente } \\
\text { competitivo e a } \\
\text { estratégia das } \\
\text { empresas que têm } \\
\text { sido identificadas } \\
\text { como } \\
\text { implementadoras } \\
\text { do Custeio Alvo. }\end{array}$ & $\begin{array}{l}\text { Ambiente } \\
\text { competitivo e } \\
\text { estratégia }\end{array}$ & $\begin{array}{l}\text { A estratégia foi avaliada } \\
\text { de acordo com as } \\
\text { tipologias de Porter e de } \\
\text { Cooper. O ambiente } \\
\text { competitivo foi avaliado } \\
\text { pelo modelo das cinco } \\
\text { forças de Porter. }\end{array}$ & $\begin{array}{l}\text { - A diferenciação de } \\
\text { produtos foi a estratégia } \\
\text { adotada com maior } \\
\text { frequência; } \\
\text { - As forças competitivas } \\
\text { foram altas para todas as } \\
\text { empresas, especialmente } \\
\text { em relação à rivalidade e } \\
\text { poder dos compradores. }\end{array}$ \\
\hline $\begin{array}{c}\text { Ax } \text { et al. } \\
(2008)\end{array}$ & $\begin{array}{l}\text { Verificar a } \\
\text { influência de } \\
\text { alguns fatores } \\
\text { contingentes na } \\
\text { adoção do } \\
\text { Custeio Alvo. }\end{array}$ & $\begin{array}{l}\text { Intensidade da } \\
\text { concorrência, } \\
\text { incerteza } \\
\text { ambiental } \\
\text { percebida e } \\
\text { tamanho da } \\
\text { empresa }\end{array}$ & $\begin{array}{l}\text { Para medir a intensidade } \\
\text { da concorrência e a } \\
\text { incerteza ambiental foi } \\
\text { feita uma adaptação do } \\
\text { construto de Gordon e } \\
\text { Narayanan (1984), } \\
\text { decompondo-o em dois, } \\
\text { sendo cinco variáveis para } \\
\text { avaliar a concorrência e } \\
\text { duas para avaliar a } \\
\text { incerteza. O tamanho da } \\
\text { empresa foi mensurado } \\
\text { pelo número de } \\
\text { empregados. }\end{array}$ & $\begin{array}{l}\text { - Foi encontrada uma } \\
\text { correlação positiva entre } \\
\text { a intensidade da } \\
\text { concorrência e a adoção; } \\
\text { - Os testes estatísticos } \\
\text { relacionados à correlação } \\
\text { negativa entre a incerteza } \\
\text { ambiental e a adoção não } \\
\text { foram significantes, mas, } \\
\text { mostraram indícios dessa } \\
\text { relação negativa; } \\
\text { A incerteza ambiental } \\
\text { modera o efeito da } \\
\text { concorrência sobre a } \\
\text { adoção da prática. }\end{array}$ \\
\hline $\begin{array}{c}\text { Bertucci } \\
(2008)\end{array}$ & $\begin{array}{l}\text { Verificar se } \\
\text { empresas } \\
\text { brasileiras de } \\
\text { autopeças } \\
\text { utilizam o } \\
\text { Custeio Alvo e se } \\
\text { alguns fatores } \\
\text { contingentes } \\
\text { influenciaram sua } \\
\text { adoção. } \\
\end{array}$ & $\begin{array}{l}\text { Estratégia, } \\
\text { porte e } \\
\text { concorrência. }\end{array}$ & $\begin{array}{l}\text { A estratégia foi avaliada } \\
\text { pela tipologia de Porter. O } \\
\text { porte pelo faturamento } \\
\text { bruto. E a concorrência foi } \\
\text { avaliada pelo nível de } \\
\text { competitividade, o número } \\
\text { de concorrentes, o grau de } \\
\text { incerteza do ambiente e o } \\
\text { grau de concentração do } \\
\text { mercado. }\end{array}$ & \\
\hline $\begin{array}{l}\text { Baines e } \\
\text { Langfiel- } \\
\text { Smith } \\
(2003)\end{array}$ & $\begin{array}{lr}\text { Investigar } & \text { as } \\
\text { relações entre } & \text { as } \\
\text { mudanças } & \text { no } \\
\text { ambiente } & \\
\text { competitivo } & \text { e } \\
\text { uma série de } \\
\text { variáveis } \\
\text { organizacionais. }\end{array}$ & $\begin{array}{l}\text { Efeito das } \\
\text { mudanças em } \\
\text { vários fatores } \\
\text { ambientais, } \\
\text { como a } \\
\text { estratégia e o } \\
\text { ambiente } \\
\text { competitivo. }\end{array}$ & $\begin{array}{l}\text { O modelo de estratégia } \\
\text { usada para estabelecer } \\
\text { hipóteses foi o de } \\
\text { diferenciação de produtos. }\end{array}$ & $\begin{array}{l}\text { Um aumento na } \\
\text { competitividade tem } \\
\text { resultado em um maior } \\
\text { enfoque nas estratégias } \\
\text { de diferenciação que, por } \\
\text { sua vez, tem influenciado } \\
\text { mudanças nas práticas } \\
\text { avançadas de } \\
\text { Contabilidade Gerencial. }\end{array}$ \\
\hline
\end{tabular}


Quadro 1: continuação

\begin{tabular}{|c|c|c|c|c|}
\hline Trabalho & Objetivo & $\begin{array}{c}\text { Fatores } \\
\text { Contingentes }\end{array}$ & Construtos & Principais Achados \\
\hline $\begin{array}{l}\text { Cadez e } \\
\text { Guilding } \\
(2008)\end{array}$ & $\begin{array}{l}\text { Examinar o efeito } \\
\text { das escolhas } \\
\text { estratégicas, } \\
\text { orientação de } \\
\text { mercado e porte } \\
\text { da companhia } \\
\text { sobre a } \\
\text { Contabilidade } \\
\text { Gerencial } \\
\text { Estratégica e, o } \\
\text { efeito mediador } \\
\text { da Contabilidade } \\
\text { Gerencial } \\
\text { Estratégica sobre } \\
\text { o desempenho da } \\
\text { companhia. }\end{array}$ & $\begin{array}{l}\text { Estratégia, } \\
\text { orientação de } \\
\text { mercado e } \\
\text { porte. }\end{array}$ & $\begin{array}{l}\text { A estratégia foi avaliada } \\
\text { pela tipologia de Miles e } \\
\text { Snow. Orientação de } \\
\text { mercado usou o } \\
\text { instrumento de Guilding e } \\
\text { McManus. Porte foi } \\
\text { mensurado pelas receitas } \\
\text { totais. }\end{array}$ & 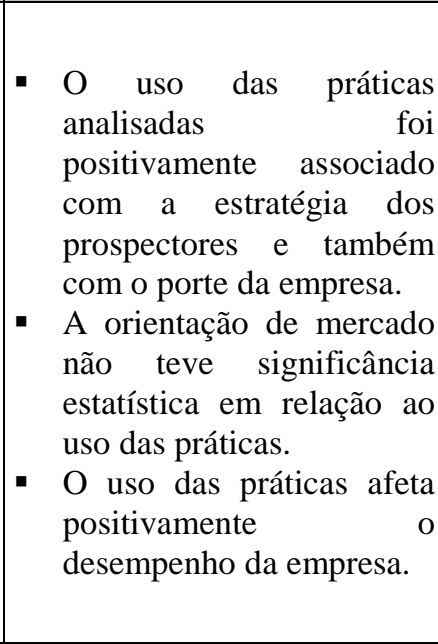 \\
\hline $\begin{array}{l}\text { Cinquini } \\
\text { e Tenucci } \\
(2010)\end{array}$ & $\begin{array}{c}\text { Investigar se a } \\
\text { estratégia do } \\
\text { negócio influencia } \\
\text { o uso de práticas } \\
\text { da Contabilidade } \\
\text { Gerencial } \\
\text { Estratégica. }\end{array}$ & Estratégia. & $\begin{array}{c}\text { Foram usadas três } \\
\text { tipologias: Miles e Snow, } \\
\text { Gupta e Govindarajan e } \\
\text { Porter. }\end{array}$ & 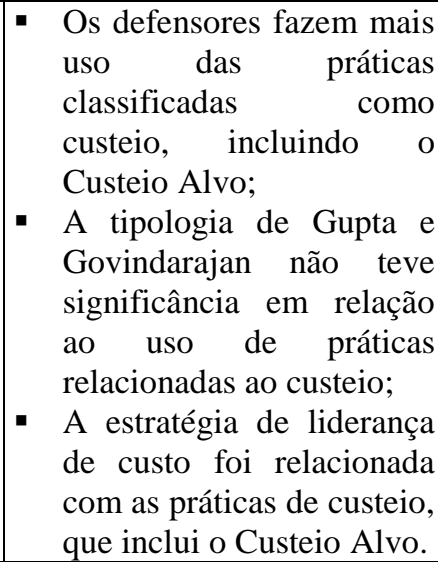 \\
\hline
\end{tabular}

\subsubsection{Análise dos Fatores Contingentes e sua Adequação em Relação ao Custeio Alvo}

Conforme pode ser observado pelo Quadro 1, as pesquisas empíricas que usaram fatores contingentes em relação à adoção do Custeio Alvo apresentam algumas inconsistências em relação aos resultados. Isso pode, em parte, ser explicado pelas críticas feitas em relação ao uso da Teoria da Contingência nas pesquisas em Contabilidade Gerencial segundo as quais as pesquisas não seguem um padrão, utilizando diferentes abordagens e medidas fazendo com que os resultados não possam ser somados ou comparados (OTLEY, 1980; CHENHALL, 2007; CHAPMAN, 1997, LANGFIELD-SMITH, 2007).

Devido a essa realidade esse tópico visa discutir, dentre os fatores contingenciais investigados, quais tipos seriam mais propícios ou adequados para a adoção e utilização do Custeio Alvo de acordo com a literatura específica envolvendo SCG, Custeio Alvo e contingência. $\mathrm{O}$ objetivo aqui é de verificar se os fatores considerados adequados estão 
presentes na organização (questão 1.1) e se esta vem obtendo um desempenho satisfatório quanto à utilização do Custeio Alvo (questão 1.7).

Antes das análises alguns destaques são importantes. Primeiro, o objetivo foi relacionar os fatores contingentes com o Custeio Alvo, mas existem relações entre os próprios fatores (por exemplo, porte influencia estrutura, estratégia influencia tecnologia e assim por diante), por isso, é difícil estabelecer a direção do relacionamento já que, geralmente, não é unidirecional (ABERNETHY; LILLIS, 1995). Além disso, alguns fatores podem funcionar como mediadores na relação com outros (por exemplo, fatores ambientais externos à organização podem influenciar os fatores internos que por sua vez podem influenciar o desenho do sistema), o que também dificulta o estabelecimento da direção. Dessa forma, a análise foi ancorada nos fatores que, de acordo com as discussões baseadas na literatura específica, seria o conjunto adequado no caso de adoção e utilização do Custeio Alvo, sem se preocupar com o direcionamento da relação nem com a relação entre os mesmos.

Segundo, é importante frisar que, conforme discutido no Capítulo 3, item 3.1.1.1, em relação ao desenho do SCG, as características das informações podem ser classificadas em contemporâneas e tradicionais (suas características foram apresentadas no item 3.2.6); sendo o Custeio Alvo uma prática classificada como "nova" que apresenta informações com características do tipo contemporâneas (conforme apresentado no Capítulo 3 itens 3.1.1.1 e 3.2.6). Dessa forma, as análises dos fatores foram baseadas nessas características das informações.

Terceiro, um problema que também dificulta o entendimento nos estudos sobre contingência, de acordo com Ferreira e Otley (2009), é que um número substancial de estudos analisa um pequeno número de variáveis contingentes por vez e isso pode ser problemático devido às características comuns partilhadas entre os fatores.

Chenhall (2007) analisa o que denomina de principais fatores contingentes relacionados ao SCG compreendendo o ambiente externo, a estratégia, a tecnologia, o porte, a estrutura organizacional e a cultura nacional. $\mathrm{Na}$ presente pesquisa todos estes fatores foram considerados com exceção da cultura. A exclusão do fator cultura se deve ao fato de que, conforme apontado por Chenhall (2007), a pesquisa nessa área tem sido limitada e um tanto exploratória, proporcionando resultados variados sobre seus efeitos em aspectos do SCG, sendo poucas as áreas onde há consenso nos resultados. Ressalta-se que os fatores estrutura e 
tecnologia não foram abordados em nenhum dos trabalhos sobre Custeio Alvo analisados no item 2.1.3, o que pode agregar diferentes insights aos achados.

Quarto, Malmi e Granlund (2009) destacam que os estudos que investigam os fatores contingentes e sua relação com o SCG geram proposições ou achados tão gerais e até certo ponto tão evidentes que resultam em pouco uso ou pouco valor incremental na prática. $\mathrm{E}$ Malmi e Brown (2008) argumentam que a falta de claridade, a ampla variação e as inconsistências na forma de conceituar o SCG, têm gerado problemas de interpretação dos resultados das pesquisas. No presente estudo, tem-se a consciência dessas limitações quanto aos achados e as proposições dos trabalhos usados como base para verificar os fatores adequados ao Custeio Alvo; por isso, os resultados estão sendo usados apenas como um direcionamento para as análises. Na medida do possível, quando da investigação desses fatores na Alfa o objetivo é gerar resultados consistentes com as especificidades dos fatores e do Custeio Alvo no contexto dessa empresa.

Por essas e outras razões já mencionadas, o uso da Teoria da Contingência nesta pesquisa se justifica por auxiliar no entendimento das circunstâncias que podem promover a adoção e a utilização de uma prática do controle gerencial como o Custeio Alvo e, principalmente, se a mesma vem sendo útil para a empresa Alfa.

A Figura 2 mostra os seis fatores analisados, sendo a estratégia, a estrutura, a tecnologia e o porte fatores internos e o ambiente que compreende outros dois fatores, a concorrência e a incerteza ambiental, representando o fator externo à organização.

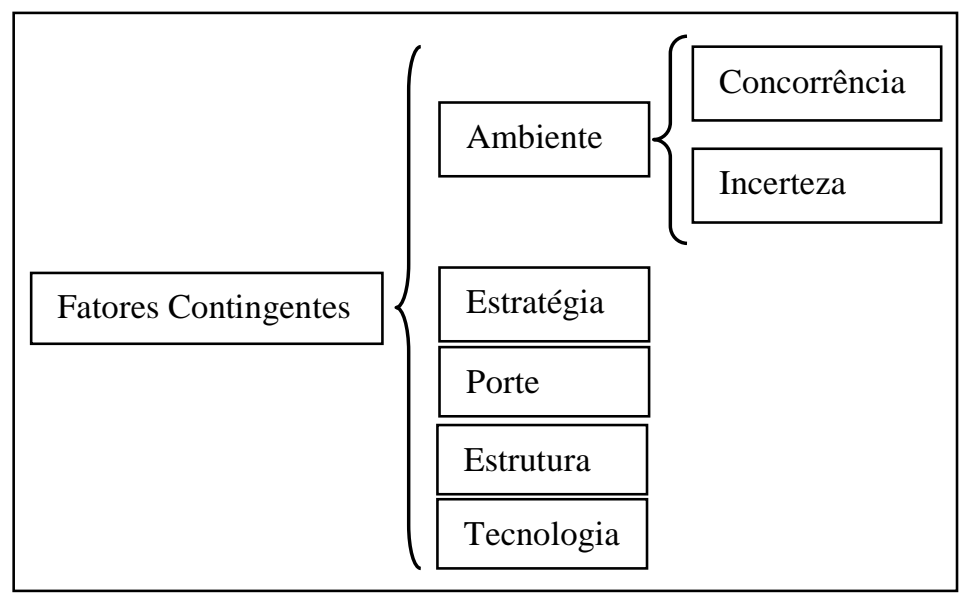

Figura 2: Fatores contingentes investigados

Na sequência foi discutido cada fator quanto à sua adequação ao Custeio Alvo em relação à literatura, destacando-se nos casos em que as pesquisas empíricas não apresentam consenso, 
qual foi o posicionamento adotado nessa pesquisa, de modo a auxiliar nas análises. Ainda, foi verificado que todos os fatores contingentes avaliados podem ser aplicáveis à empresa Alfa, de acordo com suas características.

\subsubsection{Ambiente}

O ambiente foi avaliado pela sua incerteza e pela intensidade da concorrência. Para Chenhall (2007) o aspecto mais amplamente pesquisado em relação ao ambiente talvez seja a incerteza. A lógica que faz com que o fator ambiente seja importante para os estudos da contingência se relaciona ao exposto por Gordon e Narayanan (1984) de que conforme a percepção da incerteza ambiental aumenta os tomadores de decisão buscam informações adicionais para o planejamento.

Em relação à incerteza ambiental percebida, as pesquisas sugerem que se trata de uma variável contingente chave em termos do desenho do SCG, mostrando que altos níveis de incerteza são associados com sistemas que enfatizam informações de escopo amplo (FERREIRA; OTLEY, 2009). Gordon e Narayanan (1984) concluíram com base em seu estudo empírico que quando os tomadores de decisão percebem maior incerteza no ambiente eles tendem a buscar informações externas, não financeiras e ex ante juntamente com outros tipos de informações. Então, a incerteza percebida aumenta o interesse por informações mais sofisticadas. Uma das conclusões do estudo empírico de Chenhall e Moris (1986) é que existe uma relação positiva entre incerteza ambiental percebida e a necessidade de informação com escopo amplo.

Gul e Chia (1994) sugerem que quando a incerteza ambiental percebida é baixa os gestores são capazes de ter previsões relativamente precisas sobre o mercado e quando a mesma é alta os gestores podem exigir informações adicionais para lidar com as complexidades do ambiente e, mencionam ainda, que relatórios mais sofisticados do Sistema de Informação Gerencial podem ajudar a reduzir a incerteza e melhorar a tomada de decisão gerencial.

Em relação ao Custeio Alvo e a incerteza ambiental, Ansari et al. (1997) comentam que o que torna essa prática tão importante na atualidade é a natureza do ambiente industrial contemporâneo; os negócios atuais enfrentam um ambiente competitivo globalizado que muda rapidamente e dita seu próprio conjunto de regras e o Custeio Alvo é mais adequado a 
este panorama. Esse ambiente em constante mudança caracteriza a incerteza ambiental e, nesse contexto, Ferreira e Otley (2009) argumentam que práticas de gestão de desempenho modernas, como o Custeio Alvo, têm sido propostas como meios de aumentar a eficácia organizacional permitindo que as empresas possam lidar melhor com um ambiente externo cada vez mais competitivo, dinâmico, imprevisível e incerto.

Para Tani (1995) as empresas japonesas têm adotado o Custeio Alvo como resposta ao aumento da incerteza ambiental. Dekker e Smidt (2003) encontraram uma relação significativa entre um ambiente mais imprevisível e o uso do Custeio Alvo. Deste modo, os estudos mencionados apontam que em ambientes caracterizados pela incerteza ambiental percebida o Custeio Alvo é uma prática adequada em relação ao tipo de informação que apresenta.

Ax et al. (2008) também investigaram a incerteza ambiental, mas os resultados não apresentaram significância estatística. Mesmo assim, encontraram uma relação negativa entre incerteza ambiental percebida e adoção do Custeio Alvo, argumentando que isso se deve ao fato de que as informações sobre os concorrentes e sobre os clientes são os insumos do processo e, se existe uma alta imprevisibilidade em relação às mesmas, existirá uma dificuldade em alimentar o processo (AX et al., 2008).

De fato, a dificuldade em obter dados e informações numa situação de incerteza parece existir. No entanto, o argumento usado por Ax et al. (2008) não apresenta consistência quando se consideram os demais estudos mencionados anteriormente, uma vez que, nesse ambiente, as informações de escopo amplo podem ser requeridas pelos gestores. Além disso, sabe-se que elementos ambientais de difícil previsibilidade têm impacto na estrutura organizacional, na avaliação de desempenho, no controle orçamentário e são associados a sistemas contábeis com foco mais aberto e externo (HALDMA; LÄÄTS, 2002). Assim, percebe-se que é possível gerar tais informações com sistemas mais sofisticados e que a imprevisibilidade afeta a organização de várias formas, por isso, é relevante uma análise mais minuciosa desse fato.

A esse respeito, Tillema (2005) argumenta que existe uma relação negativa entre o dinamismo do ambiente e a previsibilidade das consequências financeiras das operações. A baixa previsibilidade influencia o escopo das informações em duas direções opostas; em uma, a produção de informações mais sofisticadas e de escopo amplo é mais difícil; na outra, o uso 
de informações menos sofisticadas é menos eficiente, isso faz com que esta não seja uma simples relação linear (TILLEMA, 2005). Esses argumentos auxiliam a discussão por enfatizar que existe dificuldade de coletar informações no ambiente imprevisível, mas ao mesmo tempo elas são mais importantes nesse contexto que em ambientes previsíveis.

Os estudos sobre incerteza do ambiente geralmente não discutem a natureza dessa relação e isso pode gerar confusão nos resultados das pesquisas. As causas do ambiente dinâmico podem ser duas, a pouca idade das atividades operacionais e as mudanças inesperadas e significativas no ambiente externo (TILLEMA, 2005). Quando uma organização é nova em determinado setor, ainda não dispõe de informações sobre os resultados de suas ações e suas relações com o ambiente; mas, com o passar do tempo, o ambiente vai se tornando mais estável e mais previsível; no entanto, algumas empresas continuam enfrentando ambientes incertos mesmo tendo mais experiência e, nesse caso, o uso de informações de escopo amplo é necessário para prever as consequências das atividades futuras condicionadas à possível situação futura do mercado (TILLEMA, 2005).

Dessa forma, a análise sobre a incerteza do ambiente deve ser ampla englobando esses dois aspectos, a idade e a incerteza, e nessa pesquisa compartilhou-se desse entendimento. Então, considerou-se que em ambientes com baixa incerteza as ações e os resultados podem ser previstos com maior facilidade se a organização já possui experiência na atividade ou com maior dificuldade se a mesma estiver no início, mas, nesse caso os gestores não demandam informações de escopo amplo ou mais sofisticadas acerca do ambiente. Por outro lado, organizações com experiência e que enfrentam alta incerteza possuem mais condições de prever os resultados do que aquelas com menos experiência, no entanto, em ambos os casos necessitam de informações sofisticadas e de escopo amplo, como as fornecidas pelo Custeio Alvo. Por isso, esse é mais adequado em situações de incerteza ambiental, podendo a dificuldade de coleta dos dados do ambiente amenizada com a experiência da organização no mercado.

O outro fator ambiental analisado, a intensidade da concorrência, também tem sido considerado em relação ao desenho do SCG. Para Khandwalla (1972) a concorrência, de modo geral, induz a gestão a instituir controles formais sofisticados. A crescente globalização resultou em uma concorrência internacional agressiva e intensa, aumentando as demandas dos clientes e reduzindo o ciclo de vida dos produtos (DENT, 1996). Nesse novo cenário as organizações foram forçadas a reagir mudando suas estruturas para poder lidar com essas 
novas demandas, e novas estruturas exigem diferentes formas de controle e informações para embasar decisões e mensurar desempenho. $\mathrm{O}$ aumento da concorrência impulsionou as organizações a investirem em sistemas de informação mais refinados (HANSEN, 1998).

Baines e Langfield-Smith (2003) comentam que o crescimento da concorrência global intensificou os desafios para os gestores, que necessitam de meios mais efetivos de atingir vantagem competitiva e uma das formas de obter isso é através de sistemas contábeis inovadores. Sakurai (1997) menciona que um dos fatores responsáveis pela expansão do Custeio Alvo no Japão foi a intensificação da concorrência. O Custeio Alvo é particularmente benéfico sob intensa pressão competitiva, usado como forma de assegurar que somente produtos rentáveis sejam lançados; isso porque em ambientes altamente competitivos as organizações devem se tornar especialistas em desenvolver produtos de baixo custo e alta qualidade que tenham a funcionalidade exigida pelos clientes (COOPER; SLAGMULDER, 1997). O Custeio Alvo é uma prática que auxilia na realização dessas exigências garantindo o retorno desejado pela organização, por isso, sua importância em ambientes de intensa concorrência.

Os estudos empíricos de Dekker e Smidt (2003) e Ax et al. (2008) encontraram correlações positivas entre a intensidade da concorrência e a adoção ou uso do Custeio Alvo, corroborando as declarações abordadas anteriormente. Hibbets et al. (2003) também concluíram que as forças competitivas foram altas para todas as organizações que adotaram o Custeio Alvo. Os três estudos citados aqui usaram medidas diferentes para a intensidade da concorrência, mas chegaram a resultados semelhantes.

De acordo com a literatura apresentada a maior intensidade da concorrência é um fator que

pode influenciar a adoção do Custeio Alvo e nesta pesquisa esse também foi o posicionamento assumido, uma vez que ambientes ou segmentos com baixa intensidade de concorrência geralmente não demandam informações mais sofisticadas para planejamento de lucro e gestão de custos.

\subsubsection{Estratégia}

O fator estratégia foi introduzido nos estudos da contingência por Chandler (1962), que estudou sua relação com a estrutura organizacional. Para Snow e Hambrick (1980) os teóricos 
organizacionais veem a estratégia como o mecanismo que guia o alinhamento ambiental e fornece integração para operações internas. Por isso, pode impactar o SCG representando, de acordo com Otley (1999) e Simons (1995), um papel chave em seu desenho.

Chenhall (2007) afirma que a estratégia é um pouco diferente dos outros fatores por não se tratar de um elemento do contexto, mas de ser o meio pelo qual os gestores podem influenciar a natureza do ambiente externo, as tecnologias, a estrutura e o SCG. Muitas pesquisas consideram a premissa de que o SCG deve ser adaptado para apoiar as estratégias e aumentar a vantagem competitiva, encorajando um desempenho superior (LANGFIELD-SMITH, 2007). Vários autores (CADEZ; GUILDING, 2008; HIBBETS et al., 2003; LANGFIELDSMITH, 1997) argumentam que a estratégia é um importante fator contingencial para a adoção e uso de práticas da Contabilidade Gerencial, em especial aquelas ligadas às questões estratégicas, como o Custeio Alvo. Por essas razões é importante verificar a adequação entre as estratégias da organização e essa prática.

Desde o final da década de 1980 o Custeio Alvo se ligou fortemente à estratégia empresarial e é considerado um instrumento estratégico de gestão de custos para alcance da meta de lucro especificada no planejamento organizacional (SAKURAI, 1997). Para Ansari et al. (2007) o Custeio Alvo é a ponte que liga a formulação da estratégia com sua execução e geração de lucro; isso porque ele tanto influencia quanto é influenciado pela estratégia organizacional e funciona como um dispositivo para implementar o planejamento de lucro que emerge da estratégia organizacional. Esses comentários enfatizam a questão do alinhamento entre a estratégia e o controle, destacando o papel do Custeio Alvo nesse contexto. Na sequência a adequação entre estratégia e informações do Custeio Alvo foi discutida em relação às tipologias de Porter (1992), de Miles e Snow (2003) e de Gupta e Govindarajan (1984). Ressalta-se que as informações do Custeio Alvo foram consideradas estratégicas e de escopo amplo, conforme discutido no Capítulo 3 item 3.2.6 deste trabalho.

Porter (1992) classifica a estratégia em diferenciação e liderança de custo. A diferenciação é marcada pela busca de exclusividade em relação a algum atributo do produto ou serviço, como a qualidade e a inovação tecnológica; na de liderança de custo a empresa busca ter o menor custo em seu domínio de produto/mercado, tendo um escopo amplo de produtos ou serviços, atendendo a muitos segmentos (PORTER, 1992). 
A tipologia de Miles e Snow (2003) avalia as organizações em relação às características do mercado (com foco na taxa de mudança de produtos e mercados), classificando-as em defensoras, prospectoras, analisadoras e reatoras. As características apresentadas na sequência são baseadas em Miles e Snow (2003). As organizações do tipo defensoras possuem domínio estreito e estável de produto/mercado e os gestores tendem a não procurar novas oportunidades fora de seus domínios, sendo altamente especializados na área de operação delimitada da organização, focando sua eficiência. As prospectoras são organizações que quase continuamente buscam por oportunidades de mercado sendo geralmente as criadoras de mudança e incerteza a que seus concorrentes devem responder e, devido a essas características de inovação de produto e mercado, não são totalmente eficientes. As analisadoras são organizações que operam em dois tipos de domínio de produto/mercado, sendo que um é relativamente estável e outro em mudança; nas áreas estáveis operam de forma rotineira e eficiente, já nas áreas turbulentas acompanham as novas ideias dos concorrentes e adotam rapidamente aquelas que parecem ser mais promissoras. As reatoras são organizações em que os gestores frequentemente percebem a mudança e a incerteza que ocorrem no ambiente, mas são incapazes de responder de forma eficiente, por conta disso seu modelo de ajuste ao ambiente é inconsistente e instável.

A tipologia de ciclo de vida se baseia na estratégia de portfólio que foi desenvolvida pelo Boston Consulting Group (HOFER; SCHENDEL, 1978) com base na matriz de crescimento de participação. Gupta e Govindarajan (1984) desenvolveram uma forma de operacionalizar esse construto de acordo com os tipos construir, colher, manter e desinvestir, por isso, geralmente são creditadas a estes autores a tipologia do ciclo de vida.

A estratégia construir indica a intenção de aumentar a fatia de mercado e a posição competitiva mesmo com ganhos de curto prazo e geração de fluxo de caixa podendo ser baixos ou negativos (GUPTA; GOVINDARAJAN, 1984). A estratégia colher indica a intenção de maximizar o lucro e o fluxo de caixa em curto prazo em vez de aumentar a fatia de mercado (GUPTA; GOVINDARAJAN, 1984). A estratégia manter está entre as outras duas, objetivando manter a fatia de mercado com retorno razoável (CINQUINI; TENUCCI, 2006). A estratégia desinvestir está relacionada à descontinuidade da atividade (CINQUINI; TENUCCI, 2006) ou, como argumenta Fisher (1995), indica uma decisão de se retirar do negócio através de um lento processo de liquidação ou venda definitiva. Por essa característica essa última classificação não apareceu nos estudos analisados. 
As análises seguintes foram apresentadas mostrando o que a literatura discute em relação ao tipo de informação adequado à cada estratégia e, posteriormente, o que as pesquisas empíricas encontraram sobre essa questão. A primeira tipologia analisada foi a de Porter (1992). Quanto à liderança de custos, organizações que adotam essa estratégia competem pelo preço, fazendo com que, de acordo com Shank e Govindarajan (1992), enfatizem a redução dos custos. Assim, práticas de custeio e controle de custos que fornecem informações que auxiliem esse objetivo são necessárias. Chenhall e Langfield-Smith (1998a) observam que para atingir eficiência em custos as organizações precisam focar a melhoria dos processos existentes, principalmente o controle dos custos, por isso, técnicas tradicionais, como medida de desempenho orçamentário e análise de variância podem ser adequadas nesses casos. No entanto, esse tipo de afirmação deve ser avaliado com cautela, pois apresenta uma visão um tanto simplista da situação.

De acordo com Porter (1992), as fontes de vantagem em custos podem ser várias e depende da estrutura do setor de atuação; além disso, as empresas que adotam essa estratégia não podem desconsiderar a diferenciação, uma vez que não basta ter preços menores, seus produtos precisam ser aceitos pelos consumidores. Uma das fontes de vantagem competitiva nesse caso pode ser a busca de tecnologia superior, conforme apontado por Langfield-Smith (2007). Por isso, a depender do setor e do foco em que uma organização consegue obter vantagem em custo são necessários outros tipos de informações, podendo incluir aquelas de escopo amplo, como as oriundas do Custeio Alvo.

Ansari et al. (2007) mencionam que o Custeio Alvo é uma abordagem estratégica para planejamento de lucro e não simplesmente um método de redução de custos. Na estratégia de liderança de custos informações com foco no controle e redução de custos são essenciais e uma prática como o Custeio Alvo, que é capaz de fornecer esse tipo de informação e outras de caráter estratégico e escopo amplo, pode auxiliar na implementação desse tipo de estratégia. Por isso, a depender do setor e da fonte de vantagem em custo essa prática pode ser adequada na liderança de custo.

Quanto à diferenciação, Langfield-Smith (2007) menciona que as fontes de vantagem competitiva podem ser a qualidade, o serviço pós-venda, a disponibilidade do produto de forma ampla e a flexibilidade do produto. Oferecer produtos com algum tipo de diferencial permite às organizações um preço prêmio e o desempenho superior ocorre somente se esse preço superar os custos da diferenciação (PORTER, 1992). Para Shank e Govindarajan (1992) 
organizações com estratégia de diferenciação são mais atentas aos custos de marketing e diferenciação. Por essas características, Chenhall e Langfield-Smith (1998a), mencionam que a necessidade de uma abordagem holística, através de técnicas de planejamento estratégico, é provável de ser relativamente mais forte em organizações que enfatizam a estratégia de diferenciação, onde competem prioridades estratégicas que necessitam ser gerenciadas.

Para Abdel-Kader e Luther (2008) sem um sistema sofisticado as organizações que seguem a estratégia de diferenciação correm o risco de não serem capazes de determinar se o aumento das receitas gerado por seus produtos excedem os custos extras associados à diferenciação. $\mathrm{O}$ Custeio Alvo permite aos gestores focar na redução de custos enquanto simultaneamente mantém as expectativas dos clientes quanto à qualidade e funcionalidade (BAINES; LANGFIELD-SMITH, 2003). Desse modo, as informações do Custeio Alvo relativas às expectativas dos clientes podem ser úteis e parecem ser adequadas na estratégia de diferenciação.

A pesquisa de Baines e Langfield-Smith (2003) confirmou a hipótese de que uma mudança em direção à estratégia de diferenciação resultará no aumento do uso de práticas avançadas de Contabilidade Gerencial, entre elas o Custeio Alvo. Hibbets et al. (2003) verificaram que a estratégia de diferenciação foi a mais frequente entre as empresas que adotaram o Custeio Alvo. Já no trabalho de Cinquini e Tenucci (2010), a estratégia de liderança de custo foi relacionada com práticas como o Custeio Alvo.

Cabe explicar que Cinquini e Tenucci (2010) classificaram as onze práticas analisadas separando-as em concorrentes, consumidores, orientação para desempenho e custeio. $\mathrm{O}$ Custeio ABC/ABM, o Custeio Alvo, o Custeio da Qualidade, dentre outros, foram classificados em custeio. Com base nessa classificação, Cinquini e Tenucci (2010) levantaram a hipótese de que a taxa de uso de práticas de custeio seria maior na estratégia de liderança de custo, enquanto a taxa de uso das demais práticas seria maior na estratégia de diferenciação, no entanto, apenas a primeira hipótese foi confirmada. Pelo exposto, as pesquisas empíricas apresentaram resultados divergentes.

Considerando esses resultados, de forma lógica pode-se inferir que organizações que competem com base na liderança de custos necessitam de controle intensivo sobre os mesmos de forma a obter vantagem competitiva sobre o preço de venda. Por outro lado, as que competem por diferenciação precisam de informações que evidenciem o foco no mercado, os 
requisitos do cliente e o planejamento do lucro. Por isso, nesse trabalho foi considerado que o uso do Custeio Alvo, por fornecer as informações mencionadas, pode ser adequado tanto para a estratégia de diferenciação quanto para a de liderança em custos.

A segunda tipologia analisada foi a de Miles e Snow (2003). A literatura pesquisada sobre estratégia e Teoria da Contingência aborda apenas os tipos prospectores, defensores e analisadores e Miles e Snow (2003) comentam que a estratégia seguida pelos reatores não é viável no longo prazo; por esses motivos apenas os três primeiros tipos foram discutidos.

Organizações com a estratégia prospectora localizam e exploram oportunidades de produto e mercado através do monitoramento de uma ampla gama de condições e eventos ambientais, seu domínio de produto está em desenvolvimento constante e as tecnologias empregadas são tipicamente flexíveis para possibilitar reações rápidas para mudar com as demandas do mercado (CHONG; CHONG, 1997). Essas novas oportunidades buscadas pelos prospectores não estão restritas aos avanços tecnológicos usados para melhorar os produtos existentes, elas vão além, em busca de avanços em relação a produtos e mercados que ainda não são explorados, necessidades que ainda são latentes. Para Miles e Snow (2003) nessas empresas existe a necessidade de facilitar ao invés de controlar as operações, por isso, o controle é baseado na eficácia e orientado por resultados, especialmente aqueles com características não financeiras, como a taxa de aceitação dos produtos.

Como resultado, informações externas, não financeiras e orientadas para o futuro seriam apropriadas para os gestores e o escopo amplo da informação do SCG seria percebido como útil para a tomada de decisão (CHONG; CHONG, 1997). Algumas das características da informação mencionadas podem ser extraídas do Custeio Alvo. Simons (1987) observa que a prospectora necessita de uma gama de informações mais amplas do que as defensoras e Miles e Snow (2003) argumentam que os prospectores tendem a usar um planejamento abrangente e medidas de desempenho mais subjetivas fazendo com que tenham a tendência de desenfatizar o controle de custos dando lugar à criatividade individual e à inovação. Por isso, o Custeio Alvo seria útil para efeito de gestão de custos e não especificamente de controle de custos.

Os prospectores são descritos como criadores da mudança e da incerteza; nesse contexto, as funções de marketing e pesquisa e desenvolvimento dominam as de finanças e produção, por isso, eficiência e desempenho de lucro não são tão importantes quanto manter a liderança na inovação de produto (LANGFIELD-SMITH, 1997). Uma prática como o Custeio Alvo que é 
aplicada no projeto do produto é interessante para auxiliar nesta fase pois, segundo Sakurai (1997), o resultado do processo do Custeio Alvo é o incentivo à inovação.

Em contraste, os defensores operam em um mercado de produto estável e estreito e enfatizam a eficiência ao invés da inovação, a estabilidade de seu mercado é congruente com a confiança nas informações históricas e seu estreito domínio de produto reduz a necessidade de monitoramento extensivo das condições ambientais externas; portanto, uma informação de escopo estreito do SCG seria apropriada para os gestores de organizações defensoras (CHONG; CHONG, 1997).

Para Miles e Snow (2003) os defensores tendem a enfatizar o controle de custos, o monitoramento de tendências e a eficiência ao invés de explorar o ambiente na busca por novas oportunidades. Os defensores são mais propensos ao controle de custos porque são orientados pela eficiência e as funções críticas de sucesso nesse caso são as finanças, a produção e a engenharia, com menor ênfase no marketing e em pesquisa e desenvolvimento (LANGFIELD-SMITH, 1997). Essas empresas, por não focarem a inovação de produtos, seriam improváveis de adotarem o Custeio Alvo, por ser este associado ao desenvolvimento de novos produtos (FERREIRA; OTLEY, 2009).

No entanto, Miles e Snow (2003) mencionam que os defensores têm a habilidade de manter agressivamente sua predominância dentro do segmento escolhido para atuar e que se concentram na atualização da tecnologia de seus produtos e processos para manter a eficiência. Nesse sentido, o desenvolvimento de produtos com foco na melhoria dos modelos existentes é uma atividade chave e, por isso, uma prática como o Custeio Alvo também pode ser adequada por atuar na fase de projeto desses produtos e auxiliar no controle dos custos.

Os analisadores são um híbrido intermediário que combinam as características mais fortes dos defensores e dos prospectores (LANGFIELD-SMITH, 1997; SIMONS, 1987). Os analisadores geralmente são tão hábeis quanto os defensores na produção de seus produtos estabelecidos e, para os novos produtos, eles evitam investimentos volumosos em pesquisa como os prospectores, imitando somente as inovações de maior sucesso desenvolvidas por esses últimos (SNOW; HREBINIAK,1980). Por essas características os analisadores parecem ter mais semelhanças com os defensores, pois têm um domínio estabelecido de produto e, quanto à inovação, apenas imitam os principais concorrentes prospectores. Dessa forma, as informações do Custeio Alvo também podem ser adequadas. 
Em seu estudo empírico, Cadez e Guilding (2008) verificaram que o uso de práticas com foco estratégico, dentre elas o Custeio Alvo, foi positivamente associado com a estratégia relativa aos prospectores. Cinquini e Tenucci (2010) encontraram em seu estudo que os defensores fazem mais uso de práticas com características estratégicas classificadas como custeio. Aparentemente os estudos apresentaram resultados contraditórios; no entanto, a formulação das hipóteses nesses dois estudos pode explicar essa diferença. Enquanto Cadez e Guilding (2008) testaram a hipótese de que a taxa de uso das práticas analisadas (dezesseis no total) era maior nas empresas prospectoras do que nas defensoras, Cinquini e Tenucci (2010) aprofundaram o nível de detalhes e levantaram a hipótese de que a taxa de uso das práticas de custeio, dentre elas o Custeio Alvo, seriam mais altas para os defensores e que a taxa de uso das demais práticas seria mais alta para os prospectores.

Devido a essa diferença, não se pode afirmar que os resultados sejam contraditórios, pois não foi possível verificar, no estudo de Cadez e Guilding (2008), se o Custeio Alvo era ou não usado pelas prospectoras. De acordo com o exposto, considerou-se nesta pesquisa que as informações do Custeio Alvo podem ser adequadas tanto para os prospectores quanto para os defensores, sendo a diferença baseada no foco dado às informações, ou seja, ênfase na gestão ou no controle dos custos. Nota-se que nenhum dos estudos mencionados investigou a estratégia do tipo analisador e pelas suas características mencionadas considerou-se que suas informações também podem ser adequadas nesse caso.

A última tipologia investigada é a de Gupta e Govindarajan (1984) com os tipos construir, manter e colher. A estratégia construir objetiva melhorar participação no mercado e posição competitiva, mesmo que isso diminua os ganhos ou o fluxo de caixa de curto prazo; isso pode ser obtido se a organização tiver algum tipo de superioridade competitiva em seu setor (GUPTA; GOVINDARAJAN, 1984). Para tanto, requer orientação gerencial e competência no monitoramento e análise das características do setor, como as necessidades do consumidor e as estratégias dos concorrentes (GUPTA; GOVINDARAJAN, 1984). Por essas características, Guilding (1999) argumenta que as organizações que seguem a estratégia construir apresentam maior propensão a usar práticas de Contabilidade focadas nos concorrentes, incluindo precificação estratégica e custeio estratégico. Para Cinquini e Tenucci (2010) as empresas do tipo construtoras são mais dispostas a usar práticas com características estratégicas. Devido às características de suas informações o Custeio Alvo pode ser adequado nesse caso. 
$\mathrm{Na}$ estratégia do tipo colher a organização busca maximizar lucro e fluxo de caixa de curto prazo ao invés de aumentar participação de mercado e, nesse caso, as habilidades mais importantes englobam o apoio à eficiência interna das operações ao invés das análises externas do setor (GUPTA; GOVINDARAJAN, 1984). Por isso, informações de controle de custos são importantes e o Custeio Alvo também pode ser adequado nesse caso.

A estratégia manter é usada por organizações para proteger participação no mercado e posição competitiva com objetivo de obter um razoável retorno sobre investimento; operam com alta participação de mercado em setores com alto crescimento (LANGFIELD-SMITH, 1997). Por isso, necessitam de informações relacionadas ao planejamento do lucro e à busca de eficiência, podendo o Custeio Alvo ser adequado para gerar essas informações. Apenas o trabalho de Cinquini e Tenucci (2010) usou a tipologia de Gupta e Govindarajan (1984) empiricamente, mas os testes de sua hipótese não foram estatisticamente significantes em relação às práticas classificadas como custeio. Por isso, no caso dessa tipologia não foram encontrados resultados empíricos para embasar as análises.

Vários estudos, conforme apresentados na sequência, fizeram comparações em relação às três tipologias usadas nessa pesquisa, o que pode auxiliar as análises. Shank e Govindarajan (1992) verificaram que existe um ajuste consistente entre a classificação de Porter (1992) e a de Gupta e Govindarajan (1984), e observaram que organizações que seguem a estratégia de diferenciação com o tipo construir enfrentam a mesma incerteza ambiental. Isso pode indicar que o tipo de informação necessária nas duas estratégias também seja parecido. Por isso, Langfield-Smith (1997) argumenta que devido às suas características e à necessidade de uma ampla gama de informação, os diferenciadores, os prospectores e o tipo construir podem ser associados; os defensores, os de liderança de custos e o tipo colher também, mas ressalta que isso é uma suposição que deve ser verificada empiricamente.

Chenhall (2003) argumenta que estratégias caracterizadas por uma orientação empreendedora como os prospectores, os construtores e os diferenciadores são ligados à falta de procedimentos padronizados, são descentralizados e com resultado orientado para avaliação, tendo estruturas e processos flexíveis. Desse modo, uma vez que os tipos diferenciação, prospectoras e construir podem "teoricamente" apresentar as mesmas demandas de informação, entende-se pelo exposto anteriormente, que o Custeio Alvo pode ser adequado em organizações que atuam com esses tipos de estratégia. 
Já as estratégias caracterizadas pelos tipos colher, defensoras e que seguem a liderança de custo são associadas com sistemas de medidas de desempenho formais, incluindo metas de desempenho de orçamento mais objetivo (CHENHALL, 2003). Conforme também abordado, isso enfatiza o uso de controles de custos e a busca de eficiência, em que o uso do Custeio Alvo pode ser adequado. O tipo manter, assim como os analisadores, não foi abordado nos estudos empíricos, mas pelas suas características as informações do Custeio Alvo também podem ser adequadas em seu caso.

Kald et al. (2000) também levantaram proposições sobre a relação entre os diferentes tipos de estratégia e o SCG e abrangeram mais combinações do que Langfield-Smith (1997) e Chenhall (2007). No caso da combinação entre prospectoras, diferenciadoras e construir e as defensoras, liderança de custos e colher o tipo de SCG mais adequado foi o mesmo descrito por Chenhall (2007). As outras combinações foram defensores, manter e diferenciação ligadas ao uso de controles frouxos; e prospectoras, manter e liderança de custos ligadas a controles rígidos (KALD et al., 2000), destaca-se que estas proposições não foram testadas empiricamente.

Em relação à verificação da proposição de Lagfield-Smith (1997) (sobre a possível associação entre as estratégias prospectoras, diferenciadoras e construir e defensoras, liderança de custos e colher), o estudo de Cinquini e Tenucci (2010) encontrou empiricamente uma ligação entre as estratégias defensora e liderança de custos com a taxa de utilização de práticas classificadas como custeio, dentre elas o Custeio Alvo. Para esses autores, a análise global da estratégia como uma variável que afeta o uso e a implementação de práticas estratégicas de Contabilidade não fornece informações claras sobre o assunto; e esse acoplamento fraco entre as práticas e as estratégias sugere que uma mesma prática possa ser capaz de apoiar diferentes abordagens estratégicas. Simons (1987) também argumenta que os aspectos do sistema de controle ligados ao controle dos custos não deveriam diferir sistematicamente entre defensores e prospectores, o que pode indicar que o que difere não é o tipo de controle, mas a ênfase que se extrai dele, ou seja, como é utilizado e para quê.

Com base nesse comentário e nos achados das pesquisas empíricas analisadas, que não apontaram para uma única direção, a conclusão de Langfield-Smith (2007) de que as pesquisas que investigam a relação entre SCG e estratégia são fragmentadas e seus resultados são conflitantes tornando o conhecimento limitado, se aplica nesse caso. 
Pelo exposto, nessa pesquisa parte-se da ideia de que as informações do Custeio Alvo podem ser adequadas para os diversos tipos de estratégia analisadas aqui e o que pode diferenciar uma da outra é a ênfase e o tipo de utilização que se faz de suas informações, não apresentando um tipo único adequado, devendo ser analisado caso a caso. Por isso, a análise desse fator foi feita em relação aos tipos de estratégia encontrados na organização investigada e com qual objetivo as informações do Custeio Alvo são usadas nesse contexto de modo a verificar sua adequação.

\subsubsection{Porte}

O porte organizacional é um fator contingente interno que reflete uma característica física de dimensão. É um fator importante que pode afetar tanto a estrutura quanto outros mecanismos de controle (ABDEL-KADER; LUTHER, 2008). Baldridge e Burnham (1975) mencionam ainda que o porte afeta a capacidade de uma organização para inovações. Por essas e outras razões esse fator contingente é analisado nas pesquisas da Teoria da Contingência desde seu início, como nos estudos de Blau (1970), Pugh et al. (1963, 1969a) e Child (1973).

A lógica do porte da organização influenciar em sua estrutura pode ser entendida pela Teoria da Diferenciação Estrutural de Blau (1970), segundo a qual o aumento do número de empregados de uma organização gera uma estrutura mais elaborada aumentando suas divisões e os níveis hierárquicos. Quando o número de empregados aumenta torna-se menos prático o uso de métodos informais de comunicação e controle, como a comunicação oral e a supervisão direta, porque existe um número exponencialmente crescente de canais que exigem fluxos de informação (MERCHANT, 1984). Dessa forma, o aumento no número de funcionários pode provocar mudanças tanto na estrutura quanto nos canais de comunicação por necessitar de informações mais formalizadas e detalhadas, impactando o SCG.

A ligação do porte da organização com a necessidade de mais controle e de informações mais apuradas e sofisticadas para embasar o processo decisório está relacionada ao aumento da complexidade das operações e de outras mudanças em relação à estrutura. Além disso, o porte acaba por influenciar a relação custo/benefício das práticas capazes de gerar informações mais sofisticadas e que requerem maiores recursos para funcionar, tanto físicos quanto financeiros, favorecendo sua adoção. 
Para Cadez e Guilding (2008) os estudiosos declaram que o aumento do porte da organização significa aumento da complexidade e um aumento na necessidade de procedimentos contábeis sofisticados para gerir a mesma, e que o custo de processar a informação por unidade de resultado declina com o aumento do porte. Haldma e Lääts (2002) afirmam ainda que o porte organizacional é um dos fatores internos mais comuns que tem sido examinado nos estudos da Contabilidade Gerencial e é aparente que o nível de sofisticação de um sistema contábil de custos tende a aumentar em linha com o aumento do porte.

Organizações de grande porte têm recursos para adotar práticas mais sofisticadas da Contabilidade Gerencial do que as de pequeno porte (ABDEL-KADER; LUTHER, 2008). Essas declarações confirmam a importância do fator porte em relação à adoção de práticas sofisticadas no SCG. Cadez e Guilding (2008) concluem que em seu estudo empírico o porte da organização foi positivamente associado ao uso de práticas com natureza estratégica, dentre elas o Custeio Alvo. Pelo exposto, o porte é um fator que pode auxiliar na adoção do Custeio Alvo, sendo as organizações de grande porte mais propensas a adotá-lo.

\subsubsection{Estrutura}

A estrutura organizacional representa a especificação formal dos diferentes papéis de seus membros e influencia a eficiência do trabalho, a motivação dos funcionários, os fluxos de informação e os sistemas de controle (CHENHALL, 2007), por isso sua importância em relação ao SCG. Nesta pesquisa a estrutura foi analisada considerando-se sua relação com o Custeio Alvo no que se refere à descentralização, ao tipo de estrutura e à formação de equipes. Essa escolha se deu por causa das características da prática analisada e aos trabalhos desenvolvidos no âmbito do SCG como os de Abdel-Kader e Luther (2008), Espejo (2008), Guerra (2007), Hansen e Van der Stede (2004) e Chenhall (2007), uma vez que os artigos analisados no item 2.1.3 específicos para o Custeio Alvo não investigaram o fator estrutura.

A questão da descentralização pode ser abordada de várias maneiras, mas, de acordo com Hall (1984) a ênfase sempre está na distribuição de poder. Nesse sentido, quanto mais delegação para tomada de decisões em níveis intermediários, maior é a descentralização. Para analisar a descentralização nessa pesquisa foi usada a tipologia de Burns e Stalker (1961) que associaram um menor grau de descentralização às estruturas mecanicistas e um maior grau às orgânicas. 
De acordo com Burns e Stalker (1961) uma estrutura orgânica tem como características a tomada de decisão descentralizada, baixa especialização e formalização, já uma estrutura mecanicista conta com tomada de decisão centralizada, alta especialização e formalização. A estrutura mecanicista está ligada à formalização e a orgânica à flexibilidade (SELTO et al., 1995). Burns e Stalker (1961) relacionaram a estrutura ao ambiente e concluíram que em um ambiente estável a estrutura mecanicista é mais eficaz, enquanto num ambiente mais incerto a orgânica é mais eficaz. Donaldson (2001) comenta que uma estrutura mecânica se ajusta a um ambiente estável porque uma abordagem hierárquica é eficiente para operações de rotina, fornecendo conhecimento e informações para tomada de decisão aos gestores de níveis mais altos e, este controle centralizado, promove eficiência; já a estrutura orgânica se ajusta a um ambiente não estável porque uma abordagem participativa é requerida para a inovação neste cenário.

Baines e Langfield-Smith (2003) comentam que, para assegurar respostas rápidas e inovadoras em ambientes complexos e dinâmicos, tem havido um afastamento de controles hierárquicos e centralização de decisões para a delegação de maior responsabilidade em níveis mais baixos. Wickramasinghe e Alawattage (2007) mencionam que estruturas organizacionais que consideram flexibilidade e informalidade desenvolvem equipes, unidades descentralizadas e formas orgânicas e o SCG segue uma abordagem de escopo amplo.

Gul e Chia (1994) analisaram a relação entre incerteza ambiental, descentralização e desenho do sistema de informação gerencial com base no escopo e na agregação das informações e os resultados indicaram que a descentralização e a disponibilidade de informações de escopo amplo e agregação foram associadas com alto desempenho gerencial sob condições de alta incerteza ambiental percebida. Gordon e Narayanan (1984) analisaram as relações entre o ambiente organizacional, a estrutura e o sistema de informação e concluíram que quando os tomadores de decisão percebem uma maior incerteza ambiental tendem a procurar informações externas, não financeiras e ex ante em conjunto com outros tipos de informação e aumentam o movimento em direção a uma forma orgânica de organização.

A pesquisa empírica de Abdel-Kader e Luther (2008) revelou indícios de que companhias com estrutura gerencial mais delegada podem necessitar de práticas mais sofisticadas de Contabilidade Gerencial de forma a prover os gestores com informações relevantes para o planejamento, controle e tomada de decisão pelas quais eles são responsáveis e que existe 
uma relação positiva entre a descentralização e sistemas sofisticados de Contabilidade Gerencial.

Para Sakurai (1997) em ambientes que empregam tecnologias de produção baseadas na integração por computador a organização responde às mudanças da necessidade dos clientes via produção flexível sendo necessária uma boa comunicação entre gerência e engenharia e, nesse contexto, a tradicional forma de comando e controle já não é suficiente; por isso, a necessidade de adoção de estilos participativos de gestão. Isso remete às estruturas orgânicas, mais descentralizadas. Sakurai (1997) argumenta que neste contexto (produção integrada por computador) o Custeio Alvo é considerado muito mais poderoso devido ao seu poder de comunicação. Dessa forma, percebe-se que a estrutura orgânica apresenta mais adequação em relação à utilização do Custeio Alvo.

Em relação ao tipo de estrutura, nesse trabalho foram discutidos os três tipos principais: a funcional, a divisional e a matricial (STONER; FREEMAN, 1985; HANSEN; VAN DER STEDE, 2004). A estrutura funcional é uma forma básica de departamentalização em que as pessoas engajadas em uma atividade funcional são agrupadas numa mesma unidade, como a produção, o marketing etc. (STONER; FREEMAN, 1985). Esse tipo de estrutura é indicado para organizações que enfrentam circunstâncias estáveis de poucas mudanças, o que dificulta a adaptação e flexibilidade às mudanças externas (CHIAVENATO, 2000). Por isso, no caso de empresas que atuam em ambientes turbulentos e incertos esse tipo de estrutura não é indicado.

A estrutura divisional, também conhecida como estrutura por produto/mercado, geralmente é usada quando a departamentalização se torna muito complexa criando-se divisões semiautônomas que projetam, produzem e comercializam seus próprios produtos; porém, não se trata de entidade independente e o gestor deve se reportar à matriz em alguns tipos de decisão (STONER; FREEMAN, 1985).

A estrutura matricial é um tipo híbrido composto por equipes com pessoas de várias especialidades. Na estrutura matricial os funcionários têm dois chefes; uma das cadeias de comando é funcional ou divisional e diagramada verticalmente, a outra é horizontal e corresponde a uma equipe de projeto ou de negócio liderada por outro gestor (STONER; FREEMAN, 1985). As organizações matriciais envolvem fluxos horizontais de recursos e de informações, com base na especialização funcional (CHENHALL, 2008). 
Para o Custeio Alvo ter maior sucesso, de acordo com Sakurai (1997), é necessária sua aplicação a cada produto, com uma organização matricial que liga os departamentos de planejamento, desenho, contabilidade, produção e marketing. Sakurai (1997) comenta sobre a estrutura das organizações enfatizando que o modo tradicional de separar funções ainda é essencial, mas que no ambiente de desenvolvimento de produtos (principal função do Custeio Alvo) as estruturas funcionais cruzadas (matricial) com a composição de equipes de trabalho são indispensáveis. Pelo exposto, a estrutura do tipo matricial apresenta adequação em relação ao Custeio Alvo e, além disso, a formação de equipes também é importante para sua execução.

Baines e Langfield-Smith (2003) argumentam que em ambientes competitivos com forte orientação para o cliente tem emergido uma variedade de estruturas baseadas em equipes como as funcionais cruzadas (cross-functional). O uso de equipes é considerado uma resposta aos ambientes complexos e dinâmicos que requerem respostas rápidas e inovação, encorajando a cooperação e a coordenação entre subunidades funcionais (HANSEN; MOURITSEN, 2007).

A utilização de equipes de trabalho tem relação com o processo do Custeio Alvo, uma vez que se trata de um dos requisitos para sua execução (conforme abordado no Capítulo 3 item 3.2.3). Para Ansari et al. (1997) o processo do Custeio Alvo é realizado principalmente por equipes funcionais cruzadas que possuem como principais especialidades funcionais a engenharia, o marketing, a contabilidade, compras e produção.

Pelo exposto, de acordo com as características do processo do Custeio Alvo e de suas informações este é mais adequado em estrutura do tipo orgânica, descentralizada e que estimule a gestão participativa, com possibilidade de trabalho em equipes multifuncionais do tipo matricial.

\subsubsection{Tecnologia}

Esse fator apresenta muitos significados no comportamento organizacional e, de modo geral, se refere à forma como os processos de trabalho de uma organização operam (CHENHALL, 2007). Geralmente a tecnologia é avaliada em duas dimensões, uma relativa à tecnologia da 
informação e outra ligada à manufatura. Devido às características do Custeio Alvo e da empresa Alfa as duas dimensões foram investigadas.

A tecnologia da informação pode ser definida como o uso de computadores bem como de tecnologia relacionada à comunicação digital que tem um amplo poder para reduzir os custos de coordenação, comunicação e processamento de informação, sendo economicamente vantajosa principalmente por facilitar inovações complementares (BRYNJOLFSSON; HITT, 2000). Nesse sentido, os avanços nessa área têm orientado a inovação e a mudança na coleta, mensuração, análise e comunicação da informação tanto dentro da organização quanto entre as organizações e isso é facilitado por tecnologias como o uso de ERP (enterprise resource planning), comércio eletrônico, internet, dentre outros (BURNS; VAIVIO, 2001).

Para Hyvönen (2007) a vantagem especial da tecnologia de informação é a habilidade de ligar uma atividade com outra e tornar os dados amplamente disponíveis em tempo real. Atkinson et al. (1997) argumentam que a Contabilidade Gerencial vem mudando em resposta às mudanças ambientais e que isso pode ter um profundo efeito no modo como as organizações coletam, processam e utilizam suas informações. Dessa forma, pode-se perceber que a tecnologia da informação pode facilitar a coleta e a disseminação dos dados e das informações na organização de modo que a adoção de práticas como o Custeio Alvo, que demandam diversos tipos de dados (como financeiros, não financeiros, históricos, futuros, do ambiente externo e interno etc.), possa ser implementada.

Para Sakurai (1997) a tecnologia da informação por meio da padronização de esforços torna mais eficiente a preparação de documentos relacionados com produção, Contabilidade Gerencial, comunicações e armazenagem. Os dados e as informações geralmente requeridos para o processo do Custeio Alvo são provenientes da base de dados de setores como marketing, custos, compras, engenharia e informações sobre concorrentes, sendo necessário um compartilhamento desses dados/informações (ANSARI et al., 1997). Por isso, investimentos em tecnologia da informação auxiliam no processo do Custeio Alvo uma vez que, para Ansari et al. (1997), os dados precisam ser coletados e disponibilizados quando as equipes que lidam com Custeio Alvo necessitam e de uma forma que possam ser usados. Não foi encontrada nenhuma referência quanto à utilização de alguma tecnologia em particular, por isso, apenas se considera que o uso de tecnologias de informação pode auxiliar o processo dessa prática. 
Em relação à tecnologia ligada à manufatura, a literatura sobre SCG geralmente lida com a mesma de três formas, sendo a complexidade, a incerteza da tarefa e a interdependência (CHENHALL, 2007). Além dessas, o emprego de tecnologias contemporâneas de produção também vem sendo relacionado ao modelo desses sistemas (CHENHALL, 2007; YOUNG; SELTO, 1991). Para embasar a escolha referente a essa dimensão da tecnologia foi usado o trabalho de Abdel-Kader e Luther (2008), que investigou o uso de práticas gerenciais incluindo o Custeio Alvo, usando a complexidade e o uso de tecnologias contemporâneas, sendo estes os elementos analisados na presente pesquisa.

A complexidade está relacionada ao grau de padronização da produção podendo ser produtos não padronizados em pequenos lotes e produção padronizada de grandes lotes (WOODWARD, 1965). Nesse sentido, a diferenciação de produtos requer tecnologias de produção flexíveis capazes de trabalhar com as mudanças aumentando a complexidade, já a padronização requer automação de modo a trabalhar com tarefas repetitivas nas linhas de produtos, o que diminui a complexidade.

Para Chenhall (2007) as organizações que produzem produtos padronizados com emprego intensivo de capital e processos automatizados têm probabilidade de empregar a produção em massa e tecnologias de processo e, nesse caso, controles administrativos padronizados como o SCG tradicional (baseado em controle financeiro) é requerido. Por outro lado, a especialização e a diferenciação podem levar a processos com muitas exceções, em que os gestores podem ter um conhecimento imperfeito dos processos e baixa capacidade para medir os resultados; nesses casos, os controles deveriam encorajar respostas flexíveis, altos níveis de abertura de comunicação dentro da força de trabalho e um SCG tradicional baseado em controles financeiros não parece ser adequado nesse contexto (CHENHALL, 2007).

Sakurai (1997) menciona que a diversificação da demanda dos consumidores no Japão alterou o modelo produtivo baseado na produção em massa com variedade limitada para pequenos lotes com enorme variedade de produtos (produção flexível); isso alterou vários aspectos nas organizações tendo como consequência a necessidade de práticas de gestão e informações adequadas ao novo modelo e, isso inclui o Custeio Alvo. Empresas que adotam a produção enxuta flexível baseada em células necessitam gerenciar os custos de forma agressiva e o Custeio Alvo é uma das práticas que auxiliam na gestão de custos de futuros produtos (COOPER; SLAGMULDER, 1997). Quanto à complexidade, o processo do Custeio Alvo fornece informações que podem auxiliar as tecnologias de produção ligadas à diferenciação, 
com produção de pequenos lotes ou ordens em ambientes de produção enxuta e flexível, uma vez que faz as análises e a gestão dos custos desses produtos ainda na fase de projeto.

Em relação às tecnologias contemporâneas, Milgrom e Roberts (1995) ressaltam que nas primeiras décadas do século vinte a produção em massa se disseminou nas indústrias e tornou-se o modelo dominante de produção; nas últimas décadas do século vinte houve outra redefinição fundamental nos padrões básicos de estratégia, organização e gestão nas indústrias e, nesse novo padrão, a lógica fundamental envolve flexibilidade, rapidez, economia de escopo e foco nas competências essenciais, o que implica abordagens distintas para uma ampla gama de políticas e estruturas, sendo esse novo padrão conhecido como indústria ou manufatura moderna ou enxuta. Junto com essas mudanças os sistemas de mensuração também tiveram que evoluir para apoiar os esforços de aumento de qualidade e produtividade ajudando a justificar os investimentos nas novas tecnologias (ABDEL-KADER; LUTHER, 2008), como o JIT (Just in Time), gestão da qualidade total, dentre outras. Por isso, a implementação dessas tecnologias contemporâneas afeta aspectos como a estrutura, os fluxos de informação e o SCG.

Young e Selto (1991) argumentam que as mudanças na tecnologia devem ser consideradas no contexto organizacional e que as pesquisas deveriam considerar os efeitos dessas novas práticas no desenho dos sistemas de Contabilidade Gerencial. O foco no escopo e não na escala abre espaço para o emprego dessas tecnologias de forma a tornar a produção mais flexível, a enfatizar a qualidade e a redução de desperdício de recursos, a redução do tempo de lançamento e de fabricação de produtos, dentre outros. Isso traz também a necessidade de mecanismos de controle e de informações que se ajustem a essa realidade, por isso, o uso de tecnologias contemporâneas pelas organizações pode promover o uso de práticas de controle como o Custeio Alvo.

Para Sakurai (1997) as mudanças tecnológicas em direção à automação e à integração da produção por computador trouxeram problemas às formas tradicionais de análise da contabilidade gerencial. A introdução de novas tecnologias na produção como a produção integrada por computador e o Just in time trouxe mudança na estrutura dos custos fabris e, com isso, práticas avançadas de Contabilidade Gerencial como o Custeio Alvo e o Custeio do Ciclo de Vida parecem estar ganhando apoio nesse contexto, pois apresentam uma abordagem para gerenciar recursos que apoia o foco no cliente (BAINES; LANGFIELD-SMITH, 2003). Os achados da pesquisa de Abdel-Kader e Luther (2008) sugerem que práticas sofisticadas de 
Contabilidade Gerencial têm maior probabilidade de serem implementadas em organizações que adotam tecnologias contemporâneas de produção. Para Ansari et al. (2007) o Custeio Alvo é um processo intimamente ligado às ferramentas de gestão da qualidade total, que está inserida nas novas tecnologias de produção.

Quanto ao uso de tecnologias contemporâneas, o Custeio Alvo parece ser um processo adequado nesse contexto, uma vez que seus pressupostos não apresentam ambiguidades ou contradições com essas formas de tecnologias, mas sim uma complementaridade com as mesmas. Feitas as discussões sobre os fatores adequados em relação ao Custeio Alvo e suas informações na sequência é apresentado um quadro resumo dos mesmos (Quadro 2).

Quadro 2 - Adequação dos fatores contingentes ao Custeio Alvo

\begin{tabular}{|c|c|c|}
\hline Fatores Contingentes & Tipologia & Tipo Adequado \\
\hline Incerteza ambiental & & Alta \\
\hline Intensidade da concorrência & & Alta \\
\hline \multirow{3}{*}{ Estratégia } & $\begin{array}{l}\text { Posicionamento } \\
\text { mercado }\end{array}$ & Diferenciação ou liderança de custos \\
\hline & Características de mercado & $\begin{array}{lll}\begin{array}{l}\text { Prospectoras, } \\
\text { analisadoras }\end{array} & \text { defensoras } & \text { ou } \\
\end{array}$ \\
\hline & Ciclo de vida & Construir, colher ou manter \\
\hline Porte & & Médio-grande ou grande \\
\hline Estrutura & & $\begin{array}{l}\text { Orgânica, descentralizada, cultura } \\
\text { participativa, do tipo matricial, com } \\
\text { formação de equipes para } \\
\text { desenvolvimento de produtos }\end{array}$ \\
\hline Tecnologia da informação & & A utilização pode favorecer \\
\hline Tecnologia da produção & & 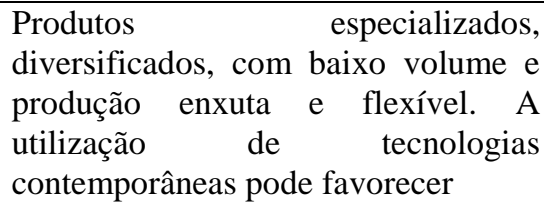 \\
\hline
\end{tabular}

\subsubsection{Definições e Medidas dos Fatores Contingentes Avaliados}

Embora os trabalhos analisados no item 2.1.3 abordem os fatores contingentes que podem ter relação com a adoção do Custeio Alvo, Ax et al. (2008) mencionam que os pesquisadores ocidentais estão mais preocupados em mapear a taxa de adoção desta prática e que os estudos que buscam verificar evidências sobre os fatores que influenciam a decisão de adotar ou não o mesmo são escassos.

Além disso, alguns problemas decorrentes dos trabalhos analisados no referido item dificultam um entendimento acerca dessas relações, podendo-se pontuar os seguintes: (1) alguns dos trabalhos mostram divergências nos resultados relativos a alguns fatores; (2) os 
objetivos e a forma de mensuração de algumas variáveis são diferentes nos estudos, dificultando comparações; (3) devido à limitação no tamanho das amostras investigadas (todos os trabalhos usaram o levantamento na coleta de dados), mencionada pela maioria dos estudos, os resultados onde aparecem as divergências foram inconclusivos; (4) características específicas relativas ao Custeio Alvo, como a formação de equipes multifuncionais, relacionadas à estrutura organizacional, não foram avaliadas; (5) a investigação da relação entre a adoção e desempenho foi testada apenas em um dos trabalhos e (6) em nenhum dos estudos foi estabelecida relação entre a adoção e os resultados esperados ou a utilidade da prática para as organizações investigadas.

De modo a contornar os problemas levantados nos estudos anteriores esta pesquisa buscou abranger os principais fatores contingentes relacionados ao SCG (de acordo com Chenhall, 2007), incluir aspectos relativos às características do Custeio Alvo, descrever em detalhes a forma de mensuração das variáveis para facilitar sua comparação com outros estudos e investigar a percepção da utilidade dessa prática na empresa investigada. Ainda, as medidas usadas foram baseadas nos aspectos analisados e discutidos do item 2.1.4 de modo a permitir uma comparação entre o que foi discutido e o que está sendo medido nessa pesquisa.

A empresa investigada é do ramo de manufatura de equipamentos, o que foi levado em conta para o estabelecimento das medidas dos fatores contingentes investigados. Destaca-se que o trabalho empírico é de caráter exclusivamente qualitativo, por isso, mesmo empregando construtos e medidas disseminadas na literatura sobre Contingência, principalmente usadas de forma quantitativa, as análises se referem às percepções extraídas de tais dados de forma qualitativa. Outros fatores contingentes que emergiram durante a pesquisa também foram analisados; no entanto, não foram usados construtos específicos para os mesmos pelo fato de que surgiram no decorrer das entrevistas.

Bisbe et al. (2007) enfatizam que na condução de pesquisas empíricas baseadas em uma teoria é de crucial importância a atenção às especificações conceituais dos construtos estudados como forma de promover o progresso na compreensão de seus efeitos dentro das organizações. Por isso, na sequência as medidas usadas para avaliar os fatores contingenciais foram apresentadas. 


\subsubsection{Ambiente}

O ambiente foi avaliado em relação à incerteza ambiental e à concorrência. Milliken (1987) chama a atenção para o fato de que a importância teórica do construto da incerteza ambiental, somada ao estado um tanto confuso da literatura empírica, sugere a necessidade de um reexame sobre sua natureza. Uma das fontes de confusão na literatura é que o termo incerteza ambiental é usado tanto para descrever o estado do ambiente organizacional como o estado da pessoa que percebe que está faltando informação sobre o ambiente; no primeiro caso existe a possibilidade de caracterizar o ambiente em termos de quão objetivamente incerto ele é e, no segundo caso, a incerteza está inerentemente no olho do espectador, devendo ser estudada como um fenômeno perceptual (MILLIKEN, 1987). Essa distinção deve estar clara nos estudos sobre a incerteza de modo a orientar as análises.

Milliken (1987) define incerteza como “[...] inabilidade de percepção de um indivíduo de prever algo com precisão.", Isso se deve à falta de informações suficientes ou uma inabilidade de distinção entre dados relevantes e não relevantes. Milliken (1987) sugere que existem três tipos de incerteza percebida sobre o ambiente: o estado de incerteza, que ocorre quando o administrador percebe o ambiente organizacional ou um componente particular do ambiente como sendo imprevisível; o efeito da incerteza, que é a inabilidade de prever a natureza do impacto de um estado futuro do ambiente ou de uma mudança ambiental; e a resposta da incerteza, que é a falta de conhecimento de possíveis respostas ou a inabilidade de prever a probabilidade das consequências de uma escolha.

O estado de incerteza é tratado na literatura como incerteza ambiental percebida (perceived environmental uncertainty) e, assim como nos estudos analisados no item 2.1.4.1, foi este construto que a presente pesquisa utilizou. Assim, a incerteza foi tratada como uma percepção do indivíduo sobre o ambiente e não do ambiente em si. A percepção da incerteza do ambiente ocorre quando os executivos são incapazes de prever mudanças futuras nos componentes do ambiente ou quando possuem um entendimento incompleto das relações entre esses componentes (MILLIKEN, 1987). De acordo com Buchko (1994) embora a incerteza ambiental possa ser parcialmente uma função de característica do ambiente sua definição enfatiza a importância do processo perceptual na determinação da mesma.

\footnotetext{
3 “[...] an individual's perceived inability to predict something accurately". Em inglês no original. Tradução livre da autora.
} 
Vários trabalhos propuseram medidas para a incerteza ambiental como Burns e Stalker (1961), Lawrence e Lorsh (1967), Duncan (1972) e Miles e Snow (2003); mas, como pode ser observado no Quadro 1, nos trabalhos relativos ao Custeio Alvo nenhuma delas foi utilizada. Dessa forma, optou-se por escolher, dentre as medidas usadas nos trabalhos analisados, a que mais se aproximasse do construto da percepção da incerteza do ambiente. A medida usada no trabalho de Ax et al. (2008) elaborada por Gordon e Narayanan (1984) expressa a percepção da incerteza do ambiente e inclui a questão da concorrência, que é o outro fator ambiental, por isso, foi escolhida para ser usada na pesquisa empírica contemplando os dois fatores contingentes externos.

Gordon e Narayanan (1984) desenvolveram um construto para medir a incerteza ambiental baseado no trabalho de Khandwalla (1972), e embora tenha o objetivo de medir a percepção da incerteza ambiental, possui elementos que caracterizam a intensidade da concorrência. $\mathrm{O}$ construto proposto compreende sete variáveis e mede a intensidade da concorrência, a imprevisibilidade e o dinamismo do ambiente externo, por isso, é um construto multidimensional. Pode ser caracterizado como medindo a incerteza de forma perceptual, ou seja, de acordo com a visão de quem está sendo avaliado, e está relacionado ao estado de incerteza, de acordo com a caracterização de Milliken (1987), já mencionada.

As sete variáveis propostas por Gordon e Narayanan (1984) e usadas nessa pesquisa foram: (1) estabilidade do ambiente, (2) novos produtos na indústria, (3) aparecimento de descobertas científicas, (4) competitividade, (5) restrições regulatórias, (6) previsibilidade dos concorrentes e (7) previsibilidade das preferências dos consumidores. Ax et al. (2008) após algumas análises estatísticas, usaram as variáveis 6 e 7 para medir a incerteza e as demais para medir concorrência, sendo esta a forma de avaliação seguida no presente trabalho.

\subsubsection{Estratégia}

Para Hofer (1975) a Teoria da Contingência foca os estudos da estratégia em dois níveis, a estratégia corporativa e a estratégia da unidade de negócios. A estratégia corporativa lida com decisões sobre o tipo de negócio em que competir (intersetores) e a estratégia de negócios em como competir dentro de um negócio particular (intra-setor) (BEARD; DESS, 1981). Neste trabalho foi avaliada a estratégia de negócios por estar mais ligada ao uso de informações como as do Custeio Alvo. 
Assim como no trabalho de Cinquini e Tenucci (2010), as taxonomias de estratégia usadas na presente pesquisa foram as de Porter (1992), Miles e Snow (2003) e Gupta e Govindarajan (1984). Optou-se pelas três com o objetivo de detectar mais detalhes em relação às estratégias de negócio da organização investigada. A tipologia de Porter (1992) está direcionada ao posicionamento da empresa (ou da unidade de negócio) em relação ao mercado, a de Miles e Snow (2003) está baseada nas características de produtos e mercados em relação aos mais estáveis e aos mais dinâmicos e a tipologia de Gupta e Govindarajan (1984) trata a estratégia no sentido de maximizar participação no mercado ou lucro.

A forma de avaliação da estratégia utilizada neste trabalho foi a autoavaliação (self-typing) proposta por Snow e Hambrick (1980) através da qual o próprio gestor avalia a estratégia da organização de acordo com descrições de suas tipologias. Por isso, a mensuração foi feita de forma perceptual com base nas três tipologias apresentadas. Para medir a classificação de Porter foi adaptado o instrumento de Hibbets et al. (2003). O modelo de Miles e Snow foi adaptado de Cinquini e Tenucci (2010) e Snow e Hrebiniak (1980). E o modelo de Gupta e Govindarajan foi adaptado de Guilding (1999).

\subsubsection{Porte}

No que se refere ao SCG e às informações da Contabilidade Gerencial, o porte pode ser medido pelo número de funcionários, mas outro prisma pode ser considerado, o que diz respeito à economia de escala da informação. Nesse sentido, quanto maior o porte da empresa maior a possibilidade financeira de investimento em novos canais de comunicação e novas fontes de informação e, dessa forma, medidas financeiras como receitas totais e ativos líquidos podem representar essa capacidade financeira. Para Pugh et al. (1969a) uma medida financeira para porte organizacional pode revelar algumas relações interessantes com a estrutura organizacional que não apareceria quando apenas o número de funcionários fosse considerado.

Qualquer um dos tipos de medida apresentada (número de funcionários ou medida financeira) é sempre um valor objetivo, não houve nos estudos analisados mensuração de porte por percepção. Em relação ao uso do número de empregados como medida, Espejo (2008) menciona duas limitações; a primeira se refere ao fato de que no Brasil um grande número de 
indústrias opta por terceirizar a mão-de-obra e a segunda é que indústrias com alto grau de automação podem apresentar reduzido número de empregados e alto volume de faturamento.

A essas limitações soma-se o fato de que o número de empregados usado como medida em estudos quantitativos deve sofrer uma transformação logarítmica para ajustá-lo aos impactos não lineares esperados (MERCHANT, 1984; PUGH et al., 1969a; CHILD, 1973). Isso ocorre porque esses estudos geralmente são feitos com empresas de setores diferentes em que o número de funcionários pode variar muito, apresentando alto desvio padrão devido às características próprias de cada setor e esse fato deve ser considerado quando da comparação entre alguns estudos.

Dado que a pesquisa empírica empreendida foi um estudo de caso de caráter qualitativo, impossibilitando mecanismos para normalizar desvios, optou-se pela forma de medida que pudesse ser empregada com menos vieses independente do setor. A medida usada foi o volume financeiro pela Receita Operacional Bruta e a classificação usada foi a do BNDES, Banco Nacional do Desenvolvimento (2012), conforme Quadro 3.

Quadro 3 - Classificação de porte de empresa

\begin{tabular}{|l|l|}
\hline \multicolumn{1}{|c|}{ Classificação } & \multicolumn{1}{c|}{ Receita Operacional Bruta Anual } \\
\hline Microempresa & Menor ou igual a R\$2,4 milhões \\
\hline Pequena empresa & Maior do que R $\$ 2,4$ milhões e menor ou igual a R\$16 milhões \\
\hline Média empresa & Maior do que $\mathrm{R} \$ 16$ milhões e menor ou igual a $\mathrm{R} \$ 90$ milhões \\
\hline Média-grande empresa & Maior do que $\mathrm{R} \$ 90$ milhões e menor ou igual a R $\$ 300$ milhões \\
\hline Grande empresa & Maior do que $\mathrm{R} \$ 300$ milhões \\
\hline
\end{tabular}

FONTE: BNDES (2012)

\subsubsection{Estrutura}

A estrutura tem sido operacionalizada e medida de várias formas. Conforme comentado anteriormente, os estudos analisados (item 2.1.3) envolvendo fatores contingentes e o Custeio Alvo não avaliaram a estrutura organizacional, dessa forma, recorreu-se aos estudos da Contabilidade Gerencial e do SCG para definir os construtos e as medidas usadas nesse trabalho, sempre considerando aquelas que podem apresentar ligação com a prática investigada.

A tipologia de Burns e Stalker (1961) vem sendo usada nos estudos da Contabilidade para operacionalizar a estrutura, como nos trabalhos de Gordon e Narayanan (1984), Gul e Chia (1994), Abdel-Kader e Luther (2008), Selto et al. (1995) e o de Espejo (2008) e Guerra 
(2007) que foram realizados no Brasil. Nessa tipologia, Burns e Stalker (1961) tratam a estrutura organizacional em relação ao grau de descentralização, representada na forma de um continuum onde um polo é representado pela estrutura orgânica e o outro pela estrutura mecanicista.

Outro modo de operacionalizar a estrutura é a sua classificação em relação ao tipo, sendo a funcional, a divisional e a matricial, como no estudo de Hansen e Van der Stede (2004). Outro elemento importante da estrutura organizacional contemporânea que tem sido pouco considerado nos estudos de SCG é o trabalho em equipe (CHENHALL, 2007).

Dessa forma, a estrutura organizacional foi caracterizada com base em aspectos referentes à descentralização, ao tipo de estrutura e à formação de equipes. A descentralização foi avaliada tomando-se por base o estudo de Gordon e Narayanan (1984) medida por quatro quesitos sendo (1) a delegação de autoridade para a tomada de decisão em relação aos seguintes itens: desenvolvimento de novos produtos, contratação e demissão do pessoal da gestão, seleção de investimentos relevantes, alocações orçamentárias e decisões de preços; (2) a formalização, (3) o nível de decisões operacionais e (4) o estilo gerencial.

O tipo de estrutura da organização foi avaliado com base em Hansen e Van der Stede (2004) classificado em: funcional, divisional e matriz; com alguns quesitos baseados em Junqueira (2010). As questões envolvendo o uso de equipes foram investigadas com base em Baines e Langfiel-Smith (2003), Abernethy e Lillis (1995) e Junqueira (2010).

\subsubsection{Tecnologia}

A tecnologia foi avaliada de duas formas, a de informação e a de produção. A tecnologia da informação foi avaliada tendo como base o instrumento de Krumwiede (1998), que avaliou características do sistema de informação como integração, disponibilidade e atualização das informações. Também foi verificada a utilização de tipos de tecnologias com base em Hyvönen (2007), que inclui troca de dados de forma eletrônica, gerenciamento da cadeia de suprimentos, armazenamento de dados e gestão de relacionamento com clientes.

Quanto à tecnologia de produção, foi mensurada a complexidade, o uso de produção enxuta e o uso de tecnologias contemporâneas de produção. A complexidade foi mensurada pelo tipo de sistema usado na produção com base no instrumento de Krumwiede (1998), separado em 
relação ao tipo de produtos e tipo de processo. Também foi verificado se a empresa utilizava técnicas de produção enxuta com base em Krumwiede (1998). Quanto ao uso de tecnologias contemporâneas foram adaptados os instrumentos de Baines e Langfield-Smith (2003) e Guerra (2007) em relação a alguns tipos de tecnologias aplicadas à produção.

Detalhes sobre o instrumento de coleta de dados e sobre como os fatores contingentes foram analisados nessa pesquisa estão apresentados na trajetória metodológica (Capítulo 4). $\mathrm{Na}$ sequência os aspectos referentes à NSI foram apresentados. 


\subsection{Nova Sociologia Institucional}

A New Institutional Sociology ou Nova Sociologia Institucional (NSI) é uma das vertentes da Nova Teoria Institucional (Neoinstitutional Theory) a qual, segundo Scott (2001), tem gerado muito interesse e atenção, se desenvolvendo como uma continuação e extensão do estudo das organizações que introduziram a concepção dos Sistemas Abertos. A NSI busca entender a lógica pela qual as estruturas são estabelecidas nas organizações. A evolução dessa teoria permitiu que as investigações e as explicações dos fenômenos ligados à estrutura organizacional, embora a mesma tenha surgido no paradigma funcionalista, tivessem um foco diferente de análise, uma lente que buscou escapar da predominância contingencialista nos estudos organizacionais na década de 1970 (CALDAS; FACHIN, 2005). Dessa forma, uma nova lógica de interpretação da estrutura organizacional formal foi levantada, aumentando o espectro de investigação no campo dos estudos organizacionais.

A NSI repousa, segundo Scott (2001), numa dimensão de instituição baseada em elementos culturais e cognitivos que enfatizam os conceitos compartilhados que constituem a natureza da realidade social e as formas pelas quais o significado é construído. Dessa forma, símbolos tais como palavras, sinais e gestos têm o efeito de moldar os significados que são atribuídos aos objetos e atividades, e o cumprimento dos ditames sociais ocorre em muitas circunstâncias, até porque outros tipos de comportamento são inconcebíveis e as rotinas são seguidas por serem taken for granted ${ }^{4}$ (SCOTT, 2001).

Muitos dos delineamentos e pressupostos dessa vertente foram baseados no trabalho de Berger e Luckmann (1967), que mostraram através de argumentos e exemplos que a realidade é uma construção social, sendo essas discussões adotadas pelos primeiros estudiosos da NSI no âmbito das organizações. Dessa forma, o entendimento de conceitos como instituição, legitimidade, institucionalização, dentre outros permitiu outra forma de explicação acerca do funcionamento organizacional. Ressalta-se que para não se tornar repetitivo, alguns conceitos utilizados na NSI (como instituição, institucionalização, decoupling, legitimidade, dentre outros) e citados neste tópico foram conceituados e discutidos com mais detalhes no tópico 2.2.2, por serem fundamentais no desenvolvimento do trabalho empírico empreendido.

Os estudos iniciais nessa área buscaram evidenciar como e porque ocorre o processo de mudança na estrutura organizacional formal quando não existe uma explicação apontando

\footnotetext{
${ }^{4}$ Embora existam traduções para esse termo como, por exemplo, "aceito sem contestação", optou-se por não traduzi-lo sob pena de perder o significado dessa expressão para a NSI.
} 
unicamente para motivos de busca de eficiência. O processo é entendido como sendo cultural e político focando a preocupação mais na legitimidade e no poder do que apenas na eficiência (CARRUTHERS, 1995). Alguns dos trabalhos iniciais dessa vertente foram os de Meyer e Rowan (1977), Zucker (1977) e DiMaggio e Powell (1983).

$\mathrm{Na}$ tradição contingencialista a estrutura organizacional formal tem propriedades objetivas; já na tradição institucional ela tem propriedades simbólicas. Para Tolbert e Zucker (2007) essa foi a ideia-chave seguida no trabalho seminal de Meyer e Rowan (1977) mostrando que as estruturas podem ser revestidas de significados socialmente compartilhados. Então, segundo a NSI, o estabelecimento de uma estrutura depende de fatores ambientais institucionais, além dos fatores ambientais técnicos, aos quais uma organização esteja exposta.

De forma resumida, o que Meyer e Rowan (1977) propuseram foi que as organizações são orientadas a incorporar práticas e procedimentos que estão institucionalizados na sociedade e que funcionam como mitos racionalizados de conduta apropriada. Esse tipo de mudança está mais inclinado para obtenção de legitimidade perante a sociedade do que para obtenção de eficiência. O uso da legitimidade ao invés da eficiência como determinante da escolha desafiou as explicações tradicionais (TOLBERT; ZUCKER, 2007). Nesse sentido, as organizações importam sua estrutura formal do ambiente externo (estado, profissões, organizações de sucesso) reproduzindo procedimentos, regras e estruturas que aumentam sua legitimidade externa (CARRUTHERS, 1995). Com isso, as estruturas das organizações tendem a ser parecidas e o foco do argumento institucional repousa no processo de isomorfismo (BECKERT, 1999), que representa a semelhança estrutural entre as organizações.

A pesquisa de Zucker (1977) analisou aspectos relacionados à persistência das instituições auxiliando no desenvolvimento da NSI ao demonstrar que a institucionalização não é dicotômica, devendo ser analisada enquanto um processo. DiMaggio e Powell (1983) voltaram seu foco de análise para os campos organizacionais, ou seja, no nível macro (interorganizacional), analisando o modo como as instituições são difundidas entre as organizações que atuam em um mesmo ambiente através dos mecanismos de isomorfismo (coercitivo, normativo, mimético).

Embora esses trabalhos iniciais sejam a base da NSI, discussões sobre alguns dos pressupostos desenvolvidos nos mesmos, especialmente no caso de Zucker (1977) e 
DiMaggio e Powell (1983), geraram muitas críticas posteriores, em especial quanto a visão determinista de mudança em relação às instituições (para maiores detalhes ver MACHADODA-SILVA et al., 2005; CRUBELLATE et al., 2004; CRUBELLATE, 2004; GREENWOOD et al., 2008). Nesse sentido, trabalhos posteriores começaram a rever alguns desses aspectos. Beckert (1999) e Greenwood et al. (2008), por exemplo, comentam que muitos dos estudos nessa área foram desenvolvidos em nível de análise macro, os quais não consideram os interesses e a diversidade de respostas que podem acontecer internamente nas organizações. Isso acontece porque, embora as estruturas tendem a ser semelhantes (isomórficas), a forma como as organizações passam a implementar ou não os mitos racionalizados pode ser muito diversa (o trabalho de Oliver, 1991 ilustra essa questão).

Para Machado-da-Silva et al. (2005) o isomorfismo não expressa necessariamente uma nãoação ou uma não-mudança, apresentando capacidade de agência ${ }^{5}$ ou escolha. Nesta perspectiva a NSI é uma abordagem “[...] interpretativista que, não negando a importância de condicionantes sociais, resguardava espaço para a autonomia no âmbito do processo de significação, elemento necessário de toda ação." (CRUBELLATE, 2007, p. 200). Isso reforçou a ideia de capacidade de escolha que já havia sido discutida desde o surgimento da Teoria Institucional (conforme apontamentos feitos por Selznick, 1996). "Essa vertente vai muito além da simples sugestão de que as organizações se adaptam a ambientes institucionais. Ela sugere que há um processo de mútua construção e reconstrução entre ambiente e organizações." (CRUBELLATE et al., 2004, p. 54).

Autores como Scott (2001), Oliver (1991), Beckert (1999) dentre outros, abordaram a questão da agência nos estudos da NSI, sendo os conceitos, níveis de análise, pressupostos e vários outros aspectos discutidos e em alguns casos reformulados, ampliando seu espectro teórico, o que leva a discussão da mesma como uma abordagem multiparadigmática (MACHADO-DASILVA et al., 2005). Esses aspectos foram discutidos nos tópicos subsequentes de forma mais pontual e detalhada por serem úteis para a construção da pesquisa empírica empreendida.

Nessa abordagem, aspectos como permanência e mudança, instituições e agência, reprodução e reconstrução, deixam de ser categorias dicotômicas para serem analisados como parte do mesmo processo, um continuum em que cada categoria tem seu espaço e seu tempo, de acordo com a interpretação dos agentes organizacionais tendo uma natureza recursiva e não

\footnotetext{
5 A definição usada nesse trabalho é de Machado-da-Silva et al. (2005, p. 24) baseada em Giddens (1984), "Agência é a capacidade de interferir em eventos, não necessariamente de modo intencional."
} 
relações causais com direção determinada (MACHADO-DA-SILVA et al., 2005). Nesse trabalho, compartilha-se da ideia de que os atores ${ }^{6}$ organizacionais agem sob influência de interesses tendo capacidade de interpretar para depois responder às pressões institucionais (MACHADO-DA-SILVA et al., 2005; OLIVER, 1991; BECKERT, 1999; CRUBELLATE, 2004). Por isso, essa foi a abordagem da NSI usada para explicar a adoção, a implementação e a utilização do Custeio Alvo.

Ressalta-se que, segundo a NSI, muito do que acontece nas organizações tem pouco a ver com as tarefas objetivas em que as mesmas estão engajadas e muito a ver com as relações sociais nas quais as organizações estão imersas (PALMER et al., 2008). Além disso, Carruthers (1995) comenta que as práticas contábeis são consideradas na NSI como um amplo conjunto de características que podem legitimar as organizações através da construção de uma aparência de racionalidade e eficiência. Por isso, a importância de entender práticas como o Custeio Alvo de acordo com essa abordagem.

\subsubsection{Aspectos Epistemológicos da NSI}

A NSI ainda não está institucionalizada e ainda não desenvolveu um conjunto central de variáveis e de metodologia de pesquisa padronizadas, nem conjunto de métodos específicos (TOLBERT; ZUCKER, 2007). Essa teoria ainda está em desenvolvimento e muitas mudanças importantes têm ocorrido em relação aos processos institucionais como elaboração e esclarecimento teórico, ampliação do escopo de aplicação das ideias, melhora nos indicadores empíricos e reforço das ferramentas metodológicas (SCOTT, 2008).

Esses comentários evidenciam que os trabalhos que se apoiam nessa teoria ainda não têm um padrão de aplicação, apresentando diferenças quanto aos níveis de análise, aos métodos, aos aspectos ontológicos e epistemológicos e em outras dimensões da pesquisa. A NSI foi compondo os traços que a caracterizam de modo a formar os pressupostos subjacentes de que se utiliza para explicar os fenômenos organizacionais, por isso, esse tópico buscou evidenciar alguns dos aspectos que foram seguidos na pesquisa empírica dessa tese não com o objetivo de esgotar o assunto, mas mostrar aspectos relevantes dessa abordagem que foram usados.

\footnotetext{
${ }^{6}$ Atores podem ser as organizações, os indivíduos, o estado (MEYER, 2008). No caso deste trabalho se referem aos indivíduos que atuam na organização.
} 
A NSI surgiu como parte do paradigma funcionalista organizacional, mas ao contrário da Teoria da Contingência que adotou um enfoque objetivista e com ele as dimensões do realismo, do positivismo e do determinismo, a mesma vem se deslocando em relação aos seus pressupostos, o que dificulta seu enquadramento em um único paradigma. Seu objetivo também é explicar as mudanças estruturais nas organizações, porém com um enfoque um pouco diferente do modelo de funcionalismo determinista e racionalista que, de acordo com Burrell e Morgan (1979), era considerado o modelo dominante nos estudos organizacionais, ou a ortodoxia. Descontentamentos com o desenvolvimento de pesquisas embasadas principalmente pelo funcionalismo em sua versão objetivista fizeram com que novas abordagens mais flexíveis nesse paradigma fossem surgindo (TOLBERT; ZUCKER, 2007; CALDAS; FACHIN, 2005; BURRELL; MORGAN, 1979), como é o caso da NSI.

Embora a NSI tenha surgido da ideia de construção social das instituições (BERGER; LUCKMANN, 1967), segundo Machado-da-Silva et al. (2005) alguns autores assumiram uma posição determinista e bastante criticada, centrada em aspectos relacionados à não-ação dos atores e à persistência das instituições, baseados na suposição de que essas limitam a ação organizacional. Com base em diversos autores da Teoria Institucional e como forma de responder a tais críticas e proporcionar uma reflexão para seu aprimoramento, Machado-daSilva et al. (2005) apresentam alguns elementos dispostos em uma versão multiparadigmática, centrada em uma abordagem recursiva do processo de institucionalização, mesclando funcionalismo com construtivismo e interpretativismo.

Machado-da-Silva et al. (2005, p. 17) tiveram como base outros estudos para sugerir que:

\begin{abstract}
Nessa linha de análise, não custa relembrar que a teoria neo-institucional se situa mais apropriadamente em posição intermediária no continuum entre as orientações determinista e voluntarista da ação organizacional. Tal posicionamento expressa a compreensão de que ela é formulada de acordo com a reciprocidade entre exigências internas e externas, a partir de escolhas guiadas pela interpretação intersubjetiva dos atores sociais sobre a racionalidade predominante no próprio contexto social [...]. Nesse caso, uma racionalidade limitada [...].
\end{abstract}

Percebe-se nessa proposta os elementos que a caracterizam: posição intermediária entre determinismo e voluntarismo, agência estratégica dos atores, intersubjetividade e racionalidade limitada. Na sequência esses elementos foram abordados de acordo com essa orientação, ressaltando-se que, para Machado-da-Silva et al. (2005), a noção de agência estratégica é o principal elemento que possibilita adotar essa abordagem. 
Uma mudança em relação ao funcionalismo ortodoxo que assume o determinismo foi a abertura da NSI para o voluntarismo. Na visão voluntarista o homem é completamente autônomo e possui livre arbítrio (BURRELL; MORGAN, 1979). Essas características representam o extremo do voluntarismo, mas para Burrell e Morgan (1979), como as teorias das Ciências Sociais estão preocupadas em entender as atividades humanas elas se inclinam explicitamente ou implicitamente para um ou outro ponto de vista (determinismo e voluntarismo) ou ainda podem adotar uma posição intermediária que permite a influência de ambos os fatores. Caldas e Fachin (2005) e Machado-da-Silva et al. (2005) argumentam que a NSI ocupa uma posição mais intermediária nesse espectro.

Isso pode ser observado já na obra de Meyer e Rowan (1977) quando afirmam que as organizações se adaptam às mudanças ambientais (especialmente em ambientes altamente institucionalizados) adotando determinados mitos institucionalizados, mas podendo responder com o decoupling quando a nova estrutura adotada não condisser com os requisitos de eficiência. Essa afirmação mostra que, embora a organização em algumas situações deva mudar sua estrutura (levando-se em conta o ambiente altamente institucionalizado), a resposta pode ser a não utilização efetiva dessa nova estrutura, ou seja, uma resposta não necessariamente determinista. De acordo com Machado-da-Silva et al. (2005, p. 28) "[...] as instituições só podem ser visualizadas como regularidades ou possibilidades, jamais como determinações, em decorrência do aspecto cognitivo-cultural característico de toda e qualquer ação social e não a despeito dele." Isso reflete a capacidade da organização em ter um tipo de resposta que seja adequada à sua situação interna e aos requisitos externos na busca por legitimidade.

De acordo com Greenwood et al. (2008) e Scott (2001), foi em 1988 que DiMaggio resgatou essa questão e incluiu na agenda de estudos da NSI a necessidade de se entender os tipos de respostas estratégicas das organizações (capacidade de agência) às demandas ambientais por mudanças institucionais, mas ainda em uma versão monoparadigmática, com foco de agência exclusivo no poder. Oliver (1991) reforçou a ideia de agência argumentando que a organização pode responder de forma estratégica às mudanças impostas pelo ambiente em uma tipologia que varia da conformidade passiva à manipulação proativa. Reconhecendo que esse tipo de comportamento (agência estratégica) pode ser orientado por interesses, Beckert (1999) se refere à mesma como sendo uma persuasão planejada dos fins com base em uma avaliação racional dos meios disponíveis e das condições estratégicas. A incorporação na NSI 
de interesses nas decisões torna possível o entendimento da importância das regras institucionais para o processo organizacional em um modelo mais abrangente (BECKERT, 1999).

A importância das regras institucionais, nesse modelo multiparadigmático, não implica em limitação de ação ou não-ação nos moldes deterministas, mas sim a noção de que existe uma recursividade entre limitação e habilitação para a ação. Com base na noção de estruturas de Giddens (1984) essa visão se amplia com o surgimento de três pontos relevantes destacados por Machado-da-Silva et al. (2005): agência e estrutura não são opostas, mas se pressupõe mutuamente; as estruturas sociais e sua regras, normas e padrões de cognição devem ser considerados tanto limitadores quanto habilitadores da ação, nunca apenas um ou outro e; o processo de institucionalização entendido enquanto estado recursivo não pode ser plenamente apreendido sem levar em conta a interpretação da ação como aspecto que possibilita o seu desenvolvimento, ou seja, "A interpretação é o mecanismo operacional, de natureza cognitivo-cultural, da recursividade inerente à institucionalização.”(p. 26).

Dessa forma, para Machado-da-Silva et al. (2005, p. 22) na noção de agência o processo de institucionalização “[...] não descarta, mas pressupõe tanto a mudança como a persistência, tanto a imersão social como a autonomia, tanto os níveis microssociais (organizações e agentes individuais) como os planos macrossociais." Percebe-se com isso que esse espectro de argumentação da NSI envolve vários pressupostos e outras formas de enxergar o funcionamento das estruturas, não tratando os mesmos enquanto elementos dicotômicos e sim como partes integrantes do mesmo processo.

Quanto à racionalidade, Tolbert e Zucker (2007) argumentam que a noção de que os decisores são dotados de racionalidade limitada (nos moldes de SIMON, 1976) tornou-se um componente básico na cartilha da pesquisa organizacional, inclusive na Teoria Institucional. Crubellate et al. (2004) apontam que essa vertente se constituiu para incorporar a noção de limites sociais da racionalidade dentro da lógica da agência estratégica. A noção de racionalidade limitada está atrelada a uma abordagem multiparadigmática uma vez que se assenta em pressupostos estruturais e interpretativistas (MACHADO-DA-SILVA et al., 2005).

Caldas e Fachin (2005) comentam que a NSI é um exemplo de teorias que passaram a salientar elementos políticos, cognitivos e culturais ou normativos do ambiente, os quais 
limitam a ação organizacional racional e neutra, favorecendo outros elementos internos e externos dessa ação. Para Machado-da-Silva et al. (2005), os padrões institucionais limitam a possibilidade de ação racional, mas também possibilitam alguma ação e com isso, alguma racionalidade. "O argumento central a ser desenvolvido é o de que, mediante referências institucionais, se encontram ações racionalmente limitadas." (MACHADO-DA-SILVA et al., 2005, p. 21).

Outra questão importante é que a NSI passou a incorporar aspectos mais subjetivos da ligação entre estrutura organizacional e ambiente, como os aspectos simbólicos. Posteriormente, a noção de construção social das instituições e da capacidade de agência estratégica, conforme apontado por Machado-da-Silva et al. (2005), trouxe uma aproximação com a capacidade de interpretação por parte dos atores organizacionais, cedendo espaço para uma visão intersubjetiva da NSI. Nessa abordagem,

A noção de intersubjetividade possibilita o estabelecimento de pontes significativas em relação aos conceitos de subjetivo e objetivo, uma vez que se refere ao compartilhamento de significados atribuídos por atores individuais em cada situação social específica, garantindo uma objetividade localizada, porque espaciotemporalmente delimitada. (MACHADO-DA-SILVA et al., 2005, p. 12).

De acordo com o exposto é possível verificar que a NSI tem assumido pressupostos que a torna uma abordagem multiparadigmática, apontando outros caminhos para questões críticas como a racionalidade e o determinismo, inerentes ao paradigma funcionalista, ao qual a mesma teve origem, assumindo postura construtivista e interpretativa. Nesses moldes,

[...] cabe aos atores sociais, mediante sua capacidade de agência, a participação no processo de construção social da realidade, a partir de condicionantes estruturais que não apenas constrangem, mas também possibilitam a ação social, na medida em que são criados pelos próprios atores sociais por meio do compartilhamento intersubjetivo de interpretações. (MACHADO-DA-SILVA et al., 2005, p. 12).

Devido à abertura que essa abordagem traz em relação às possibilidades de interpretação das respostas estratégicas organizacionais relativas ao processo de institucionalização, a mesma foi adotada na presente investigação como forma de entender o significado atribuído ao Custeio Alvo na Alfa. 


\subsubsection{Fundamentos da Nova Sociologia Institucional}

Conforme mencionado, a NSI ainda está em desenvolvimento, por isso, aspectos fundamentais como conceitos, a pressão e interação entre ambientes institucionais e econômicos, os níveis de análise, dentre outros, podem ser tratados de várias maneiras. Dessa forma, é importante verificar como esses aspectos foram considerados na presente pesquisa. Ressalta-se que o objetivo aqui foi de abordar e conceituar os tópicos de interesse sob a perspectiva que foi usada no trabalho, não tendo a pretensão de elaborar resgates históricos nem esgotar o assunto. Detalhes a respeito da operacionalização e mensuração de alguns dos aspectos analisados foram tratados no item 2.2.5 e no Capítulo 4 referente à metodologia.

\subsubsection{Instituição e Institucionalização}

Meyer e Rowan (1977), Zucker (1977), Scott (2001), dentre outros utilizam a definição de institucionalização e de instituições de Berger e Luckmann (1967) para embasar suas ideias. Segundo Berger e Luckmann (1967) a institucionalização é um processo através do qual as instituições são construídas socialmente e, as instituições são tipificações recíprocas de ações tornadas habituais por tipos de atores. As tipificações institucionais devem ser sempre recíprocas e partilhadas, sendo o processo de formação de hábitos precedente a toda institucionalização (BERGER; LUCKMANN, 1967). O ponto fundamental dessa definição está na construção social das instituições, ou seja, num processo que envolve a participação ativa dos atores em sua formação. Esta formação engloba várias fases, por isso, seu processo é denominado de institucionalização. Para Berger e Luckmann (1967) o processo de institucionalização ou de criação de tipificações passa por três fases: a externalização, a objetivação e a internalização, que é quando a tipificação está sedimentada na sociedade, ou seja, institucionalizada.

Meyer e Rowan (1977) explicam que as instituições inevitavelmente envolvem obrigações normativas e que frequentemente entram na vida social principalmente como fatos que devem ser levados em conta pelos atores. Para Meyer e Rowan (1977, p. 341) a "Institucionalização envolve o processo pelo qual os processos sociais, obrigações ou realidades assumem um status de regra no pensamento e na ação social."7 Jepperson (1991) considera como exemplos

\footnotetext{
${ }^{7}$ Institutionalization involves the process by which social processes, obligations, or actualities come to take on a rulelike status in social thought and action. Em inglês no original. Tradução livre da autora.
} 
de instituições o casamento, o aperto de mão, o voto, as férias, os cargos acadêmicos, dentre outros, mostrando como podem ter diferenças significativas em relação às suas características e mesmo assim serem instituições. Para Jepperson (1991) as instituições não apenas restringem a ação, elas simultaneamente capacitam e controlam; são veículos para a atividade dentro das restrições.

Estas características são encontradas no conceito de instituições na abordagem multiparadigmática da NSI. Crubellate et al. (2008, p. 79) comentam que "[...] a nova teoria institucional caminhou paulatinamente para o reconhecimento de que o papel das instituições, no que tange à ação, é tanto restritivo quanto constitutivo, certamente com uma ou outra preponderância, de acordo com o contexto espaciotemporal." Quanto às suas características, Scott (2001, p. 49) resume que “[...] instituições são multifacetadas, estruturas sociais duráveis, compostas de elementos simbólicos, atividades sociais e recursos materiais."8

Jepperson (1991) ainda menciona que uma instituição depende do contexto analítico em que está inserida, ou seja, o que é uma instituição em um país ou em uma empresa pode não ser em outra e, que as instituições de alguma maneira se tornam taken for granted porque elas tanto são tratadas como fixações relativas em um ambiente social quanto são explicadas como elementos funcionais daquele ambiente, indicando alguma consideração social comum da sua existência e propósito.

Nessa pesquisa instituição e institucionalização seguem o conceito de Berger e Luckmann (1967), discutidas e aceitas pelos autores citados, sendo a institucionalização tratada como um processo avaliado através de fases que permitiram verificar em que nível ou fase se encontra o Custeio Alvo na organização investigada. Quanto às instituições é relevante mencionar que seu conceito recebeu destaque devido ao fato de que nessa pesquisa o Custeio Alvo foi considerado como uma prática institucional, seguindo a linha de trabalhos que consideram a contabilidade dessa forma (CARRUTHERS, 1995; RICHARDSON, 1987; SCAPENS, 1994, BURNS; SCAPENS, 2000, dentre outros). As práticas de Contabilidade Gerencial podem ser consideradas rotinas organizacionais, e como são legalizadas (enacted) e reproduzidas ao longo do tempo elas podem se tornar institucionalizadas (BURNS; SCAPENS, 2000). Powell (1991) acrescenta que as práticas contábeis são fortemente modeladas pelas expectativas e pressões institucionais.

\footnotetext{
8 “[...] institutions are multifaceted, durable social structures, made up of symbolic elements, social activities, and material resources." Em inglês no original. Tradução livre da autora.
} 
Uma prática organizacional sob essa ótica representa o uso rotineiro do conhecimento de uma organização para a realização de determinada função que evoluiu ao longo do tempo sob a influência da história da organização, das pessoas, dos interesses e das ações (KOSTOVA; ROTH, 2002). Considerar o Custeio Alvo enquanto prática organizacional institucional confere ao mesmo todos os aspectos e características contempladas pela NSI.

\subsubsection{Legitimidade}

A legitimidade é uma lógica subjacente à NSI. Enquanto a eficiência é o coração do fator técnico, a legitimidade constitui a essência do fator institucional (CARRUTHERS, 1995). Para Meyer e Rowan (1977) as organizações buscam aumentar sua legitimidade incorporando práticas e procedimentos que estão institucionalizados na sociedade. Trata-se de um conceito central no institucionalismo organizacional e frequentemente os autores o empregam em seus estudos, mas poucos o definem (DEEPHOUSE; SUCHMAN, 2008).

Uma das razões pela busca da legitimidade é a garantia de sobrevivência das organizações (MEYER; ROWAN, 1977), uma vez que, de acordo com Abrahamson (1991), uma inovação que faz com que uma organização pareça inovadora ou ética pode ajudá-la a levantar capital de outras organizações bem como atrair clientes. A legitimidade, desta forma, não presume a eficiência em termos econômicos ou de maximização da utilidade, mas funciona como um tipo de racionalidade em relação ao que é aceitável em determinada sociedade, apresentando um significado naquele contexto.

Suchman (1995, p. 574) define legitimidade como sendo “[...] uma percepção ou suposição generalizada de que as ações de uma entidade são desejáveis, próprias ou apropriadas dentro de algum sistema de normas, valores, crenças e definições socialmente construídas." definição é abrangente e considera a legitimidade como uma construção social do que é ou não aceito em algum ambiente. Nesse sentido, Neilsen e Rao (1987) mencionam que o estabelecimento da legitimidade em uma organização é um processo coletivo de construção de significado em que líderes, seguidores e stakeholders participam de forma conjunta. Por outro lado, Meyer e Rowan (1977) e DiMaggio e Powell (1983) argumentam que as

\footnotetext{
9 " $[\ldots]$ a generalized perception or assumption that the actions of an entity are desirable, proper, or appropriate within some socially constructed system of norms, values, beliefs, and definitions." Em inglês no original. Tradução livre da autora.
} 
organizações que atuam em ambientes altamente institucionalizados e se tornam isomórficas a eles ganham legitimidade.

Portanto, percebe-se que a legitimidade tanto pode ser um estado ou um resultado da institucionalização quanto pode contribuir para ela (JEPPERSON, 1991). Por isso, para Suchman (1995), a legitimidade pode ser gerenciada pela organização. Assim, pode-se supor que decidir qual, quando e de que forma uma instituição deve ser adotada de modo a gerenciar a legitimidade leva ao entendimento de que a capacidade de agência se aplica nesse caso.

Enquanto a obtenção de legitimidade é o estado ou resultado, a legitimação é o processo pelo qual a mesma muda ao longo do tempo (DEEPHOUSE; SUCHMAN, 2008), ou seja, como ela é formada. Dado que o objetivo da presente pesquisa foi investigar como o Custeio Alvo foi institucionalizado, a legitimidade foi analisada enquanto estado/resultado desse processo, ou seja, se sua institucionalização gerou algum tipo de legitimidade para a organização. Por isso, é necessário verificar algumas formas de como esse resultado pode ser analisado.

A legitimidade atribuída a uma organização pode ter várias fontes. Para Ruef e Scott (1998) quem determina se uma organização está ou não legitimada ou está mais ou menos legitimada, são todos os observadores que avaliam sua conformidade a padrões ou modelos específicos; dessa forma todos os stakeholders participam desse processo com diferentes graus de conhecimento e influência sobre os níveis de legitimidade. Além disso, Ruef e Scott (1998) acrescentam que essas fontes podem ser internas, como trabalhadores, gestores, membros do conselho, ou externas à organização como a mídia e outros. Conhecer essas fontes é importante para verificar como a legitimidade é avaliada e por quem.

Como a organização investigada nessa pesquisa é uma subsidiária de classe mundial é importante verificar como essa característica pode afetar as fontes de legitimidade. Kostova e Zaheer (1999) analisaram vários aspectos referentes à legitimidade em organizações multinacionais, por isso, seu trabalho serviu de base para esclarecimento e definição de pontos que foram avaliados na presente pesquisa.

A legitimidade organizacional no caso de multinacionais pode ser examinada no nível da multinacional como um todo (compreendendo a matriz e as demais subunidades) ou no nível das subunidades em cada país (KOSTOVA; ZAHEER, 1999). Este último foi o caso da presente pesquisa. Nesse sentido, duas fontes podem conferir legitimidade para a subsidiária, a matriz juntamente com as demais subunidades e o ambiente institucional no qual está 
localizada, que representam a legitimidade interna e a externa, respectivamente (KOSTOVA; ZAHEER, 1999). Para Kostova e Zaheer (1999) a legitimidade interna é suscetível de resultar quando da adoção, por uma subunidade, de estruturas, políticas e práticas institucionalizadas dentro da multinacional como um todo.

Devido ao controle que a matriz impõe sobre as subunidades, essas ficam suscetíveis a seguir as regras e normas estabelecidas, por isso, podem apresentar a legitimidade interna. Além disso, Kostova e Zaheer (1999) relembram que a dependência de recursos como capital e conhecimento torna importante a conformidade às imposições da matriz, como forma de obtenção de legitimidade interna. Essa necessidade de conformidade pode gerar problemas quando os requerimentos de legitimidade externa, existentes no país onde a subsidiária está instalada, forem muito diferentes daqueles relativos à legitimidade interna, podendo gerar inconsistências (KOSTOVA; ZAHEER, 1999), resultando em diferentes respostas por parte das subsidiárias. Isso acontece porque, segundo Machado-da-Silva et al. (2005, p. 29),

[...] a interpretação também está vinculada estreitamente com a legitimidade como aspecto fundamental de toda instituição, permitindo compreender porque uma regularidade qualquer de coisas não é considerada instituição: enquanto tal aquela regularidade deve ser explicada pelo fato de os indivíduos submetidos à sua vigência aceitarem a sua legitimidade.

Dessa forma, para Machado-da-Silva et al. (2005), as ações empreendidas na organização por meio da interpretação dos fatores externos e internos (agência) são legitimadas mediante compartilhamento e socialização e, nesse sentido, somente ações consideradas legítimas pelos envolvidos são reproduzidas e se consolidam como padrões institucionalizados. Pelo exposto percebe-se a importância do conceito de legitimidade nos estudos relativos à NSI e, nesse trabalho, a mesma foi considerada como um resultado, tendo como fontes os observadores internos e externos e podendo ser interna e externa, com atenção especial ao significado atribuído pelos atores em relação à legitimidade obtida com a utilização do Custeio Alvo.

\subsubsection{Decoupling e Loose Coupling ${ }^{10}$}

A adoção de regras institucionalizadas pode causar muitas inconsistências na estrutura organizacional. Meyer e Rowan (1977) levantaram essa questão mostrando que o esforço de uma organização para se conformar às regras institucionalizadas pode criar conflitos e

\footnotetext{
${ }^{10}$ A literatura algumas vezes aborda o termo loose coupling (como em MEYER; ROWAN, 1977, POWELL, 1991), mas com o mesmo sentido de decoupling.
} 
inconsistências na estrutura formal e, por serem essas regras transmitidas por mitos, as mesmas podem conflitar, uma vez que estes podem surgir de diferentes partes do ambiente. Uma das formas de resolver essas inconsistências é pelo decoupling entre a estrutura formal e as atividades rotineiras, ou seja, uma adoção do tipo cerimonial (MEYER; ROWAN, 1977). Dessa forma, a conformidade não é a única resposta, outras podem ser construídas e significadas, sendo o decoupling uma delas.

$\mathrm{Na}$ adoção cerimonial a prática ou a regra institucionalizada é adotada formalmente com o objetivo de legitimidade, mas sua adoção não interfere nas atividades rotineiras da organização, ou seja, não existe a crença em seu real valor para a organização ou existem conflitos em relação à eficiência (MEYER; ROWAN, 1977). As práticas da Contabilidade Gerencial institucionalizadas de forma cerimonial funcionam como rituais usados para preservar o status quo e o poder ou interesse de determinado grupo ou de alguns indivíduos, não auxiliando a tomada de decisão (BURNS; SCAPENS, 2000).

Meyer e Rowan (1977) não definem explicitamente o decoupling, mas dão algumas diretrizes para mostrar como o mesmo funciona, afirmando que esse dispositivo capacita as organizações a manter sua estrutura formal padronizada e legitimada enquanto suas atividades variam em resposta às considerações práticas. Para eles a suposição de que a estrutura formal está realmente funcionando é suficiente para protegê-la das inconsistências e anomalias inerentes da atividade técnica.

Para Carruthers (1995) a sociedade ocidental moderna privilegia uma forma particular de racionalidade e as organizações que operam em um contexto cultural ganham mais legitimidade se puderem reproduzir de forma simbólica essa racionalidade. A organização tem muito mais a fazer em relação à sua apresentação do que com as coisas que realmente acontecem em seu interior, sendo a estrutura formal mítica e cerimonial, funcionando como uma fachada simbólica (CARRUTHERS, 1995).

Uma primeira impressão retirada desses comentários leva a crer que o decoupling serve para "fazer de conta" que a organização realmente implementou ou está usando na prática as regras institucionalizadas que adotou. Para Powell (1991) essa primeira interpretação seguida em muitos estudos é inapropriada, pois não é bem assim que este dispositivo funciona; os argumentos usados associaram as organizações como não estando preocupadas com o 
desempenho das tarefas, atuando como manipuladoras de aparências, buscando exclusivamente legitimidade.

Meyer e Rowan (1977) mencionam que a atividade cerimonial tem significado em relação às regras categóricas e não em relação aos seus efeitos práticos e que as organizações frequentemente enfrentam o dilema de que as atividades que contemplam regras institucionais são custos puros em relação à eficiência. Por isso, o decoupling é uma forma de a organização mostrar que atende exigências institucionais sem necessariamente mostrar a perda de desempenho que traria e, por conseguinte, a perda da legitimidade. Carruthers (1995) argumenta que quando o resultado organizacional é facilmente mensurável, as tecnologias de produção são bem definidas e os critérios de sucesso não são ambíguos a eficiência técnica tem importância e, quando os resultados, as tecnologias e os critérios são altamente incertos o aspecto mítico das estruturas racionalizadas parece ter mais importância. Boxenbaum e Jonsson (2008) discutem que o decoupling pode ser uma resposta estratégica e que mais estudos a esse respeito são necessários.

Um exemplo de decoupling nos estudos da Contabilidade Gerencial está no trabalho de SitiNabiha e Scapens (2005) sobre a implantação da Gestão Baseada em Valor em uma subsidiária por imposição da matriz. O estudo relata que, embora a prática tenha sido implantada e os relatórios sejam preparados para cumprir os procedimentos e enviados para a matriz, a subsidiária não utiliza tais informações para avaliar o desempenho dos gestores e dos departamentos, que é o objetivo da prática. Isso mostra que o decoupling não se refere ao não uso da prática, mas devido a alguma razão as organizações reagem dissociando a estrutura das rotinas da organização. No exemplo citado, a prática não foi, por algum motivo, entendida como sendo importante ou que trouxesse algum benefício, por isso, mesmo tendo sido implementada ela não mudou a rotina em relação à avaliação dos gestores e departamentos.

O decoupling nessa pesquisa foi considerado como uma possível resposta estratégica da organização (conforme discutido por Meyer; Rowan, 1977 e Boxenbaum; Jonsson, 2008) e foi avaliado na Alfa de modo a verificar de que forma o Custeio Alvo está relacionado ao sistema de controle, ou seja, se está funcionando de forma acoplada às atividades práticas ou se é feito apenas para cumprir os requisitos da matriz, levando em conta a capacidade de agência dos atores. Ainda foi verificado se existem conflitos, inconsistências ou ambiguidades em relação ao uso do Custeio Alvo e a estrutura da organização. Isso ajuda esclarecer o que a 
organização espera em relação ao Custeio Alvo apontando para os efeitos da prática, auxiliando no esclarecimento de aspectos e circunstâncias sobre seu funcionamento.

\subsubsection{Ambiente Econômico e Ambiente Institucional}

Ambientes econômicos ou técnicos são aqueles em que um produto ou serviço é produzido e trocado em um mercado de modo que as organizações são recompensadas pelo controle efetivo e eficiente de seu sistema produtivo e o ambiente institucional se refere àquele caracterizado pela elaboração de regras e requerimentos aos quais as organizações devem se conformar se quiserem receber apoio e legitimidade (SCOTT; MEYER, 1991).

Para Meyer e Rowan (1977) as organizações podem ser técnicas e institucionais e, nesse sentido, pode ser estabelecido um continuиm em que as organizações podem estar dispostas; de um lado as organizações com foco de mercado sob forte controle de resultados e de outro as organizações cujo sucesso depende do alcance de isomorfismo com as regras institucionais. Scott e Meyer (1991) argumentam que modelos de explicação da relação organizaçãoambiente se baseavam principalmente no aspecto técnico, mas aspectos sociais e culturais representam outra forma de explicar essa relação e defendem que esses dois ambientes não deveriam ser vistos como estados mutuamente excludentes, mas sim podendo coexistir.

Em relação ao uso da NSI, Powell (1991) argumenta que talvez o fato de muitos trabalhos empíricos focarem empresas sem fins lucrativos e agências públicas pode ter levado a uma compartimentação do universo organizacional. Para o autor esse tipo de distinção entre as organizações tinha uma pretensão analítica, mas levou muitos leitores a enxergar essas categorias como descrições de organizações diferentes, confundindo uma distinção analítica com uma questão empírica. Tratar esses dois setores como alternativas dicotômicas é problemático porque é muito difícil separar de forma nítida os dois processos (POWELL, 1991).

Esse tipo de interpretação por parte de alguns pesquisadores, tratando as organizações como se fossem exclusivamente baseadas no mercado ou exclusivamente baseadas em instituições racionalizadas, acabou por gerar diversos problemas teóricos que mais tarde começaram a ser debatidos e ajustados. Powell (1991) relata alguns exemplos desses problemas como: tratar uma organização exclusivamente baseada em instituições pode levar ao falso entendimento de 
que a mesma tende a ser ineficiente, uma vez que sua preocupação é se tornar similar institucionalmente com outras sem ser necessariamente eficiente; outro problema é que aparentemente esse tipo de organização tem mais facilidade de se tornar isomórfica ao ambiente uma vez que a institucionalização ocorre de forma simbólica passando a impressão de que esse processo é rápido, fácil e barato e o que é pior, essas organizações vivem as instituições incorporadas como um faz de conta, apenas de forma cerimonial.

Algumas soluções foram propostas para aproximar a distinção analítica da classificação empírica. Scott e Meyer (1991) propuseram que todas as organizações operam simultaneamente nos dois ambientes (técnico e institucional) e que o nível de pressão sofrida em cada um varia entre os diferentes tipos de organizações. Essa solução é interessante uma vez que operando nos dois ambientes, a ideia anterior de que organizações institucionais tendem a ser ineficientes é amenizada, pois mesmo tendo forte inclinação institucional também apresentam algum grau de pressão técnica. Por outro lado existe a dificuldade em distinguir quanto de pressão existe em cada ambiente.

Powell (1991) exemplifica isso mostrando que atividades variadas, como a adoção de práticas contábeis ou de formas multidivisionais, são fortemente modeladas por expectativas e pressões institucionais e conforme uma organização cresce em tamanho e se torna envolvida nas atividades do setor e em densas redes de intercâmbio as expectativas institucionalizadas de outras firmas, dos consumidores e do governo exercem muita influência sobre seu comportamento. Segundo Scott (2008) as regras, as normas e os sistemas de crença embasam todo sistema social estável inclusive o econômico. Isso mostra que as organizações, independente de suas características, estão sujeitas aos dois tipos de pressão.

Para ampliar o desenvolvimento da NSI em relação aos ambientes, Powell (1991) enfatiza que os estudos empíricos nessa abordagem não fiquem restritos às organizações públicas e sem fins lucrativos, sugerindo que esforços devem ser direcionados também para o estudo de setores essenciais da economia como o industrial e o financeiro. Esse é o caso da presente pesquisa, uma vez que investigou em uma organização industrial privada como essas duas pressões foram interpretadas na adoção e na implementação do Custeio Alvo. 


\subsubsection{Mecanismos de Isomorfismo Institucional}

A questão do isomorfismo, ou seja, da semelhança estrutural entre as organizações é assunto debatido na NSI por vários autores dentre os quais Meyer e Rowan (1977) e DiMaggio e Powell (1983). Para DiMaggio e Powell (1983) as causas da mudança estrutural das organizações parecem ser cada vez menos orientadas por eficiência e competição e a tese defendida é de que as formas de mudança organizacional ocorrem como resultados de processos que tornam as organizações mais similares sem fazer com que as mesmas necessariamente ganhem eficiência.

A ênfase nos mecanismos de isomorfismo se dá no contexto de campos organizacionais. Campos organizacionais são definidos como “[...] organizações que em agregados constituem uma área reconhecida da vida institucional: fornecedores chave, consumidores de recursos e produtos, agências reguladoras e outras organizações que produzem serviços ou produtos similares." ${ }^{\prime 1}$ (DIMAGGIO; POWELL, p. 148, 1983).

Para DiMaggio e Powell (1983) os campos organizacionais que são altamente estruturados apresentam um contexto em que esforços individuais para lidar de forma racional com a incerteza geralmente levam de maneira conjunta à homogeneidade estrutural, cultural e de resultados, pois, forças poderosas emergem no sentido de tornar as organizações integrantes desse contexto mais similares. Esta homogeneização é captada pelo isomorfismo que é um processo que força as partes de um campo a se assemelhar (DIMAGGIO; POWELL, 1983).

Esses autores defendem dois tipos de isomorfismo: o competitivo e o institucional. $\mathrm{O}$ competitivo é mais adequado nos campos que enfrentam competição livre e aberta, podendo ser aplicável à adoção antecipada de inovações. $\mathrm{O}$ isomorfismo institucional deriva do fato de as organizações não competirem somente por recursos e clientes, mas também por poder político e legitimidade, por adequação social tanto quanto econômica. Os três mecanismos de mudança isomórfica propostos DiMaggio e Powell (1983) são o coercitivo, o mimético e o normativo. Essa tipologia é analítica e os conceitos podem se misturar no contexto empírico, mas os mesmos derivam de condições diferentes, então a tendência é de que possam levar a resultados distintos.

\footnotetext{
${ }^{11}$ organizations that, in the aggregate, constitute a recognized area of institutional life: key suppliers, resource and product consumers, regulatory agencies, and other organizations that produce similar services or products. Em inglês no original. Tradução livre da autora.
} 
Pressões formais e informais que as organizações experimentam exercidas por organizações das quais depende e pelas características culturais da sociedade em que atuam resultam no isomorfismo coercitivo. Neste processo os autores destacam o decoupling discutido por Meyer e Rowan (1977), mostrando que as organizações estão cada vez menos determinadas estruturalmente pelas restrições impostas por atividades técnicas e menos integradas por controles de resultados, usando, nessas circunstâncias, controles ritualizados de referenciais e a solidariedade de grupo. Esse isomorfismo também foi observado em empresas não governamentais, como as subsidiárias que são obrigadas a adotar práticas contábeis, avaliação de desempenho e planos orçamentários de acordo com as políticas da matriz (DIMAGGIO; POWELL, 1983). Pelas características da organização investigada nessa pesquisa, é possível que este mecanismo tenha sido o responsável pela adoção do Custeio Alvo, uma vez que se trata de subsidiária de multinacional asiática conhecida na literatura como usuária dessa prática.

O isomorfismo mimético é derivado da incerteza que encoraja a imitação; quando problemas como ambiguidade das metas, incerteza simbólica criada pelo ambiente e a incompreensão de tecnologias afetam as organizações elas podem usar outras como modelo e esse comportamento constitui uma resposta à incerteza e gera uma economia de ação humana que representa uma vantagem do mimetismo (DIMAGGIO; POWELL, 1983). Esse mecanismo também pode ter sido responsável pela adoção do Custeio Alvo na Alfa, mas com uma probabilidade menor do que o coercitivo uma vez que para isso a Alfa deve ter um grau de liberdade em relação às escolhas de suas práticas em relação ao que a matriz determina.

A profissionalização pode conduzir as mudanças organizacionais de forma normativa. Membros de uma classe profissional buscam estabelecer uma base cognitiva e legitimação para a autonomia de sua profissão. $\mathrm{O}$ isomorfismo normativo pode ter dois aspectos, um se refere ao apoio da educação formal e da legitimação produzidos por especialistas universitários e o segundo, é a constituição e o crescimento de redes profissionais que passam pelas organizações e pelos quais novos modelos são rapidamente difundidos (DIMAGGIO; POWELL, 1983). Esse mecanismo parece ser o menos viável de aplicação no caso da Alfa, dadas as suas características bem como as da prática.

Analisar a questão do isomorfismo é importante para verificar como as inovações são difundidas nos campos organizacionais. Além disso, a forma como tais inovações chegam às organizações (coerção, normas, imitação) pode impactar no tipo de resposta em relação às 
mesmas. Para Scott (2001) a conformidade não é a única resposta às pressões isomórficas uma vez que os processos institucionais se combinam com outras forças para modelar estrutura e ação. Assim, existe o espaço para a agência, ou seja, a organização pode reagir à adoção de forma diferente das demais mesmo estando em ambientes institucionais similares. Variações nas respostas podem gerar diferenciação ao invés do isomorfismo e, verificar essa ocorrência requer um foco sobre os processos institucionais internos (Zucker, 1991). Por isso, foi verificado nessa pesquisa qual dos mecanismos pode ter sido responsável pela adoção do Custeio Alvo na Alfa de forma a auxiliar a análise do tipo de resposta da mesma.

\subsubsection{Nível de Análise}

É importante reconhecer em qual nível a NSI empreende seus esforços para entender a estrutura organizacional. Scott (2008) menciona que os elementos institucionais operam em vários níveis de análise podendo ir desde o micro ou interpessoal ao macro ou transnacional. As organizações são compostas por muitos desses elementos, como regras, normas ou crenças que são moldados em interações constantes; outros são trazidos do ambiente e, nesse contexto, os estudiosos podem focar suas análises nas organizações, nas populações organizacionais ou nos campos organizacionais (SCOTT, 2008).

Para Greenwood et al. (2008) embora as instituições existam no nível do indivíduo, da organização, de campo ou de sociedade, o institucionalismo organizacional se preocupa mais com as instituições e os processos institucionais em dois níveis, o da organização e o de campo organizacional. A análise de elementos institucionais em nível de campo é interessante porque foca as interações da organização com seu ambiente (inter-organizacional). Mas, para Scott (2008), a mudança de nível dos estudos institucionais para o campo fez com que formulações iniciais da teoria dessem muita atenção às características relacionais e estruturais do campo, negligenciando elementos simbólicos ou culturais. Dessa forma, a análise em nível organizacional pode ser útil para retomar essas questões. A análise em nível organizacional aborda de forma mais profunda como os elementos institucionais são significados em uma organização, envolvendo sua criação ou adoção, sua implementação, seu contexto histórico e cultural na investigação.

Trabalhos empíricos baseados na NSI como os de Dambrin et al. (2007), Nor-Aziah e Scapens (2007), Granlund (2001), Järvinen (2006), Kholeif et al. (2007), Kostova e Roth 
(2002), Ma e Tayles (2009), Ribeiro e Scapens (2006), Soin et al. (2002), dentre muitos outros na área da Contabilidade Gerencial foram desenvolvidos em nível organizacional. Esses trabalhos buscam entender como determinado fenômeno ocorre em uma organização. Seguindo essa linha de estudos, na presente pesquisa o nível organizacional foi a base para as análises.

\subsubsection{Estágios do Processo de Institucionalização}

Conforme abordado anteriormente a institucionalização do Custeio Alvo foi considerada como um processo e, dessa forma, a mesma deve ter fases ou estágios que permitem uma classificação. Como mostram Berger e Luckmann (1967), a institucionalização das instituições passa pela externalização, pela objetivação e pela internalização e, somente quando atingem esta última é que estão institucionalizadas.

Para que se possa classificar o processo é necessário um modelo que possibilite sua análise de forma a identificar em qual fase se encontra. Nesse sentido, Hasselbladh e Kallinikos (2000) desenvolveram um modelo conceitual que considera a institucionalização enquanto processo e que pode ser usado em nível organizacional (DAMBRIN et al., 2007) e, por isso, foi escolhido para auxiliar no trabalho empírico no que diz respeito à identificação dos níveis de institucionalização do Custeio Alvo na Alfa.

Hasselbladh e Kallinikos (2000) argumentam que as organizações são entidades sociais imersas em complexas redes de crenças, cultura e convenções que acabam por modelar tanto seus objetivos quanto suas práticas. Por isso, esses elementos sociais devem ser levados em consideração quando do estudo da estrutura organizacional. Partindo dessas constatações Hasselbladh e Kallinikos (2000) propõem um modelo conceitual que busca envolver as questões ligadas à construção social de uma instituição.

Baseados em Foucault sobre a noção de que os discursos são meios distintivos de definir a realidade, Hasselbladh e Kallinikos (2000) ilustram que os discursos, as técnicas e as operações associadas a eles envolvem métodos de estabelecer domínios delimitados ou especializados que codificam regras de conduta bem como elaboram sistemas alfanuméricos para estruturar tarefas organizacionais e medir seus resultados, como exemplo a Contabilidade Financeira e a Gerencial. 
O discurso, nesse sentido, funciona como um meio pelo qual ideias podem ser ligadas à ação e, por isso, pode ter a capacidade de evidenciar como uma realidade foi construída. De modo geral, as instituições são geradas compondo-se de ideias básicas desenvolvidas em distintas formas de definir e agir sobre a realidade, como os discursos; e são apoiadas por elaborados sistemas de medidas e documentação que servem para controlar os resultados e as ações (HASSELBLADH; KALLINIKOS, 2000). Três pontos chave são considerados nesse caso, a ideia, o discurso e as técnicas de controle e, quando uma instituição apresentar esses pontos, não necessariamente nessa ordem, ela estaria em tese objetificada.

Uma distinção analítica desses pontos é necessária. A despeito de essa distinção passar uma impressão de processo por etapas, a pretensão é de que funcionem como um dispositivo analítico de forma a demarcar a complexa totalidade que compõe esse processo (HASSELBLADH; KALLINIKOS, 2000). Isso significa que empiricamente podem existir dificuldades nesta demarcação pelo fato de que esses três pontos podem estar interrelacionados e o processo pode não ser tão linear quanto um dispositivo analítico evidencia ou sugere.

O modelo de Hasselbladh e Kallinikos (2000) apresenta em um extremo os ideais, que se expressam de maneira muito vaga; depois vem os discursos, desenvolvidos com base nos ideais e, na sequência estão as técnicas de controle, que especificam de maneira muito precisa as relações que procuram regular. A distinção entre os três níveis está no grau de detalhe e precisão que eles descrevem sobre o item social a que se referem e são avaliados em relação às formas de objetificação que, neste caso são: linguagem oral, linguagem escrita e codificação formal (HASSELBLADH; KALLINIKOS, 2000). Estas representações podem ser visualizadas na Figura 3 na sequência.

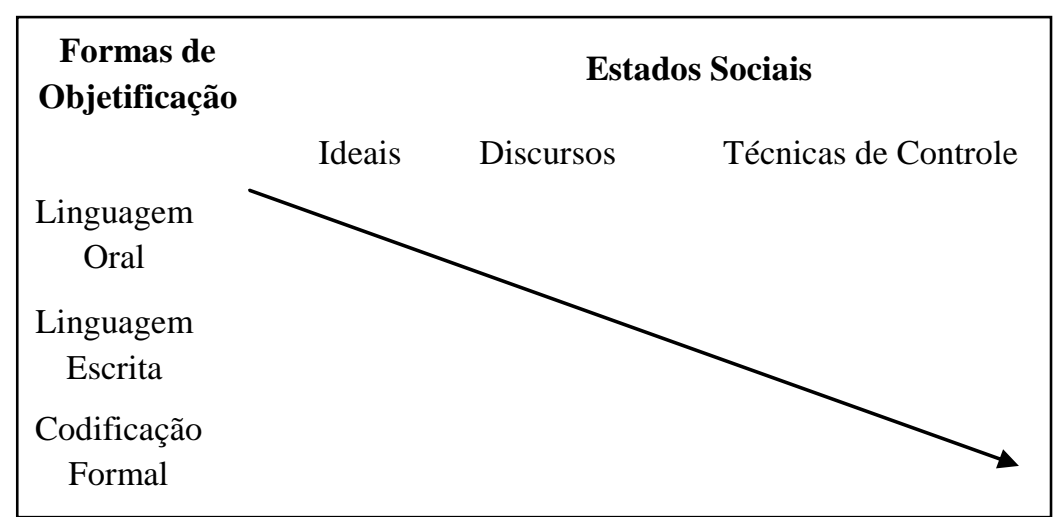

Figura 3 - Estados sociais e formas de objetificação FONTE: Hasselbladh e Kallinikos (2000, p. 705) (Tradução livre) 
Esta figura representa uma distinção analítica e a direção da seta aponta uma tendência, não devendo ser interpretada de forma a implicar uma correspondência na forma de um para um, conforme mencionado anteriormente. É possível verificar pela Figura 3 que os mecanismos que promovem a mudança dos ideais em direção aos discursos e as técnicas de controle são analisados sob três formas principais, sendo a intersubjetividade através da fala e comunicação oral, a textualização pela linguagem escrita e a codificação formal que controla e avalia as relações anteriores (HASSELBLADH; KALLINIKOS, 2000). Os três estados sociais e suas respectivas formas de objetificação são explicados a seguir.

Os ideais são ideias estáveis, impregnadas e valorizadas que ajudam a promover um senso de orientação nas complexas relações sociais e neste estado a narrativa é a forma de comunicar tais ideais, que correspondem a noções básicas de um caráter complexo que ainda não foram diferenciadas em esquemas práticos ou conceituais (HASSELBLADH; KALLINIKOS, 2000). Os ideais são definidos como ideias básicas e têm como característica serem expressos de forma vaga e grosseira (DAMBRIN et al., 2007).

Os ideais emergem no campo organizacional devido ao surgimento de mudanças ambientais que impactam as organizações. Devido a essa característica abrangente e vaga este estágio foi considerado, para efeito da pesquisa empírica, em nível de campo organizacional e os demais foram considerados em nível organizacional. Portanto, em relação ao nível organizacional, que é o foco dessa pesquisa, os estágios que interessam para a análise são os discursos e as técnicas de controle.

Quando os ideais são desenvolvidos e especificados em sistemas elaborados de relações e modelos causais eles se transformam em discursos; os discursos alcançam tanto uma espécie de delimitação significativa no conteúdo ou no significado dos ideais quanto uma especificação das relações e dos itens envolvidos (HASSELBLADH; KALLINIKOS, 2000). Os discursos são construídos principalmente na forma da linguagem escrita porque esta fornece uma estabilidade que ajuda a transcender o caráter limitado ao contexto da linguagem oral (HASSELBLADH; KALLINIKOS, 2000). A forma escrita de linguagem tende a tratar as ideias de uma maneira mais concreta do que a oral.

Os discursos destacam o domínio de aplicação e definem os objetivos relevantes a serem realizados e os papéis envolvidos; além disso, decifram o critério de verdade e indicam teorias causais e esquemas de ação e interpretação (HASSELBLADH; KALLINIKOS, 2000). 
Através dos discursos as noções introduzidas pelos ideais são trazidas para um nível maior de detalhes e explicações de forma que se consiga visualizar como fazer para colocar os ideais em prática. Trata-se da forma de estabelecer relações que consigam fazer com que os ideais sejam imersos na realidade, ou seja, comecem a ser desempenhados.

Em relação à pesquisa empírica, as evidências extraídas dos dados se deram através da análise de textos corporativos e de entrevistas com membros da Alfa e puderam auxiliar na classificação do estágio em que se encontra o Custeio Alvo. Dessa forma, os discursos não foram analisados unicamente em textos, mas também na linguagem oral dos entrevistados, diferindo um pouco em relação ao proposto por Hasselbladh e Kallinikos (2000), que mencionam apenas discursos escritos.

As técnicas de controle são expressas geralmente na forma numérica ou outras formas de apresentação como os sistemas contábeis, os sistemas de medida e outros e, a construção desses sistemas de codificação, torna possível agir sobre as relações objeto-sujeito constituídas por um discurso (HASSELBLADH; KALLINIKOS, 2000). Essas técnicas geralmente são comunicadas por meio da linguagem oral ou escrita, mas não são construídas por elas; através da codificação, várias facetas da relação principal-agente podem se tornar alvos de cálculos, reflexões, comparações e manipulações que contribuem para a imersão social das categorias do discurso (HASSELBLADH; KALLINIKOS, 2000).

Dessa forma, a existência desse tipo de controle através de relatórios, por exemplo, é um indicativo de que a prática investigada possa estar objetificada, lembrando-se que pode não ser um processo linear. Hasselbladh e Kallinikos (2000) enfatizam que esses três estados são relacionados um ao outro e que cada um pode existir independente dos demais, por exemplo, a ideia de organização socialmente responsável é apenas um ideal, já um sistema contábil é uma técnica de controle que pode servir a vários tipos de discurso. A utilização empírica desta distinção analítica requer atenção em relação aos estados e às formas de objetificação.

De forma resumida, o processo de institucionalização envolve: (1) a delimitação semântica ou fechamento dos ideais realizados por estratégias e definições específicas verbais e escritas, (2) a especificação das tarefas e dos papéis sociais envolvidos e o delineamento de suas relações e (3) o desenvolvimento de modelos de ação e sistemas de medida e avaliação (HASSELBLADH; KALLINIKOS, 2000). 
Esses estágios se referem ao lado objetivo do processo de institucionalização, ou seja, as técnicas e procedimentos pelos quais as facetas da vida organizacional se tornam objetificadas. No entanto, conforme mencionado anteriormente, Berger e Luckmann (1967) apontam três fases do processo de institucionalização, a exteriorização, a objetivação e a internalização. Portanto, o modelo de Hasselbladh e Kallinikos (2000) auxilia as análises até o segundo estágio do processo, a objetivação ou objetificação e, para esses autores, embora essa seja uma fase de influência decisiva no processo de institucionalização, não esgota o mesmo.

A internalização se refere à subjetificação da instituição. Hasselbladh e Kallinikos (2000) argumentam sobre a importância de ir além da objetificação e analisar como objetos moldam a maneira como os atores entendem a si mesmos e o seu papel. Por isso, o grau de codificação e as formas cognitivas pelos quais as ideias, modelos e técnicas são agrupados se relacionam à sua capacidade de se tornar objetificado e institucionalizado em cenários particulares, de se difundir de um contexto para outro retendo suas características básicas e de modelar as modernas formas de desempenho do papel do ator, ou seja, subjetificar (HASSELBLADH; KALLINIKOS, 2000).

Nesse sentido, Hasselbladh e Kallinikos (2000) sugerem que deve ser levada em consideração nas análises a facilidade com que as instituições são reproduzidas (reprodutibilidade), quão transitórias ou duráveis elas são (durabilidade) e como se dá sua imediata compreensibilidade (comunicabilidade). Essas qualidades estão envolvidas no processo de institucionalização modelando os passos e os procedimentos em que os atores organizacionais normalmente seguem quando legalizam (enact) seu papel (HASSELBLADH; KALLINIKOS, 2000). Essa é a proposta para analisar a subjetificação e consequente internalização da instituição. Embora os autores utilizem essas qualidades em sentido amplo em relação ao campo organizacional elas podem ser aplicadas em situações específicas, por exemplo, uma organização. Por isso, na pesquisa empírica essas foram as características avaliadas quanto à subjetificação da instituição que leva à internalização.

A reprodutibilidade se refere à capacidade de reproduzir um padrão de forma quase idêntica e representar a relação que ela implica, essa característica é amplamente dependente de regras e procedimentos bem definidos e explícitos subjacentes à construção do padrão (HASSELBLADH; KALLINIKOS, 2000). A durabilidade se refere à capacidade que uma instituição tem de resistir à passagem do tempo e também sua transferência de um contexto para outro sem alterações semânticas significativas ou outras distorções (HASSELBLADH; 
KALLINIKOS, 2000). A comunicabilidade se refere à facilidade em que uma instituição cruza um campo organizacional, seja entendida e transportada à outros que não aqueles envolvidos em sua concepção, construção e uso inicial (HASSELBLADH; KALLINIKOS, 2000).

De acordo com Berger e Luckmann (1967) para manter a realidade subjetiva o aparelho da conversa deve ser contínuo e coerente e, as rupturas nessas qualidades se constituem em ameaças. Berger e Luckmann (1967) explicam que o sucesso entre uma realidade objetiva e subjetiva, o que denominam de socialização bem sucedida, ocorre quando existe um elevado grau de simetria entre as duas realidades e, o contrário, seria uma assimetria nessa relação resultando em uma socialização mal sucedida; porém, alcançar tanto um extremo quanto outro é antropológicamente impossível.

Pelo exposto, o modelo sugerido pode ser usado com alguns ajustes em nível organizacional e, dessa forma, atinge a externalização (corresponde aos ideais), a objetificação (corresponde aos discursos e às técnicas de controle) e a internalização do processo de institucionalização. Isso pode ser observado pela Figura 4.

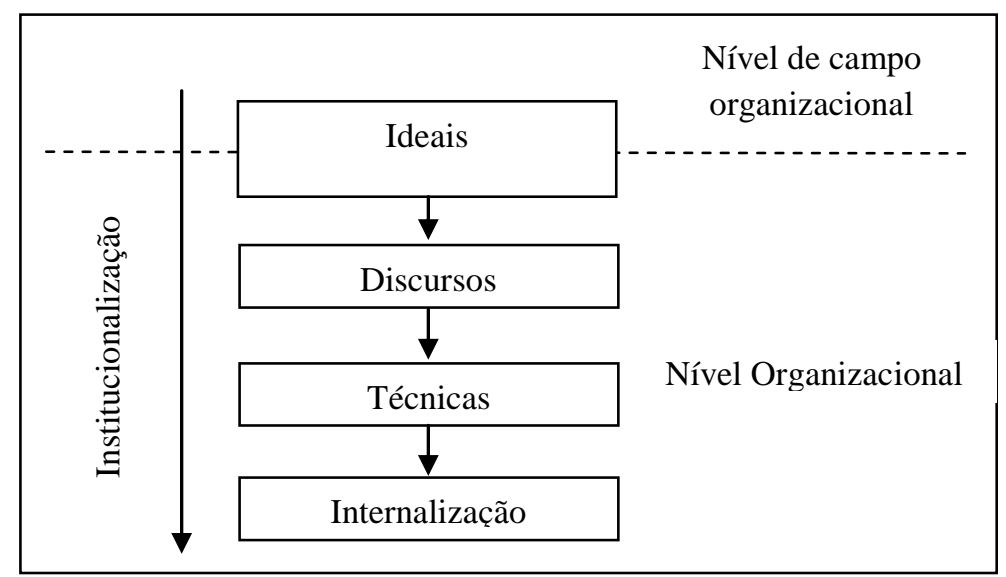

Figura 4 - Estágios do processo de institucionalização FONTE: Dambrin et al. (2007, p. 178), adaptado

Phillips et al. (2004) também propõem a utilização do discurso para análise de assuntos relativos à institucionalização e para eles a linguagem é fundamental nesse processo pois ela ocorre com atores interagindo e aceitando definições compartilhadas de realidades e que é através do processo linguístico que essas definições são constituídas. Esses autores também se baseiam em Foucault e Berger e Luckmann para argumentarem em defesa da análise do discurso propondo um modelo para investigação. Devido à sua importância no contexto dessa 
pesquisa na sequência algumas ideias e proposições do trabalho de Phillips et al. (2004) foram abordadas.

O modelo proposto mostra as condições sob as quais o processo de institucionalização tem maior probabilidade de ocorrer. É importante ressaltar que o modelo se baseia em textos, no entanto, Phillips et al. (2004) deixam claro que textos podem ser de diversos tipos incluindo documentos escritos, relatórios verbais, palavras faladas, símbolos, dentre outros. Dessa forma, algumas proposições extraídas do modelo de Phillips et al. (2004) mostram um meio interessante para dar direcionamento às análises dos dados extraídos dos textos corporativos e das entrevistas na presente pesquisa.

Uma das proposições declara que as ações que requerem um sentido (sensemaking) organizacional são mais prováveis de resultar na produção de textos amplamente disseminados e consumidos (PHILLIPS et al., 2004). Quando existe um sentido para uma instituição, de alguma forma isso promove um nível de aceitação maior do que aceitar sem entender o porquê ou sem estar certo de sua importância.

Outra proposição tem um caráter mais crítico e sugere que textos que são produzidos por atores que são entendidos como tendo um poder legitimado para falar, que tem poder sobre recursos ou autoridade formal ou que sejam localizados de forma central num campo são mais prováveis de se tornarem imersos no discurso (PHILLIPS et al., 2004). Essa questão é importante na pesquisa empírica uma vez que foi entrevistado um membro da alta gestão e que, portanto, satisfaz esses requisitos de poder. O discurso desse membro é relevante para verificar o alinhamento com o discurso dos demais entrevistados que estão em posições diferentes na hierarquia. Destaca-se que a questão do poder não faz parte dos objetivos dessa tese, sendo essa proposição usada apenas para detectar essa particularidade.

A próxima proposição é essencial para a comparação das diferentes entrevistas na mesma organização. Discursos que são mais coerentes e estruturados são mais prováveis de produzir instituições (PHILLIPS et al., 2004). Obviamente quando uma instituição está completamente institucionalizada, a coesão entre os discursos sobre as mesmas deve ser provável.

Outra proposição declara que os discursos que são apoiados por discursos mais amplos e não são altamente contestados por discursos concorrentes são mais prováveis de produzir instituições (PHILLIPS et al., 2004). Isso é importante para detectar a existência de discursos que confrontam a importância do uso do Custeio Alvo ou a importância de outra prática ao 
invés do mesmo. Esses pontos levantados juntamente com o modelo escolhido para a pesquisa empírica se mostraram úteis tanto para auxiliar a classificação do estágio de institucionalização do Custeio Alvo quanto para analisar as evidências a respeito da percepção ou não da importância do mesmo para a Alfa.

\subsubsection{Nova Sociologia Institucional e a Contabilidade Gerencial}

Os estudos que envolvem perspectivas interpretativas como a NSI entendem a Contabilidade Gerencial como tendo implicação na construção social da realidade ao invés de a mesma ser um reflexo passivo da realidade como em outras perspectivas (COVALESKI et al., 1996). Dessa forma, novos horizontes se desenham na busca por respostas aos problemas que envolvem a Contabilidade Gerencial, em especial, ao modo pelo qual suas práticas são imersas nas organizações.

Na sequência foram apresentados alguns estudos sobre o assunto, porém, não se trata de abordar o tema em sua evolução e sim evidenciar aspectos que se mostraram importantes para auxiliar na presente investigação. O objetivo foi verificar em que os trabalhos que abordam a NSI e a Contabilidade Gerencial puderam auxiliar no desenvolvimento dessa pesquisa. Por isso, foi feita uma busca em periódicos internacionais e nacionais como: Accounting Horizons, Accounting, Organizations and Society, Management Accounting Research, Revista de Administração Contemporânea, Revista de Administração de Empresas, Revista de Administração da USP e Revista Contabilidade e Finanças, referente aos últimos dez anos, por ser este um tema mais recente na área. Essa análise permitiu que se encontrassem diversos artigos envolvendo os temas mencionados, inclusive em outros periódicos. Não foram encontrados trabalhos que abordassem o Custeio Alvo em particular, por isso, a busca se estendeu à Contabilidade Gerencial. Na sequência são apresentados os pontos de interesse de alguns desses estudos.

Kostova e Roth (2002) examinaram a adoção (implementação e internalização) da Gestão da Qualidade em subsidiárias de multinacionais sob a ótica da NSI. Foram identificados fatores que influenciam a adoção da prática e foram especificadas condições sob as quais pode haver uma adoção do tipo cerimonial. Pelos assuntos abordados esse estudo tem especial importância para a presente pesquisa pelo fato de a empresa Alfa, conforme mencionado, ser 
uma subsidiária multinacional e por envolver a adoção e implementação de uma prática da Contabilidade Gerencial. Por isso, esse trabalho foi abordado de forma mais detalhada.

Para Kostova e Roth (2002) existe um domínio por parte da matriz de uma corporação multinacional que define um conjunto de pressões aos quais todas as unidades devem se conformar; afirmam ainda que uma subsidiária não é uma entidade independente e, como consequência, se uma prática é exigida pela matriz esta é obrigada a obedecer. As organizações multinacionais possuem características diferentes de empresas locais, pois lidam com pressões em níveis globais (a organização e seus concorrentes mundiais) e locais (referentes a cada país onde as subsidiárias se localizam). Kostova e Roth (2002) mencionam que a subsidiária sofre pressões isomórficas tanto da matriz quanto do país onde está situada e precisam manter a legitimidade nesses dois contextos, isso foi denominado de dualidade institucional.

É importante reconhecer que as práticas que a matriz tenta difundir são formuladas em seu próprio contexto institucional, por isso, as subsidiárias podem apresentar vários tipos de respostas à sua imposição, caracterizando a capacidade de agência (KOSTOVA; ROTH, 2002). É interessante ressaltar que os achados empíricos de Kostova e Roth (2002) comprovaram que as subsidiárias estrangeiras apresentam respostas diferentes ao mandato de adoção de uma mesma prática pela matriz.

Devido a essas diferentes pressões, a adoção cerimonial pode ser esperada quando um perfil regulatório, que é ligado ao mecanismo coercitivo, exige e faz cumprir a prática ao mesmo tempo em que os perfis cognitivos e normativos são menos favoráveis (KOSTOVA; ROTH, 2002). Para essas autoras a resposta da subsidiária ao mandato da matriz é influenciada pelas suas interpretações e percepções da prática, que são modeladas tanto pelo contexto institucional externo quanto pelo contexto relacional interno entre matriz e subsidiárias.

Kostova e Roth (2002) apresentam uma análise desse contexto relacional através de três características, a dependência, a confiança e a identidade. A dependência da subsidiária em relação à matriz diz respeito à dependência de recursos principais como tecnologia, capital e expertise e implica a noção de que dependência é subordinação e controle, refletindo uma natureza hierárquica não simétrica de relações entre ambas. A hipótese formulada nesse caso foi que as subsidiárias que percebem essa dependência têm uma tendência a cumprir os mandatos da matriz quanto à adoção; porém, quanto à internalização dos mesmos a tendência 
é de ter uma relação negativa. A subsidiária, de forma geral, interpreta o mandato como algo coercitivo principalmente se ela percebe a dependência, então, a tendência é de não internalizar o mesmo, não percebendo sua importância nem sua utilidade. Os resultados empíricos mostraram que a dependência foi fortemente relacionada à implementação, porém com efeito negativo, contrariando a hipótese sobre a adoção e confirmando sobre a internalização.

Quanto à confiança da subsidiária em relação à matriz se baseia na crença comum de que a matriz tem esforços de boa fé para se comportar de acordo com os compromissos explícitos e implícitos, é honesta em qualquer discussão que precedem tais compromissos e não leva vantagem excessiva sobre a filial, mesmo quando houver oportunidade. A hipótese é de que tanto a implementação quanto a internalização de uma prática exigida pela matriz é positivamente relacionada ao nível de confiança da subsidiária em relação à matriz. O teste empírico confirmou as hipóteses.

A terceira característica é a identificação, definida como o grau em que os funcionários da subsidiária experimentam um estado de ligação com a matriz. Os funcionários sentem que são parte da matriz pertencendo a ela e, em parte, derivam sua auto-identidade a partir desta adesão organizacional. Por isso, a hipótese é de que tanto a implementação quanto a internalização são positivamente relacionadas ao grau em que a subsidiária se identifica com a matriz. O teste empírico confirmou as hipóteses.

Os resultados empíricos mostraram ainda que o contexto relacional influencia a implementação da prática. As autoras sugerem que o que realmente importa para a internalização da prática é o conhecimento social sobre a mesma e que isso auxilia as pessoas a entendê-la corretamente e ter um conjunto de valores e crenças sociais consistentes com a mesma, o que aumenta a probabilidade de ver a prática como eficiente e valiosa para a subsidiária.

Outro trabalho analisado foi o de Siti-Nabiha e Scapens (2005) que exploraram a relação entre a estabilidade e a mudança na Contabilidade Gerencial focando o modo cerimonial em que um novo sistema de Gestão Baseada em Valor foi implementado em uma subsidiária. Através de um estudo de caso, a Velha Economia Institucional e a NSI foram usadas para entender como se deu esse processo. Os resultados mostraram que o sistema foi implementado por imposição da matriz e, para apresentar uma imagem de racionalidade e preservar a 
estabilidade dos arranjos institucionais existentes na subsidiária, o sistema era usado de forma cerimonial.

Segundo os autores, a subsidiária trabalha com uma visão orientada pela produção e um sistema como a Gestão Baseada em Valor é mais focado em finanças, por isso, todas as regras relacionadas ao novo sistema foram seguidas, mas os valores subjacentes às atividades da subsidiária permaneceram inalterados. Dessa forma, o sistema é operado e os índices de avaliação são apresentados à matriz, porém, servem apenas para efeito de prestação de contas. Os gestores da subsidiária não utilizam as informações desse sistema para decisões nem para avaliações de desempenho, existindo o decoupling entre a estrutura e as ações.

Como achados os autores perceberam a existência simultânea da mudança (implantação do novo sistema) e da estabilidade (os valores e as atividades rotineiras permaneceram inalteradas) e argumentam que as mesmas não são necessariamente contraditórias ou forças opostas, mas que podem estar entrelaçadas num processo de mudança evolutivo. Comentam ainda que o decoupling é normalmente entendido como uma resposta organizacional, mas no caso estudado ele foi organizado como um processo dinâmico e complexo de resistência à mudança contábil.

O trabalho de Järvinen (2006) explorou a lógica e a motivação da mudança do método de custeio em dois hospitais finlandeses sob a ótica da NSI. Dois estudos de caso foram empreendidos para estudar a adoção e implementação do Custeio Baseado em Atividades levando em consideração duas motivações, a lógica econômica e a pressão institucional. Em um dos hospitais a adoção foi voluntária e baseada na fé de que o sistema iria auxiliar na eficiência econômica; a pressão institucional era fraca e a implementação ocorreu de forma diversa, não interconectada e não uniforme, em que cada clínica do hospital usava o sistema de modo diferente. No segundo caso a adoção foi motivada por uma forte pressão institucional da mídia, dos auditores e dos financiadores ocasionando a adoção coercitiva; o modelo de implementação foi uniforme e centralizado, mas inicialmente não foi usado.

Um dos achados mostrou que os objetivos relacionados à eficiência e à legitimidade podem interagir e ambas as forças modelam os sistemas de Contabilidade Gerencial nas organizações. Outro achado mostrou que os dois sistemas eram muito distintos e que o isomorfismo institucional somente influenciou o nome do Custeio Baseado em Atividades, mas não sua estrutura e o seu conteúdo. Essas constatações mostram que os antecedentes da 
adoção são úteis para explicar o tipo de resposta da organização e que a capacidade de agência faz com que a mesma prática possa ser usada de forma diferente.

Kholeif et al. (2007) empreenderam um estudo de caso para analisar o fracasso na customização do ERP em uma empresa pública egípcia com base na NSI. O trabalho explicou como essa falha na implementação do ERP foi modelada pela interação entre as práticas contábeis institucionalizadas, as instituições conflitantes, as relações de poder e as forças de mercado. Os achados mostraram que a inabilidade do ERP para se adequar às exigências contábeis essenciais das autoridades de controle foi a razão explícita para o fracasso de sua implementação. As exigências para a uniformidade do sistema contábil impostas externamente e o planejamento dos orçamentos foram usados como resistência tanto para as pressões institucionais quanto das pressões de mercado e da concorrência.

James (2009) realizou um estudo de caso em uma empresa pública australiana do setor elétrico para analisar o impacto da política de concorrência na implementação do Balanced Scorecard com base na NSI, em especial no conceito de isomorfismo. O autor propõe, a partir de seus achados, que as organizações consideram seu ambiente externo e tentam modelar sua estrutura para parecer legitimada; no entanto, elas também adotam procedimentos racionais técnicos que permitem estar estrategicamente colocadas em um ambiente competitivo. Como conclusões, a organização avaliada teve não apenas um comportamento isomórfico de imitar práticas que a tornariam legitimada no ambiente como também adotou procedimentos técnicos racionais para capacitar seu posicionamento estratégico. Isso mostra que as duas pressões podem estar conectadas nas organizações e, mesmo uma empresa pública pode enfrentar os dois tipos de pressão, a eficiência e a legitimidade.

Tsamenyi et al. (2006) debateram a relação entre forças de mercado e institucionais na escolha de práticas de Contabilidade Gerencial e mencionaram que poucos estudos têm abordado a interação dessas duas forças. Usaram também a interação entre a força institucional e as relações de poder na organização para entender o processo de mudança do sistema de informação financeiro e contábil em uma companhia de eletricidade espanhola. Como conclusões apontaram que a mudança foi motivada tanto por forças institucionais quanto de mercado (competição) e que a empresa implementou as mudanças não só para obter legitimidade, mas também para responder à concorrência. Concluíram também que não ocorreu conflito entre a demanda institucional e a de mercado e que isso pode ser uma evidência de que uma complementou a outra. Quanto à interação entre as demandas 
institucionais e as relações de poder concluíram que houve resistência entre os funcionários para aceitarem a mudança do sistema, mas que isso foi amortecido pela aceitação e pelo empenho da alta gestão em facilitar a sua implementação.

Nor-Aziah e Scapens (2007) estudaram uma empresa do setor público na Malásia que introduziu práticas gerenciais do setor privado como forma de resolver o problema da ineficiência financeira naquele setor. Foram introduzidas novas regras para o orçamento na tentativa de aumentar a lucratividade da empresa e foram contratados contadores recémgraduados para operar o sistema. As conclusões apontam que a forma como ocorreu a mudança causou tensões e conflitos entre os contadores e os gerentes de operações. Por isso, com o decorrer do tempo o orçamento foi se tornando separado das outras atividades organizacionais, operando de forma loose coupling. Os autores concluem que o loose coupling não foi uma resposta organizacional automática nem surgiu com o propósito de mudança cerimonial. Os achados apontam que essa forma de operar o orçamento foi o resultado de um processo de loose coupling construído socialmente através das interações dos contadores e dos gerentes operacionais combinando confiança, resistência e poder.

Ma e Tayles (2009) fizeram um estudo de caso em uma companhia farmacêutica para explorar as questões que cercam a mudança e capacitam a adoção de práticas estratégicas da Contabilidade Gerencial tendo como base a NSI e a Velha Economia Institucional. A empresa adotou algumas práticas estratégicas de Contabilidade Gerencial como resposta à pressão econômica para apoiar uma nova estrutura organizacional e formas de trabalho. Como achado os autores sugerem que a lógica por traz da adoção de novas práticas é a existência de uma adequação entre a agenda estratégica da organização e das práticas de Contabilidade Gerencial, mostrando muita importância para os objetivos estratégicos da organização. Sugerem também que as organizações não estão adotando essas práticas por um modismo e sim como uma resposta ao desafio de novas formas organizacionais e novas condições de mercado.

Os trabalhos encontrados que abordaram a Contabilidade Gerencial em relação à NSI não foram muitos. Dentre os trabalhos um estudou a relação entre estabilidade e mudança, cinco investigaram a relação entre fatores econômicos e institucionais, um a influência dos fatores econômicos e outro a influência do contexto relacional das subsidiárias na resposta estratégica. Embora alguns deles abordem temas semelhantes ao desta pesquisa, pode-se 
verificar que a proposta levantada aqui é diferente dos demais, o que pode trazer novos insights para a área e para a NSI.

\subsubsection{Conteúdo da Pesquisa Empírica em Relação à NSI}

A pesquisa empírica que trata da adoção e implementação do Custeio Alvo se refere a um estudo qualitativo cujos conteúdos avaliados no instrumento de coleta de dados foram baseados em percepções. No entanto, não possuem medidas com certo grau de consolidação como na Teoria da Contingência. Conforme mencionado anteriormente a NSI ainda não dispõe de um conjunto de medidas consolidadas para seus objetos de interesse. Na pesquisa foram avaliados os fatores institucionais, fatores econômicos, o estágio do processo de institucionalização e a forma de institucionalização do Custeio Alvo. As fontes de dados para análise desses fatores foram as entrevistas e os textos corporativos.

Os fatores institucionais investigados foram os mecanismos de mudança isomórfica e a legitimidade. Quanto ao isomorfismo o que se buscou foram indícios do tipo predominante mimético, coercitivo ou normativo - (DIMAGGIO; POWELL, 1983) em relação à adoção do Custeio Alvo na empresa Alfa. A legitimidade foi investigada em relação ao seu estado/resultado, por isso, foi verificado se existe ou não pressão do ambiente de atuação para a adoção do Custeio Alvo. Dois tipos de legitimidade foram avaliados, um relacionado à matriz e outro ao ambiente externo em que a Alfa se situa (legitimidade interna e externa). Dessa forma, qualquer indício de pressão relativa à busca de legitimidade nesses dois ambientes serviu como indicador de sua presença. Como a conformidade às demandas institucionais podem se conflitar com a eficiência (MEYER; ROWAN, 1977) também foi avaliada a presença de conflitos e ambiguidades que podem prejudicar ou atrapalhar a institucionalização e a utilização do Custeio Alvo na Alfa.

Também foi investigada a pressão por eficiência referente aos fatores econômicos. Na fase de adoção foram investigados indícios da presença de fatores econômicos relativos ao aumento (redução) de lucro ou resultado, aumento (redução) de participação no mercado, aumento (redução) de vendas, dentre outros que possam caracterizar essa categoria. $\mathrm{Na}$ fase de implementação foram procurados termos nos discursos que possam ser ligados ao aspecto econômico e à busca de eficiência como retorno, redução de custo, atingir metas, dentre outros. 
Cabe ressaltar novamente que a interpretação com base na busca por eficiência, relacionada aos fatores econômicos, foi avaliada enquanto termos chaves nas respostas dos entrevistados que indicam a presença dessa categoria. No entanto, não faz parte do escopo dessa pesquisa investigar a construção do significado de eficiência do ponto de vista institucional, ou seja, qual o significado de eficiência para a organização.

Quanto à implementação do Custeio Alvo, os estágios do processo de institucionalização de acordo com o modelo de Hasselbladh e Kallinikos (2000) foram investigados tendo como base os passos necessários para adoção e implementação do Custeio Alvo descritos por Ansari et al. (2006). Esses passos são apresentados no Capítulo 3 item 3.2.8.

Além desses passos, foi usado o conteúdo do trabalho de Hasselbladh e Kallinikos (2000) para a elaboração de questões adicionais com o objetivo de reforçar as evidências sobre os estágios do processo de institucionalização. Assim, as noções gerais de ideais, discursos e técnicas de controle foram usadas na construção de tais questões. Também foi verificada, nessa fase, a presença de fatores institucionais e econômicos que pudessem ter influência na institucionalização. Cabe ressaltar aqui que o tratamento da institucionalização enquanto processo e sua avaliação por estágios oferece mais confiabilidade em relação ao resultado do processo, ou seja, se está ou não institucionalizado, do que apenas questionar aos entrevistados se o Custeio Alvo está ou não institucionalizado.

O decoupling e o coupling foram avaliados enquanto resultado/estado do processo de institucionalização, ou seja, enquanto respostas estratégicas, tendo por base o conteúdo das entrevistas e as análises do processo. Nenhuma questão específica foi elaborada a esse respeito. Maiores detalhes sobre o instrumento de coleta de dados e sobre como as categorias foram avaliadas foram evidenciados na trajetória metodológica (Capítulo 4).

O próximo capítulo apresenta o SCG enquanto campo de estudo, em especial sob a lente da Teoria da Contingência, e o Custeio Alvo enquanto prática que faz parte do SCG, abordando suas especificidades no contexto dessa pesquisa. 


\section{SISTEMAS DE CONTROLES GERENCIAIS}

Este capítulo tem o objetivo de apresentar os aspectos relacionados ao SCG discutidos no contexto da presente pesquisa como sua definição, as dimensões avaliadas e as medidas usadas. Ainda, apresenta o Custeio Alvo que foi a prática do SCG investigada, detalhando suas características, seu conceito, seu processo e como o mesmo foi avaliado.

\subsection{Sistema de Controle Gerencial}

O Sistema de Controle Gerencial (SCG) é uma área de estudo que não possui unanimidade em relação à sua definição nem ao seu escopo. Diversos autores apresentam diferentes definições e objetivos para o mesmo que vão dos mais específicos para os mais amplos (MALMI; BROWN, 2008). Com o intuito de esclarecer de que forma o SCG foi abordado nesta pesquisa, na sequência foram apresentados o objetivo, a definição, as dimensões avaliadas e as medidas usadas em relação ao presente trabalho. É importante mencionar que devido à existência de outros trabalhos no Brasil relacionados ao SCG e que apresentaram de forma detalhada o desenvolvimento desse tema, como os de Cintra (2011) e Nascimento (2011), optou-se por não fazer o mesmo aqui.

Merchant e Otley (2007) argumentam que, em termos gerais, um SCG é projetado para ajudar uma organização a se adaptar ao ambiente em que está inserida e atingir os resultados esperados pelos interessados; para tanto, os gestores implementam controles ou conjuntos de controles para auxiliar na obtenção desses resultados, protegendo a organização contra as ameaças. Uma organização sob controle tem probabilidade de atingir um bom desempenho quanto aos seus objetivos (MERCHANT; OTLEY, 2007). Neste sentido, o SCG é entendido como um meio de possibilitar que os objetivos da organização sejam atingidos considerandose sua interação com o ambiente.

Partindo-se desse objetivo geral é necessário delimitar sua abrangência estabelecendo seu escopo. Anthony e Govindarajan (2008) mencionam que existem duas correntes acerca do escopo do SCG. Uma delas considera que o SCG deve ser ajustado à estratégia das organizações, ou seja, primeiramente a estratégia é estabelecida por um processo formal e 
racional e a partir disso o SCG é elaborado (ANTHONY; GOVINDARAJAN, 2008). Nesse caso tal sistema tem a função exclusiva de implementar as estratégias estabelecidas. Merchant e Van der Stede (2007) discutem o SCG sob esse enfoque, priorizando aspectos como sua utilização para influenciar o comportamento dos empregados de forma a atingir o objetivo organizacional.

A segunda corrente mencionada por Anthony e Govindarajan (2008) considera que as estratégias surgem pela experimentação e são influenciadas pelos sistemas de gerenciamento, ou seja, esses sistemas podem afetar o desenvolvimento das estratégias. Sob este escopo o SCG tanto pode ser modelado pelas estratégias estabelecidas quanto pode moldar as mesmas. Simons (1990) segue essa corrente e conclui, a partir de suas pesquisas empíricas, que o SCG é importante tanto para a implementação quanto para a formulação das estratégias. Por compreender um escopo mais amplo, essa foi a corrente do SCG assumida no presente estudo.

Com base nesse escopo, Simons (1990, p. 128) define SCG reconhecendo que são mais do que dispositivos de restrições e monitoramento, “[...] são os procedimentos e sistemas formalizados que usam informação para manter ou alterar padrões na atividade organizacional." 12 Sob esse aspecto, o SCG não serve apenas para direcionar o comportamento dos empregados (visão discutida por MALMI; BROWN, 2008; MERCHANT; VAN DER STEDE, 2007); ele vai além, sendo usado para várias finalidades como monitoramento, aprendizagem, sinalização, constrangimento, vigilância, motivação, dentre outros (SIMONS, 1990). Por outro lado, Malmi e Brown (2008) discutem que não apenas os sistemas (conforme apontado por SIMONS, 1990), mas que as regras, as práticas, os valores e outras atividades usadas para direcionar o comportamento dos empregados deveriam ser chamados de controles gerenciais. Essa definição amplia as fontes de controle, enquanto a de Simons (1990) amplia sua finalidade, por isso, entende-se que a junção dessas duas definições é importante para captar o sentido do SCG de forma mais abrangente.

Um ponto em comum que existe na definição proposta por Simons (1990) e por Malmi e Brown (2008) se refere ao fato de que os sistemas, procedimentos, práticas e outros que apenas são usados para tomada de decisão não são considerados SCG. Nessa pesquisa o SCG foi considerado dessa forma, ou seja, esses sistemas, procedimentos, etc. não são usados

\footnotetext{
12 "[...] are the formalized procedures and systems that use information to maintain or alter patterns in organizational activity.” Em inglês no original. Tradução livre da autora.
} 
apenas para a tomada de decisão, mas também para manter ou alterar padões nas atividades da organização.

As organizações são entidades criadas para atingirem objetivos específicos, mas são também sistemas sociais e, ainda, conjuntos de relações entre participantes com interesses próprios, cada qual balanceando o seu bem estar com as necessidades da organização (SIMONS, 1995). De acordo com Simons (1995), considerar apenas uma dessas facetas leva a uma visão incompleta da organização. Por isso, a necessidade de considerar a empresa e suas relações de forma mais abrangente, para que se possam balancear essas tensões de modo a atingir seus objetivos.

No domínio das pesquisas sobre SCG essas várias facetas e relações são estudadas de acordo com os diferentes paradigmas usados para entender o funcionamento desses sistemas. Chenhall (2007) argumenta que de maneira mais convencional os SCG são percebidos como ferramentas passivas que fornecem informações para auxiliar os gestores; esse é o caso dos estudos que seguem a Teoria da Contingência. Em abordagens que seguem orientação sociológica interpretativa, Chenhall (2007) menciona que os SCG são vistos de forma mais ativa, fornecendo poder aos indivíduos para atingirem seus próprios fins. $\mathrm{Na}$ presente pesquisa essas duas abordagens foram empregadas de modo a verificar como esses aspectos influenciaram a adoção, a implementação e o uso do Custeio Alvo.

Em relação à Teoria da Contingência buscou-se verificar a adequação entre os fatores contingentes e o Custeio Alvo quanto à busca pela eficiência e, sob o enfoque da NSI, a preocupação foi verificar o tipo de resposta da organização em relação à adoção e implementação do Custeio Alvo no tocante à busca pela legitimidade, considerando-se o aspecto social da construção da realidade e o significado desta prática para a empresa Alfa. $\mathrm{Na}$ sequência foram apresentadas as dimensões de análise do SCG em relação ao Custeio Alvo sob as lentes da Teoria da Contingência. Os aspectos relativos ao Custeio Alvo e a NSI foram apresentados no Capítulo 2.

\subsubsection{As Dimensões do SCG}

Para Simons (1995) o SCG representa o controle do processo de formação e implementação da estratégia. Otley (1999) argumenta que existe a necessidade de conectar as estratégias e o 
SCG de forma que este possa refletir os objetivos organizacionais e os planos que são desenvolvidos para atingir tais fins. Por isso, entender a relação entre o contexto estratégico e o SCG é importante na medida em que pode auxiliar as organizações a atingirem seus objetivos e uma das maneiras para auxiliar nesse entendimento é analisar o desenho e o uso desse sistema. Além dessas, o desempenho é outra dimensão que pode ser avaliada, principalmente quando se trata de verificar se a estrutura de um sistema é apropriada ou não.

Ferreira e Otley (2006) mencionam que os estudos nessa área tendem a enfatizar o desenho ou o uso e que poucos têm se dedicado a investigar a inter-relação entre essas duas dimensões. Por isso, este estudo buscou contribuir com a construção do conhecimento avaliando além das dimensões desenho e uso, seu desempenho. É importante ressaltar que essas dimensões foram investigadas tendo como base os pressupostos da Teoria da Contingência. Na sequência foi evidenciada a forma como essas dimensões foram consideradas na pesquisa.

\subsubsection{Desenho do SCG}

Os estudos que buscam verificar a estrutura adequada de um SCG têm considerado a influência do contexto em que operam usando os pressupostos da Teoria da Contingência (CHENHALL, 2007). Isso se deve ao fato de que, segundo essa teoria, não existe um SCG que seja efetivamente aplicado a todas as organizações e o modelo apropriado vai depender das circunstâncias enfrentadas pelas mesmas (OTLEY, 1999). Por isso, é relevante estudar o aspecto técnico relativo ao desenho do SCG e sua relação com os fatores contingentes.

Quanto à dimensão técnica do SCG as pesquisas geralmente avaliam dois elementos, representados pelas características da informação produzida e pelas técnicas particulares utilizadas pelas organizações (FERREIRA; OTLEY, 2006). Em relação às características da informação, os SCG têm evoluído a partir de um foco em informações mais formais e financeiramente quantificáveis para outro que engloba informações com escopo bem mais amplo (CHENHALL, 2007). Dessa forma, os estudos buscam verificar qual tipo de informação é mais apropriada em cada contexto. Ferreira e Otley (2006) apresentam um modelo de avaliação do desenho dos SCG com base em duas categorias desenvolvidas a partir da análise de outros estudos acerca desse tema. As categorias são as informações tradicionais e as contemporâneas, sendo apresentadas e discutidas no item 3.2.6. 
Em relação às técnicas particulares empregadas nos SCG, Ferreira e Otley (2006) analisaram a literatura e usaram uma classificação baseada em ordem cronológica em que aquelas que foram propostas de meados da década de 1980 em diante foram denominadas de "novas" e as demais consideradas "convencionais".

Com base nesses comentários o presente estudo investigou a dimensão desenho não em relação ao SCG e sim ao Custeio Alvo. Ferreira e Otley (2006) classificam o Custeio Alvo como uma técnica "nova" e suas informações estando mais relacionadas às contemporâneas. Para efeito dessa pesquisa a classificação não levou em conta apenas o que Ferreira e Otley (2006) apresentaram como resultado de sua classificação. Adicionalmente foi feita uma análise particular das informações do Custeio Alvo, concluindo que o mesmo apresenta características de escopo amplo e de informações contemporâneas, como evidenciado no item 3.2.6 deste Capítulo.

Dadas essas características, a presente pesquisa buscou verificar a adequação desta prática e de suas informações com os fatores contingenciais vivenciados pela empresa Alfa. Nesse sentido, Aguiar e Frezatti (2007, p. 34) comentam que "[...] assume-se que a escolha da estrutura apropriada de um sistema de controle gerencial tem que considerar as características da informação e as técnicas necessárias para que os gestores influenciem o comportamento de outros membros organizacionais na direção de estratégias adotadas em um determinado contexto de atuação."

Dessa forma, o presente estudo investigou os fatores contingentes (ambiente, estratégia, porte, estrutura e tecnologia, conforme detalhados no Capítulo 2) que estavam presentes na empresa e sua relação com o Custeio Alvo. "Destaca-se que um sistema de controle gerencial terá uma estrutura apropriada quando for capaz de cumprir seu papel organizacional em um determinado contexto estratégico de atuação.” (AGUIAR; FREZATTI, 2007, p. 25). Dessa forma, a adequação entre os fatores contingentes e as informações provenientes do Custeio Alvo indica a existência de alinhamento entre os mesmos.

É importante destacar que existem várias estruturas ou modelos conceituais disponíveis na literatura que se destinam a avaliar um SCG como a de Otley (1999), Ferreira e Otley (2005), Herath (2007) e Simons (1995). No entanto, tais modelos são úteis para a avaliação do SCG como um todo e não apenas para alguma de suas técnicas, como é o caso desta pesquisa. Por isso, esses modelos não foram utilizados. 


\subsubsection{Uso do Sistema de Controle Gerencial}

A literatura que versa sobre os SCG sugere que sua eficácia depende tanto do seu desenho (dimensão técnica) quanto do uso da informação gerada (SIMONS, 1995; OTLEY, 1978; BISBE; OTLEY, 2004). Examinar apenas uma dessas dimensões pode resultar em uma perspectiva limitada a respeito da operação dos SCG e um entendimento mais completo englobando as duas dimensões pode ter um valor particular tanto para os acadêmicos quanto para a prática (FERREIRA; OTLEY, 2006). Dada essa importância a dimensão uso do SCG também foi empregada nessa pesquisa. Os estudos geralmente utilizam o modelo de Simons (1990, 1995) para avaliar o tipo de uso do SCG, podendo ser o uso interativo, o diagnóstico e o disfuncional. Essa tipologia foi aplicada para verificar de que forma o Custeio Alvo e suas informações vêm sendo usadas na Alfa.

Simons (1990) argumenta que de modo geral as organizações complexas possuem tipos similares de sistemas de controle; no entanto, existem diferenças na forma como os mesmos são usados pela alta gestão. Esse comentário mostra que a análise do aspecto técnico do SCG, referente aos tipos de práticas e de informações disponibilizadas, pode evidenciar um alto grau de semelhança entre as organizações que enfrentam o mesmo ambiente e uma das possíveis explicações para a diferença no desempenho das mesmas pode ser a forma de uso desses sistemas.

Quanto ao uso interativo, Simons (1990) argumenta que, embora as organizações estejam competindo em um mesmo ambiente e enfrentando as mesmas incertezas, a estratégia adotada é que vai influenciar fortemente quais incertezas são críticas para o alcance dos objetivos estipulados e, dessa forma, os gestores escolhem usar um sistema de modo interativo se o mesmo disponibilizar informações sobre essas incertezas estratégicas.

Um controle tem seu uso de modo interativo dependendo da quantidade de atenção que a alta gestão dispensa ao mesmo. Quando a alta gestão usa um controle para pessoalmente e de maneira regular se envolver nas decisões dos subordinados o mesmo é denominado interativo (SIMONS, 1991). Esse tipo de uso se refere ao modo construtivo de lidar com a informação do sistema de controle e de criar e sustentar vantagem competitiva (SIMONS, 1995). O objetivo de usar um controle de modo interativo é focar a atenção e forçar o diálogo e o aprendizado por toda a organização, sendo a análise das incertezas estratégicas que influencia a escolha desse tipo de uso (SIMONS, 1994). 
Quando um sistema é usado de forma interativa ele apresenta geralmente quatro características: 1) a informação gerada pelo SCG é uma agenda importante e recorrente dirigida pelos níveis mais altos da gestão; 2) o processo demanda atenção frequente e regular dos gestores de operação de todos os níveis; 3) os dados são interpretados e discutidos em reuniões de superiores, subordinados e seus pares e 4) o processo se apóia em desafios e debates contínuos dos dados fundamentais, suposições e planos de ação (SIMONS, 1995).

Nesse tipo de uso o gestor claramente interage com o sistema participando ativamente e durante esse processo as questões relativas à formulação, implementação da estratégia bem como a avaliação dos resultados emergem. Este tipo de uso enfatiza o aprendizado. A atenção intensiva e focada da alta gestão sobre um sistema de controle específico indica que sinais são fornecidos para a organização toda para guiar a coleta da informação e a busca por entendimentos (SIMONS, 1991). Em sua pesquisa empírica Simons (1991) encontrou o uso de forma interativa em cinco tipos de sistemas; dentre estes os que mais necessitam das informações do Custeio Alvo são o sistema de planejamento do lucro e os sistemas de gestão de programas, que servem para monitorar programas ou projetos como a melhoria dos atributos dos produtos. Isso pode indicar que o Custeio Alvo pode ser usado de forma interativa quando as incertezas estratégicas estejam ligadas a esses sistemas.

Tani (1995) analisou o uso interativo do Custeio Alvo em empresas japonesas através da participação de gestores de níveis altos e médios em reuniões de planejamento de produtos e reuniões de custos, mostrando que estas agem como dispositivos para o controle interativo. A conclusão foi de que o uso interativo do Custeio Alvo ajuda a gerar ideias únicas para o desenvolvimento de produtos e para a redução de custos e que o mesmo é um subsistema chave da gestão estratégica de custos (TANI, 1995). É possível verificar que o Custeio Alvo, enquanto prática de gestão de lucro e redução de custos, pode ser usado de forma interativa. Dessa forma, o envolvimento da alta gestão no processo do Custeio Alvo pode indicar a percepção de sua importância como fonte de informação para tomada de decisões estratégicas, em especial para a implementação das estratégias.

Quanto ao uso diagnóstico, Simons (1995) menciona que o mesmo ocorre quando o SCG é designado para monitorar o desempenho organizacional, corrigindo os desvios existentes. Nesse tipo de uso os gestores dedicam pouca atenção ao mesmo. Dessa forma, o uso diagnóstico ajuda no monitoramento dos resultados e na correção dos desvios em relação às metas estabelecidas quando estes sistemas não são influenciados pelas incertezas estratégicas. 
Como a alta gestão não dispõe de tempo nem de recursos para se envolver com todo o SCG pessoalmente, os controles diagnósticos são acompanhados de forma periódica ou na forma de gerenciamento por exceção (SIMONS, 1991). A análise das variáveis críticas de desempenho relativas às estratégias estabelecidas é que influencia este tipo de uso (SIMONS, 1995). O uso diagnóstico também pode ser relacionado ao Custeio Alvo devido ao estabelecimento de metas e seu acompanhamento, característica inerentes a essa prática (conforme abordado neste Capítulo no item 3.2).

Simons (1995) chama a atenção para o fato de que o controle usado de forma diagnóstica pode ter efeitos colaterais chamados de uso disfuncional. Esses efeitos colaterais podem estar relacionados aos erros nas medidas de variáveis de desempenho, à construção de folgas nas metas estabelecidas, ao jogo com o sistema para aumentar recompensas, dentre outros (SIMONS, 1995). O uso interativo também pode gerar uso disfuncional, mas a pesquisa de Ferreira e Otley (2006) mostrou que o uso diagnóstico contribui mais para o disfuncional do que o interativo.

É possível perceber que existe relação entre o desenho e o uso dos SCG na medida em que a alta gestão define quais tipos de técnicas ou de informações usar de modo interativo ou diagnóstico. Isso não significa que um tipo de uso é melhor que outro, pois conforme Simons (1995), as duas formas de uso são importantes. Mas, é interessante verificar a forma de uso para entender se a prática analisada é usada para gerenciar as incertezas estratégicas ou para a análise das variáveis críticas de desempenho.

Destaca-se ainda que, para Aguiar e Frezatti (2007), o desenho do SCG pode sofrer a influência de fatores institucionais e não necessariamente ser movido pela busca de eficiência através da adequação entre contingências e SCG. Dessa forma, algum componente do SCG pode ter sido modelado não pela necessidade da informação do usuário e sim por pressões institucionais. Por isso, “[...] a dimensão uso pode ser entendida como aquela relacionada a aspectos cognitivos e culturais dos agentes, ou seja, pode ser entendida como apresentando uma dimensão institucional." (AGUIAR; FREZATTI, 2007, p. 30). Assim, se o Custeio Alvo foi implementado na Alfa apoiado principalmente por pressões institucionais isso deve ser refletido, em última instância, em seu uso. 


\subsubsection{Desempenho em relação ao SCG}

O desempenho é outra dimensão de avaliação do SCG e se mostra importante por evidenciar se o mesmo está ou não cumprindo com seu papel, ou seja, desde que esteja adequado às contingências encontradas na organização o SCG deve ser capaz de gerar um desempenho positivo. Sob este enfoque, o desempenho pode ser avaliado de várias formas; para Chenhall (2007) as medidas de resultado nos estudos de contingência em Controle Gerencial podem ser feitas pelo uso ou utilidade do sistema (usando variáveis como o grau de uso, a utilidade da informação, a satisfação com o sistema, dentre outras), pelos resultados comportamentais (usando a satisfação no trabalho) e pelos resultados organizacionais (geralmente feita por uma auto-avaliação dos processos onde os indivíduos fornecem um indicador de seu desempenho ou de sua unidade de negócios).

Aguiar e Frezatti (2007) argumentam que a contribuição do SCG para o desempenho organizacional não representa um construto ideal para captar se ele está cumprindo seu papel, pois ele não demonstra se de fato o mesmo vem sendo usado, se os usuários estão satisfeitos com o seu uso ou se existe algum impacto individual advindo desse uso. Ferreira e Otley (2009) também discutem esse assunto e comentam que a avaliação do desempenho do SCG, e não o da organização, tem maior probabilidade de refletir a adequação de seu desenho em relação às informações de que a empresa necessita.

Os efeitos da adoção de um tipo de sistema ou de determinadas práticas em detrimento de outras são difíceis de serem medidos em relação ao desempenho, em especial ao desempenho organizacional. Até que ponto uma organização aumenta ou diminui desempenho pela adoção de uma prática de controle gerencial ou pela adequação de seu sistema de controle às contingências? Como isolar o acréscimo ou decréscimo de desempenho organizacional relativo à mudança no sistema ou à sua adoção? Esses comentários refletem a dificuldade de considerar os resultados organizacionais devido à complexidade envolvida nesse processo, representada por uma gama de variáveis que podem impactar os mesmos dificultando isolar apenas aquelas que se relacionam ao SCG.

Por isso, Aguiar e Frezatti (2007) propõem uma estrutura para avaliação do desempenho do SCG que envolve a percepção geral dos seus benefícios líquidos e Ferreira e Otley (2009) propõem o que eles denominam de desempenho do SCG. Em ambos, o que se avalia é o desempenho do sistema e não o da organização. Ressalta-se que esses dois modelos foram 
propostos para avaliar o SCG; no entanto, podem ser adaptados para avaliar uma prática em particular. O modelo de Ferreira e Otley (2009) contempla apenas a satisfação do usuário e o modelo de Aguiar e Frezatti (2007) considera a satisfação do usuário e o impacto individual. Por ser mais amplo, optou-se por usar o modelo de Aguiar e Frezatti (2007).

Nesse modelo, a percepção geral dos benefícios líquidos do SCG é representada pelo uso do sistema, pela satisfação do usuário e pelo seu impacto individual. A dimensão uso, nesta pesquisa, foi avaliada de acordo com a tipologia de Simons (1995), conforme evidenciado no item 3.1.2. A inclusão das outras duas categorias adiciona informações sobre a percepção de utilidade do sistema.

A percepção da satisfação do usuário pode lançar importantes contribuições para a compreensão do papel do sistema para a organização, sendo mais apropriado um sistema que provoca maior satisfação em seus usuários que são, por sua vez, entendidos como os gestores que utilizam esse sistema (AGUIAR; FREZATTI, 2007). O impacto individual indica se os gestores efetivamente estão influenciando o comportamento dos membros organizacionais em direção às estratégias adotadas a partir das informações oriundas do sistema e quanto maior for o impacto individual provocado pelo sistema, mais apropriada tende a ser a estrutura desse sistema (AGUIAR; FREZATTI, 2007).

Dessa forma, dada a dificuldade em se analisar o impacto do SCG em relação ao resultado organizacional (OTLEY, 2001), o desempenho do Custeio Alvo foi avaliado de acordo com sua utilidade e seu resultado comportamental, verificando-se a satisfação do usuário e o impacto individual relativos ao mesmo.

\subsubsection{Medidas da Pesquisa quanto às Dimensões Avaliadas}

Conforme abordado anteriormente o Custeio Alvo foi avaliado em três dimensões, de acordo com o modelo de Ferreira e Otley (2006) e Aguiar e Frezatti(2007), como mostra a Figura 5. Na sequência foi apresentada a forma como cada uma foi mensurada. 


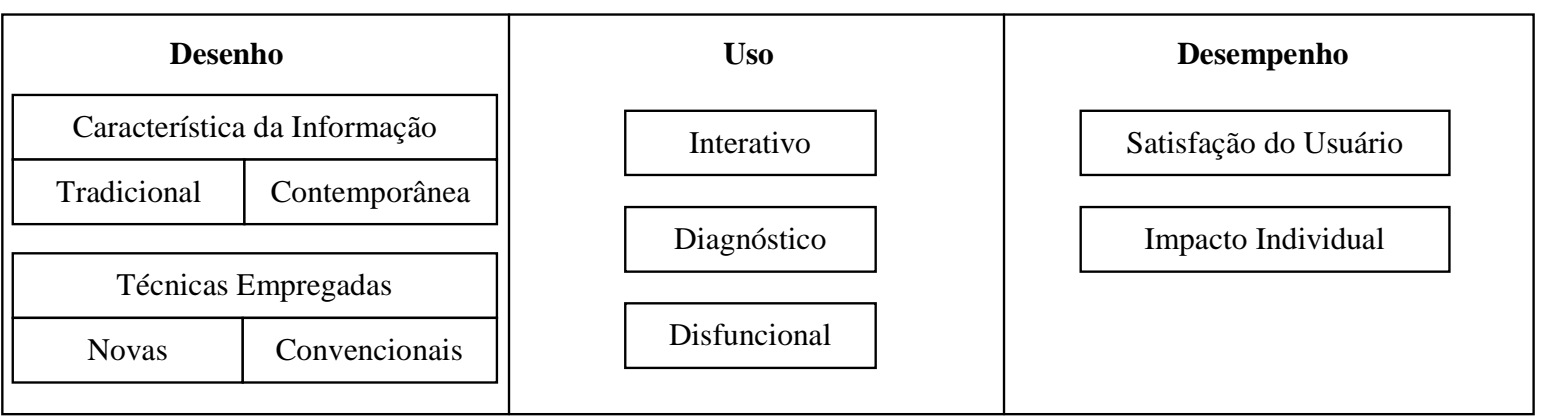

Figura 5 - Dimensões avaliadas em relação ao SCG

FONTE: adaptado de Ferreira e Otley (2006) e Aguiar e Frezatti (2007)

Quanto à dimensão desenho, as características da informação e as técnicas foram avaliadas em relação ao Custeio Alvo; por isso, antes mesmo da realização da pesquisa empírica, foi possível fazer esta classificação. Dessa forma, com base na classificação e nas características da informação apresentadas por Ferreira e Otley (2006), essa prática foi classificada como "nova" e suas informações possuem características de escopo amplo e contemporâneas (conforme discutido no item 3.2.6 deste Capítulo). Ainda nessa dimensão e de acordo com essa classificação foi avaliada a adequação entre os fatores contingentes e o Custeio Alvo, sendo os detalhes dessa investigação bem como os aspectos relativos à Teoria da Contingência evidenciados no Capítulo 2.

Quanto à dimensão uso do Custeio Alvo foi empregado o modelo de Simons (1995) e a medida teve como base o instrumento de Ferreira e Otley (2006) que apresenta características do uso diagnóstico, interativo e disfuncional.

Quanto ao desempenho relativo ao Custeio Alvo, a medida foi construída considerando-se as duas dimensões investigadas (satisfação do usuário e impacto individual), com base no trabalho de Rai et al. (2002) e DeLone e McLean (1992). É interessante notar que o instrumento de Rai et al. (2002) considera o que eles denominam de utilidade percebida como representando o impacto individual.

O próximo item apresenta o Custeio Alvo que foi a prática do sistema de controle investigada nessa pesquisa. 


\subsection{Custeio Alvo}

O Custeio Alvo vem sendo estudado no campo da Contabilidade Gerencial há vinte anos (ANSARI et al., 2007) e sua base diferenciada na forma de tratar os custos chama a atenção por se afastar dos modelos normalmente usados e discutidos na academia antes do seu surgimento. Não se trata de um método de custeio como o absorção, o custeio direto ou o custeio baseado em atividades (EVERAERT et al., 2006) e, um fato também interessante é seu desenvolvimento advindo da prática ao invés das pesquisas científicas (KATO, 1993; FEIL et al., 2004). Devido à sua importância no contexto estratégico da gestão de custos vem despertando o interesse dos gestores e dos pesquisadores que buscam entender seu funcionamento nas organizações.

Notadamente a literatura aponta muitas características relativas a esta prática (ANSARI et al., 2006; SWENSON et al., 2003; COOPER; SLAGMULDER, 1999; EWERT; ERNST, 1999; ELLRAM, 2002; KATO, 1993; COOPER; SLAGMULDER, 1997) destacando-se sua importância no contexto estratégico, fornecendo informações e subsídios que propiciam um melhor posicionamento da organização na cadeia de valor.

Mudanças no mercado e no comportamento do consumidor ajudaram a alavancar o uso do Custeio Alvo uma vez que o modelo de produção em massa usado para economia de escala foi sendo substituído por modelos que privilegiam um ciclo de vida cada vez mais curto para os produtos (SAKURAI, 1997; COOPER; SLAGMULDER, 1997). Isso gera a necessidade de análises de lucratividade mais apuradas para que a continuidade da empresa seja preservada através de retornos positivos no intervalo do ciclo de vida do produto. Além disso, o aumento da oferta de produtos similares faz com que as organizações tenham reduzido seu poder de fixar preços de venda devido às pressões do mercado consumidor, afetando diretamente a lucratividade.

O cenário originado por esta situação acabou causando um grande problema para as organizações. Se a redução no ciclo de vida dos produtos reduz também o tempo necessário para que determinado produto traga retorno para a empresa (o lucro é essencial para sua sobrevivência) e, ainda, tendo o agravante de que o preço de venda em grande parte é o mercado que estabelece, resta somente uma variável para que a empresa possa manipular com o objetivo de atingir o lucro desejado. Levando em consideração que o lucro, de modo geral, é o resultado da confrontação entre receitas e despesas (pode-se considerar aqui os custos) resta 
gerenciar o custo de forma a conseguir a lucratividade desejada e garantir uma continuidade de forma sustentável.

Estes fatos, mostrados de forma bastante simplista, levaram as organizações a utilizar o Custeio Alvo como uma prática capaz de possibilitar o retorno desejado através do gerenciamento estratégico dos custos. Primeiramente seu uso foi difundido no Japão, mas desde a década de 1980, quando foi amplamente reconhecido como o maior fator para a posição competitiva superior das companhias japonesas, muitos esforços têm sido empregados para levar o Custeio Alvo para as companhias ocidentais (FEIL et al., 2004).

Os estudos sobre Custeio Alvo publicados na literatura acadêmica internacional nos últimos vinte anos em periódicos como Accounting Horizons; Accounting, Organizations and Society e Management Accounting Research, podem ser agrupados em: 1) estudos sobre o conceito, objetivos e processos do Custeio Alvo (ANSARI et al., 2006; SWENSON et al., 2003; COOPER; SLAGMULDER, 1999; EWERT; ERNST, 1999; ELLRAM, 2002; KATO, 1993); 2) aplicação de levantamentos para verificar a taxa de adoção da prática e suas características (TANI et al., 1994; WIJEWARDENA; DE ZOYSA, 1999; CHENHALL; LANGFIELDSMITH, 1998b; GUILDING et al., 2000, DEKKER; SMIDT, 2003), 3) estudos que trabalham com fatores contingentes para verificar as circunstâncias em que seu uso seria mais apropriado ou desejável (HIBBETS et al., 2003; TANI, 1995; DEKKER; SMIDT, 2003, AX et al., 2008) e 4) estudos de como ele é aplicado nas empresas (ELLRAM, 2006; FEIL et al., 2004; FILOMENA et al., 2009; TANI et al., 1994).

No Brasil, dentre os trabalhos envolvendo o Custeio Alvo publicados em periódicos das áreas de Administração e Contabilidade com avaliação da Capes (até março de 2012) nos estratos A1, A2, B1, B2 e B3, destacam-se os de Souza et al. (2005), Camacho e Rocha (2008), Colauto et al. (2004), Cardoso e Beuren (2006), Reckziegel et al. (2007) Ono e Robles Júnior (2004), Souza et al. (2003), Biazebete et al. (2009), Brito et al. (2008,) Souza et al. (2010a), Cruz e Rocha (2008), Machado e Souza (2006), Faria et al. (2009) e Souza et al. (2010b). Ainda existem as teses e dissertações que envolvem o tema como a de Soutes (2006), Bertucci (2008), Lima Júnior (2006), Camacho (2004), Bomfim (2006), Hansen (2002), Scarpin (2000), dentre outras.

Pode se observar que o Custeio Alvo é um assunto que vem fazendo parte das pesquisas principalmente nos últimos anos, inclusive alguns dos trabalhos citados mostram que o 
interesse por essa prática vem crescendo também por parte das empresas no Brasil. No entanto, nos trabalhos encontrados e analisados sobre Custeio Alvo, tanto no exterior quanto no Brasil, poucos tiveram o objetivo de investigar os motivos que levam uma organização a adotá-lo e como ele é utilizado. Por isso, essa pesquisa buscou esclarecer estes pontos considerando tanto a busca de eficiência quanto de legitimidade como forma de entender seu funcionamento na organização Alfa, objeto do estudo de caso.

\subsubsection{Histórico}

Embora as ideias iniciais do Custeio Alvo sejam creditadas a organizações japonesas (KATO, 1993), principalmente à Toyota (FEIL et al., 2004; MONDEN, 1995; SAKURAI, 1997), Feil et al. (2004) mostram que a ideia de maximizar atributos desejáveis de produtos ao mesmo tempo em que seus custos sejam minimizados foi criada pelos americanos com o nome de Engenharia de Valor no período de escassez de recursos pós Segunda Grande Guerra e, posteriormente, essa prática foi usada pela Toyota com o nome de Genka Kikaku.

O Custeio Alvo vai além da Engenharia de Valor e da redução de custos (ANSARI et al., 1997) e, mesmo advindo dessas ideias, sua filosofia é diferenciada, abrangendo o planejamento do lucro. Para Ansari et al. (1997) ele é tão importante no Japão que, de acordo com pesquisas mostradas em seu trabalho, mais de $80 \%$ das indústrias de montagem japonesas utilizavam essa prática, destacando-se empresas como a Toyota, Nissan, Olympus, Komatsu, Sony, Canon dentre outras empresas líderes. O desenvolvimento do Custeio Alvo foi marcado por intensas mudanças internas e externas no ambiente corporativo e para um melhor entendimento é importante verificar em quais circunstâncias isso aconteceu.

A mudança no ambiente de negócios refletida em diversos fatores como na concorrência, nas necessidades dos clientes, na redução do ciclo de vida dos produtos, dentre outros, fizeram com que essa prática tivesse aceitação entre as organizações, principalmente aquelas que operam em ambientes dinâmicos. Ansari et al. (1997) comentam sobre essas mudanças e mostram as características desse ambiente: em relação à concorrência, os preços estavam sendo reduzidos em muitos setores e os novos entrantes possuíam estruturas de custos menores; a valorização das moedas japonesa e alemã frente ao dólar fez com que as empresas reduzissem custos para não aumentar os preços no mercado norte americano; a entrada de concorrentes asiáticos, que apresentavam regulações ambientais menos rigorosas, mão de 
obra qualificada relativamente barata, tecnologia sofisticada e regulações governamentais menores; em relação aos produtos a redução do seu ciclo de vida aumentou a taxa de lançamento de novos produtos, havendo menor tempo de resposta às mudanças do mercado e, em relação à demanda, consumidores sofisticados demandam produtos de melhor qualidade com mais características a um preço acessível e, nesta situação, reduzir a qualidade ou aumentar preços não são estratégias viáveis no longo prazo.

Outros reflexos dessas mudanças ambientais são mencionados na literatura. Nos últimos vinte anos houve uma mudança nas prioridades de produção, reduzindo-se a fabricação de produtos padronizados a um custo baixo para prioridades estratégicas focando responder às demandas dos consumidores por maior diversidade de produtos, sendo que estas novas condições de concorrência desafiaram a validade dos sistemas convencionais de custeio (ABERNETHY et al., 2001). Mudanças na tecnologia e nos sistemas de produção como o JIT também trouxeram a necessidade de outros mecanismos de controle e gestão de custos (KATO, 1993). Além disso, como uma forma de sobreviver à ruptura da bolha econômica da década de 1990, o foco estratégico das principais companhias japonesas mudou do aumento da participação no mercado para a obtenção de lucro (FEIL et al., 2004). Percebe-se que as mudanças foram profundas e envolveram inclusive a mudança de estratégia das organizações, o que passou a demandar informações de caráter estratégico para poder gerir os custos.

Nesse contexto, para Ansari et al. (1997), as organizações devem se antecipar às mudanças ambientais antes de ser afetada por elas; as operações devem ser melhoradas continuamente; deve ser dada atenção ao foco externo contemplando as necessidades dos consumidores e as ameaças competitivas e todos os elementos internos e externos devem ser relatados sistematicamente para que sejam resolvidos holisticamente e não de forma incremental, sendo o Custeio Alvo mais adequado a essas necessidades.

\subsubsection{Objetivo do Custeio Alvo}

Conhecendo o ambiente de negócios que propiciou condições para o desenvolvimento e o uso dessa prática pode-se conhecer seus objetivos. Refletindo a importância do gerenciamento de custos de acordo com as estratégias da organização, muitas empresas japonesas desenvolveram programas de gerenciamento de custos integrados que criaram uma disciplina 
completa para reduzir custos através de todo ciclo de vida dos produtos, sendo o Custeio Alvo um dos componentes desse programa (COOPER, 1996).

O Custeio Alvo foi se desenvolvendo na medida do seu uso, passando a contemplar mais características com o passar do tempo, o que pode indicar a geração de informações mais adequadas ao objetivo a que se propõe. De acordo com Kim et al. (1999) seu uso se intensificou e como resultado suas metodologias têm melhorado. Para Feil et al. (2004) o Custeio Alvo começou como um instrumento simples para controle de custos de compras em poucos produtos e partes e evoluiu para um instrumento abrangente de gestão de lucro. A pesquisa empírica de Tani et al. (1994) mostrou que o Custeio Alvo possui múltiplos objetivos, como redução de custos, garantia de qualidade, introdução oportuna de novos produtos no mercado e desenvolvimento de produtos para atrair os clientes, sendo designado para lidar com inovações tecnológicas aceleradas e necessidades diversificadas dos clientes.

O processo do Custeio Alvo é desenvolvido, de acordo com Kato (1993), com o objetivo de reduzir os custos do ciclo de vida dos produtos nas fases anteriores à produção assegurando qualidade, confiabilidade e outros requisitos dos clientes, mas não se limita somente a isso, ele faz parte de um abrangente gerenciamento estratégico do lucro. Cooper e Slagmulder (1997) também entendem que o Custeio Alvo é tanto uma ferramenta de gestão de lucro quanto de custo e, Ansari et al. (1997) também compartilham que seu objetivo é assegurar lucros adequados pelo emprego simultâneo do planejamento do lucro e do custo. Percebe-se que a finalidade do processo é a obtenção da margem de lucro objetivada e o meio usado para isso é a gestão estratégica dos custos.

As raízes intelectuais do Custeio Alvo advêm da Teoria dos Sistemas Abertos, segundo a qual é melhor gerenciar um sistema proativamente, antes que ele se desvie de seu caminho pretendido, do que ter que efetuar ações corretivas depois dele ter-se desviado (ANSARI et $a l ., 1997)$. Assim, essa prática busca uma interação entre a organização e seu ambiente, de forma a obter uma conduta proativa. Esse ponto foi fundamental para seu desenvolvimento. Primeiro, porque mudou o foco da gestão dos custos de dentro da organização para fora dela; segundo, porque está diretamente relacionado à estratégia pela qual a empresa opta para interagir no mercado; e terceiro porque a conduta proativa baseia-se em gerenciar os custos antes que eles aconteçam. 
Baseado nesses comentários pode-se de forma resumida considerar que o objetivo do Custeio Alvo é gerenciar estrategicamente os custos antes que eles ocorram de forma a obter o retorno desejado pela organização considerando-se os requisitos dos clientes. É interessante mencionar que, pelo fato de o mesmo ter começado seu desenvolvimento em organizações de manufatura, a literatura frequentemente menciona seu uso para o desenvolvimento de produtos e raramente de serviços; no entanto, o trabalho de Camacho (2004) mostra que é possível o desenvolvimento do mesmo em organizações prestadoras de serviços. Para entender as características e atributos dessa prática, na sequência foram abordados os fundamentos do Custeio Alvo.

\subsubsection{Fundamentos e Características do Custeio Alvo}

A primeira homologação abrangente dos limites do Custeio Alvo foi estabelecida pelo CAM-I (Consortium for Advanced Manufacturing-International) (ANSARI et al., 2007) quando do estabelecimento dos seis princípios chaves que descrevem os fundamentos dessa prática. Os seis princípios, de acordo com o CAM-I, são: custeio orientado pelo preço, foco sobre os clientes, foco sobre o projeto, envolvimento de equipes multifuncionais, envolvimento da cadeia de valor, redução de custo do ciclo de vida do produto (ANSARI et al., 2006). Cruz e Rocha (2008) analisaram vários trabalhos que trataram desses princípios e verificaram que a nomenclatura usada para os mesmos foi diversa, incluindo-se termos como princípios, características, requisitos e premissas. Após fazerem comparações entre os diversos trabalhos analisados, Cruz e Rocha (2008) concluem que esses princípios devem ser separados em duas categorias sendo os princípios, que são as razões fundamentais para existência e delineamento do Custeio Alvo, e os requisitos, que são as condições desejáveis que contribuirão para o sucesso desse processo. Dessa forma, para Cruz e Rocha (2008) os princípios incluem o custo conduzido pelo preço, a satisfação dos clientes, o custo definido essencialmente no projeto e, adicionam outro não contemplado pelo CAM-I, o de que o lucro é garantia de sobrevivência; os requisitos incluem o envolvimento multifuncional, a orientação pelo ciclo de vida do produto e o envolvimento da cadeia de valor.

Pelo fato de que essa separação auxilia no entendimento do processo do Custeio Alvo e, ainda, adiciona a questão do lucro como garantia de sobrevivência, essa forma de nomenclatura foi usada nessa pesquisa. Assim, os princípios e requisitos mencionados 
caracterizam o Custeio Alvo delimitando sua abrangência, podendo ser entendidos como fundamentos que o diferenciam dos demais custeios ou de outras práticas da Contabilidade Gerencial mostrando seu funcionamento. A análise desses fundamentos é importante para que se possa entender as características e a filosofia dessa prática. Na sequência os mesmos foram apresentados.

O princípio do lucro como garantia de sobrevivência considera a questão da continuidade da organização no mercado e ressalta o objetivo do Custeio Alvo de obtenção do retorno desejado pela organização.

O princípio do custeio orientado ou conduzido pelo preço indica que os cálculos e análises dos custos são efetuados com base no preço de venda que o cliente está disposto a pagar por um produto ou serviço, caracterizando a orientação de mercado dessa prática. O preço, para efeito de utilização do Custeio Alvo, decorre da estratégia de diferenciação, da capacidade de gerar valor para os clientes e do poder de mercado que a empresa possui (BACIC, 2008).

No Custeio Alvo o custo é função de determinado preço de mercado (ANSARI et al., 2007) e, sob esta abordagem, é visto como uma entrada (input) no processo de projeto do produto e não como um resultado (output) dele (COOPER; SLAGMULDER, 1997). Isto significa que a ideia central, relativa aos custos, inerente ao Custeio Alvo, é totalmente diferente de todos os demais custeios existentes. O que se busca com os custeios de maneira geral é o cálculo dos gastos (custos e/ou despesas) de determinado objeto (produto/serviço) de custeio para: (1) poder deduzi-lo de seu preço de venda e apurar o lucro, ou seja, o lucro é decorrência da sobra entre preço e custo, ou (2) usar o custo como base para precificar o objeto, ou seja, o custo orienta o preço. A escolha desses enfoques depende, por exemplo, do tipo de mercado que a empresa está inserida como monopólio, concorrência, monopsônio, dentre outros (para maiores detalhes ver Bertucci, 2008) e do posicionamento da empresa no mercado (líder de preço ou seguidora de preço).

No Custeio Alvo, ao contrário, o custo alvo é orientado pelo preço, ou seja, ao invés de apenas calcular os custos incorridos para produzir um objeto, ele parte do preço de mercado (quanto o cliente está disposto a pagar), considera uma margem de lucro planejada (desejada) pela organização e daí calcula e gerencia o custo que deve ser o máximo permitido para que o produto/serviço traga esse retorno desejado. Por isso, apesar do nome "Custeio Alvo", essa 
prática está mais relacionada à gestão estratégica do custo e do lucro, conforme análises de Camacho (2004) e Rocha (1999), do que ao custeio em si de um produto/serviço.

O próximo princípio diz respeito ao foco no cliente ou à satisfação dos clientes, que preconiza a atenção dispensada às suas exigências, sendo esta mais uma característica de orientação pelo mercado. O cliente tem o poder de manter ou não uma empresa no mercado exercendo um papel de soberania em relação ao que deseja (MISES, 1995). Esse autor ainda argumenta que os donos dos fatores produtivos devem conformar suas atividades de acordo com as ordens dos consumidores, pois, se assim não for "O mais insignificante desvio, seja intencional ou causado por erro, mau julgamento ou ineficiência, restringe ou suprime seus lucros. Um desvio mais acentuado resulta em perdas, reduzindo ou absorvendo inteiramente sua riqueza." (MISES, 1995, p. 271).

Pela filosofia do Custeio Alvo os requisitos exigidos pelos clientes devem ser atendidos, ou seja, não basta reduzir custos para gerar o lucro desejado, é necessário atender esse pressuposto também. Ansari et al. (2006) ressaltam que os requisitos do cliente para qualidade, custos e tempo estão simultaneamente nos produtos e nos processos de decisão e guiam a análise de custos, devendo ser o valor percebido sobre qualquer característica e funcionalidade agregados ao produto maior do que o custo de fornecer tais características.

O foco sobre o projeto ou o "custo é definido essencialmente no projeto" é outro princípio que distingue o Custeio Alvo salientando a importância de gerir os custos nos estágios iniciais do ciclo de vida do produto, ou seja, na fase de projeto. Para Rocha (1999) esta fase consiste no principal determinante de custos de um produto. Esse princípio também diferencia o Custeio Alvo dos outros custeios uma vez que os demais geralmente são usados apenas quando o produto já está sendo fabricado, ou seja, no estágio de produção.

Uma estatística geralmente citada informa que cerca de $80 \%$ a $95 \%$ dos custos dos produtos são determinados na fase de projeto (COOPER; SLAGMULDER, 2004) o que significa que somente de $20 \%$ a $5 \%$ dos custos podem ser reduzidos após o produto começar a ser fabricado. Por isso, na fase de planejamento e projeto é que se aplica o Custeio Alvo (SAKURAI, 1997; MONDEN, 1995; COOPER; SLAGMULDER, 1997). A chave para a gestão de custos é projetar os custos de determinado produto antes do início da sua produção ao invés de confiar em economias de escala, curvas de aprendizado, redução de desperdícios e melhoramento da produção para reduzir os custos, ou seja, trata-se de uma prática proativa e 
não reativa. Isso não significa que o Custeio Alvo se aplique apenas para novos produtos, Shank e Fisher (1999) argumentam que ele pode ser aplicado também nos produtos existentes em seu reprojeto.

Quanto aos requisitos para o Custeio Alvo, o primeiro diz respeito ao envolvimento de equipes multifuncionais no processo dessa prática. O Custeio Alvo é um processo amplo e para que o mesmo funcione é necessário que haja a disponibilização de muitas informações (relativas aos produtos/serviços, aos clientes, aos fornecedores, ao planejamento do lucro, aos custos etc.) e a realização de muitas tarefas; por isso, é necessário o envolvimento de vários setores da organização. Sakurai (1997) menciona que para atingir o objetivo do Custeio Alvo são necessários os esforços integrados de departamentos como marketing, engenharia, produção e contabilidade. Isso evidencia que o funcionamento do mesmo leva em consideração o envolvimento de equipes multifuncionais em todas as suas etapas. Além disso, para Ansari et al. (1997) essas equipes também incluem participantes de fora da organização como fornecedores, clientes, revendedores, distribuidores, fornecedores de serviços e recicladores e são responsáveis por um produto desde sua concepção até a produção.

A orientação pelo ciclo de vida do produto/serviço é outro requisito e considera que aspectos relativos à redução de custos sejam observados tanto nas fases de produção quanto naquelas em que os produtos/serviços estejam com o cliente. Existe a preocupação com a redução de custos no processo produtivo, na venda, na utilização do produto e no seu descarte pelo cliente, ou seja, de acordo com Ansari et al. (1997) seu objetivo é reduzir os custos do ciclo de vida tanto para o produtor quanto para o cliente, minimizando o custo durante toda a vida útil do produto.

Além disso, as fases que antecedem a produção e as de distribuição também são analisadas e gerenciadas, evidenciando que o envolvimento da cadeia de valor é importante no processo do Custeio Alvo, sendo este o último requisito. Ansari et al. (2006) mencionam que todos os membros da cadeia de valor como fornecedores, distribuidores, fornecedores de serviços e clientes estão inclusos no processo de Custeio Alvo. Essa prática é baseada em relações benéficas recíprocas e de longo prazo entre os membros da cadeia de valor (ANSARI et al., 1997).

Conforme mencionado os princípios e requisitos representam os fundamentos e delimitam a abrangência do Custeio Alvo permitindo que o mesmo possa ser diferenciado de outros 
processos ou mesmo de outras práticas de gestão de custos. Conhecidos esses atributos é possível apresentar sua definição.

\subsubsection{Definição do Custeio Alvo}

Vários autores apresentam definição para Custeio Alvo levando em consideração suas características e a visão que cada um tem a seu respeito. Nesse trabalho foram considerados os objetivos e fundamentos do Custeio Alvo bem como as análises e definições feitas por outros autores para se chegar à definição proposta. Para não tornar a análise repetitiva discutindo pontos já levantados, parte-se de trabalhos mais recentes como o de Camacho (2004) que analisou as definições de Custeio Alvo de vários autores e, posteriormente teceu sua própria definição e, o de Ansari et al. (2007), que analisaram o desenvolvimento do tema em questão apresentando também sua definição.

Após as análises sobre a definição de vários autores, Camacho (2004, p. 17) argumenta que "Custeio Alvo é um processo de gerenciamento de custos por meio do qual se busca o alcance do Custo Alvo" e, posteriormente adiciona à esta definição cinco corolários que caracterizam o mesmo, sendo o envolvimento de equipes multifuncionais, o foco no projeto, orientação pelas necessidades dos consumidores, contemplar custos relevantes de uso e de propriedade e contemplar um segmento relevante da cadeia de valor.

A definição de Camacho (2004) é interessante por apresentar o Custeio Alvo como um processo. Esse é um ponto em que a literatura sobre o assunto não tem unidade sendo por vezes tratado como um sistema (ANSARI et al. 2007; MONDEN; HAMADA, 1991), como um processo (SAKURAI, 1997, ROCHA, 1999; EVERAERT et al., 2006; BHIMANI; OKANO, 1995), como abordagem (COPER; SLAGMULDER, 1997), como ferramenta (BRAUSCH, 1994), como método (FREEMAN, 1998; CADEZ; GUILDING, 2008), como modelo (SCARPIN, 2000), como artefato (WICKRAMASINGHE; ALAWATTAGE, 2007) e como técnica (KATO, 1993). Percebem-se aqui duas categorias de classificação, sendo uma relacionada à prática em si (podendo ser denominada de técnica, artefato ou abordagem) e outra relacionada ao seu funcionamento (podendo ser tratado como sistema, modelo ou processo) e, em relação a esta última categoria, é necessário um esclarecimento visto ser fundamental para sua operacionalização. 
Nesse sentido, Camacho (2004) analisa a natureza do Custeio Alvo em comparação com um sistema, um processo e um modelo e conclui que o mesmo se relaciona mais com um processo. Para Wickramasinghe e Alawattage (2007) e Baker (1995) o Custeio Alvo faz parte do Sistema de Controle Gerencial. Com base nessas observações, neste trabalho o mesmo foi considerado como um processo que é operacionalizado por meio e no âmbito de um sistema, no caso o SCG.

Ainda com relação à definição proposta por Camacho (2004) o Custeio Alvo é estabelecido como um processo de gerenciamento de custos sem menção à questão do planejamento do lucro que é importante e representa sua base, juntamente com a consideração do preço de mercado. $\mathrm{O}$ autor menciona ainda como sua finalidade o alcance do custo alvo, que não deve ser confundido com Custeio Alvo e é parte fundamental nesta filosofia. Camacho (2004, p. 18) esclarece a questão mencionando que “[...] Custeio Alvo é o processo e custo alvo é um dos componentes e objetivo principal do Custeio Alvo [...]." Mais detalhes sobre o custo alvo foram discutidos juntamente com a definição proposta. Em relação aos corolários elencados por Camacho (2004), trata-se dos fundamentos do Custeio Alvo estabelecidos pelos princípios e requisitos, com exceção do custeio orientado pelo preço, que não foi elencado.

A segunda definição analisada foi a de Ansari et al. (2007, p. 507), segundo os quais "Custeio alvo é um sistema de planejamento de lucro e gerenciamento de custo que assegura que novos produtos e serviços atendam o preço determinado pelo mercado e o retorno financeiro." ${ }^{13} \mathrm{De}$ maneira mais ampla, os autores consideram tanto o gerenciamento de custo como o planejamento do lucro em sua definição, no entanto, alguns pontos merecem comentários. Primeiro, conforme visto anteriormente o Custeio Alvo é indicado tanto para produtos novos como para os que já existem, por isso, o termo "novos" usado na definição não faz sentido. Segundo, não é mencionado que atender o preço de mercado e atingir o retorno desejado se dá pela obtenção do custo alvo. Terceiro, faltou complementar que seu funcionamento leva em consideração que os requisitos dos clientes sejam atendidos. Quarto considera o Custeio Alvo como um sistema, e conforme abordado, trata-se de um processo que parte de um sistema.

Considerando-se os objetivos e as características do Custeio Alvo apresentados anteriormente, considerando-se as definições de Camacho (2004) e Ansari et al. (2007) e feitas as observações julgadas necessárias, propõe-se como definição:

\footnotetext{
${ }^{13}$ Target costing is a system of profit planning and cost management that ensures that new products and services meet market determined price and financial return. Em inglês no original. Tradução livre da autora.
} 
Custeio Alvo é um processo de gerenciamento de custo de um produto/serviço através da determinação e da obtenção do custo alvo assegurando que durante seu ciclo de vida gere o retorno desejado pela organização garantindo os requisitos dos clientes.

Nessa definição parte-se do pressuposto de que a gestão do custo para atingir o retorno desejado leva em consideração os requisitos do cliente, ou seja, toda e qualquer redução de custo em um projeto deve avaliar o que os clientes entendem como tendo "valor" em um produto/serviço, garantindo qualidade, confiabilidade, preço, oportunidade etc.

Quanto à forma de obtenção do retorno desejado na filosofia do Custeio Alvo se dá através da gestão do custo alvo e a definição proposta levou em consideração o argumento de Ansari et al. (1997) de que uma visão mais ampla dessa prática leva em consideração tanto a determinação do custo alvo quanto sua obtenção. Essas diferentes etapas fazem parte do processo do Custeio Alvo conforme apresentado na sequência (item 3.2.5). Em relação à determinação do custo alvo é interessante observar que a literatura apresenta duas formas. Em uma ele é calculado como sendo a diferença entre o preço de mercado e o retorno desejado (ANSARI et al., 2006; FEIL et al., 2004; KATO, 1993; SWENSON et al., 2005), ou seja:

\section{Custo Alvo = preço de mercado $\boldsymbol{-}$ retorno desejado}

$\mathrm{Na}$ outra o custo alvo representa a diferença entre o custo estimado do produto/serviço e o custo máximo permitido ou admissível (COOPER; SLAGMULDER, 1997; ROCHA, 1999; CAMACHO, 2004; EVERAERT et al., 2006), ou seja, ele representa o alvo de redução de custos, o gap que deve ser gerenciado. Nessa abordagem aparece o conceito de custo máximo permitido que é obtido de forma dedutiva pela diferença entre o preço de venda que o cliente está disposto a pagar e retorno desejado pela empresa.

Nessa forma de determinação o custo máximo permitido representa quanto um produto deve custar (no máximo) a fim de obter a margem objetivada quando vendido pelo preço de mercado (EVERAERT et al., 2006). Já o custo alvo representa o montante de custos que deve ser eliminado ou aumentado de forma que o custo estimado se ajuste ao máximo permitido (ROCHA, 1999). São descritos pelas seguintes equações: 


\section{Custo Máximo Permitido = preço de mercado - margem objetivada}

\section{Custo Alvo = custo estimado - custo máximo permitido}

De acordo com as equações, o custo alvo é a variável dependente tanto do preço de mercado quanto da margem objetivada; portanto, sua obtenção garante que as outras duas variáveis também sejam obtidas. Assim, pode-se dizer que a essência do Custeio Alvo está na determinação e na obtenção do custo alvo, que reflete o processo de gerenciamento estratégico do custo. Por entender que essa forma representa de modo mais adequado a noção de determinar o custo alvo a mesma foi empregada no desenvolvimento desse trabalho. Ressalta-se ainda, que o retorno desejado nessa pesquisa está sendo denominado de margem objetivada e não lucro objetivado, em conformidade com as discussões de Rocha (1999), uma vez que o retorno pode ser expresso em relação à margem de contribuição e não apenas ao lucro.

\subsubsection{Processo do Custeio Alvo}

De acordo com os objetivos, os fundamentos, as características e a definição do Custeio Alvo é possível visualizar seu processo. Conforme mencionado, Ansari et al. (1997) argumentam que existem duas fases em relação a essa prática, a determinação do custo alvo e sua obtenção; no entanto, esses autores não trabalham com o conceito de custo máximo permitido, que foi a forma assumida nesta tese. Ansari et al. (1997) usam apenas o conceito de custo alvo e a diferença para o custo estimado é denominada "cost gap" ou diferença de custo, portanto, o que para eles é a determinação do custo alvo neste trabalho foi considerada a determinação do custo máximo permitido para posteriormente encontrar o custo alvo. Desta forma, o processo apresentado na sequência foi baseado em Ansari et al. (1997), mas difere neste ponto.

A primeira fase busca a determinação do custo máximo permitido e Ansari et al. (1997) estabelecem como atividades nessa etapa a pesquisa de mercado, a análise da concorrência, a determinação do cliente ou do nicho de mercado, a determinação dos requisitos dos clientes, a definição das características dos produtos, o estabelecimento do preço de mercado que o cliente está disposto a pagar e o estabelecimento do lucro alvo requerido pela organização. 
Para Ansari et al. (1997) o custo alvo, que aqui representa o custo máximo permitido, é estabelecido dentro de parâmetros que são definidos pela estratégia de produto da organização e pelo planejamento de longo prazo do lucro e especificam o mercado, os clientes e os produtos que se pretende desenvolver. Nesta fase é que a questão estratégica do Custeio Alvo emerge, tanto na definição do mercado que se pretende atingir (definindo nicho, escopo, participação no mercado etc.) quanto na definição do retorno que se espera com o produto (definindo o plano estratégico de lucro da organização, o posicionamento no mercado etc.). Estabelecidas essas estratégias o processo tem seu andamento de modo a gerenciar os custos para que as mesmas sejam alcançadas, por isso, é que essa prática liga a estratégia da organização à sua execução fornecendo meios para que isso ocorra. Após o estabelecimento do preço de mercado e do lucro desejado é possível a determinação do custo máximo permitido e, neste ponto acaba a primeira fase.

A segunda fase está preocupada em atingir o custo alvo e também possui atividades para isso. De acordo com Ansari et al. (1997) essas atividades ocorrem principalmente durante o desenvolvimento do conceito do produto (concepção), o teste de viabilidade e o estágio de desenvolvimento do projeto; compreende computar a diferença entre o custo estimado ou corrente e o custo máximo permitido, encontrando o custo alvo; analisar os custos envolvidos no projeto e empreender esforços de forma a atingir o alvo e liberar ou não o produto para fabricação.

Nessa fase a organização calcula os custos estimados do produto para deduzir do custo máximo permitido e encontrar o custo alvo. Os custos estimados também chamados de custos correntes, custos em andamento (ongoing cost) ou custos flutuantes (drifting costs) consistem na melhor estimativa dos futuros custos do produto (EVERAERT et al., 2006). Cooper e Slagmulder (1997) mencionam que os custos correntes do novo produto são determinados pela soma dos custos de produção correntes de cada função principal do novo modelo. É interessante observar de forma mais específica quais custos são objetos dessa análise. Para Cooper e Slagmulder (1997) o processo foca principalmente os custos diretos, mas também pode ser usado para reduzir os custos indiretos.

De forma diferente, Ansari et al. (1997) mencionam que a análise dos custos envolvidos no processo deveria abranger o custo pleno, ou seja, todos os custos e todas as despesas relativas ao ciclo de vida do produto, abrangendo pesquisa e desenvolvimento, produção, vendas, distribuição, serviços, apoio e descarte. Para esses autores isso deveria ser feito pelo fato de o 
planejamento do lucro e os preços estipulados pelos clientes estarem em nível de custo total. No entanto, na opinião de Ansari et al. (1997) muitas organizações não fazem dessa forma e devido ao foco no projeto do produto colocam uma indevida ênfase nos custos de partes compradas e manufaturadas.

Depois de calculado o custo alvo o projeto do produto passa a ser o foco da análise e o que se busca é atingir esse custo através de seu gerenciamento. Os setores que atuam de forma mais intensa nessa atividade são a engenharia, compras, contabilidade e administração, mas como esse é um processo iterativo todos os departamentos são envolvidos em maior ou menor grau em algum momento. A Figura 6 mostra o processo do Custeio Alvo dividido em duas fases, conforme apontado por Ansari et al. (1997) e englobando seu foco interno e externo, mas com a inclusão do custo máximo permitido.

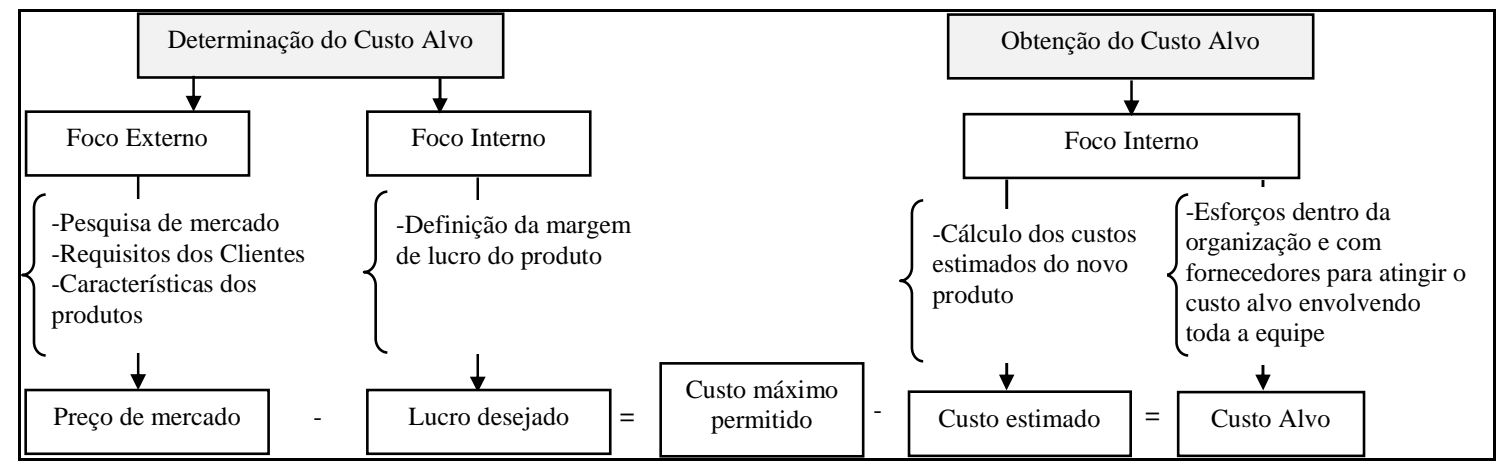

Figura 6 - Processo do Custeio Alvo

FONTE: adaptado de Ansari et al. (1997)

A etapa em que se procura atingir o custo alvo consiste na necessidade da abertura dos custos do produto para que se possam estudar as alternativas possíveis de serem aplicadas em sua redução. Esse processo consiste em reduzir custos e comparar os estimados com o custo alvo até que se consiga atingir o mesmo sendo um processo iterativo. Ansari et al. (1997) mencionam que a redução de custos através do projeto requer uma resolução de forma recursiva usando quatro atividades chave sendo o projeto do produto, a análise de custo e de valor, a engenharia de valor e a estimativa de custos. A estimativa de custos é usada durante todo o processo na segunda fase visto que a cada mudança no projeto do produto uma nova estimativa precisa ser feita para continuar a comparação entre o máximo permitido e o estimado.

O processo de Custeio Alvo nesta fase necessita de técnicas e ferramentas para poder se desenvolver. Ansari et al. (1997) mostram que essas podem ser de dois tipos: as ferramentas 
essenciais, como o projeto para capacidade de produção, análise de valor e a engenharia de valor, e outras ferramentas e processos, como capacidade de mensuração, desenho auxiliado por computador (CAD) e produção auxiliada por computador (CAM), tabelas de custos e análises de regressão. Além disso, são necessários métodos e práticas que capacitam o Custeio Alvo como a análise de exigência de cliente, a decomposição do custo alvo, a estimativa de custos, a análise dos trade-offs de custos, o monitoramento do status do custo alvo (ANSARI et al., 2006).

Ainda nesta fase existe a decisão de lançar o produto e começar sua produção ou não lançar. De acordo com os princípios do Custeio Alvo um produto só é lançado se conseguir trazer o retorno desejado pela organização, por isso, uma vez atingido o custo alvo o produto pode ser lançado e ter iniciado seu processo produtivo. Cooper e Slagmulder (1997) apontam que o Custeio Alvo se apoia na regra fundamental segundo a qual o custo alvo de um produto nunca pode ser excedido e sem isso o processo perde sua eficiência. No entanto, Camacho (2004) e Cruz e Rocha (2008) discutem que o gap entre o custo alvo e o custo estimado é igual a zero em termos teóricos, pois na prática o que ocorre é uma aproximação entre esses valores, devendo existir um intervalo de tolerância em que essa diferença seja aceitável pela organização. Assim, quando não se consegue atingir o custo alvo, nesse intervalo, deve haver uma decisão para lançar ou não o produto, ou seja, quebrar ou não a regra.

Sakurai (1997) menciona que uma vez iniciada sua fabricação as organizações podem continuar monitorando os custos do produto para checar se o mesmo está sendo produzido dentro do alvo e, nesta etapa de fabricação, ainda existem esforços para redução de custos e melhoria contínua, como a utilização do Kaizen e dos programas de qualidade. Dessa forma, em algumas organizações que usam o Custeio Alvo os custos são analisados e gerenciados antes da fabricação do produto e após o início de sua fabricação.

\subsubsection{Características das Informações Extraídas do Processo do Custeio Alvo}

Conforme apresentado anteriormente o objetivo do Custeio Alvo é gerenciar estrategicamente os custos antes que eles ocorram de forma a obter o retorno desejado pela organização considerando-se os requisitos dos clientes. Para que isso ocorra, as informações disponibilizadas pelo e para o mesmo devem ser capazes de cumprir esse intento. $\mathrm{Na}$ sequência foram discutidas algumas das características dessas informações de modo a poder 
verificar qual sua natureza preponderante (de acordo com a discussão de Ferreira e Otley, 2006, apresentada no item 3.1.1.1 deste Capítulo), sem a pretensão de esgotar o assunto. O objetivo dessa discussão é auxiliar as análises no que diz respeito à adequação entre o Custeio Alvo e os fatores contingentes investigados (conforme discussão no Capítulo 2 item 2.1.4).

O modelo de avaliação do desenho do SCG proposto por Ferreira e Otley (2006) e usado na presente pesquisa considera, para efeito de classificação das práticas de controle, o escopo da informação, conforme desenvolvido no estudo de Chenhall e Morris (1986), e outras características apresentadas na sequência. Chenhall e Morris (1986) avaliam a informação de acordo com seu foco (interno ou externo), a quantificação (financeira ou não financeira) e o horizonte de tempo (histórica ou prospectiva), sendo consideradas de amplo escopo as informações que apresentarem características de foco externo, não financeira e prospectiva; e de escopo estreito aquelas que apresentam as características contrárias.

De acordo com Ferreira e Otley (2006), as informações com características internas, financeiras, históricas, quantitativas, agregadas, imprecisas, simples, não sofisticadas, pouco dispendiosas e não personalizadas são classificadas como tradicionais. As informações tradicionais têm um caráter mais tático (GUILDING et al., 2000). Exemplos de práticas que reportam essas informações são o orçamento, o custeio padrão, o custeio baseado em atividades e os sistemas e técnicas de Contabilidade de Custos (SCAPENS, 2010).

As informações com características prospectivas, externas, não financeiras, qualitativas, oportunas, detalhadas, precisas, sofisticadas, complexas e caras são classificadas como contemporâneas (FERREIRA; OTLEY, 2006). O Custeio Alvo e o Custeio do Ciclo de vida do produto, por exemplo, são práticas que geram esse tipo de informação (FERREIRA; OTLEY, 2006, WICKRAMASINGHE; ALAWATTAGE, 2007). Na sequência as informações extraídas do processo do Custeio Alvo foram avaliadas em relação a essas características.

Por ser uma prática orientada pelo mercado, parte de suas informações são baseadas no ambiente externo. $\mathrm{O}$ foco externo da informação diz respeito às características e requisitos dos clientes, que são informações não financeiras e qualitativas e, ainda, o quanto os mesmos estão dispostos a pagar pelo produto. Embora em um primeiro momento essas questões sejam consideradas como um insumo do processo, ou seja, um dado, em fases posteriores são usadas para tomada de decisões de gestão de custos, tornando-se informações. Dessa forma, o custo 
máximo permitido reflete a característica externa da informação de forma financeira; e na fase em que se procura atingir o custo alvo as informações sobre os requisitos dos clientes (não financeiras) são usadas pela engenharia de valor de modo a conformá-las ao custo alvo, através da gestão desses custos. Informações coletadas dos fornecedores para avaliar o custo de materiais e componentes também é um exemplo de informação do ambiente externo usada no Custeio Alvo.

O retorno desejado pela organização advindo do planejamento do lucro reflete a estratégia e a gestão de médio a longo prazo, a depender da duração do ciclo de vida do produto. Isso porque o lucro desejado é calculado e estabelecido sobre o futuro produto, uma vez que é analisado na fase de projeto e deve ser considerado em relação a cada produto no intervalo de seu ciclo de vida. Dados relativos ao tamanho do mercado para o novo produto, sua participação nesse mercado, volume estimado de vendas e outros são analisadas e fazem parte do estabelecimento do retorno desejado. Essas informações têm características de orientação futura e externas.

Parte das informações do Custeio Alvo também reflete a característica de escopo estreito. Os cálculos dos custos de produção estimados, que são usados para obter o custo alvo, refletem em parte o foco interno da informação e o horizonte temporal histórico, uma vez que são baseados, também, em dados passados oriundos da organização. Existem exceções, como no caso do preço dos insumos a serem adquiridos.

Sobre o horizonte de tempo, Gordon e Narayanan (1984) argumentam que as informações ex ante pertencem aos eventos futuros e as ex post aos eventos passados. Algumas das informações sobre os custos estimados são baseadas em dados históricos (ex post) e as referentes ao custo máximo permitido tem natureza ex ante, uma vez que buscam refletir o presente antes da ocorrência do fato. Além disso, o custo máximo permitido reflete quanto um produto deverá custar, quando começar a ser fabricado, influenciando seu custo futuro. Isso caracteriza sua natureza de orientação futura e proativa. $\mathrm{O}$ objetivo de redução de custos e de lucratividade considerando o ciclo de vida do produto caracteriza a natureza de longo prazo para a gestão de custos e lucro. Ainda, para subsidiar a gestão dos custos são necessárias informações detalhadas e precisas a respeito dos mesmos (ANSARI et al., 1997), de modo a se poder verificar o impacto das decisões de redução em relação ao custo alvo considerandose as características dos produtos e dos requisitos dos clientes. 
Devido à grande quantidade de informações necessárias para o processo do Custeio Alvo e à sua complexidade, englobando várias fontes de dados como informação sobre preço de mercado, requisitos dos clientes, dados de custos, dados de fornecedores, do planejamento estratégico de lucro, dentre outras, sua obtenção não é facilmente acessível, devendo as organizações investir em sistemas capazes de prover as mesmas, o que as tornam caras (ANSARI et al., 1997).

Conforme a classificação relativa às características da informação apresentadas por Ferreira e Otley (2006), percebe-se que considerável parte das informações extraídas do processo do Custeio Alvo se encaixa no perfil das informações de escopo amplo e contemporâneas, sendo essa a classificação das informações do Custeio Alvo adotada nessa pesquisa.

Outra característica das informações do Custeio Alvo se refere à sua natureza estratégica, defendida por autores como Sakurai (1997), Guilding et al. (2000), Tani (1995), Monden (1995), Cooper e Slagmulder (1997), Chenhall e Langfield-Smith (1998a), Ansari et al, (2007). De modo a diferenciar as informações estratégicas das denominadas tradicionais, Chenhall e Langfield-Smith (1998b) esclarecem que as práticas de Contabilidade Gerencial tradicionais, tais como análise de variação de custos e medidas de desempenho baseadas no lucro, focam questões internas da organização e são financeiramente orientadas; em contraste, as técnicas contemporâneas combinam informações financeiras e não financeiras tendo um foco estratégico explícito.

Ansari et al. (2007) mencionam que o Custeio Alvo é uma abordagem estratégica para planejamento de lucro e não simplesmente um método de redução de custos. Práticas como o Custeio Alvo são consideradas estratégicas por afastar o custeio de uma questão de monitoramento para uma filosofia que é prospectiva e estreitamente alinhada com a questão da vantagem competitiva e, ainda, o foco externo subjacente a essas filosofias gerenciais se torna evidente quando é reconhecido que os mesmos são custeios orientados pelo mercado ao invés de preço orientado pelo custo (GUILDING et al., 2000).

Ewert e Ernst (1999) argumentam que uma das características do Custeio Alvo é que seu foco principal está no gerenciamento de custo no longo prazo, o que caracteriza sua natureza estratégica. Além dessa questão, o fato de o mesmo ligar a organização com seu ambiente, através das informações sobre os clientes, mercados, concorrentes etc. contribui de forma 
incisiva para sua orientação estratégica. Pelo exposto, pode-se verificar que as informações do Custeio Alvo possuem características estratégicas.

\subsubsection{Utilização do Custeio Alvo na Prática}

Sendo um processo que liga a organização ao seu ambiente de forma que consiga atingir seus objetivos em relação aos custos e por fim ao lucro, o Custeio Alvo necessita de alguns requisitos para que possa funcionar. Para Ansari et al. (1997) uma das implicações para sua prática é que para seu uso ser efetivo deve-se acreditar tanto em seus conceitos intelectuais construídos sobre a Teoria dos Sistemas Abertos quanto em seus princípios fundamentais que são enraizados na prática. A outra implicação é que o mesmo é tanto uma ferramenta de negócios quanto uma maneira holística de gerenciamento dos negócios.

Estudos empíricos buscam descrever como essa prática é feita nas organizações para que se possa ter um melhor entendimento a seu respeito. Na sequência, alguns desses achados são evidenciados para mostrar como e em que ambientes ele está sendo empregado. Os resultados relativos aos fatores contingentes foram evidenciados no Capítulo 2 item 2.1, não sendo repetidos aqui.

Tani et al. (1994) investigaram o uso do Custeio Alvo em empresas japonesas e descobriram que a taxa de adoção foi maior em indústrias de montagem, especialmente maquinaria, elétrica e eletrônica e equipamentos de transporte. Nesses setores o mesmo é implementado sistematicamente de forma corporativa, pelo menos em nível divisional. Embora com menor frequência, outros setores como as indústrias de processamento também têm usado o Custeio Alvo, como as indústrias químicas. Os departamentos que têm papel central no processo são planejamento do produto, desenvolvimento do produto, tecnologia de produção e contabilidade. Quando de sua adoção, o principal objetivo para sua utilização era a redução de custos e quando de seu uso efetivo o objetivo foi a redução de custos acompanhada pelo melhoramento da qualidade. Para $37,6 \%$ das empresas pesquisadas havia uma função específica para as atividades do Custeio Alvo. Em relação às áreas de atuação dos membros que compõem as equipes, os autores verificaram que a maioria era do setor de desenvolvimento, design, tecnologia de produção e compras. O setor de contabilidade foi o penúltimo ficando na frente apenas dos fornecedores que são externos à organização. A maioria das empresas respondeu que usam o processo apenas para as peças do modelo base e 
não para todos os produtos. Os custos que tiveram maior índice de resposta para entrar nas análises foram os custos diretos de conversão, os custos diretos de materiais e as partes compradas. Os custos dos concorrentes foi o mais frequente como fator chave para o estabelecimento do Custeio Alvo, ficando para trás fatores como planejamento de longo prazo e taxa de redução de custos. A maioria das empresas monitora o custo alvo durante a fabricação dos produtos. Muitas das empresas pesquisadas estão transferindo ou planejando transferir a prática para as subsidiárias estrangeiras motivadas principalmente pela cooperação com fornecedores.

No estudo de Dekker e Smidt (2003) assim como no de Tani et al. (1994) as indústrias de montagem foram as que tiveram a maior taxa de adoção da prática. A maioria das empresas que não adotou respondeu que a razão para isso é que a prática não foi considerada útil devido à natureza da companhia. Quanto aos objetivos iniciais para adoção e os benefícios do uso não mudaram no decorrer do tempo e o item preponderante nas respostas foi a redução de custos seguido pela introdução do produto no tempo oportuno. Quanto ao grau de importância dos departamentos envolvidos no processo os três primeiros são o desenvolvimento do produto, desenho do produto e compras e o último foi o departamento de finanças ou contabilidade. A maioria respondeu que o processo é organizado por equipes.

Swenson et al. (2003) estudaram quatro companhias que adotaram o Custeio Alvo para documentar suas melhores práticas e encontraram aspectos comuns em suas operações e na forma em que apoiaram o processo da prática. Todas tinham estruturas organizacionais muito eficientes, respondiam à "voz do cliente", agilizavam seu processo de desenvolvimento de produtos e engajavam ativamente sua cadeia de suprimento para atingir os objetivos do Custeio Alvo.

É possível observar pelo número de estudos mencionados que ainda existem poucos trabalhos que mostram como o Custeio Alvo é usado na prática e, mesmo sendo possível observar que muitos dos fundamentos e das características do Custeio Alvo são levados em conta pelas organizações, esse panorama reflete a necessidade de mais estudos a respeito dessa prática. 


\subsubsection{Conteúdo da Pesquisa Empírica em Relação ao Custeio Alvo}

O que foi apresentado sobre o Custeio Alvo é importante para que se possa delimitar como o mesmo foi investigado na presente pesquisa, por isso, na sequência os aspectos usados para verificar a adoção e a implementação dessa prática na Alfa foram apresentados.

Para efeito da pesquisa empírica, a adoção do Custeio Alvo significa que a organização está de alguma maneira utilizando essa prática, mesmo que não seja em sua totalidade. Por exemplo, está usando em algum projeto, ou ainda tem o envolvimento de poucos setores da empresa, ou ainda é algo incipiente. Então, a adoção se refere a indícios da utilização da prática mesmo que de forma parcial e esporádica.

Em relação às medidas usadas nas pesquisas analisadas sobre a adoção dessa prática, Dekker e Smidt (2003) usaram uma definição ampla de Custeio Alvo baseada em suas características gerais e no uso do conceito de custo máximo permitido para verificar se as empresas investigadas adotaram ou não essa prática. Esse tipo de abordagem em que se usa uma ampla noção do objeto em estudo requer muito cuidado na análise dos dados, pois em linhas muito gerais uma empresa pode responder que possui esse tipo de prática, no entanto, pode não ser bem assim pelo fato de não haver uma delimitação mais estreita em relação ao que se está investigando. Por exemplo, calcular a diferença entre o preço de mercado e o lucro desejado não significa necessariamente que se usa o Custeio Alvo, outros fundamentos e princípios são necessários para sua caracterização, conforme delineados anteriormente.

Como Dekker e Smidt (2003) consideraram as características do Custeio Alvo de forma ampla, muitos respondentes informaram que usavam outros nomes para a prática e, ainda, outras descrições sobre o que efetivamente usavam ou faziam em suas empresas. Isso pode ser problemático no sentido de que os achados da pesquisa podem conter vieses que mascaram ou dificultam a percepção do tipo de prática usada pela organização. Ou seja, o que a empresa está usando efetivamente é o Custeio Alvo? Everaert et al. (2006) também levantaram essa questão mencionando a necessidade de examinar as características da prática e seu significado como forma de evitar distorções nos resultados das pesquisas.

Ax et al. (2008) investigaram a adoção com base no instrumento de Dekker e Smidt (2003), mas usaram uma definição mais detalhada de Custeio Alvo contendo suas características principais de forma a delimitar sua abrangência. Nesse tipo de abordagem o risco de má interpretação por parte do respondente também existe, mas é menor em relação ao uso de 
definições muito amplas em relação ao objeto de estudo. Levando isso em consideração o presente estudo procurou abranger características do Custeio Alvo que refletem sua adoção ou não pela organização investigada, baseadas no custo máximo permitido como ponto de partida do processo levando em consideração os seguintes pontos:

- Existência de um processo de planejamento e controle de custos antes do lançamento de novos produtos;

- O processo de planejamento e controle de custos de cada produto começa com informações trazidas de fora da empresa, relativas ao preço máximo que pode ser praticado;

- $\quad$ Existência de uma meta individualizada para a margem a ser obtida com cada produto;

- Apuração do valor do custo máximo admissível para cada produto considerando o preço máximo que pode ser praticado e a margem objetivada;

- A decisão tomada quando o custo estimado do produto for maior que o máximo permitido.

Com essas informações foi possível verificar se a organização investigada adotou o Custeio Alvo e até que ponto usa seus conceitos fundamentais, tentando evitar uma possível confusão com outras práticas ou com o uso de apenas alguns aspectos do mesmo. Além disso, este tipo de medida não levou em consideração o nome da prática.

Em relação à implementação do Custeio Alvo, foi verificado o modo como vem sendo usado. O termo "implementação" foi escolhido por significar "Levar à prática por meio de providências concretas" (MICHAELIS, on line). Outro termo igualmente usado nos trabalhos analisados na fundamentação teórica se refere ao "uso" da prática. No entanto, pela definição de implementação esse termo se mostra mais completo por evidenciar as providências concretas que levam ao uso e não apenas o uso. Assim, para estar implementado necessariamente deve haver o uso e, além disso, o modo como está sendo usado.

A investigação sobre a implementação do Custeio Alvo relacionado à NSI e aos estágios do processo de institucionalização foi baseada no trabalho de Ansari et al. (2006), que descreve os passos com os requisitos mínimos necessários que uma organização deve ter e fazer para implementar o mesmo. Os requisitos são avaliados nos níveis técnico, comportamental, 
cultural, político e de comunicação e, ainda, os autores delinearam características necessárias para que o mesmo seja considerado institucionalizado na organização.

Tomando como base os princípios gerais do Custeio Alvo, Ansari et al. (2006) estabeleceram mudanças e procedimentos a serem seguidos para sua implantação, partindo das ideias iniciais de adoção pela organização. Na sequência foi feito um breve comentário sobre esses passos. Primeiro foi considerado o nível técnico que, de acordo com Ansari et al. (2006), inclui preocupações em relação às tarefas inerentes ao processo do Custeio Alvo, como formação de equipes multifuncionais, parcerias com os membros da cadeia de suprimento e investimentos em informação, processos e ferramentas importantes para o seu desenvolvimento.

No nível comportamental, Ansari et al. (2006) incluem considerações relacionadas ao comportamento desejado como o respeito entre os membros da equipe, a adoção de uma perspectiva voltada ao cliente, a eliminação de barreiras quando existirem, a busca pelas oportunidades de melhoria através dos dados de benchmark e a melhoria contínua através da cadeia de valor.

Considerando os fatores culturais, Ansari et al. (2006) mencionam que a organização deveria encorajar as decisões baseadas em fatos, a confiança e o foco no cliente, sendo que para permitir isso é necessário um ambiente com compartilhamento aberto e honesto das informações. Quanto às considerações políticas a adoção do Custeio Alvo muda o controle sobre recursos e conhecimento e, portanto, afeta os padrões de poder e influência na organização, então deve-se reconhecer essas mudanças e usar a arte da persuasão para resolver os problemas que possam surgir (ANSARI et al., 2006)

$\mathrm{O}$ aspecto da comunicação diz respeito à existência de planos de comunicação sobre seu processo de modo a manter todos informados sobre o que acontece em sua implementação (ANSARI et al., 2006). Assim, o comentário se refere apenas à comunicação acerca do processo durante a implementação; no entanto, outro aspecto também foi avaliado: a comunicação das informações extraídas do Custeio Alvo para os interessados. Devido à necessidade da equipe multifuncional no processo, vários membros são ao mesmo tempo provedores e usuários das informações, além da alta gestão que é seu usuário por excelência. Por isso, acredita-se que investigar esse tipo de comunicação também é importante, principalmente quando o mesmo já esteja implementado, como forma de verificar se tais informações são efetivamente usadas e disseminadas entre os membros e outros interessados. 
Ansari et al. (2006) também sugerem algumas preocupações relacionadas à institucionalização do Custeio Alvo e nesse sentido estabelecem seis características que devem ser avaliadas. A primeira se refere ao imperativo estratégico de que o Custeio Alvo, assim como qualquer atividade principal que apoia a estratégia competitiva da organização, deve ser um processo padrão requerido toda vez que um novo produto seja desenvolvido ou quando algum seja reprojetado (ANSARI et al., 2006).

A segunda diz respeito à incorporação do mesmo nas políticas formais e nos manuais de procedimentos que servem como um guia para o comportamento organizacional e codificação das rotinas (ANSARI et al., 2006). A terceira menciona que o Custeio Alvo deve ter uma sede oficial que pode variar de acordo com o tipo de produto e de organização, por exemplo, empresas que exigem amplos investimentos de capital no desenvolvimento de um novo produto podem sediar o mesmo no setor de finanças.

A quarta se preocupa com as medidas de desempenho em que informações do Custeio Alvo podem ser usadas como inputs de outras práticas como o Balanced Scorecard (ANSARI et al., 2006). A quinta característica menciona a existência de recompensas e compensação para os envolvidos no processo de forma a motivar a participação e o engajamento no mesmo (ANSARI et al., 2006). A última lida com a cultura organizacional e menciona que quando o Custeio Alvo já está incorporado nas rotinas da organização ele se torna um "modo de vida" e os líderes devem reforçar esta abordagem conversando com os envolvidos sobre suas atividades e sobre seu sucesso para a organização (ANSARI et al., 2006).

A inclusão de todos esses requisitos no instrumento de coleta de dados permitiu uma investigação abrangendo vários níveis e vários temas acerca da implementação do Custeio Alvo, possibilitando que os dados coletados pudessem auxiliar na percepção de aspectos importantes do processo de institucionalização bem como no reconhecimento do estágio em que o mesmo se encontra institucionalizado, de acordo com o modelo de Hasselbladh e Kallinikos (2000).

Delineados os pontos relevantes acerca da fundamentação teórica e do objeto de pesquisa, no próximo capítulo foi apresentada a trajetória metodológica que serviu como base para o estudo empírico. 


\section{TRAJETÓRIA METODOLÓGICA}

A presente pesquisa teve como objetivo verificar as deduções e inferências que podem ser extraídas acerca da adoção e implementação do Custeio Alvo à luz da teoria da Contingência e da NSI. O Referencial teórico evidenciado nos Capítulos 2 e 3 foi levantado com o intuito de guiar as análises e identificar os fatores relevantes que circundam esse processo. Tão importante quanto saber o que fazer e qual a fundamentação teórica que vai auxiliar na busca por respostas é conhecer o caminho que leva às respostas, ou seja, o como fazer. Para elucidar essa questão, na sequência foram delineados os principais pontos relativos à trajetória metodológica empregados nessa pesquisa.

\subsection{Delineamento Geral da Pesquisa}

Para que a pesquisa empírica se alinhasse aos objetivos estabelecidos foi escolhida a estratégia de estudo de caso único. Abordagens como o estudo de caso são justificadas dentre outras questões, quando o fenômeno específico a ser estudado só pode ser captado por observação ou interação, ou ainda quando o que se quer conhecer é o funcionamento de uma estrutura social em que o estudo do seu processo se torna necessário (MARTINS; THEÓPHILO, 2007). Isso vai ao encontro da proposta de estudar o processo de institucionalização do Custeio Alvo.

Além disso, ressalta-se que as questões investigadas nessa pesquisa podem ser elucidadas usando-se essa estratégia. A esse respeito, Cooper e Morgan (2008) mencionam que a sensibilidade em relação ao contexto proporcionada pelo estudo de caso permite e encoraja pesquisadores a considerarem questões que podem não ser averiguadas com outras abordagens de pesquisa, sendo o mesmo extremamente útil para levantar questões, destacar questões, desenvolver e testar teorias e fornecer um guia para a solução de problemas.

Scapens (2004) também destaca que estudos de caso são essenciais para entender a natureza da prática da Contabilidade Gerencial nas organizações contemporâneas e Dekker e Smidt (2003) afirmam que a pesquisa em profundidade, como o estudo de caso, pode ser a metodologia de pesquisa adequada para descobrir como práticas do tipo do Custeio Alvo são 
realmente concebidas e utilizadas. Feitas essas observações, entende-se que essa estratégia se mostrou adequada visto que interessa entender o funcionamento do Custeio Alvo e de seu significado para a empresa, justificando sua escolha.

Quanto aos aspectos epistemológicos e ontológicos esse trabalho foi baseado na interpretação e numa visão de mundo intersubjetiva, em que a realidade é socialmente construída. Essa escolha se deve à necessidade de entender aspectos da Contabilidade Gerencial, e especificamente do SCG, não necessariamente relativos aos "números" que são apresentados. Para Carruthers (1995), a Contabilidade tem sofrido com uma reputação desmerecida e enganosa de ser considerada como um tópico estreito e técnico. Esses adjetivos são empregados no sentido de que a Contabilidade se restringe a apresentar a situação patrimonial de uma organização através de técnicas amplamente aceitas e que demonstram uma situação de forma estática, através de uma única perspectiva. Nesse sentido, Morgan (1988) argumenta que a Contabilidade é estruturada por uma metáfora abrangente que incentiva uma visão numérica da realidade.

Essa é uma discussão epistemológica que identifica a Contabilidade com uma visão puramente quantitativa e que busca um afastamento do seu objeto, o patrimônio das organizações. Quantificar e evidenciar o patrimônio sob este ponto de vista afasta a Contabilidade de questões como poder, conflito, racionalidade, interesses dentre outras que emergem de comportamentos e muitas vezes não podem ser quantificáveis, mas sim entendidas.

Morgan (1988) sugere outra perspectiva para a Contabilidade a qual reconhece que os sistemas contábeis fazem mais do que monitorar ou espelhar a realidade, eles também modelam a mesma e, pode-se acrescentar, também são modelados por ela. Embora esses comentários se referem à Contabilidade de um modo geral, mais especificamente também existe esse movimento no caso da Contabilidade Gerencial (maiores detalhes ver em OTLEY, 2001; BERRY et al., 2009; BAXTER; CHUA, 2003).

Essa mudança epistemológica aponta para uma visão interpretativa da realidade e a consideração de aspectos que não podem ser quantificáveis. Para Llewellyn (1993) a pesquisa interpretativa procura verificar as conexões entre o sujeito e o objeto e entre os significados e as práticas. Baker e Bettner (1997) mencionam que a pesquisa interpretativa busca descrever, entender e interpretar os significados que os atores aplicam aos símbolos e às estruturas aos 
quais se encontram. Por isso, a inclinação para uma visão interpretativa que busca entender a construção da realidade ${ }^{14}$, ao invés apenas da sua representação, foi o ponto de partida para o estabelecimento do problema investigado nessa pesquisa, bem como para a busca das respostas.

A pesquisa empreendida também possui um enfoque sistêmico, uma vez que investigou o fenômeno à luz de fatores (contingentes, institucionais e econômicos) relacionados tanto ao ambiente interno quanto externo à organização como forma de entender o problema. Burrell e Morgan (1979) comentam que o conceito de sistemas abertos é essencialmente processual e os mesmos são caracterizados por uma troca com seu ambiente se engajando em transações de modo a importar, exportar e mudar eles mesmos no processo. Essa pesquisa buscou entender o funcionamento do Custeio Alvo não de forma reducionista, mas no que diz respeito às suas interações com os ambientes interno e externo, que podem sofrer pressões de fatores contingentes, institucionais e econômicos sendo, portanto, empregadas as características da abordagem sistêmica.

Quanto à ontologia, Crotty (1998) discute que a pesquisa interpretativa é compatível tanto com a visão realista quanto com a relativista. Essas duas formas de considerar o fenômeno se mostraram adequadas ao objetivo do estudo, em especial no tocante às análises que envolveram a NSI, sendo, portanto, ambas empregadas na pesquisa. A realista por estar considerando a descrição do Custeio Alvo e de seu significado na organização investigada. A relativista por considerar que a construção da realidade (no caso do significado e da forma de resposta estratégica) não gera significados absolutos, os mesmos podem mudar no decorrer do tempo e no espaço sendo, portanto, relativos ao contexto espaço temporal em que a pesquisa foi empreendida.

Em relação ao tratamento dos dados nos estudos de caso a evidência pode ser qualitativa e quantitativa (EISENHARDT, 1989; YIN, 1981) ou apenas qualitativa (GODOY, 2006). Nessa pesquisa foi usada a abordagem qualitativa. Para Creswell (2007) a pesquisa qualitativa começa com suposições, uma visão de mundo, o possível uso de lentes teóricas e o estudo de questões de pesquisa que se preocupa com os significados que indivíduos ou grupos atribuem a um problema social ou humano. Martins e Theóphilo (2007) abordam a pesquisa qualitativa e argumentam que em função dos propósitos e das abordagens metodológicas empreendidas

\footnotetext{
${ }^{14}$ A construção da realidade nesse trabalho tem o mesmo sentido daquele apresentado por Berger e Luckmann (1967) em relação ao processo de institucionalização das instituições.
} 
em alguns tipos de pesquisa as informações, dados e evidências obtidas não são passíveis de mensuração, ao invés disso, pedem descrições, compreensões, interpretações e análises de informações, fatos, ocorrências e evidências que naturalmente não são expressas de forma numérica.

Segundo Maanen et al. apud Cooper e Schindler (2003, p. 132) "Qualidade é o caráter ou a natureza essencial de alguma coisa [...]. Qualitativo se refere ao significado, à definição, à analogia, ao modelo ou à metáfora caracterizando alguma coisa [...].” A pesquisa qualitativa implica capturar os significados e interpretações que os atores atribuem subjetivamente aos fenômenos a fim de descrever e explicar o seu comportamento através da investigação de como eles vivenciam, sustentam, articulam e compartilham com os outros estas realidades diárias socialmente constituídas (JOHNSON et al., 2006).

Outro fato interessante da pesquisa qualitativa é que a mesma enfatiza o processo e não o resultado (TRIVIÑOS, 2008; MARTINS; THEÓPHILO, 2007), ou seja, a forma como as explicações vão emergindo durante a investigação é mais importante do que o resultado encontrado através dela. A orientação pelo processo visa esclarecer de forma profunda como determinado fenômeno ocorre e é entendido. Os comentários evidenciados se aproximam do que foi proposto nesse trabalho, por isso, a escolha da abordagem qualitativa.

Ainda em relação ao delineamento da pesquisa, é interessante atentar para a questão das triangulações, uma vez que, de acordo com Lapsley (2004) quanto mais pontos de triangulação na pesquisa maior a probabilidade de obtenção de informações válidas e confiáveis. Nesse trabalho foi empregada a triangulação de fontes de dados que, segundo Martins e Theóphilo (2007), é o tipo de triangulação mais usada pelos pesquisadores. Nesse caso a triangulação se deu entre os dados das entrevistas e os dados da pesquisa documental.

Outro ponto importante em relação à pesquisa é abordado por Eisenhardt (1989), em que a comparação dos conceitos, teorias ou hipóteses emergentes com a literatura existente é um passo importante das pesquisas de estudo de caso e a chave deste processo é a consideração de uma ampla gama de literatura. Por isso, houve uma preocupação com o referencial teórico nesse trabalho de modo que o mesmo abordasse todos os pontos considerados bem como os principais autores em cada assunto. Isso é importante, pois amarrar os achados da pesquisa com a fundamentação teórica aumenta a validade interna do estudo (EISENHARDT, 1989). 
Eisenhardt (1989) comenta ainda que as literaturas que são conflitantes com os achados da pesquisa representam uma oportunidade, pois a justaposição de forças conflitantes força os pesquisadores a um modo de pensar mais criativo e o resultado pode ser uma análise mais profunda. Esse também foi um ponto observado na pesquisa empírica de modo que quando a literatura se mostrou divergente dos achados estes pontos foram investigados na busca por um aprofundamento acerca da questão, como forma de contribuir com a teoria ou de rever a forma de abordagem do problema.

Quanto ao nível de análise da pesquisa foi o organizacional, relativo à empresa objeto do estudo de caso e a unidade de análise foi composta pelos entrevistados na empresa. Detalhes sobre os entrevistados e as entrevistas foram esclarecidos em tópicos subsequentes.

\subsection{Coleta dos Dados}

O estudo de caso é uma estratégia que para atingir seu objetivo utiliza várias técnicas de pesquisa e coleta de dados. Os estudos de caso combinam técnicas de coleta de dados como entrevistas, arquivo, questionários, relatórios verbais e observações (EISENHARDT, 1989; YIN, 1981). Nessa pesquisa foram usadas as técnicas de pesquisa documental e de entrevista semi-estruturada, sendo ambas as fontes de dados primárias.

O objetivo da pesquisa documental foi levantar informações que pudessem subsidiar o conteúdo das entrevistas e também auxiliar no conhecimento da organização estudada. Para tanto, foram feitos levantamentos de informações pertinentes em fontes públicas como jornais e revistas da mídia de massa publicadas na web e levantamento de informações pertinentes nos sites da web oficiais da matriz e da Alfa. Os dados coletados nos sites são relacionados principalmente à forma como a empresa lida com a questão de relacionamento com fornecedores, com clientes, com os valores da organização, com funcionários, dentre outros. Ainda, a forma como dissemina seus valores entre os funcionários e entre as empresas do grupo.

Essas informações expostas na forma textual puderam auxiliar a triangulação com os dados coletados nas entrevistas, podendo confirmar evidências encontradas. Além disso, a análise desse tipo de discurso (textos corporativos) pode trazer à tona pontos não captados nas entrevistas. Nesse sentido, existe a questão de que os textos corporativos estão impregnados 
de mensagens que visam expor a organização de forma positiva perante a sociedade, mas também existe a preocupação a este respeito por parte da pesquisadora tendo-se o cuidado de filtrar as informações e sempre que possível confrontar os textos com o conteúdo das entrevistas e, quando existirem, com textos de jornais e revistas da mídia de massa que reportam a Alfa.

Yin (2010) menciona como pontos fortes da pesquisa documental a estabilidade, uma vez que a informação pode ser revista repetidamente; sua discrição pelo fato de não ser criada em função do estudo de caso; sua exatidão por conter nomes, referências e detalhes exatos de um evento e uma ampla cobertura, pois pode cobrir um longo período de tempo, muitos eventos e muitos ambientes. Esse tipo de informação também tem a vantagem de contextualizar o ambiente externo e o ambiente interno da organização investigada. As informações sobre os planos da empresa e sobre as relações com os envolvidos, suas crenças e valores permitem uma contextualização a seu respeito. Nos estudos que tratam da institucionalização o aspecto contextual é importante, uma vez que uma instituição é construída pelos envolvidos em seu contexto social.

Quanto ao uso da entrevista semi-estruturada, Triviños (2008) menciona que se trata de uma das mais importantes técnicas de coleta de dados nos estudos de caso com enfoque qualitativo, pois tanto valoriza a presença do investigador quanto oferece todas as perspectivas possíveis para que o informante alcance a liberdade e a espontaneidade necessárias. O levantamento pelas entrevistas buscou extrair a opinião dos entrevistados sobre os assuntos investigados. Destaca-se que durante algumas entrevistas foram mostradas algumas informações oriunda do processo do Custeio Alvo disponibilizadas no sistema gerencial da Alfa. Essas informações foram usadas apenas como exemplo da aplicação da prática na empresa, não sendo escopo da pesquisa avaliar as mesmas. Ainda, foi feita uma visita na fábrica em que vários aspectos discutidos nas entrevistas puderam ser observados.

Como se buscou um entendimento acerca do funcionamento do Custeio Alvo tem-se como condição necessária que a organização investigada tivesse pelo menos adotado o mesmo, por esta razão o caso foi selecionado por conveniência. O nome da organização investigada surgiu através de uma conversa sobre a possibilidade de a mesma ter adotado a prática uma vez que se trata da subsidiária de uma empresa asiática que a literatura especializada aborda como sendo usuária do Custeio Alvo. Como mencionado anteriormente essa empresa foi denominada de Alfa. Primeiro foi feito contato via telefone com o chefe de controle de custos 
que verificou junto ao presidente da organização a possibilidade de participarem do estudo. Dois dias após foi dada a resposta positiva para a participação, isso ocorreu em julho de 2010.

Para que as informações obtidas pela entrevista pudessem ser filtradas em relação ao seu conteúdo diminuindo vieses oriundos de julgamentos pessoais individuais optou-se por entrevistar diferentes pessoas na mesma organização. Com isso foi possível triangular as informações entre as entrevistas obtidas, o que aumenta a confiabilidade acerca das opiniões sobre o objeto em análise. Seguindo essa linha de raciocínio, foi entrevistado um funcionário que lida diretamente com o processo do Custeio Alvo, ligado basicamente ao fornecimento de informações (setor de controle de custos), outro que tanto fornece informações quanto utiliza as informações fornecidas por outros setores (setor de desenvolvimento e compras) e dois ligados à alta gestão, sendo usuários das informações oriundas do processo (presidente e diretor industrial). O resultado foi a obtenção de quatro visões sobre o mesmo objeto permitindo comparações no intuito de extrair as percepções comuns a seu respeito.

Um ponto importante neste tipo de procedimento é que alguns tipos de questão podem não fazer sentido a depender do entrevistado. Por exemplo, perguntas sobre informações técnicas de custos ou sobre o processo de forma mais profunda não são de interesse ou talvez do conhecimento do presidente e do diretor industrial. Além disso, o tempo disponível de cada entrevistado pode ser diferente devendo o roteiro ser ajustado a esse fator. Por isso, foi formulado um instrumento de coleta de dados que pudesse ser ajustado a cada entrevistado de acordo com o tipo de informação que o mesmo pudesse oferecer bem como ao tempo disponível para a entrevista.

As entrevistas foram feitas em duas rodadas. A primeira foi marcada para 13/04/2011 na sede da empresa e, nessa mesma ocasião foram entrevistados nessa ordem: o presidente da Alfa, a duração da entrevista foi de 12 minutos e foi acompanhada pelo Diretor Financeiro e uma tradutora visto que este último não falava português, ressalta-se que devido aos compromissos do presidente da organização a entrevista não pode ser mais longa; o gerente de desenvolvimento e compras, a duração da entrevista foi de 22 minutos e 15 segundos e o chefe de controle de custos, a duração foi de 52 minutos e 45 segundos. Pelo fato de o chefe de controle de custos ter sido o contato na empresa o mesmo acompanhou as demais entrevistas. 
As entrevistas foram realizadas na sala de reuniões na sede da Alfa e todas foram gravadas com consentimento dos envolvidos e transcritas posteriormente. Por se tratar de um roteiro semi-estruturado, algumas questões precisaram ser ajustadas de acordo com o respondente e outras não foram questionadas devido às características apresentadas pela Alfa. Por exemplo, as questões referentes ao período da implantação do Custeio Alvo não puderam ser feitas uma vez que isso se deu provavelmente na década de 1970 e todos os respondentes estavam na empresa, na data da entrevista, há menos tempo.

A segunda rodada de entrevistas foi marcada para 31/05/2012 na sede da empresa e foram entrevistados nessa ordem: o diretor industrial, a duração da entrevista foi de aproximadamente 45 minutos e novamente o chefe de controle de custos, a duração foi de 21 minutos aproximadamente. As entrevistas foram realizadas na sala do presidente na sede da Alfa e, desta vez, não foi obtido o consentimento para a gravação das mesmas. Os comentários foram transcritos no momento das entrevistas.

Ressalta-se que, embora fossem entrevistas semi-estruturadas o número total de questões (sessenta e oito) foi expressivo, considerando-se esta modalidade. No entanto, devido aos vários aspectos que precisavam ser esclarecidos e que foram duas rodadas e quatro pessoas entrevistadas, não se encontrou outra forma a não ser abranger os pontos necessários. As questões foram direcionadas de acordo com o entrevistado e, por isso, cada um respondeu parte do roteiro e não o total de questões e, sempre que possível, os entrevistados eram estimulados a aprofundar alguns assuntos ou eram questionados sobre pontos que emergiam dos próprios comentários, complementando o roteiro. Maiores detalhes sobre o instrumento estão apresentados no item 4.2.1.

É importante ressaltar que a forma de uso dos dados dessa pesquisa, oriundos das coletas tanto na web quanto nas entrevistas, garantem o anonimato dos entrevistados e da empresa investigada. Quaisquer características ou detalhes que remetam ao nome da organização foram omitidos e as fontes de tais informações foram mantidas em sigilo, podendo ser evidenciadas apenas quando requisitado por instâncias competentes. A omissão do nome da organização e dos participantes da pesquisa é um direito garantido que respeita questões éticas nas pesquisas em Ciências Sociais. 


\subsubsection{Instrumento de Coleta de Dados}

O instrumento de coleta de dados foi usado para as entrevistas, sendo as mesmas semiestruturadas e do tipo focada. De acordo com Yin (2010) a entrevista focada é feita em um período de cerca de uma hora e pode ser aberta ou seguir um determinado conjunto de questões. $\mathrm{O}$ instrumento completo de coleta de dados foi apresentado no Apêndice 1 dessa tese, cujo modelo apresentado contém, em alguns casos, objetivos das questões e as âncoras usadas para as análises; isso foi feito para facilitar o entendimento do mesmo, em especial, para aqueles que irão consultá-lo em suas investigações. Ressalta-se que a versão aplicada nas entrevistas não continha informações como bibliografia base nem as âncoras usadas em algumas questões.

É importante mencionar que o instrumento inicialmente estabelecido passou por um pré-teste com o intuito de verificar sua aplicabilidade e ajustar possíveis problemas nas questões. A entrevista pré-teste foi feita com uma pessoa que trabalhou em uma empresa que usava uma prática com algumas características do Custeio Alvo e, ainda, havia elaborado um trabalho acadêmico de mestrado nessa área. Por isso, foi uma pessoa com um perfil chave para participar do pré-teste. A entrevista pré-teste durou uma hora e dez minutos. Após a entrevista seguida pelo roteiro (instrumento de coleta de dados) foram colocados os pontos fracos que necessitavam de ajustes. Após discussões foram feitos os ajustes pertinentes e estabelecida sua versão final.

Os trabalhos e temas discutidos na fundamentação teórica se constituíram na base para o desenvolvimento das questões. O roteiro possui informações sobre a identificação dos entrevistados e blocos de assuntos relacionados ao objeto investigado compreendendo a "adoção e implementação do Custeio Alvo", os "fatores contingentes", o "uso do Custeio Alvo", o "desempenho" e os "estágios do processo de institucionalização". Foram apresentados na fundamentação teórica (Capítulo 2 e 3) os trabalhos analisados que serviram de base para a elaboração do instrumento de acordo com cada assunto.

Quando uma questão elaborada teve por base um material bibliográfico este foi indicado na mesma. Para facilitar a interface com os entrevistados procurou-se fazer, na medida do possível, questões curtas em uma linguagem simples sem uso de termos técnicos ou muito restritos a linguagem acadêmica. Devido à quantidade total de questões (sessenta e oito), quando possível as mesmas foram elaboradas com formato fechado, mas sempre deixando 
campo para maiores explicações por parte dos entrevistados uma vez que o aprofundamento nas respostas é positivo para auxiliar nas análises.

O campo de identificação possui seis questões das quais quatro identificam o entrevistado, uma o ramo de atuação e outra se refere a um dos fatores contingentes analisados (porte). $\mathrm{Na}$ primeira rodada de entrevistas, o primeiro bloco se referiu à adoção e implementação do Custeio Alvo. Conforme discutido no Capítulo2 item 2.3.8, quanto à adoção buscou-se desenvolver uma forma de avaliação que levasse em consideração alguns aspectos envolvidos na utilização do Custeio Alvo, evitando questões dicotômicas do tipo "usa ou não usa", uma vez que isso pode induzir a resposta e torná-la superficial. Além disso, questionar sobre a utilização do Custeio Alvo pode incorrer no problema de a organização usar a prática, mas não tratá-la por este nome, conforme abordado na literatura (DEKKER; SMIDT, 2003), podendo distorcer os resultados. Foram elaboradas cinco questões (itens 7.1 a 7.5) buscando ao mesmo tempo descrever etapas do Custeio Alvo e oferecer indícios de utilização destas na Alfa.

Foram elaboradas outras questões relacionadas à adoção da prática (item 8), fatores ligados à sua adoção (item 9), seus antecedentes técnicos/econômicos (item 10) e institucionais (item 11 e 12), bem como outros pontos (itens 13 e 14). Ainda existem duas questões (itens 15 e 16) que abordam tanto a adoção quanto a implementação e foram elencados na literatura pesquisada (ANSARI et al., 2006) como tendo importância no processo de adoção.

As questões sobre a implementação do Custeio Alvo também fazem parte do primeiro bloco do roteiro da entrevista e, conforme discutido no Capítulo 3 item 3.2.8, foi focada no trabalho de Ansari et al. (2006), que evidencia os passos e as etapas que uma organização deve considerar para implementar o Custeio Alvo. Estas etapas são separadas em níveis sendo o técnico, o comportamental, o cultural e o político. Ainda, aborda pontos relativos à comunicação e à institucionalização. Essa questões estão dispostas do item 17 ao 44 do roteiro.

O segundo bloco se refere às categorias investigadas com base na Teoria da Contingência. As questões foram desenvolvidas tendo por base as medidas dos fatores e dos demais itens usados em trabalhos publicados e analisados na fundamentação teórica (Capítulo 2, item 2.1.5) para este objetivo. Foram avaliados na primeira rodada os fatores ambiente, composto pela concorrência e pela incerteza ambiental e as estratégias, compostas pelo posicionamento 
de mercado, pelas características do mercado e pelo ciclo de vida. Os itens vão da questão 45 à 48 do roteiro. $\mathrm{O}$ fator porte está na seção de identificação.

O item 45 foi ancorado em dois níveis para as respostas, sendo um representando o mínimo e o outro o máximo, como forma de avaliar o fator. Por se tratar de pesquisa qualitativa essas âncoras serviram apenas como indicativo para facilitar as resposta, podendo os entrevistados optar por níveis intermediários ou até outras respostas, mas isso não ocorreu em nenhum caso. É importante reforçar que embora as âncoras tenham sido numeradas (1 e 2), seu objetivo foi facilitar a coleta dessas informações. O objetivo foi captar a opinião de acordo com os indicativos da âncora e considerar essas respostas como dados qualitativos que não sofreram qualquer tipo de tratamento estatístico, sendo somente interpretados à luz da teoria de base. Informações sobre a forma de classificação e interpretação desse tipo de resposta foram abordadas no item 4.4.1.

O terceiro bloco se refere aos estágios do processo de institucionalização e as questões foram baseadas no trabalho de Hasselbladh e Kallinikos (2000), discutido no Capítulo 2 item 2.2.3. Essa parte abrange os itens 49 à 51 do roteiro. Além dessas, outras questões elaboradas no bloco de implementação também tiveram o objetivo de captar informações sobre esse processo.

$\mathrm{Na}$ segunda rodada de entrevistas foram investigados os fatores contingentes estrutura, tecnologia da informação e tecnologia da produção (questões 52 a 63) e os detalhes dessas avaliações foram apresentados no Capítulo 2 item 2.1.5. O uso do sistema (questão 64) e o desempenho do sistema (questões 65 a 67) foram outros itens avaliados e foram discutidos no Capítulo 3 item 3.1.2. Foi elaborada também uma questão sobre a importância do Custeio Alvo. Com exceção da última questão todas foram ancoradas da mesma forma que a questão 45 da primeira rodada.

Um aspecto importante considerado na elaboração do instrumento de coleta de dados é a sua validade e confiabilidade e, pelo fato de a estratégia escolhida nesse trabalho ser o estudo de caso alguns pontos foram considerados. Para Martins e Theóphilo (2007) a validade se refere à capacidade do instrumento em medir o que de fato se propõe medir e a confiabilidade se relaciona à constância dos resultados obtidos.

A confiabilidade garante a possibilidade de replicação de um estudo, estando implícito que o pesquisador deve seguir certos procedimentos inerentes à pesquisa científica. Nesse sentido, a 
replicação com resultados constantes não pode ser considerada nesse tipo de pesquisa, uma vez que o estudo de caso visa analisar em profundidade certo aspecto da vida social de forma a interpretá-la não sendo base para generalização de comportamentos.

Scapens (2004) argumenta que no estudo de caso a confiabilidade é processual, ou seja, se baseia na importância de saber se o pesquisador adotou métodos e procedimentos adequados e confiáveis. A pesquisa deve ter um bom projeto que mostre as questões de pesquisa, um plano de pesquisa, notas de campo coerentes e abrangentes e uma análise documentada, isso faz com que o pesquisador demonstre que os achados do estudo de caso são confiáveis e, em termos contábeis isso pode ser descrito como uma trilha de auditoria (SCAPENS, 2004).

Situações como o fato de que o próprio instrumento de coleta de dados pode ser alterado no decorrer da pesquisa, novos dados que não foram previstos e que podem ser inclusos nas análises dentre outros são fatores inerentes a este tipo de abordagem e lhe dão uma peculiaridade em relação a outras estratégias. No entanto, por se tratar de pesquisa científica a confiabilidade deve ser assegurada esclarecendo esses aspectos, o que foi feito nessa pesquisa.

Outra forma de obter confiabilidade em estudos de caso é através da triangulação das fontes de evidências. Como geralmente não se tem possibilidade de replicar um caso, sua confiabilidade será mostrada fundamentalmente por triangulações de dados, fruto da prática de diversos instrumentos de coleta de dados, encadeamento de evidências e rigor em todos os procedimentos realizados ao longo de toda pesquisa (MARTINS, 2008). Conforme comentado anteriormente este quesito foi considerado nesse trabalho pela escolha de diferentes fontes de dados (diversos entrevistados e pesquisa documental) e sua triangulação.

Quanto à validade Martins e Theóphilo (2007) apontam que se trata de um critério de significância de um instrumento de medidas. No desenvolvimento do roteiro das entrevistas foram observados alguns cuidados em relação à validade, em especial, relacionando as questões com a fundamentação bibliográfica. No entanto, por ser um roteiro semi-estruturado que pode ser passível de mudanças durante sua aplicação, a questão da validade também não pode ser tão rígida quanto em um estudo de abordagem quantitativa. Além do mais o roteiro de entrevista não foi preparado para quantificar o fenômeno e sim para entendê-lo, portanto, isso tem que ser considerado no tocante à validade. Dessa forma, sempre que possível procurou-se esclarecer em detalhes como os itens foram investigados. 


\subsection{Tratamento dos Dados}

Para Berger e Luckmann (1967) as definições de realidade são constituídas através de processos linguísticos e para Phillips et al. (2004) a linguagem é fundamental para a institucionalização. Alvesson e Karreman (2000) comentam que a linguagem está cada vez mais sendo entendida como o fenômeno mais importante na pesquisa social e organizacional, sendo acessível para a investigação empírica. Feitos esses comentários e considerando-se a natureza qualitativa desta pesquisa, a linguagem ou o discurso foi usado como fonte dos dados, tanto na pesquisa documental quanto nas entrevistas, sendo os mesmos tratados mediante a técnica de análise de conteúdo.

De acordo com Bardin (1977), a análise de conteúdo é um conjunto de técnicas usadas para analisar as comunicações e seu objetivo descrever, inferir e interpretar o conteúdo das mensagens. Desse modo, essa técnica pode ser usada para analisar os significados extraídos dos discursos e não apenas a forma das mesmas, o que pareceu apropriado para o objetivo desse trabalho.

Essa técnica possui dois enfoques, o quantitativo, no qual o que serve de informação é a frequência com que surgem certas características do conteúdo; e o qualitativo, que é a presença ou a ausência de uma dada característica de conteúdo ou de um conjunto de características num determinado fragmento de mensagem que é levado em consideração (BARDIN, 1977). Com base nessas declarações a análise de conteúdo foi empregada nessa pesquisa apenas em seu enfoque qualitativo, ou seja, a preocupação foi verificar a presença e a interpretação de características relativas aos aspectos investigados.

Dentre as várias técnicas discutidas por Bardin (1977) a análise temática ou categorial diz respeito à análise dos significados com a finalidade de interpretar as comunicações. Nesse tipo de análise, segundo Bardin (1977), busca-se descobrir os núcleos de sentido que compõe a comunicação, sendo que sua presença pode significar alguma coisa para o objetivo analítico escolhido. Por isso, a mesma se mostrou apropriada para utilização nesta pesquisa. Essa técnica trabalha com rubricas significativas que permitem a classificação dos elementos de significação constitutivos da mensagem, podendo ser separadas em unidades de registro e unidades de contexto (BARDIN, 1977).

A unidade de registro se refere a unidade de significação a codificar, podendo ser uma palavra, um tema, uma frase; a unidade de contexto serve de unidade de compreensão para 
codificar a unidade de registro (BARDIN, 1977). Nessa pesquisa a unidade de contexto foi separada nos aspectos investigados com base na Teoria da Contingência e na NSI e, a unidade de registro foi separada por tema. O tema enquanto unidade de registro corresponde a uma regra de recorte de sentido e não de forma, e geralmente é usado quando a finalidade é estudar as motivações de opiniões, de atitudes, valores, crenças e tendências (BARDIN, 1977).

Como unidades de registro foram definidos os temas investigados relativos à NSI. Assim, os fatores institucionais, os fatores econômicos, os conflitos e ambiguidades e a forma de institucionalização foram recortados como sendo temas a serem investigados nas mensagens. Desta forma, a menção nas entrevistas ou nos textos corporativos de qualquer um dos temas investigados é suficiente para indicar o significado para, posteriormente, ser interpretado à luz das teorias utilizadas. Além da presença das unidades de registro também foram avaliadas as co-ocorrências, que é quando o discurso referente a um tema tangencia ou remete a outro tema (BARDIN, 1977). Uma parte de uma matriz de avaliação foi apresentada no Apêndice 2, como exemplo.

A análise de conteúdo foi usada nessa pesquisa para mapear o entendimento e os significados que os entrevistados atribuem ao fenômeno investigado; buscar e analisar as regularidades ou padrões estabelecidos nas diferentes entrevistas; buscar e analisar as inconsistências encontradas entre as entrevistas ou entre as entrevistas e os textos corporativos e extrair a síntese do entendimento e do significado acerca do fenômeno.

\subsection{Aspectos Metodológicos Específicos}

Para atingir o objetivo desta pesquisa duas teorias foram usadas para direcionar a investigação bem como para embasar as análises. Devido às diferenças epistemológicas e ontológicas inerentes a cada uma, conforme exposto no Capítulo 2, a aplicação empírica também suscita aspectos metodológicos específicos. Por isso, na sequência esses aspectos foram explicitados no âmbito da Teoria da Contingência e da NSI de modo a prover os subsídios necessários para a investigação. 


\subsubsection{Aspectos Metodológicos Relativos ao Uso da Teoria da Contingência}

De acordo com a problemática da pesquisa foi estabelecido que fatores contingenciais podem influenciar (inibindo ou favorecendo) a adoção e a utilização do Custeio Alvo. Na sequência foram apresentados os aspectos metodológicos referentes à aplicação empírica dos pressupostos da Teoria da Contingência. Ressalta-se que as definições operacionais das categorias, as medidas usadas para operacionalizar os fatores contingentes, o uso e o desempenho foram discutidos de forma mais detalhada nos capítulos anteriores. O objetivo aqui é especificar de que modo tais pressupostos foram operacionalizados.

\section{- Modo de operacionalização das categorias}

As premissas da Teoria da Contingência da Contabilidade Gerencial abordadas no referencial teórico e seguidas no estudo foram: primeiro existe uma associação entre fatores contingentes e sistemas ou práticas gerenciais; segundo, a contingência determina o sistema ou a prática e terceiro, existe uma adequação/ajuste (fit) de algum nível da variável do sistema ou da prática gerencial a cada nível de contingência que conduz a um aumento de desempenho, enquanto um desajuste (misfit) conduz a uma redução no desempenho.

Como o estudo empírico se baseia em análises qualitativas a noção de adequação (fit), inerente aos estudos que usam a Teoria da Contingência, foi estipulada como representando os fatores indicados como sendo propícios ou adequados pela literatura específica (envolvendo contingência, SCG e Custeio Alvo) e, posteriormente, foi verificada a utilidade do Custeio Alvo e o impacto individual, representando o desempenho. Selto et al. (1995) mencionam que definir uma adequação ideal entre contingências, sistemas e desempenho é problemático e que geralmente isso é feito de maneira circular em que o encaixe ideal é a configuração da organização que tem ótimo desempenho. Esse encaixe é medido de forma quantitativa em relação a um benchmark de organizações com desempenho ótimo (SELTO et al., 1995). Note-se que o desempenho a que se referem esses autores é o da organização.

Como isso não foi possível no presente estudo, devido às características da estratégia de estudo de caso, a adequação foi avaliada em comparação com a literatura (que serviu como um benchmark) e com o desempenho em relação à utilidade do Custeio Alvo para a Alfa e não o desempenho da empresa. Essa forma de investigar a adequação encontrou respaldo na 
afirmação de Ferreira e Otley (2009) de que quando o desenho do SCG não corresponde às contingências da organização algumas informações fornecidas não serão percebidas como úteis. Essa afirmação foi respaldada pela pesquisa empírica desses autores, mostrando que um desenho não adequado de SCG tem um efeito negativo sobre o desempenho desse sistema.

Com base nesses comentários, nesta pesquisa entende-se que a adequação dos fatores contingentes da Alfa em relação ao Custeio Alvo favorece sua adoção e utilização, apontando para a percepção de sua utilidade. Nesse sentido, a adequação indica uma similaridade entre os fatores contingentes considerados adequados pela literatura (Quadro 2.2, Capítulo 2) e aqueles encontrados na Alfa. Há que se ressalvar aqui que os fatores encontrados na pesquisa empírica e que se encaixaram no que sugere a literatura não indica que se trata do "modelo ótimo" e sim que, na Alfa, uma determinada conjunção dos fatores avaliados em relação à adoção e utilização do Custeio Alvo está levando a uma determinada percepção de sua utilidade. Nesse caso, são apontadas tendências que devem ser analisadas quando da decisão de adotar essa prática.

Não é interessante para a Teoria da Contingência a tentativa de prever modelos ótimos de organização, uma vez que a mesma surgiu exatamente contra essa tendência da Teoria Clássica da Administração, por isso, não se deve considerar que toda empresa que tiver o mesmo conjunto de fatores deva usar o mesmo modelo de sistema (GUERRA, 2007). Como observado, nessa pesquisa os achados foram interpretados enquanto fatores que podem ter inibido ou favorecido a adoção e a utilização da prática, levando em conta a forma como os mesmos foram avaliados e o contexto da organização; sem a pretensão de afirmar ou sugerir que quando os fatores que podem estar ligados ao favorecimento da adoção do Custeio Alvo estiverem presentes em outras organizações estas “devam” adotá-lo.

A categoria uso não faz parte das premissas da Teoria da Contingência apresentadas, mas foi avaliada pelo fato de que a literatura sugere que a eficácia do SCG também depende da forma de uso das informações fornecidas pelo mesmo (FERREIRA; OTLEY, 2009), sendo aplicada de forma análoga ao Custeio Alvo.

Ressalta-se que a categoria uso do Custeio Alvo (interativo, diagnóstico e/ou disfuncional) não interfere na percepção de sua utilidade em sentido amplo, a menos que existam indícios de uso disfuncional. Isso significa que a percepção de utilidade independe de seu uso predominante ser diagnóstico ou interativo, uma vez que em qualquer dos casos existe um 
objetivo predominante (acompanhamento de variáveis críticas de desempenho ou analisar incertezas estratégicas, respectivamente). Simons (1995) menciona que as duas formas de uso são importantes e complementares, por isso, as duas podem ser encontradas na empresa concomitantemente, mas sempre com uma sendo preponderante à outra. Desse modo, essa categoria foi usada para verificar qual a forma de uso da prática preponderante na Alfa. Por outro lado, se forem encontrados indícios de uso disfuncional a questão merece maior aprofundamento visto que isso pode afetar o funcionamento da prática de modo diverso do que seja seu objetivo.

Finalmente, destaca-se que o estabelecimento dos fatores contingentes adequados ao Custeio Alvo bem como as demais categorias analisadas (uso e desempenho) foram baseados na literatura, por isso, trata-se de um esquema teórico que, quando aplicado empiricamente, pode apresentar respostas diferentes do esperado. Isso não invalida o esquema uma vez que foi usado para auxiliar as análises de forma comparativa e se refere a uma tendência. No entanto, reconhecer sua limitação é importante como forma de verificar, principalmente, no caso de respostas diferentes, as possíveis causas; uma vez que isso pode interferir no funcionamento da prática e em seu desempenho. Assim, as semelhanças (entre as contingências adequadas e as da pesquisa empírica) serviram para apontar os fatores que favoreceram a adoção e utilização, confirmando o que a literatura apresenta; as diferenças serviram para levantar pontos que ainda não foram investigados ou que podem ser relevantes no estudo dessas questões, contribuindo para o desenvolvimento da teoria.

\section{- $\quad$ Forma de classificação das categorias investigadas}

Conforme evidenciado anteriormente, os itens do roteiro de entrevistas específicos relativos à investigação com base na Teoria da Contingência foram coletados tendo por base uma âncora com dois níveis para as respostas, a qual pode variar a depender da questão. A exceção são as questões relativas à estratégia. Por isso, torna-se necessário estabelecer um parâmetro para as respostas dos entrevistados de modo a evidenciar o que cada variável significa para a análise. Esse parâmetro foi construído de forma qualitativa e a forma de classificação dos dados foi baseada na fundamentação teórica. A matriz que resume a forma de classificação foi evidenciada no Quadro 4, sendo as explicações dessa classificação apresentadas na sequência. 
Quadro 4 - Matriz de classificação das categorias investigadas

\begin{tabular}{|c|c|c|c|}
\hline Variável Investigada & Rótulo Usado & Classificação & Indicativo \\
\hline $\begin{array}{c}\text { Ambiente: } \\
\text { Concorrência }\end{array}$ & $\begin{array}{l}\text { 1-Muito estável } \\
\text { 2-Muito dinâmico }\end{array}$ & & Favorece \\
\hline $\begin{array}{c}\text { Ambiente: } \\
\text { Incerteza ambiental }\end{array}$ & $\begin{array}{l}\text { 1-Muito dinâmico } \\
\text { 2-Muito estável }\end{array}$ & & Favorece \\
\hline $\begin{array}{c}\text { Estratégia: } \\
\text { Característica de } \\
\text { mercado (Miles, } \\
\text { Snow) }\end{array}$ & $\begin{array}{l}\text { Nominal de acordo } \\
\text { com as } \\
\text { características da } \\
\text { organização }\end{array}$ & $\begin{array}{l}\text { Prospectora } \\
\text { Analisadora } \\
\text { Defensora }\end{array}$ & $\begin{array}{c}\text { Pode favorecer a } \\
\text { depender do objetivo do } \\
\text { uso da informação }\end{array}$ \\
\hline $\begin{array}{c}\text { Estratégia: } \\
\text { Ciclo de vida (Gupta, } \\
\text { Govindarajan) }\end{array}$ & $\begin{array}{l}\text { Nominal de acordo } \\
\text { com as } \\
\text { características da } \\
\text { organização }\end{array}$ & $\begin{array}{l}\text { Construir } \\
\text { Manter } \\
\text { Colher }\end{array}$ & $\begin{array}{c}\text { Pode favorecer a } \\
\text { depender do objetivo do } \\
\text { uso da informação }\end{array}$ \\
\hline $\begin{array}{c}\text { Estratégia: } \\
\text { Posicionamento de } \\
\text { mercado (Porter) }\end{array}$ & $\begin{array}{l}\text { Nominal de acordo } \\
\text { com as } \\
\text { características da } \\
\text { organização }\end{array}$ & $\begin{array}{l}\text { Diferenciação } \\
\text { Baixo Custo }\end{array}$ & $\begin{array}{l}\text { Favorece } \\
\text { Favorece }\end{array}$ \\
\hline Porte & $\begin{array}{l}\text { Receita Operacional } \\
\text { Bruta }\end{array}$ & $\begin{array}{l}\text { BNDES (2012) } \\
\text { Média-grande } \\
\text { Grande }\end{array}$ & $\begin{array}{l}\text { Favorece } \\
\text { Favorece }\end{array}$ \\
\hline $\begin{array}{c}\text { Estrutura: } \\
\text { Descentralização } \\
\text { (questões 52 a 56) } \\
\end{array}$ & $\begin{array}{l}\text { 1-Centralização } \\
\text { 2-Descentralização }\end{array}$ & & Favorece \\
\hline $\begin{array}{c}\text { Estrutura: } \\
\text { Forma estrutural }\end{array}$ & $\begin{array}{l}\text { 1-Pouca utilização } \\
\text { 2-Utilização intensa }\end{array}$ & $\begin{array}{l}\text { Funcional } \\
\text { Divisional } \\
\text { Matricial } \\
\text { Flexível }\end{array}$ & $\begin{array}{l}\text { Favorece para a forma } \\
\text { matricial e flexível }\end{array}$ \\
\hline $\begin{array}{c}\text { Estrutura: } \\
\text { Forma de trabalho }\end{array}$ & $\begin{array}{l}\text { 1-Pouca utilização } \\
\text { 2-Utilização intensa }\end{array}$ & $\begin{array}{l}\text { Uso de equipes } \\
\text { Forma das equipes } \\
\text { Cultura participativa }\end{array}$ & $\begin{array}{c}\text { Favorece para a utilização } \\
\text { de equipes e cultura } \\
\text { participativa }\end{array}$ \\
\hline $\begin{array}{l}\text { Tecnologia da } \\
\text { Informação: } \\
\text { Qualidade } \\
\end{array}$ & $\begin{array}{l}\text { 1-Baixa intensidade } \\
\text { 2-Alta intensidade }\end{array}$ & & $\begin{array}{c}\text { Favorece para o indício de } \\
\text { presença das } \\
\text { características } \\
\end{array}$ \\
\hline $\begin{array}{l}\text { Tecnologia da } \\
\text { Informação } \\
\text { Uso } \\
\end{array}$ & $\begin{array}{l}\text { 1-Pouca utilização } \\
\text { 2-Utilização intensa }\end{array}$ & & $\begin{array}{c}\text { Favorece para utilização } \\
\text { de tecnologias (análise } \\
\text { individual) }\end{array}$ \\
\hline $\begin{array}{c}\text { Tecnologia da } \\
\text { Produção: } \\
\text { Complexidade do } \\
\text { sistema produtivo }\end{array}$ & $\begin{array}{l}\text { 1-Pouca utilização } \\
\text { 2-Utilização intensa }\end{array}$ & & $\begin{array}{l}\text { Favorece para utilização } \\
\text { de produtos } \\
\text { especializados, } \\
\text { diversificados, baixo } \\
\text { volume e produção enxuta } \\
\text { e flexível. }\end{array}$ \\
\hline $\begin{array}{l}\text { Tecnologia da } \\
\text { Produção: } \\
\text { Complexidade do } \\
\text { ambiente }\end{array}$ & $\begin{array}{l}\text { 1-Pouca utilização } \\
\text { 2-Utilização intensa }\end{array}$ & & $\begin{array}{l}\text { Favorece para utilização } \\
\text { de produção enxuta }\end{array}$ \\
\hline $\begin{array}{c}\text { Tecnologia da } \\
\text { Produção: } \\
\text { Tecnologias } \\
\text { contemporâneas } \\
\end{array}$ & $\begin{array}{l}\text { 1-Pouca utilização } \\
\text { 2-Utilização intensa }\end{array}$ & & $\begin{array}{c}\text { Favorece para utilização } \\
\text { de tecnologias (análise } \\
\text { individual) }\end{array}$ \\
\hline Uso do Custeio Alvo & $\begin{array}{l}\text { 1-Pouca utilização } \\
\text { 2-Utilização intensa }\end{array}$ & $\begin{array}{l}\text { Interativo } \\
\text { Diagnóstico } \\
\text { Disfuncional }\end{array}$ & $\begin{array}{l}\text { Verificar o tipo de uso } \\
\text { predominante sendo que } \\
\text { os itens "a até e" indica } \\
\text { uso diagnóstico; "f até i" } \\
\text { uso interativo e "j até l" } \\
\text { uso disfuncional }\end{array}$ \\
\hline
\end{tabular}


Quadro 4 - Continuação

\begin{tabular}{|c|c|c|c|}
\hline Variável Investigada & Rótulo Usado & Classificação & Indicativo \\
\hline $\begin{array}{c}\text { Desempenho do } \\
\text { sistema: } \\
\text { Satisfação do usuário }\end{array}$ & $\begin{array}{l}\text { 1-Pouco satisfeito } \\
\text { 2-Muito satisfeito }\end{array}$ & & Favorável \\
\hline $\begin{array}{l}\text { Desempenho do } \\
\text { sistema: } \\
\text { Impacto individual }\end{array}$ & $\begin{array}{l}\text { 1-Baixo impacto } \\
\text { 2-Alto impacto }\end{array}$ & & Favorece \\
\hline $\begin{array}{l}\text { Desempenho do } \\
\text { sistema: } \\
\text { Impacto individual }\end{array}$ & $\begin{array}{l}\text { 1-Baixo impacto } \\
\text { 2-Alto impacto }\end{array}$ & & Favorece \\
\hline
\end{tabular}

De acordo com o roteiro de entrevistas primeiro foram avaliados os fatores contingentes. Para estes foram apresentados na matriz de classificação as âncoras de cada variável investigada e, em alguns casos a forma de classificação. Posteriormente, foi apresentado o indicativo decorrente da classificação. O indicativo foi baseado nos tipos de cada fator considerado como adequado para o Custeio Alvo de acordo com a fundamentação teórica. Note-se que foi apontado apenas o indicativo referente ao favorecimento. Em nenhum caso foi apontado o tipo que pode inibir a adoção ou a utilização do Custeio Alvo. Isso pelo fato de que, conforme mencionado anteriormente, o esquema usado para comparação se baseia na literatura em relação aos fatores adequados.

No entanto, empiricamente os resultados podem diferenciar dos tipos adequados que foram apontados, por isso, as diferenças devem ser analisadas individualmente e interpretadas em relação à forma como a Alfa utiliza a prática. Desse modo, os fatores que não estão dispostos da forma estabelecida no benchmark não devem ser interpretados de forma a indicar que podem inibir a adoção ou a utilização da prática, mas sim devem ser analisados se, no caso específico da Alfa, eles estão favorecendo ou inibindo.

As questões referentes ao tipo de estratégia (característica de mercado, ciclo de vida e posicionamento de mercado) foram formuladas de acordo com assertivas sobre cada tipologia. A escolha de cada uma indica os tipos de estratégia utilizados pela Alfa. As análises de cada tipologia foram feitas em relação a cada tipo encontrado na Alfa, visto que os estudos analisados no Capítulo 2 apresentaram resultados contraditórios ou que não podiam ser comparados, não sendo possível estabelecer um benchmarking nesse caso.

Outros fatores também necessitaram de análises individuais para uma posição a respeito de favorecer ou inibir a prática, como é o caso da tecnologia da informação referente ao uso de alguns tipos especificados e da tecnologia de produção referente ao uso de tecnologias 
contemporâneas. Isso porque não é a utilização de mais ou menos itens apresentados que caracterizam o indicativo, e sim o fato de que a presença de alguns deles pode facilitar a adoção e utilização da prática. Por isso, a análise deve ser individual e de forma interpretativa, considerando o que foi encontrado na literatura e na Alfa, sem a possibilidade ou a expectativa de inferir quantos ou quais dos tipos devem ser necessários para indicar o favorecimento ou não.

A próxima categoria investigada se refere ao uso do Custeio Alvo e teve o objetivo de verificar o tipo predominante de uso e não relacionar com o favorecimento uma vez que tanto o uso diagnóstico quanto o disfuncional tem seus objetivos e são importantes, conforme mencionado anteriormente. A análise de conteúdo das entrevistas referentes a outros assuntos abordados também puderam fornecer subsídios para uma conclusão a repeito do tipo de uso. A última categoria se refere ao desempenho da prática incluindo a satisfação do usuário e o impacto individual e foi usado o mesmo raciocínio dos demais fatores em relação ao favorecimento da prática.

Ressalta-se que essa categoria (referente aos fatores contingentes, uso e desempenho) também foi usada nas análises para confrontar com o modo como os entrevistados lidam com o Custeio Alvo (abordado pela NSI), de modo a verificar se existe algum tipo de relação, usando para isso a análise de conteúdo. Na sequência os detalhes do uso da NSI foram apresentados.

\subsubsection{Aspectos Metodológicos Relativos ao Uso da NSI}

As categorias investigadas no estudo de caso referentes à NSI foram os fatores institucionais, os fatores econômicos, o estágio do processo de institucionalização do Custeio Alvo e a forma como o mesmo foi institucionalizado. Na sequência foi apresentada a forma como essas categorias foram usadas e interpretadas nas análises.

Primeiro, é importante mencionar que de acordo com a NSI uma prática pode ser institucionalizada em busca de legitimidade (MEYER; ROWAN, 1977; DIMAGGIO; POWELL, 1983), mas as organizações operam concomitantemente em ambientes institucionais e econômicos (SCOTT; MEYER, 1991). Por isso, fatores econômicos e a busca pela eficiência também podem estar presentes neste tipo de decisão, em especial no caso de 
empresas privadas, que é o caso estudado. Fatores institucionais e econômicos não são dicotômicos e ambos podem exercer pressões sobre as organizações (POWELL, 1991). Isso foi levado em conta nessa pesquisa seguindo os estudos de James (2009) e Tsamenyi et al. (2006).

Com base nos desenvolvimentos da NSI, abordados na fundamentação teórica, parte-se da seguinte premissa: a adoção de uma prática como o Custeio Alvo pode apresentar respostas diferentes (BECKERT, 1999; MACHADO-DA-SILVA et al. 2005; CRUBELLATE, 2004) (que variam do coupling ao decoupling) em relação à sua institucionalização a depender da forma como a mesma foi interpretada (podendo indicar objetivo de obtenção de legitimidade e/ou eficiência), bem como de aspectos que podem representar conflitos e/ou ambiguidades em relação às rotinas e objetivos organizacionais (MEYER; ROWAN, 1977; CARRUTHERS, 1995).

Além disso, o mecanismo de difusão pode influenciar a resposta especialmente por se tratar de uma subsidiária (KOSTOVA; ROTH, 2002). Esses mecanismos podem se dar pelo cumprimento de uma ordem (coerção por parte da matriz), por necessidade de conformação com o ambiente social (mimetismo) ou por normativismo (relacionado à profissionalização) (DIMAGGIO; POWELL, 1983). Nesse sentido, Kostova e Roth (2002) sugerem que o uso do tipo cerimonial (decoupling) é particularmente provável nas subsidiárias (especialmente no caso de coerção pela matriz) por diversos motivos, dentre eles a percepção de que a prática não tem valor, não formando atitudes positivas quanto a mesma; a falta de conhecimento dos funcionários para entender e interpretar a prática; a falta de consistência da prática com as crenças e valores da organização ou, ainda, por verem a prática como uma moda passageira que surgiu no ambiente institucional da matriz, o qual pode ser distinto daquele da subsidiária.

No entanto, Kostova e Roth (2002) também defendem que características do contexto relativo da subsidiária, especialmente a confiança na matriz e a identificação da subsidiária com a matriz, podem auxiliar numa possível internalização da prática sem o decoupling. Isso significa que a adoção de uma prática mesmo quando motivada pela busca de legitimação pode resultar na sua utilização de forma coupling (embora autores como Meyer e Rowan, 1977 e DiMaggio e Powell, 1983, consideram que a conformação aos ditames sociais ocorre mais pela busca de legitimidade do que de eficiência). Como a Alfa é uma empresa privada que atua no mercado de forma global, a busca pela eficiência também é crucial, sendo uma questão de sobrevivência tanto quanto a legitimidade (SCOTT; MEYER, 1991; POWELL, 
1991). Com base no exposto, interessa saber através de qual mecanismo de difusão o Custeio Alvo foi adotado, uma vez que isso pode influenciar a interpretação e a resposta organizacional.

O processo de institucionalização na forma "interpretação e resposta" (caracterizando a agência estratégica), conforme discutido na fundamentação teórica, não foi considerado linear nem dicotômico, mas recursivo. Para Crubellate (2004, p. 106) nessa forma de compreender a relação entre pressões institucionais e ação organizacional "O contexto ambiental, tanto quanto as respostas estratégicas, são constituídos simultaneamente por padrões institucionalizados e pela agência dos atores sociais, pelo menos nos aspectos relevantes para a própria ação." Desse modo, as instituições e ações não apenas se afetam, elas são constituídas mutuamente, sendo os aspectos interpretativos entendidos como centrais, considerados como o lócus e o mecanismo dessa circularidade (CRUBELLATE, 2004). Entende-se com isso que o significado de uma instituição é construído pelos atores de acordo com suas interpretações, influenciadas pelas pressões internas e externas. Com base nas premissas expostas de acordo com a NSI foi apresentado o modelo teórico (Figura 7) usado para guiar o estudo empírico.

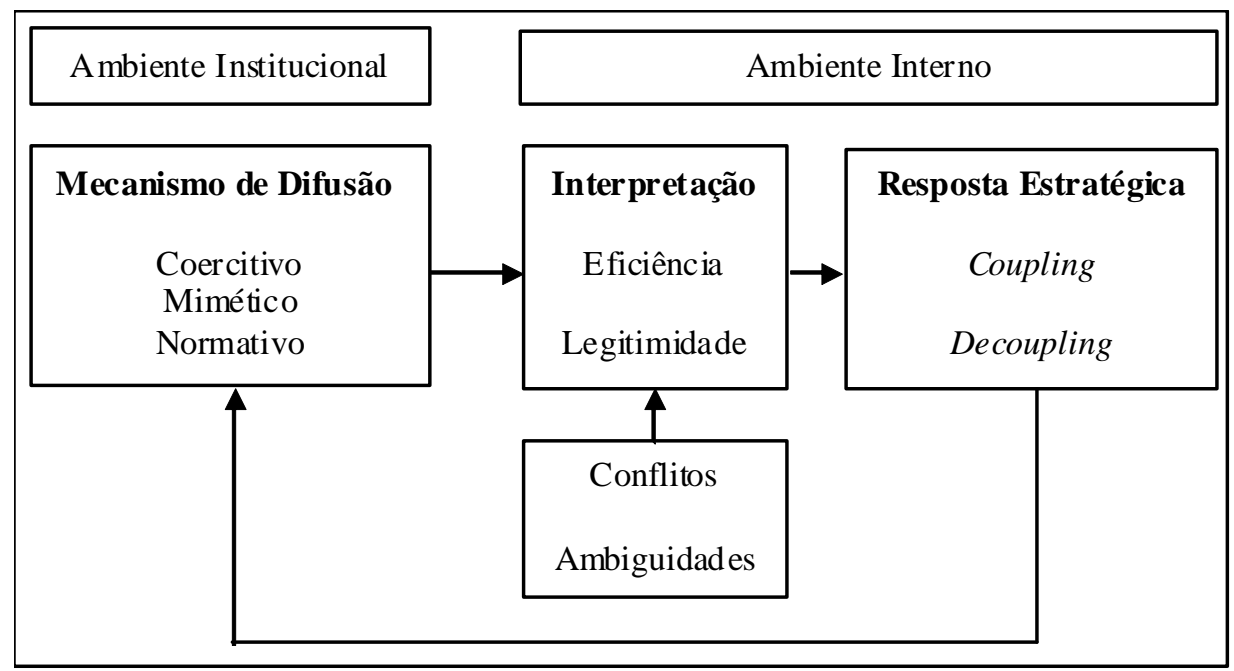

Figura 7 - Modelo Teórico Proposto (baseado em CRUBELLATE, 2004)

De acordo com o modelo (Figura 7) a resposta pode ser influenciada pelos ambientes institucionais e organizacionais. A interpretação pode estar baseada nos fatores institucionais (tendo como motivação a legitimidade e a crença de que seguir as demandas institucionais sem interferência na rotina é suficiente) e econômicos (tendo como motivação a eficiência e a crença na validade técnica do Custeio Alvo, interferindo na rotina), que por sua vez pode ser influenciada pela presença de conflitos e/ou ambiguidades entre a estrutura e a prática. 
Há que se considerar que este modelo é teórico e serve apenas para guiar as análises, de forma que na pesquisa empírica a inter-relação entre os dois fatores (institucional e econômico) pode dificultar a separação entre as duas formas de interpretação. Ainda, as respostas estratégicas podem apresentar, de acordo com Crubellate (2004, p. 314), graus de conexão diferentes. Por isso, pode ser encontrada uma resposta intermediária entre o coupling e o decoupling. No entanto, pelo tipo de pesquisa empreendida essas variações podem ser captadas.

A premissa seguida em relação à NSI levou em conta a capacidade de agência dos atores para interpretar e responder às demandas institucionais de forma recursiva, de modo que essas demandas tanto restringem quanto capacitam a ação, auxiliando no entendimento do funcionamento do Custeio Alvo na Alfa. Conforme Selznick (1996), ao identificar formas específicas de pensar e agir em relação aos processos organizacionais ganha-se uma melhor compreensão de como as ideias são formadas nesse contexto com significantes consequências para a interação e tomada de decisão.

Para utilizar esse modelo torna-se necessário estabelecer a definição operacional dos aspectos avaliados, sendo eles: ambiente institucional, ambiente organizacional, interpretação, resposta estratégica, conflitos e ambiguidades, crenças e valores.

Ambiente Institucional: foi considerado aquele em que estão situadas a matriz e as subsidiárias.

Ambiente Interno: é o ambiente interno da Alfa.

Interpretação: a forma como o Custeio Alvo foi interpretado, se referindo ao modo predominante de significação (para obter eficiência ou obter legitimidade) captada pelo conteúdo das entrevistas.

Resposta estratégica: indica a capacidade de agência dos atores organizacionais em relação à conformação ou não com as regras e requerimentos institucionais, representadas nesse caso pelo Custeio Alvo. Nessa pesquisa a resposta foi avaliada em relação a dois tipos: a aceitação, se a empresa institucionalizar o Custeio Alvo acoplado (coupling) às rotinas organizacionais, de modo que o mesmo tenha interferência nas atividades e/ou nas decisões; ou a rejeição ou resistência, se a empresa institucionalizar o Custeio Alvo de forma cerimonial, desacoplado (decoupling) das rotinas organizacionais, ou seja, de modo que o mesmo não tenha interferência nas atividades e/ou nas decisões em nenhum momento. 
Conflitos: representam conflitos de qualquer natureza entre a forma como a organização está estruturada e a prática adotada. Por exemplo, conflitos técnicos que dificultam o processo do Custeio Alvo.

Ambiguidades: representam divergências relativas aos objetivos organizacionais e a utilização da prática.

Todos os fatores e aspectos investigados relativos à NSI foram identificados e avaliados através da análise de conteúdo das entrevistas e dos textos corporativos tendo como base sua avaliação conforme apresentada no Capítulo 2 item 2.2.5, com exceção das categorias conflitos e ambiguidades que, assim como no caso dos fatores econômicos, foram avaliadas em relação à sua presença nos discursos dos entrevistados ou dos textos corporativos, de forma a captar algum indício de sua ocorrência.

\subsection{Análise dos Dados e Resultados da Pesquisa Empírica}

Na pesquisa qualitativa as fases de coleta e análise são simultâneas e o processo é iterativo. A fase da coleta dos dados foi discutida anteriormente. Quanto à análise na pesquisa qualitativa, Martins e Theóphilo (2007) comentam que as tendências, padrões e regularidades captados na fase de coleta são reavaliadas buscando-se relações e inferências em um nível de abstração mais elevado. Esta é uma fase relevante da pesquisa, pois através dela as informações analiticamente interpretadas são convertidas em conclusões. Eisenhardt (1989) menciona que os estudos de caso publicados geralmente descrevem os locais onde a pesquisa foi realizada e os métodos de coleta de dados, mas pouco espaço é dado para a discussão da análise e geralmente um grande abismo separa os dados das conclusões.

Na tentativa de evitar essa deficiência foi observado o que Martins e Theóphilo (2007) sugerem a esse respeito. Esses autores apresentam três atividades que são consistentes com a análise dos dados nas pesquisas qualitativas, são elas a redução dos dados (processo de seleção, simplificação, abstração e transformação dos dados originais), a apresentação dos dados (organização dos dados de forma a possibilitar a tomada de decisão do pesquisador e extrair as conclusões através de textos, matrizes, gráficos etc.) e o delineamento e busca das conclusões (identificando padrões, possíveis explicações, configurações e fluxos de causa e efeito seguidos de verificação, retomando as anotações do campo e a literatura). 
Essas atividades foram seguidas no presente trabalho. Primeiro os dados foram reduzidos com base na matriz de análise de conteúdo e na matriz de classificação das categorias relativas à Teoria da Contingência. Posteriormente esses dados foram apresentados na forma de informações extraídas dessas reduções, de modo a possibilitar as análises e inferências entre eles e as teorias de base. Finalmente foram delineadas as inferências e conclusões acerca dos assuntos investigados.

Nessa pesquisa a análise foi apresentada de forma linear, seguindo a ordem das questões formuladas na introdução; e de modo analítico, evidenciando o assunto discutido, as informações extraídas dos dados e sua análise. Para embasar as análises, as interpretações e as conclusões os assuntos discutidos foram confrontados com as teorias utilizadas. Conforme Martins e Theóphilo (2007) a validação dos achados na pesquisa qualitativa é checada pela consistência através do exame detalhado entre elementos da plataforma teórica e os achados da pesquisa empírica. Por isso, esse cuidado também foi observado nessa pesquisa permitindo que os resultados da análise estejam amparados por modelos lógicos de desenvolvimento dos argumentos e ao mesmo tempo, que tenham a capacidade de refletir a realidade estudada.

\subsection{Delimitação Temporal e Limitação do Estudo de Caso}

O estudo de caso foi desenvolvido de forma transversal em relação à dimensão temporal. "Os estudos transversais são feitos uma vez e representam um instantâneo de um determinado momento." (COOPER; SCHINDLER, 2003, p. 129). A coleta de dados referente às entrevistas se deu entre 2011 e 2012, mas não foi considerada a dimensão tempo, ou seja, o aspecto longitudinal.

Devido às peculiaridades da estratégia de estudo de caso sua limitação geralmente é discutida. A validade externa define o domínio para o qual as descobertas do estudo podem ser generalizadas (YIN, 2010). Isso engloba algumas ações que permitem algum tipo de generalização dos resultados. Obviamente não se trata de generalização estatística (inferência por amostragem) e sim de um tipo de generalização que Yin (2010) denomina de analítica, ligada a uma teoria ampla. Martins e Theóphilo (2007) também argumentam que os estudos de caso são baseados em generalizações analíticas em que se busca generalizar um conjunto particular de resultados a uma teoria mais abrangente. Nesse sentido, o foco está no 
entendimento de uma realidade social e não na possibilidade de previsão do fenômeno, de acordo com a lógica de outras abordagens de pesquisa.

Lukka e Kasanen (1995) tratam do problema da generalização na pesquisa contábil e sugerem que existem três tipos básicos de retóricas sobre generalização, e estas compreendem a estatística, a de contextualização e a construtiva. A retórica estatística se refere à generalização baseada em amostras e populações estatísticas; a de contextualização diz respeito aos estudos de caso e se refere à possibilidade de ampliar a validade dos resultados para além das observações primárias pela triangulação eficiente dos elementos dos dados; e a retórica construtiva está relacionada à resolução de um problema do mundo real dos negócios desenvolvendo uma nova solução que tem uma contribuição científica.

Dentro dessas categorias, conforme mencionado, o presente estudo de caso se relaciona à retórica de contextualização, por isso, esse é o tipo de generalização buscada nesse trabalho. De acordo com o exposto, o que se buscou com o estudo de caso empreendido foi um entendimento acerca do funcionamento de uma prática do SCG em seu contexto social e sob a ótica dos envolvidos em seu processo, apoiando-se nas teorias de base de modo a ancorar as análises e os resultados através da generalização analítica. O próximo capítulo apresenta a empresa Alfa e as discussões e análises da pesquisa. 


\section{APRESENTAÇÃO E ANÁLISE DOS RESULTADOS DO ESTUDO DE CASO}

Neste capítulo foram apresentados os seguintes itens: a descrição da empresa Alfa; a descrição do processo de Custeio Alvo na Alfa; as informações e análises efetuadas à luz das duas teorias de base, separadamente, de modo a responder as questões secundárias de pesquisa e, finalmente, as discussões e análises gerais do caso com o objetivo de responder a questão orientadora da pesquisa.

\subsection{Descrição da Empresa Alfa}

A organização investigada teve seu nome alterado e algumas informações omitidas para preservar sua confidencialidade, sendo denominada para efeito dessa pesquisa de Alfa. Tratase de uma empresa asiática, de classe mundial, que atua no ramo de fabricação de equipamentos pesados e serviços. Além da matriz existem as subsidiárias e filiadas ao redor do mundo num total de cento e oitenta e quatro empresas pertencentes ao grupo. A matriz foi fundada há mais de noventa anos e a subsidiária brasileira, objeto do estudo, tem quase quarenta anos e foi a primeira fábrica do grupo a ser instalada fora da sede. Na sequência foram apresentadas as descrições da organização enquanto grupo e, posteriormente, relativas à subsidiária brasileira.

\subsubsection{O Grupo Alfa}

Para auxiliar o entendimento do que ocorre na subsidiária brasileira, é importante o esclarecimento de alguns pontos relativos ao funcionamento da companhia principal (a partir daqui tratada como matriz) que são seguidos pelas demais empresas do grupo.

A organização se empenha para maximizar seu valor corporativo através da promoção da "qualidade e confiabilidade", sendo esses requisitos tratados como valores e disseminados entre todas as empresas do grupo. Existe a crença de que a confiança da sociedade e dos stakeholders na organização reflete seu valor corporativo, sendo o cumprimento das regras da comunidade de negócios importante para a obtenção dessa confiança. As regras não dizem 
respeito somente às leis e regulações inerentes às atividades do negócio, mas também àquelas que são reconhecidas e respeitadas na comunidade de negócios. Por isso, existe um código de conduta de negócios estabelecido pela matriz que prescreve seu regimento, ao qual todos os funcionários do grupo devem ler atentamente, entender e respeitar.

Existe ainda uma metodologia, denominada nesse trabalho de "Alfa X", aplicada aos produtos e serviços e que representa os princípios a serem seguidos, sendo o pilar que mantém a força corporativa do grupo. O “Alfa X" representa o sentido dos valores e a força da Alfa que deve ser globalmente herdado independente de qualquer alteração em seus membros. Com isso, o código de conduta é o responsável por implementar esse sentido relativo aos valores e a força da empresa expressos pelo "Alfa X", sendo ambos importantes princípios orientadores. Além desses, recentemente foram distribuídos às empresas do grupo os "Princípios de Observância”, que resumem o que os funcionários devem respeitar. É importante destacar que em seus comunicados corporativos, quando a organização se refere aos funcionários, sempre está explícito que se trata de todos, a começar pela alta gestão.

Para a organização a promoção da "qualidade e confiabilidade" é naturalmente aplicável aos seus produtos e serviços para assegurar que os mesmos sejam altamente valorizados pelos seus clientes; e é aplicável também a aspectos como a estrutura organizacional, operações de negócios, funcionários e a gestão de forma geral. Para obter "qualidade e confiabilidade" a organização disponibiliza um guia com o que deve ser feito tanto pela gestão quanto por qualquer funcionário do grupo no desempenho de suas atividades do dia a dia e é composto por normas como: sempre pensar nas necessidades dos clientes e se esforçar para oferecer produtos, serviços e sistemas que sejam favoráveis ao meio ambiente, seguros e inovadores; sempre buscar inovação de tecnologia e de gestão por iniciativa própria; promover gestão consolidada a partir da perspectiva global; contribuir para o bem estar da comunidade local como um bom cidadão corporativo e fornecer aos funcionários oportunidades de iniciativas próprias para inovação e realizações.

Quanto à relação com os stakeholders a organização aponta os clientes em primeiro lugar, como os mais importantes para o negócio. Busca oferecer aos mesmos informações relevantes de acordo com suas necessidades e exigências, ouvir suas percepções e proporcionar as soluções mais adequadas de forma a entregar produtos e serviços que sejam seguros, ecologicamente corretos, inovadores e de qualidade superior. Outro stakeholder citado nos textos corporativos e que interessa para este estudo representa os integrantes da cadeia de 
suprimentos. A organização considera os mesmos como parceiros e procura estabelecer relações estáveis de longa duração na base da confiança mútua, incentivando-os também a cumprir as regras disseminadas para o grupo. A seleção desses parceiros é feita com base na qualidade, custo, entrega e outros critérios objetivos e operacionais bem como do ponto de vista do cumprimento das regras.

De acordo com um comunicado do presidente da matriz, devido à crise econômica de 2008 a Alfa tem implementado reformas estruturais para se tornar mais enxuta e mais forte. A matriz apresentou em seu plano de gestão de médio prazo do biênio 2007-2009 as suas forças competitivas que englobaram: produtos competitivos e exclusivos; vendas globais e redes de serviços espalhadas pelo mundo todo e operação industrial flexível, contando com colaboração interdivisional e o Kaizen. Apresentou ainda como uma de suas metas a redução contínua dos custos fixos.

No plano bianual de 2010-2012 a redução contínua dos custos fixos ainda era meta. Em relação às atividades de gestão são objetivos: desenvolver recursos humanos e fortalecer as relações com os clientes e o grupo e promover o crescimento dos membros nos países onde a empresa atua. Em relação às atividades das operações do negócio se propõe: aumentar o valor agregado dos produtos com aplicação de tecnologia de informação; atualizar a responsabilidade ambiental; reforçar ainda mais as operações nos mercados em crescimento para atender a mudança estrutural da demanda de mercado e sustentar e melhorar a capacidade organizacional a fim de vencer a competição global.

\subsubsection{A Alfa do Brasil}

A Alfa do Brasil, subsidiária do grupo, tem como função a fabricação de equipamentos de construção e aço vazado. A Alfa segue as mesmas diretrizes da matriz, compartilhando a mesma filosofia de "qualidade e confiabilidade", o código de conduta, o "Alfa X" e os Princípios de Observância. Recebeu por duas vezes um prêmio interno devido ao excelente desempenho e altíssimo nível de qualidade dos produtos fabricados. Tanto seu presidente quanto o diretor financeiro são oriundos do país de origem da matriz. Em todas as empresas do grupo essa é a configuração mais comum; somente em alguns casos os presidentes são originários do país onde a subsidiária atua ou de outros países que não o da matriz. 
É necessário esclarecer que por se tratar de subsidiária muitas de suas diretrizes são estipuladas e determinadas pela matriz e isso influencia suas operações. Empresas que operam em dimensão global possuem questões que devem ser observadas no desenho e no uso do sistema de controle, pois elementos organizacionais, culturais e sociais podem afetar seus mecanismos formais e informais de controle (FREZATTI et al., 2009). Por isso, é importante verificar essa questão na Alfa.

Busco et al. (2007) apresentam os principais modelos de gestão de empresas internacionais de acordo com características específicas, sendo classificados em empresas globais, multinacionais e transnacionais. De acordo com as características da Alfa (apresentadas no decorrer do Capítulo 5) a mesma se enquadra como empresa global. Nesse tipo de organização as diretrizes estratégicas geralmente são determinadas pela matriz havendo alto nível de centralização das decisões (BUSCO et al., 2007). Nessas empresas o controle gerencial adotado é baseado no modelo de comando e controle (FREZATTI et al., 2009). Isso significa que aspectos como a escolha das estratégias a serem seguidas e o processo de seu desenvolvimento, bem como a adoção e implementação de práticas como o Custeio Alvo são determinados pela matriz e não escolhas da Alfa. Essas peculiaridades foram consideradas no desenvolvimento do estudo empírico, tanto pela Teoria da Contingência quanto pela NSI.

É importante destacar que foram entrevistadas quatro pessoas na Alfa: o presidente, o diretor industrial, o chefe de controle de custos e o gerente de desenvolvimento e compras, que foram denominados a partir daqui de funcionários A, B, C e D respectivamente. Esses funcionários foram escolhidos levando-se em consideração o fato de serem usuários das informações oriundas do processo do Custeio Alvo e, ainda, os funcionários C e D serem também participantes do processo de geração de algumas de suas informações. $\mathrm{O}$ funcionário $\mathrm{C}$ foi o contato na organização desde o início, por isso, além das informações extraídas de sua entrevista, várias conversas informais ocorreram ao longo do trabalho gerando também informações importantes para esclarecimentos no decorrer desta etapa.

Para ilustrar a hierarquia funcional dos entrevistados foi apresentada na Figura 8 parte do organograma da Alfa com os setores aos quais os mesmos estão alocados. Nota-se que o setor de controle de custos está diretamente subordinado à diretoria industrial, não havendo nível intermediário como no caso do setor de desenvolvimento e compras que está subordinado à engenharia de produção. Segundo o funcionário C não há nível de gerência entre a função de chefe de controle de custos e a alta gestão (diretoria e presidência) por se tratar de atividade 
que envolve dados e informações estratégicas, sendo feito dessa forma para evitar manipulações e problemas com as informações.

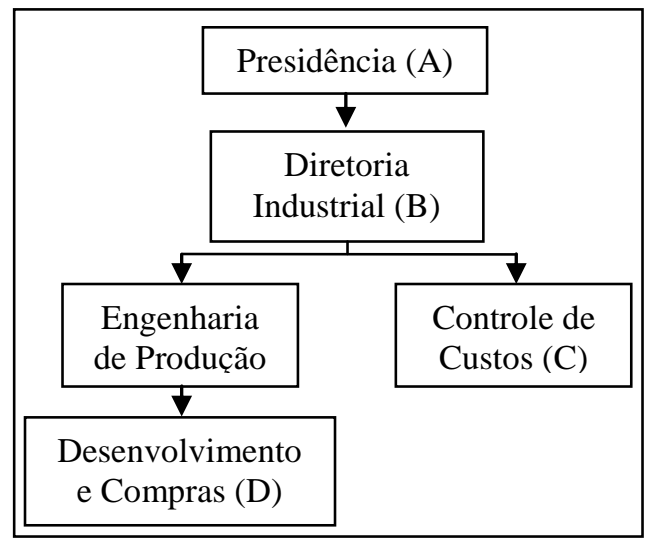

Figura 8 - Nível hierárquico dos setores dos entrevistados

Outro fato interessante em relação à estrutura é que a Alfa conta com uma empresa separada responsável exclusivamente para as vendas de seus produtos, sendo essa uma empresa comercial. Por isso, na empresa industrial da Alfa (que é o objeto desse estudo) o setor de vendas está subordinado à diretoria industrial por ter como algumas de suas funções fazer estudos sobre os requisitos dos clientes em relação aos produtos e cotações de preço de venda que o cliente está disposto a pagar, que são os insumos iniciais do processo do Custeio Alvo; previsões de demanda de mercado para estipular a quantidade de produtos a ser fabricada periodicamente, dentre outras funções. Na sequência foram apresentadas as características gerais do processo de Custeio Alvo na Alfa.

\subsection{O Custeio Alvo na Alfa}

O Custeio Alvo foi o foco principal dessa pesquisa e esse tópico teve o objetivo de analisar se essa prática existe na Alfa através da verificação de suas características e de seu funcionamento de modo a embasar as análises posteriores. Ressalta-se que as características analisadas aqui se limitam aos aspectos gerais do processo do Custeio Alvo, as análises mais específicas e detalhadas sobre os princípios e requisitos dessa prática foram feitas em tópico posterior relativo à sua implementação (item 5.4.3).

Para estudar o Custeio Alvo enquanto prática do sistema de controle e também o seu processo de institucionalização é indispensável que o mesmo exista na empresa, independente da forma e da intensidade de sua utilização; por isso, este foi o primeiro aspecto investigado. A Alfa foi 
escolhida para o caso devido ao fato de a literatura acadêmica usada na fundamentação teórica mencionar que a matriz utiliza o Custeio Alvo, o que pode ser indício de que as subsidiárias também utilizem, por se tratar de empresa global. Conforme expectativa inicial, desde o primeiro contato com a organização já houve uma resposta afirmativa a respeito de sua utilização.

No entanto, apenas uma afirmação a respeito de sua utilização não é suficiente para considerar que o mesmo tenha sido adotado e venha sendo utilizado. Por isso, o roteiro da entrevista contemplou questões para averiguar se o que a empresa faz se aproxima das características do Custeio Alvo descrito na literatura. O que se segue são os apontamentos e descrições extraídas das entrevistas que expressam as percepções e opiniões acerca do processo do Custeio Alvo e seu funcionamento no que diz respeito aos indícios de sua adoção.

A organização possui um processo de planejamento e controle de custos de novos produtos e de produtos remodelados ou reprojetados. Para a Alfa os reprojetos envolvem mudanças estruturais nas características dos produtos, sendo considerados novos produtos. Nenhum produto é lançado e iniciado no processo produtivo sem um planejamento detalhado a respeito de seus custos.

O início desse processo de planejamento é feito pelo setor de vendas que é encarregado de buscar informações a respeito das demandas e necessidades dos clientes em potencial bem como do preço que os mesmos estão dispostos a pagar pelo produto final. De acordo com o funcionário $\mathrm{C}$ "Existe uma área de vendas que verifica a necessidade de um novo produto e vem com a característica da máquina que gostaria de poder fabricar no Brasil e o preço de venda que o mercado está disposto a pagar. [...].”. Com isso, as características dos produtos não são definidas internamente pela engenharia e sim estipuladas de acordo com os requisitos dos clientes, ou seja, são orientadas pelo mercado.

Nesse planejamento inicial é estipulada uma meta de margem de contribuição individualizada por produto que deve ser obtida com sua venda. Dessa forma, o planejamento engloba o que o cliente quer e quanto está disposto a pagar e, ainda, a margem de contribuição desejada pela empresa para aquele produto, representando o retorno desejado. Com essas informações é calculado o custo máximo admissível variável do produto. Destaca-se que o planejamento do lucro de forma abrangente é discutido no plano de negócios anual e as metas de retorno da Alfa são estipuladas pela matriz. 
Posteriormente, são feitos os cálculos do custo variável estimado do produto para comparação com o máximo admissível, chegando-se ao valor do custo alvo. Na Alfa ele é denominado de "custo objetivo" e não custo alvo, mas trata-se da mesma coisa, possuem a mesma característica. Sobre o processo de cálculo dos custos estimados o funcionário $\mathrm{C}$ comentou que:

\begin{abstract}
Na realidade é o seguinte, é um negócio que pela experiência que a gente tem, por exemplo, eu pego uma máquina inteira, tem coisas que são comuns! Parafusos esse tipo de coisa é tudo comum, então essas coisas comuns é [sic] possível inclusive custear e tem alguns outros tipos de custos que eu tenho referência, por exemplo, [...], qual o nível de custo de mão de obra, qual o nível de custo de matéria prima, [...]. Essas relações a gente tem. E a margem de erro é normalmente, olha é bem abaixo de $5 \%$.
\end{abstract}

Nessa fase, o setor de desenvolvimento e compras é o responsável por verificar os custos dos itens integrantes do produto a serem comprados bem como dos componentes específicos que devem ser fabricados pelos fornecedores e pela Alfa. Nesse processo são utilizadas tabelas de custos que auxiliam no levantamento do custo estimado total de materiais e componentes que irão compor o produto. De acordo com o funcionário $\mathrm{D}$, a depender do produto essas tabelas são extensas devido ao número de materiais e componentes, por isso, essas informações são repassadas de forma resumida aos setores interessados.

Nesse procedimento foi verificada a existência de dois tipos de atividades de análise e cotação. Uma para os itens similares aos dos produtos existentes e que podem ser comparados, segundo o funcionário D, “[...] para o que já é similar a gente usa uma tabela chamada WCT de custo [...].". A outra atividade se refere aos itens que não possuem uma boa base de comparação e são necessários estudos mais aprofundados pelo fato de ter mais componentes e mão de obra agregados. Nesse caso, de acordo com o funcionário D,

[...] a gente se utiliza de uma planilha que a gente criou e virou um padrão onde temos os custos de tudo que é componente, os custos de matéria prima, os custos de mão de obra, então a gente acredita ter conhecimento para poder fazer os processos e sair um custo objetivo em cima do ideal [...]. Então temos uma tabela que fazemos passo a passo a peça, discriminamos a peça passo a passo como se fosse fazer um custo dela e daí nós comparamos com o preço que a gente recebe do mercado. Então nós temos acertado em torno de 95 a $96 \%$ [...].

Com essas informações foi possível verificar que a empresa possui uma estimativa dos custos dos materiais disponíveis no mercado e daqueles que são específicos, sendo necessária sua fabricação pelos fornecedores. Essa declaração também indica que o Custeio Alvo é utilizado tanto para os produtos como para alguns dos componentes que o integram. Outras declarações dos funcionários $\mathrm{B}$ e $\mathrm{C}$ comprovaram esse tipo de uso. $\mathrm{O}$ funcionário $\mathrm{B}$ mostrou o resultado da análise de custo alvo de um dos componentes de um produto, exemplificando como era 
feito e como essa informação é disponibilizada no sistema. Nesse tipo de processo de Custeio Alvo de componentes o preço de venda considerado nos cálculos é o preço de venda do fornecedor. O uso do Custeio Alvo tanto para produtos quanto para componentes aumenta a variedade de itens sobre os quais são despendidos esforços para redução de custos.

Foi verificado que apenas os custos variáveis com materiais, componentes, mão de obra direta e energia elétrica fazem parte do custo alvo e do custo estimado. Na Alfa os custos fixos são discutidos no plano de negócios anual e são analisados como um montante de custos não distribuídos aos produtos, em relação ao qual a margem de contribuição total tem que ser suficiente para cobrir e gerar o retorno desejado pela Alfa e pela matriz.

Antes da decisão final sobre o lançamento do produto existe um esforço para a redução de custos para atingir o custo alvo, usando recursos como a engenharia de valor, tabelas de custos e outros. Em relação a essa atividade o funcionário A comentou que a Alfa sempre tenta reduzir o custo para se chegar ao alvo, mas isso tem um limite e quando não conseguem atingir a margem objetivada o projeto é arquivado. Isso indica que a informação a respeito do alcance do custo alvo é primordial para a decisão de lançar o produto.

Segundo o funcionário $\mathrm{C}$ a organização trabalha esta etapa de forma a lançar o produto com um mínimo de condição, nem sempre atingindo o retorno desejado pela Alfa do Brasil, mas sempre atingindo o retorno desejado para o grupo Alfa. O planejamento do lucro é feito de forma global, a matriz estipula a margem a ser trabalhada e as subsidiárias buscam alcançar esta meta. Assim, os lançamentos de produtos não estão sujeitos apenas à margem individual, mas também à margem do grupo. Por isso, existem casos em que mesmo o retorno não sendo aquele inicialmente proposto para a subsidiária, o produto pode ter liberação da matriz para lançamento, desde que a margem obtida pelas demais empresas do grupo compense a meta de retorno do grupo. Um ponto importante nessa fase é que a decisão de lançar ou não o produto deve ter o aval da matriz por envolver licença de produção e pagamento de royalties, mas sempre com base na obtenção do custo alvo. Dessa forma, a Alfa não tem autonomia para lançar um produto sem o aval da matriz, mesmo quando este atinge o custo alvo.

Existem projetos de produtos que são analisados pelas subsidiárias de vários países simultaneamente. $\mathrm{O}$ funcionário $\mathrm{C}$ cita o caso de um projeto que envolveu algumas empresas do grupo sob a coordenação da matriz. Foram feitos estudos para a produção de determinado 
modelo no Brasil, na Índia e na Tchecoslováquia e a conclusão foi de que sua produção era mais interessante na Índia, sendo essa a decisão final da matriz.

Outra informação importante foi um comentário do funcionário C sobre o fato de que o custo alvo de um produto aceito para lançamento é transformado e adaptado em seu custo padrão quando do início de sua produção. Assim, após o início da produção os custos dos produtos são acompanhados e controlados através da comparação entre o custo padrão e o custo real. Foi verificado também junto ao funcionário $\mathrm{C}$ que o custo real é disponibilizado pelo setor de contabilidade em tempo real no sistema. Desse modo, o Custeio Alvo é usado tanto para auxiliar na tomada de decisão de lançamento de produtos quanto para controlar custos no projeto e na produção. Por essas características o Custeio Alvo da Alfa pode ser considerado uma parte do SCG, de acordo com a definição de Simons (1990) e de Malmi e Brown (2008) discutida no Capítulo 3 (item 3.1).

Essas informações mostram como é o processo de desenvolvimento e lançamento de produtos na Alfa utilizando o planejamento de lucro e a gestão de custos para embasar a decisão final. Conforme definição proposta no Capítulo 3, Item 3.2.4, o Custeio Alvo é "um processo de gerenciamento de custo de um produto/serviço através da determinação e da obtenção do custo alvo assegurando que durante seu ciclo de vida gere o retorno desejado pela organização garantindo os requisitos dos clientes" e, pelas evidências e discussões apresentadas, essas características tiveram aderência com o processo de Custeio Alvo usado pela empresa. Por isso, a partir desta etapa do trabalho o Custeio Alvo foi considerado como parte do processo de desenvolvimento de produtos e componentes na Alfa, indicando que o mesmo foi adotado e vem sendo usado permitindo que as demais análises sejam feitas.

Foi verificado que algumas características desse processo são específicas da Alfa, como o fato de o retorno desejado poder ser referente ao grupo Alfa e não apenas à subsidiária e que a matriz pode usar a análise do custo alvo para o mesmo produto em diferentes países para verificar onde é mais vantajoso o lançamento. Essas características ampliam as fontes de planejamento de lucro e de gerenciamento dos custos.

O fato de os entrevistados chamarem o custo alvo de custo objetivo trouxe à tona um problema levantado na fundamentação teórica que evidenciou que as questões sobre adoção e utilização de práticas gerenciais por meio de levantamentos (surveys) com aplicação de questionários devem ser cautelosamente elaborados, de modo a tentar captar com maior 
confiabilidade se determinada prática existe ou não na empresa. As questões não devem apenas incluir os nomes das práticas ou descrições muito resumidas de seu funcionamento, pois isso prejudica o entendimento do respondente e pode enviesar os dados. Isso pôde ser constatado durante as entrevistas. É interessante que as características mais específicas das práticas sejam destacadas de modo a verificar se as mesmas existem e como funcionam. Deve-se também evitar denominações técnicas, tanto da prática quanto de suas características.

Verificado que o Custeio Alvo foi adotado e vem sendo utilizado pela Alfa na sequência foram tratados os aspectos relativos às teorias de base usadas na fundamentação do estudo empírico, analisando seu processo com maior detalhamento tendo por objetivo responder as questões de pesquisa secundárias. Para tanto, alguns esclarecimentos são necessários.

Como abordado anteriormente a Alfa atua no Brasil há quase quarenta anos, mas os funcionários participantes da pesquisa foram contratados há menos tempo. O funcionário D apresentou o maior tempo de trabalho na empresa atuando há vinte e cinco anos. Por isso, o ano exato da adoção da prática pela Alfa não foi possível de ser averiguado com certeza. Esse fato fez com que algumas adaptações fossem necessárias no roteiro das entrevistas. Primeiramente foi verificado que o processo de desenvolvimento de produtos da forma como descrito já era usado na empresa quando do ingresso do funcionário $\mathrm{D}$, então vem sendo usado há pelo menos vinte e cinco anos, isso é o que se pode afirmar. Devido a isso, questões relativas ao período antecedente bem como informações sobre o processo de adoção e implantação da prática não chegaram a ser formuladas aos respondentes.

O que se procurou fazer para contornar essa situação foi questionar sobre possíveis causas que ainda hoje podem ser percebidas como responsáveis pela adoção e utilização. No caso dos fatores contingentes foram verificados quais estavam presentes na Alfa à época das entrevistas e se existe adequação entre os mesmos e o uso da prática. A seguir foram feitas as análises com base na Teoria da Contingência.

\subsection{Análise das Categorias Investigadas à Luz da Teoria da Contingência}

Este tópico foi separado de acordo com as categorias avaliadas, englobando os fatores contingentes, a forma de uso do Custeio Alvo e seu desempenho. 


\subsubsection{Fatores Contingentes}

A investigação dos fatores contingentes teve como objetivo verificar aqueles que podem favorecer ou inibir a adoção e a utilização do Custeio Alvo na Alfa, apontando para a percepção de sua utilidade. Como o estudo empírico se baseia em análises de uma única empresa a noção de adequação ( $f i t$ ), inerente aos estudos que usam a Teoria da Contingência, foi estipulada de acordo com os fatores indicados como sendo propícios ou adequados pela literatura específica. Nesse sentido, a adequação indica uma similaridade entre os fatores contingentes considerados adequados pela literatura (conforme estipulado pelo Quadro 2, Capítulo 2 e pela matriz de avaliação exposta no Quadro 4, Capítulo 4) e aqueles encontrados na Alfa.

As questões relativas a essa categoria foram aplicadas aos funcionários $\mathrm{A}, \mathrm{B}$ e C por serem as pessoas com maior envolvimento com o ambiente mais amplo de atuação da organização. Pelo fato de que as entrevistas foram realizadas em duas rodadas com pessoas diferentes, é importante esclarecer como foram operacionalizadas. Os funcionários A e C fizeram parte da primeira rodada de entrevistas e foram questionados sobre os fatores ambiente, estratégia e porte. Os funcionários $\mathrm{B}$ e $\mathrm{C}$ fizeram parte da segunda rodada de entrevistas e foram questionados sobre os fatores estrutura e tecnologia. $\mathrm{O}$ funcionário $\mathrm{B}$, por fazer parte da alta gestão, também foi questionado sobre o uso e o desempenho do sistema. É importante mencionar ainda que partes das entrevistas não diretamente relacionadas aos fatores contingentes puderam ser usadas nesta categoria por apresentarem pontos interessantes e relacionados à mesma. Os dados oriundos das entrevistas e da pesquisa documental foram triangulados para verificar a existência de inconsistências de modo que possam refletir confiabilidade acerca de seu conteúdo.

\subsubsection{Fator Ambiente}

Este fator foi avaliado pela intensidade da concorrência e pela incerteza ambiental percebida. Quanto à intensidade da concorrência os funcionários $\mathrm{A}$ e $\mathrm{C}$ mencionaram ser muito dinâmica e extremamente intensa. A pesquisa documental também evidenciou esse tipo de ambiente, uma vez que se trata de empresa de classe mundial concorrendo em escala global, corroborando o conteúdo das entrevistas. A concorrência é um fator que pode influenciar a adoção e utilização do Custeio Alvo, pois em ambientes onde não existe concorrência intensa 
a organização pode ter certa flexibilidade para determinar e manipular preços de modo a obter o retorno desejado. Em ambientes com intensa concorrência a gestão e o controle dos custos são importantes quando a margem para manipulação de preços pela organização for pequena.

Um dos itens avaliados no fator concorrência que evidencia muita proximidade com o Custeio Alvo foi a frequência de lançamento de novos produtos. O lançamento de novos produtos é o foco principal para utilização dessa prática já que ela atua na gestão dos custos antes da sua ocorrência, ainda na fase de projeto. Assim, quanto mais frequente é o desenvolvimento de novos produtos mais interessante se torna sua utilização. Isso porque quanto mais frequentes são as mudanças nos produtos, os investimentos em pesquisa e desenvolvimento tendem a aumentar e o risco atrelado ao retorno quando do lançamento desses produtos também. Por isso, uma prática como o Custeio Alvo pode auxiliar na gestão desse risco por informar antecipadamente quais produtos podem trazer ou não o retorno desejado.

Além disso, a frequência de lançamento de novos produtos também está atrelada à duração do seu ciclo de vida, sendo que quanto mais frequentes são as mudanças nos modelos, menor é seu ciclo de vida e menor o tempo para obter o retorno. De acordo com o exposto e com a matriz de classificação dos fatores (Quadro 4), a intensidade da concorrência, considerada muito dinâmica, favorece a adoção e utilização do Custeio Alvo.

Quanto à incerteza ambiental percebida, ambos entrevistados responderam ser muito baixa, uma vez que para eles tanto a previsibilidade da concorrência quanto a das preferências do cliente são estáveis e apresentam alta previsibilidade. De acordo com o tipo de questão usada no instrumento de coleta de dados, uma alta previsibilidade indica uma baixa incerteza ambiental. Em relação à pesquisa documental e às outras informações das entrevistas muito foi comentado sobre as preferências dos clientes e sobre a necessidade de obtenção dessa informação para disparar o processo de desenvolvimento de novos produtos. Em nenhum momento foi mencionada qualquer dificuldade para realização dessa atividade. Um ponto que merece destaque é que a percepção das pessoas em relação à incerteza pode ser diferente, além disso, se fosse considerada a percepção de incerteza em relação à matriz a resposta poderia ser diferente.

Uma possível explicação para a alta previsibilidade das preferências dos consumidores e das atitudes dos concorrentes é o tempo de atuação da Alfa no mercado, apontado na fundamentação teórica por Tillema (2005). Estar no mercado há quase quarenta anos é indício 
de experiência no ramo, podendo resultar em certa facilidade ou habilidade para prever esses tipos de informações do ambiente. Isso não significa que a Alfa não enfrenta problemas com as previsões do ambiente. $\mathrm{O}$ funcionário $\mathrm{C}$ mencionou que às vezes a empresa não consegue acertar em todas as exigências dos clientes, mas que isso é corrigido assim que é detectada qualquer diferença.

Conforme as discussões e a matriz de classificação dos fatores contingentes, a incerteza ambiental se mostrou muito estável, o que não foi apontado como favorecendo a adoção e utilização do Custeio Alvo. No entanto, alguns comentários a esse respeito são necessários. A incerteza ambiental é um fator importante em relação ao tipo de informação necessária para atuar no ambiente. Em ambientes imprevisíveis são necessárias informações de escopo amplo para tentar prever os resultados das ações praticadas na organização e também a dos concorrentes e clientes. Se a empresa conta apenas com informações internas, históricas e financeiras a probabilidade é de que a sua relação com o mercado seja reativa. Para haver um comportamento proativo são necessárias informações que possibilitem um entendimento acerca desse ambiente, em especial quando a concorrência é intensa; por isso, a necessidade de informações de escopo amplo.

Além disso, quando da estabilidade do ambiente pode-se deduzir que informações históricas sejam suficientes para prever os resultados das ações, no entanto, há que se considerar que as demandas dos clientes e as atitudes dos concorrentes podem mudar em relação ao passado, não podendo ser captadas por informações históricas, confirmando a necessidade de informações externas e ex ante.

Dessa forma, o fato de a Alfa ter uma alta previsibilidade ou uma baixa incerteza ambiental não significa que as informações do Custeio Alvo não sejam importantes ou que isso dificulte a adoção e a utilização do mesmo. Como mencionado, o fato de a Alfa usar essa prática há algum tempo possibilita que as informações relativas aos clientes e aos concorrentes não sejam de difícil previsibilidade. De fato, o que ocorre é o inverso, ou seja, o uso da prática facilita a previsão devido à experiência obtida com seu processo. $\mathrm{O}$ funcionário $\mathrm{C}$ confirmou isso quando mencionou que o tempo de atuação da empresa e de uso dessa prática ajuda a prever as reações do mercado e as instabilidades do negócio.

Uma empresa que trabalha com certa frequência de lançamento de produtos como a Alfa deve ter conhecimento do que o mercado quer e do que os concorrentes estão fazendo de forma a 
não perder participação. Por isso, mesmo apresentando uma baixa incerteza ambiental entende-se que no caso da Alfa as informações oriundas do processo do Custeio Alvo são importantes e necessárias para atingir os resultados esperados. O que se deduz dessa discussão é que a incerteza ambiental deve ser cuidadosamente analisada nas pesquisas empíricas, pois por se tratar de fator externo outros aspectos podem ser importantes em sua relação com o ambiente interno, como o tempo de atuação e as estratégias seguidas pela organização, que é o próximo fator analisado.

\subsubsection{Fator Estratégia}

O fator estratégia foi avaliado em relação às características de mercado, ao ciclo de vida e ao posicionamento de mercado. Na primeira foram avaliados os tipos defensores, prospectores e analisadores. As respostas dos funcionários A e C mostraram que a Alfa opera com a estratégia prospectora. As prospectoras são organizações que sempre buscam por oportunidades de mercado, sendo geralmente as criadoras de mudança e incerteza no ambiente, também consideradas como empreendedoras. Porém, uma característica interessante dessa estratégia é o crescimento horizontal, sendo a organização prospectora uma definidora de produtos e mercados (MILES; SNOW, 2003) e não uma defensora no caso dos modelos já existentes.

Essa característica (crescimento horizontal) não foi encontrada no conteúdo das entrevistas nem nos textos corporativos da Alfa, o que pode indicar que não se trata de uma prospectora. O conteúdo dos discursos mostrou que a Alfa busca por oportunidades de melhorias em seus produtos existentes, como o lançamento de uma máquina híbrida que consome menos recursos, tendo um apelo ambiental, e as mudanças frequentes nos motores da marca visando um melhor desempenho de seus produtos. Um dos textos corporativos afirma que "A Alfa dispõe de uma tecnologia incomparável em suas máquinas que soma-se em produtividade e economia.". Outro texto publicado pela matriz afirma que a empresa sempre pensa nas necessidades dos clientes e que se esforça para fornecer produtos, serviços e sistemas ecologicamente corretos, seguros e inovadores.

Essas informações evidenciam que a organização se esforça por fornecer produtos diferenciados (em especial quanto à qualidade e tecnologia), mas não que essa busca seja horizontal. Não foi verificado qualquer indício a respeito de expansão das linhas de produtos 
ou de abrangência de nichos de mercado ainda não explorados. Conforme abordado no fator tecnologia de produção (item 5.3.1.5), a Alfa possui quatro tipos de produtos com diversos modelos, mas todos são voltados para o mesmo escopo, equipamentos pesados.

Pelo exposto, não foi verificado que a Alfa tenha objetivo de lançar produtos com escopo diferente dos atuais ou que abram novas possibilidades de mercado, mas sim que seu objetivo é melhorar as características de seus produtos relacionados às necessidades dos clientes e às novas tecnologias. Essas características evidenciam a estratégia do tipo defensora, pois reforçam que seu domínio de mercado é estreito e estável, conforme Miles e Snow (2003).

Outro ponto destacado sobre a organização prospectora é que pelo fato de priorizar a inovação, o controle dos custos não é enfatizado, tendendo a usar medidas mais subjetivas e planejamento abrangente, buscando eficácia e não eficiência (MILES; SNOW, 2003; CHENHALL, 2007; LANGFIELD-SMITH, 1997). Entretanto, o que foi observado na Alfa também difere dessa característica, ficando evidente a ênfase no gerenciamento e controle dos custos e na busca de eficiência. Isso pode ser observado pela forma como a empresa conduz as atividades relacionadas aos produtos, detalhadas no item 5.3.2. De forma resumida, na fase de desenvolvimento de produtos a gestão dos custos é feita antes de seu lançamento via utilização do Custeio Alvo e, posteriormente, quando o produto começa a ser fabricado seu acompanhamento e controle é feito pelo custo padrão, sendo a avaliação de desempenho baseada nessa medida. Essa constatação reforça a evidência do foco no controle e na gestão dos custos buscando eficiência, o que é típico de empresas defensoras.

Uma característica dos defensores é a percepção da estabilidade do ambiente que escolheram para atuar, uma vez que criam essa estabilidade através de suas ações e decisões (MILES; SNOW, 2003), ou seja, na implementação desse tipo de estratégia. Esse tipo de percepção foi verificada no fator incerteza ambiental, analisado anteriormente, e foi constatado uma baixa incerteza ambiental percebida, sendo outro ponto que aproxima da estratégia defensora. Por isso, a estratégia defensora também ajuda a explicar porque a percepção da incerteza na Alfa foi baixa.

Como os defensores priorizam a eficiência, os setores chave são os de finanças e produção (MILES; SNOW, 2003). Isso também pode ser verificado nas entrevistas, o funcionário C mencionou que "[...] na realidade quando a gente lança um projeto a gente envolve praticamente toda a empresa, então vem desde uma área de vendas, uma área de PCP, área de 
custo, área de compras e as fábricas." Com exceção do setor de vendas, os demais estão relacionados à produção, mas destaca-se que, conforme já mencionado, o setor de vendas atua na Alfa exclusivamente para captar as informações do mercado para o desenvolvimento de produtos e para o PCP (planejamento e controle da produção). O setor de finanças (diretor financeiro) participa das discussões de avaliação dos resultados financeiros, devido à ênfase na eficiência. Desse modo, finanças e produção são os setores chave na Alfa, típico de empresa defensora.

A tipologia prospectores e defensores estão em lados opostos de um continuum e, por isso, necessitam utilizar as informações de forma diferente para poder implementar com sucesso suas escolhas. As prospectoras têm como problema administrativo a necessidade de facilitar ao invés de controlar suas operações, já as defensoras necessitam controlar suas operações (MILES; SNOW, 2003). Pelas evidências apresentadas a Alfa atua com a estratégia defensora focando o controle dos custos e usando o Custeio Alvo para essa finalidade.

Miles e Snow (2003) mencionam que os defensores têm a habilidade de manter agressivamente sua predominância dentro do segmento escolhido para atuar e que se concentram na atualização da tecnologia de seus produtos e processos para manter a eficiência. Por isso, uma prática como o Custeio Alvo é adequada para garantir que novas tecnologias e necessidades dos clientes sejam agregadas aos produtos considerando o retorno desejado pela organização, sendo o custo alvo usado para controlar e avaliar a eficiência.

A estratégia do tipo analisadora possui características dos defensores, competindo em um domínio estreito e estável, e dos prospectores, competindo em um domínio amplo e dinâmico (MILES; SNOW, 2003). Na Alfa não foi encontrado indício de que esse segundo domínio existe e, por isso, não se trata de empresa analisadora.

A estratégia relativa ao ciclo de vida avaliou os tipos construir, manter e colher. Para ambos entrevistados a Alfa é do tipo manter, ou seja, busca manter participação no mercado e obter um retorno razoável sobre o investimento. A esse respeito foi possível verificar pela pesquisa documental que a Alfa tem um posicionamento relevante no mercado nacional (segunda posição) e o grupo Alfa tem um posicionamento destacado no mercado internacional (segunda posição), figurando como um dos principais líderes de mercado no mundo.

Conforme pontuado no Capítulo 2, a estratégia manter geralmente é implementada por empresas que buscam manter a participação no mercado e a posição competitiva, obtendo um 
retorno razoável sobre o investimento, geralmente operando com alta participação em setores com alto crescimento. Ser a segunda no mercado é indício de alta participação. Quanto ao crescimento do mercado, uma reportagem da mídia de massa (revista de negócios norte americana) de 2005 sobre o grupo Alfa informou que em 2010 as vendas em mercados em rápido desenvolvimento como o Brasil provavelmente aumentariam para $20 \%$ do total, havendo muito mais crescimento pela frente e que a Alfa estava em uma excelente posição para explorar isso.

Em relação ao retorno sobre o investimento, um texto institucional da matriz menciona que maximizar os benefícios dos acionistas não significa se concentrar nos lucros de curto prazo (que seria o objetivo do tipo colher), mas sim que o objetivo é a busca do crescimento do negócio em longo prazo. Isso mostra que a preocupação em manter sua participação no mercado faz sentido por ser alta, assim como a busca por retornos razoáveis ao invés de seu sacrifício na busca por mais participação, que seria o caso do tipo construir.

Para manter sua participação e obter retornos razoáveis a Alfa precisa implementar ações para defender sua posição e ao mesmo tempo ser eficiente. Isso evoca a estratégia do tipo defensora. A mídia de massa (revista de negócios norte americana) publicou uma reportagem no final de 2009 informando que o grupo Alfa sabe que não pode competir com a primeira do setor (empresa não asiática) em todas as frentes, por isso, sua estratégia era defender o mercado asiático onde sua participação era maior. Essas informações também constam no plano bianual de 2007/2009 da matriz. Além disso, esta reportagem também mostrou que as ações para defender a participação no mercado asiático foram acompanhadas de reduções de custos, fazendo menos modelos e fechando fábricas em outros países, e também redução de estoques para melhorar o fluxo de caixa. Essas ações são indícios de que a Alfa não tem intenção de sacrificar seu retorno, como na estratégia construir.

Pelo exposto, a Alfa busca defender sua posição competitiva e ao mesmo tempo retornos razoáveis buscando eficiência, por isso, está situada no intermediário entre as estratégias construir e colher. Isso evidencia que a estratégia manter apontada pelos entrevistados, está condizente com as outras fontes de dados (pesquisa documental e outras informações das entrevistas).

Na estratégia manter é necessária a introdução constante de produtos buscando a melhoria de qualidade (KALD et al., 2000) e desenvolvimento tecnológico, de modo a atingir os objetivos 
desejados. Pelas características apresentadas o Custeio Alvo pode favorecer a implementação dessa estratégia, pois auxilia o lançamento de produtos com as características requeridas pelos clientes e que tragam o retorno desejado pela organização.

A estratégia de posicionamento de mercado avaliou os tipos diferenciação e liderança de custo. Na Alfa as respostas dos entrevistados foram enfáticas para a diferenciação assim como o conteúdo da pesquisa documental, sendo este um ponto recorrente nos textos corporativos da matriz, da Alfa e nas entrevistas. Um exemplo foi um comentário do funcionário $\mathrm{C}$ a respeito de produtos que não conseguiram atingir o custo alvo:

\footnotetext{
Tem alguns modelos de máquinas que a gente sabe que é proibido a gente lançar aqui no Brasil. Por exemplo, você perguntou para o presidente: é preço ou é qualidade que nós vendemos, ou diferencial? Nós vendemos diferencial e não máquina barata. Então, por exemplo, tem máquinas, tem mercado que a gente não consegue entrar. Exatamente porque a gente prioriza qualidade, $o$ diferencial na máquina, a gente não consegue atingir o custo alvo.
}

Um dos textos corporativos da empresa menciona que "O grupo Alfa, [...] consagrou a sua marca por atender integralmente as necessidades de seus clientes, se destaca por possuir uma tecnologia inovadora e a excelência de qualidade é [sic] presente em seus produtos.", em outro afirma que "Todos esses diferenciais que criteriosamente pesquisados e colocados à disposição para os clientes, determinam a Alfa como uma empresa reconhecida mundialmente." e que possuem "Compromisso com a qualidade e confiabilidade.". No seu plano bianual 2007/2009 a matriz destaca que uma das suas forças são os produtos únicos e competitivos. Essas constatações reforçam a diferenciação como posicionamento estratégico.

Pelo conteúdo dos textos pode-se verificar que a Alfa busca a diferenciação com base na qualidade e inovação tecnológica e que isso conduz à confiabilidade de seus produtos, proporcionando fidelidade à marca. Essas características distinguem a diferenciação enquanto estratégia, conforme pontuou Simons (1990). Não foi encontrado indício de que a Alfa utiliza a estratégia de liderança de custos em qualquer um dos textos analisados. Ao contrário, na mesma reportagem de 2009 feita por uma revista de negócios norte americana, foi mencionado que a Alfa se defende de seus concorrentes asiáticos, os quais vendem seus equipamentos a preços mais baixos, distinguindo seus produtos via diferenciação para evitar a guerra de preços com os mesmos. A reportagem citou ainda alguns dos desenvolvimentos tecnológicos da Alfa que a diferencia dos concorrentes e que a mesma estava apostando em reforçar sua reputação como a mais inovadora do setor. 
Embora tenha sido constatado que a Alfa atua com a estratégia de diferenciação e não concorre via "guerra" de preços, algumas características da estratégia de liderança de custo foram encontradas nos discursos. Simons (1990) argumenta que a liderança de custos busca baixo preço, foca a alta participação no mercado, produtos padronizados, economias de escala e controle de custos rigoroso. Dentre esses objetivos foi constatado que a Alfa possui produtos padronizados (discutido no fator tecnologia da produção) e controle de custos rígido, buscando eficiência na produção. Essas características também se aproximam daquelas da estratégia do tipo defensora, já discutida.

Isso evidencia que embora a Alfa atue se defendendo via diferenciação de produtos, várias ações são implementadas com a finalidade de controle de custos e avaliação de desempenho, baseadas na eficiência do processo produtivo. Porter (1992) argumenta que as duas estratégias podem ser combinadas, mas que não é possível obter eficiência em custos e diferenciação bem como retornos acima da média por um longo período. Chenhall (2007) destaca essa situação mencionando que as estratégias estão se tornando complicadas, pois a maioria das organizações necessita tanto ter baixo custo quanto fornecer alta qualidade e entregas oportunas e confiáveis.

Por esses comentários o que parece contraditório é o fato de que uma organização possa competir com produtos diferenciados ao menor preço (e não ao menor custo), especialmente quando se considera o período subsequente de lançamento de um novo modelo, visto que a organização tem um período de tempo para trabalhar com o preço prêmio antes dos concorrentes lançarem sua versão do produto. Mas, o fato de competir via diferenciação e buscar eficiência não parece ser o caso de objetivos contraditórios e sim muito semelhantes à estratégia do tipo defensora, que busca eficiência num segmento escolhido trabalhando com qualidade e inovação tecnológica para não perder mercado. Langfield-Smith (2007) menciona que alguns estudos têm reconhecido que as organizações podem buscar estratégias de negócios caracterizadas por diversos aspectos da diferenciação e da liderança de custos.

Cinquini e Tenucci (2010) confirmaram a hipótese de que a taxa de uso de práticas de "custeio" (dentre elas o Custeio Alvo) é maior em organizações que competem via liderança de custos. De certa forma, é até uma questão óbvia, visto que se a empresa compete pelo menor preço, se quiser retornos acima da média também deve ter o menor custo. Mas, não significa que o contrário seja falso, ou seja, que empresas que competem pela diferenciação não precisam se preocupar com eficiência, em especial quando objetivam obter retornos 
razoáveis (como é o caso dos tipos manter ou colher e das defensoras). Obter eficiência em custo não é o mesmo que vender ao menor preço ou competir pelo menor preço.

Desse modo, competir com as estratégias defensora, manter e diferenciação, não parece ser inviável ou contraditório, e as evidências apontam que esse é o caso da Alfa. Implementar esses tipos de estratégias requer informações de escopo amplo, em especial as informações referentes ao mercado e com caráter prospectivo. Além disso, a atenção às informações de custos é importante para controlar e gerir os custos da diferenciação buscando eficiência. Por isso, uma prática como o Custeio Alvo pode auxiliar na geração informações de escopo amplo (sobre as necessidades dos clientes) e de informações para determinar e gerenciar custos ainda na fase de projeto, verificando se os produtos atendem às demandas dos clientes e são capazes de trazer o retorno esperado pela organização.

Pelo exposto, as análises sugerem que as estratégias adotadas pela Alfa referentes às três tipologias investigadas são favoráveis à adoção e à utilização do Custeio Alvo. Isso significa que essa prática não apresenta inconsistências ou conflitos para a implementação dessas estratégias; ao contrário, auxilia para que as mesmas sejam colocadas em ação. Além disso, foi verificado que as estratégias da organização não são ambíguas, estão claramente definidas e alinhadas aos meios usados para sua obtenção (aqui a atenção foi dada especialmente ao Custeio Alvo, objeto da pesquisa). Isso indica a existência de coordenação e controle, uma vez que as informações do processo de Custeio Alvo são usadas para avaliar e monitorar os custos desde a fase de desenvolvimento até a fabricação do produto.

Destaca-se que as respostas dos funcionários A e C foram confrontadas com o conteúdo da pesquisa documental bem como de todas as entrevistas e apenas no caso da tipologia de Miles e Snow foram encontradas contradições. Por isso, as declarações que avaliaram essa tipologia de estratégia no roteiro de entrevistas foram reavaliadas após essas análises. A conclusão foi de que alguém que não possui familiaridade com as características explanadas por Miles e Snow (2003) não consegue captar a diferença fundamental entre a prospectora e a defensora, qual seja, a inovação no caso da prospectora se dá em produtos e mercados ainda não explorados, enquanto nas defensoras a inovação é buscada no segmento (produtos e mercado) em que a organização escolheu para atuar. Essa diferença não ficou clara na questão usada no instrumento de coleta de dados para avaliar essa tipologia, sugerindo que em futuros trabalhos isso seja ajustado. 


\subsubsection{Fator Porte}

Quanto ao fator porte, a Alfa apresentou em 2010 uma receita operacional bruta superior a R \$700.000.000,00 e, de acordo com o BNDES (2012, on line), é classificada como empresa de grande porte. Devido a isso a empresa tem capacidade de investir mais recursos em sistemas e práticas sofisticadas, como é o caso do Custeio Alvo. Além disso, a complexidade do fluxo de informações devido ao tamanho do porte favorece a adoção e utilização das mesmas. Pela matriz de classificação (Quadro 4) o porte considerado grande favorece a adoção e utilização do Custeio Alvo.

\subsubsection{Fator Estrutura}

Em relação à estrutura foram analisadas a delegação de autoridade, o tipo de estrutura e a forma de trabalho. As questões sobre delegação de autoridade foram direcionadas ao funcionário B. Quanto às classes de decisões investigadas nesse quesito foi mencionado que o lançamento de novos produtos é discutido nas reuniões das equipes responsáveis pelo desenvolvimento de produtos, e embora o presidente esteja envolvido no processo e exerça a primeira fase de decisão, o lançamento é decidido pela matriz em última instância, com base na informação do custo alvo.

Pelo fato de a Alfa ser uma subsidiária é importante esclarecer que a delegação de autoridade é bastante influenciada pelas diretrizes da matriz, em especial na relação entre matriz e subsidiária. Isso porque alguns aspectos como a taxa de retorno objetivado são determinados pela matriz e estabelecidos no plano de negócios anual que é aprovado pela mesma. Isso é refletido nos demais aspectos ligados à centralização, uma vez que a Alfa realiza suas atividades operacionais da forma estipulada pela matriz para que possam ser acompanhadas e controladas. Assim, a obrigação da prestação de contas para a matriz em conformidade com os requisitos exigidos e por se tratar de empresa global, diminui a capacidade ou o espaço para a descentralização em algumas classes de decisões.

O funcionário B mencionou que possui delegação para as decisão de contratação e demissão de pessoal da gestão, seleção de investimentos relevantes e alocação de verbas orçamentárias. Há que se ressalvar aqui um relato interessante do funcionário $\mathrm{B}$ a respeito da tomada de decisões na Alfa. Esse funcionário enfatizou que a Alfa é diferente das empresas americanas 
em que os gestores tomam decisões de forma isolada e individual sem o envolvimento com outros níveis hierárquicos. Segundo ele, na Alfa as decisões são discutidas de forma colegiada, em reuniões compostas por funcionários de diferentes setores e níveis hierárquicos, sendo considerado o ponto de vista de gerentes e chefes que fazem parte dessas reuniões, além da alta gestão.

Por esses comentários percebe-se que a delegação de autoridade na Alfa é tratada e exercida de forma diferente de uma organização com estrutura funcional. Embora exista a hierarquia e as responsabilidades atreladas aos cargos da alta gestão, as decisões não são individuais, sendo debatidas em fóruns específicos. Quanto à formação de preços a decisão é baseada no preço levantado em pesquisa de mercado pelo setor de vendas e, portanto, o preço não é definido pela Alfa e sim pelo mercado, não havendo decisão de formação ou determinação de preços internamente.

Pelo exposto, a delegação de autoridade na Alfa apresentou aspectos peculiares que vão desde a centralização no caso de decisão de lançamento de produtos, havendo completa influência da matriz, passando pela descentralização em nível de diretoria com a presença de delegação de algumas classes de decisões até a não consideração da formação de preço como uma classe de decisão. Em relação aos outros níveis hierárquicos (gerências e chefias) existe a participação nas decisões que são discutidas em conjunto nas reuniões. Isso indica que a descentralização ocorre de forma horizontal e não vertical.

Por essas constatações o que se observa é que existe delegação de autoridade em algumas classes de decisões e que essa descentralização funciona de forma colegiada e não individual, promovendo a cultura participativa na organização. Por isso, a estrutura não é totalmente rígida (mecanicista) nem totalmente flexível (orgânica).

Quanto à formalização das funções foi verificado que existe a especificação de cargos e funções apenas de forma geral e o funcionário $\mathrm{C}$ comentou que os critérios de avaliação de desempenho são estabelecidos para grupos de funcionários e não por funções. Ainda em relação à formalização foi verificado que o manual de procedimentos apresenta especificação apenas de questões básicas e de forma geral em relação às atividades e às regras a serem seguidas e não aos cargos. Sobre a existência do manual de procedimentos o comentário do funcionário $\mathrm{C}$ foi o seguinte: "Sim, tem. Na realidade, por exemplo, para eu fazer um business plan existe todo um procedimento para fazer um business plan. Desenvolvimento de novos 
produtos existe todo um procedimento." O funcionário D comentou que quando um funcionário é contratado para o setor de desenvolvimento e compras a integração deste ocorre da seguinte forma:

Não tem manual, ele recebe uma integração, primeiro de forma macro [...] certo, depois ele dentro do setor a gente vai explicando como funciona o sistema operacional, a gente chama sistema operacional e essas dúvidas vão acontecendo todo dia e todo dia a gente vai procurando [...], mas nós temos normas de procedimentos para aquisição de material, como desenvolver, qual é o fluxo da documentação, isso a fabrica tem. [...].

Esses comentários evidenciam que os manuais apresentam questões gerais de procedimentos ligadas às atividades principais da organização e não à especificação de cargos e funções, enfatizando que a formalização não é totalmente rígida, apresentando certa flexibilidade.

Em relação ao nível de decisões operacionais o funcionário B mencionou que ficam mais a cargo dos executivos seniores, mas existe a participação e discussão dos problemas e das soluções em conjunto com funcionários de níveis intermediários, conforme comentado anteriormente. Quanto ao estilo gerencial as evidências mostraram que existe um estilo uniforme, mas não parece ser formal, uma vez que os assuntos são discutidos com os demais membros da equipe.

Foi discutido que a descentralização favorece a adoção e utilização do Custeio Alvo (conforme Quadro 4) e, de um modo geral, as análises apontam para uma relativa flexibilização e descentralização na Alfa, em especial em alguns dos quesitos da delegação de autoridade, da especificação de cargos e funções e do estilo de gestão. Essa questão bem como a classificação em estrutura mecanicista e orgânica pode ser explorada em maior detalhe em conjunto com as próximas análises sobre o tipo de estrutura e a formação de equipes, discutidas na sequência.

O quesito referente ao tipo de estrutura organizacional foi avaliado em conjunto com a forma de trabalho e foi verificado que a Alfa apresenta duas características. A primeira remete à estrutura do tipo funcional em que as funções são definidas pela especialização das atividades existindo setores como vendas, engenharia de produção, engenharia de processo, desenvolvimento e compras, controle de custos, contabilidade, dentre outros. Os funcionários alocados a esses setores possuem atribuição de tarefas específicas, mas não são formalizadas em detalhes no manual de procedimentos. 
A segunda remete à composição de equipes temporárias para desenvolvimento de produtos e de projetos, sendo compostas por funcionários de vários setores em que um dos envolvidos é o responsável pelas atividades. Um exemplo de projetos foi dado pelo funcionário $\mathrm{C}$ que mencionou a formação de uma equipe para estudar o impacto do custo da mão de obra versus o custo de robôs na fabricação dos produtos. Devido a este tipo de estrutura em equipes os gestores de cada setor são subordinados à alta gestão e ao responsável pelas equipes das quais faz parte, existindo o comando duplo. Por isso, embora existam características funcionais as evidências apontaram para a formação de estrutura do tipo matricial. Os textos corporativos também enfatizam o trabalho em equipe funcional cruzada mencionando que na Alfa a competitividade de produção requer a junção de atividades integradas com o envolvimento de departamentos e setores relevantes. Além disso, no plano de negócios publicado pela matriz foi destacado que o método usado para tornar os objetivos visíveis é o trabalho em equipe intraorganizacional.

Este tipo de estrutura permite flexibilidade por proporcionar a discussão dos problemas e suas soluções de forma colegiada, o que aumenta a possibilidade de comunicação informal com fluxo horizontal agilizando as respostas; isso porque os representantes de todos os setores envolvidos com a questão a ser discutida estão presentes e participando dos debates. Segundo os funcionários $\mathrm{B}$ e $\mathrm{C}$ isso também permite o conhecimento geral das atividades da organização e de seus problemas por todos os membros das equipes e não que os gerentes e chefes conheçam apenas os problemas de seu setor. Além disso, permite que as mudanças necessárias para adaptação ao ambiente externo ocorram de modo mais ágil do que se essas informações fossem disponibilizadas de forma isolada, para cada gestor de cada setor para análise e deliberação.

Cruzando-se as informações encontradas na Alfa sobre a delegação de autoridade e a centralização com o tipo de estrutura e a forma de trabalho foi possível verificar que alguns aspectos descritos estão ligados à estrutura do tipo mecanicista e outros do tipo orgânica. As características de centralização de decisão na cúpula, em alguns casos com decisão final da matriz, e sistemas rígidos de controle impostos pela matriz estão relacionados ao tipo mecânico de estrutura. Já as características de flexibilidade como a formalização em manuais de apenas alguns procedimentos, preocupação com a visão geral da organização para realização das funções e resolução de problemas, utilização de comunicações informais, ênfase nos princípios de relacionamento humano devido ao trabalho em grupo, formação de 
equipe funcional cruzada permitindo uma integração horizontal e maior amplitude de controle, estão relacionadas ao tipo orgânico de estrutura. Destaca-se aqui a dificuldade encontrada para "encaixar" as características da estrutura da Alfa em um modelo específico, ou apenas mecanicista ou apenas orgânico, conforme aponta a literatura (CHENHALL, 2007). Esta dificuldade foi encontrada em outros estudos como o de Nascimento (2011).

Pelo modo como as características de cada tipo de estrutura estão distribuídas percebe-se que o que se refere às decisões estratégicas (lançamento de produtos e busca de eficiência) e à realização de atividades operacionais chaves (desenvolvimento de novos produtos e controle dos custos de produção) para a implementação das estratégias estabelecidas, são rigidamente acompanhadas pela matriz (em tópicos posteriores essa questão do acompanhamento foi aprofundada). Por outro lado, embora exista determinação da matriz para a realização de atividades, procedimentos e controles, as atividades operacionais são realizadas, discutidas e acompanhadas de forma colegiada através da formação de equipes, o que promove uma maior flexibilidade e agilidade do que se fossem realizadas de forma isolada pelos setores.

Esse mix que integra rigidez e flexibilidade, que são forças opostas, talvez seja a forma encontrada pela Alfa para cumprir as exigências da matriz comprometendo-se com as metas estipuladas, devido à integração de seus membros nas atividades e discussões. Dentro da padronização de procedimentos exigida pela matriz está o processo de desenvolvimento de produtos com a utilização do Custeio Alvo. A literatura examinada apontou que a adoção e utilização do Custeio Alvo são favorecidas em ambientes descentralizados, mas na Alfa existem características de centralização por ser uma subsidiária. No entanto, talvez pelo fato de a rigidez corresponder ao relacionamento com a matriz e a flexibilidade à realização das tarefas rotineiras e às relações pessoais, o processo do Custeio Alvo encontra ambiente propício para ser executado.

Dessa forma, em relação à estrutura as evidências apontaram para o tipo matricial com estabelecimento de equipes funcionais cruzadas, apresentando flexibilidade para reações às mudanças ambientais e cultura participativa. De acordo com o Quadro 4 a adoção e utilização do Custeio Alvo são favorecidas para o tipo matricial e flexível e com utilização de equipes e cultura participativa. Nesses quesitos as características encontradas na Alfa favorecem a utilização do Custeio Alvo. 


\subsubsection{Fator Tecnologia}

O fator tecnologia foi separado em tecnologia da informação e tecnologia da produção. Em relação à primeira foi avaliada a qualidade do sistema de informação e os tipos de sistemas usados. Quanto aos tipos de sistemas de informação usados, segundo o funcionário C o comércio eletrônico não é feito na Alfa, pois existe uma empresa específica para vendas e relações com clientes, que operacionaliza esse sistema. Foi comentado que a Alfa também possui relação com clientes, em especial por causa do levantamento de suas necessidades, mas não existe um sistema de gerenciamento dessa relação. Quanto às outras tecnologias presentes no roteiro de entrevistas o funcionário $\mathrm{C}$ mencionou que todas são usadas com bastante intensidade.

O sistema de gestão é integrado do tipo ERP denominado BAAN, integrando informações de setores como produção, finanças, contabilidade, vendas, etc. Algumas informações desse sistema são atualizadas semanalmente e outras em tempo real; por exemplo, os dados de produção e outros operacionais, incluindo os custos reais, são atualizados em tempo real. O sistema gerencial é o Hyperion da Oracle ${ }^{\circledR}$ e é alimentado com os dados do BAAN, sendo um sistema de business inteligence e atualizado em tempo real.

Existem em alguns setores da Alfa (contabilidade e controle de custos, por exemplo), painéis que projetam informações do Hyperion em tempo real e os funcionários também podem ter acesso através de seus computadores e notebooks. Desse modo, os sistemas possuem integração e acessibilidade entre os diversos setores. Para o funcionário B o sistema gerencial (Hyperion) é considerado amigável, pois disponibiliza as informações também na forma de gráficos, o que facilita seu entendimento. O funcionário B também comentou que este sistema disponibiliza uma ampla variedade de dados de custos e avaliação de desempenho.

Existe também um sistema de armazenamento de dados (data warehouse) responsável por integrar o BAAN e o Hyperion, uma vez que os dados do BAAN não são armazenados no próprio sistema. De forma geral, a Alfa utiliza vários sistemas relacionados à tecnologia de informação e os funcionários $\mathrm{B}$ e $\mathrm{C}$ foram unânimes em relação à qualidade dessa tecnologia, sendo que todas as declarações apontaram para isso. De acordo com o Quadro 4, indícios da presença de tecnologia de informação e da percepção de sua qualidade favorecem a utilização do Custeio Alvo, uma vez que pode facilitar a coleta e a disseminação dos dados e das informações na organização. A utilização do Custeio Alvo demanda diversos tipos de dados 
(como financeiros, não financeiros, históricos, futuros, do ambiente externo e interno etc.) e a tecnologia da informação permite que o mesma possa ser implementado.

Quanto à tecnologia da produção os primeiros itens avaliados foram a diversidade de produtos e o sistema produtivo. Os produtos da Alfa disponibilizados ao mercado são apresentados em quatro tipos principais dentro dos quais existem vários modelos padronizados, num total de vinte e dois modelos. Para esses produtos padrões a Alfa também disponibiliza alguns opcionais. Os produtos são produzidos (tanto o modelo padrão quanto a inclusão dos opcionais) de acordo com a demanda prevista pelo setor de vendas, sendo os lotes programados por demanda prevista. O setor de vendas verifica a demanda anual e mensal e de acordo com isso o PCP dispara o processo, distribuindo essa produção por modelos durante os dias do mês, resultando em pequenos lotes. Com isso, os produtos são fabricados em série (de acordo com a demanda prevista), mas também existem as encomendas (que são encaixadas no processo produtivo).

O fluxo de produção é contínuo, com presença de repetitividade nas tarefas da produção, mas existe também certa flexibilidade, no caso da troca de modelo que pode ser feita a qualquer momento para atender encomendas específicas. A produção é do tipo empurrada e controlada pelo PCP. Quanto aos produtos acabados existe estoque, uma vez que a produção é feita pela demanda prevista, o armazenamento é feito na empresa, mas não em grandes quantidades.

Em relação à adequação do sistema produtivo, o Quadro 4 aponta que a utilização do Custeio Alvo é favorecida pela utilização de produtos especializados, diversificados, com baixo volume e produção enxuta e flexível. Pelas declarações percebe-se que algumas dessas características existem na Alfa o que favorece sua utilização. Os produtos são padronizados; existe um baixo nível de especialização (apenas em relação aos opcionais); a empresa disponibiliza vinte e dois modelos, o que caracteriza certa diversidade; a produção é em série e por encomenda; com volume de pequenos lotes previstos de acordo com a demanda de mercado, possuindo certo grau de flexibilidade.

Para complementar essa análise é importante verificar a complexidade do sistema produtivo, que foi outro item avaliado na tecnologia de produção. O tempo de set up varia muito em relação ao tipo de máquina usada na fabricação dos produtos, mas a empresa sempre trabalha com a política de redução desse tempo. Em relação à formação de estoques de materiais e componentes existe muita variação, podendo existir itens que operam no modelo JIT, como os 
materiais e componentes nacionais; os quase JIT, no caso de peças fabricadas internamente e que possuem pouco estoque; e a formação de estoques como no caso dos materiais e componentes importados. Neste último caso a transação para sua aquisição leva de 4 a 5 meses até chegar os componentes na fábrica, por isso, são comprados para estoque por período aproximado de 1 a 2 meses, uma vez que a falta desses componentes pode interromper o processo produtivo. Por isso, a formação de estoques depende do tipo do material e do componente, mas a regra é estocar sempre o mínimo possível dentro da margem de segurança, não havendo recebimento de materiais e componentes em grandes lotes. Isso pode ser observado em visita à fábrica.

O layout da fábrica também não é padronizado. Existem células de produção em alguns processos, como na usinagem, e existe a produção em série, como no caso do chassi. Em relação ao controle de falhas no processo também depende do tipo. A usinagem faz a inspeção por lotes e a calderaria por processo. No caso da solda é feita auditoria de inspeção quando se trata de componentes fabricados por fornecedores, pois os mesmos já vêm soldados. Existe o treinamento dos funcionários para a rotatividade em várias funções, sendo utilizada com bastante intensidade. $\mathrm{O}$ funcionário $\mathrm{C}$ mencionou que a produção tem bastante flexibilidade em relação à rotatividade da mão de obra entre as diversas atividades na produção.

Esses aspectos dos produtos e do sistema produtivo evidenciam a existência de características de produção enxuta e de complexidade. Um dos textos corporativos da matriz evidencia que as empresas do grupo utilizam o sistema de manufatura flexível, o qual é considerado uma das forças competitivas da organização. Conforme Quadro 4 a produção enxuta e a complexidade do sistema produtivo da Alfa favorecem a adoção e utilização do Custeio Alvo.

É relevante mencionar que, apesar de disponibilizar modelos de produtos padronizados, a Alfa é uma organização defensora que trabalha com a diferenciação. Por isso, novos modelos de produtos devem continuamente ser desenvolvidos para atender as necessidades dos clientes, especialmente por se tratar de produtos que envolvem alta tecnologia e estarem ligados à inovação no mercado em que atuam. Devido a isso, a utilização do Custeio Alvo pode atender alguns dos requisitos informacionais para implementação dessas estratégias, conforme já mencionado. Nesse sentido, a duração do ciclo de vida dos produtos parece fazer mais sentido na avaliação sobre a utilidade do Custeio Alvo do que a característica dos produtos (padronizados ou especializados). 
Em relação ao uso de tecnologias contemporâneas foi possível verificar pelo conteúdo das entrevistas que a Alfa utiliza a gestão da qualidade total, o Kaizen, as certificações ISO 9001 e 14001, o sistema de produção flexível em alguns casos, o CAD, a manufatura integrada por computador (CIM), o CAM, planejamento de requisições de materiais, planejamento de recursos da produção e o kanban. A utilização dessas tecnologias pela Alfa auxilia o processo produtivo e podem favorecer o uso do Custeio Alvo (de acordo com o Quadro 4), em especial no caso da manufatura flexível e da gestão da qualidade total por estarem ligadas ao processo dessa prática.

\subsubsection{Outros Aspectos}

Durante a análise dos dados outros aspectos, como a duração do ciclo de vida e o ramo de atuação, que podem auxiliar ou favorecer a adoção e utilização do Custeio Alvo emergiram. No entanto, estes não são tratados na literatura como fatores contingentes, por isso, não foram discutidas na fundamentação teórica questões como sua mensuração e avaliação bem como sua adequação em relação à prática analisada.

Um ponto mencionado de forma recorrente na literatura é que a redução do ciclo de vida dos produtos influenciou o desenvolvimento do Custeio Alvo, por isso, também pode favorecer sua adoção e utilização pelas organizações. Esse aspecto foi mencionado em algumas das análises anteriores. Na Alfa, segundo o funcionário C, até seis anos atrás o produto conseguia ficar no mercado brasileiro cerca de cinco a sete anos, sem renovação de modelo ou características, e hoje segue o ritmo do mercado mundial com ciclo de vida de cerca de dois anos. Para o funcionário C “[...] essa característica mudou bastante, principalmente com esses novos entrantes que são coreanos, chineses [...], hoje o que é lançado lá fora logo em seguida já é lançado aqui no Brasil.”. Em 2011 a organização trabalhou com o lançamento de cinco produtos, sendo que dois já haviam sido lançados entre janeiro e março.

Como a Alfa trabalha para atingir a margem desejada com o produto dentro desse período (média de dois anos), a gestão dos custos ainda na fase de projeto é essencial. Conforme mencionado, para competir com estratégias do tipo defensora, manter e diferenciação, a organização necessita atualizar seus produtos constantemente, o que reduz o ciclo de vida dos modelos disponíveis no mercado, mas ao mesmo tempo busca atingir as metas de retorno. Por isso, as incertezas estratégicas estão relacionadas ao sistema produtivo, desde o 
desenvolvimento de produtos até sua fabricação, priorizando a busca de eficiência com foco no controle de custos. A utilização de uma prática como o Custeio Alvo se encaixa nesses objetivos e, conforme mencionado nas entrevistas, suas informações são centrais para essa finalidade. Nesse sentido, a duração do ciclo de vida pode ser um aspecto que favorece a adoção e a utilização do Custeio Alvo, pelo fato de haver a necessidade de análises de lucratividade mais apuradas para atender as estratégias estabelecidas nesse intervalo.

O ramo de atuação foi um aspecto investigado em alguns estudos sobre Custeio Alvo mostrando que o ramo de manufatura apresentou maior frequência entre os adotantes dessa prática, seguidas pelas indústrias de processamento. Outras pesquisas buscaram demonstrar que essa prática pode ser usada em setores diversos incluindo o de serviços. Por isso, entendese que esse não é um aspecto que possa influenciar a adoção do Custeio Alvo, mas pode favorecer ou inibir sua utilização dependendo das características apresentadas pelos produtos e serviços. A Alfa atua no ramo de fabricação de equipamentos pesados e não foi verificada nenhuma inconsistência de sua utilização nesse tipo de produto.

O Quadro 5 mostra um resumo dos fatores contingentes presentes na Alfa em relação aos considerados adequados pela literatura. 
Quadro 5 - Resumo da análise dos fatores contingentes

\begin{tabular}{|c|c|c|c|}
\hline $\begin{array}{l}\text { Fatores } \\
\text { Contingentes }\end{array}$ & & Adequação pela Literatura & Alfa \\
\hline $\begin{array}{l}\text { Incerteza } \\
\text { ambiental }\end{array}$ & & Alta & Baixa \\
\hline $\begin{array}{l}\text { Intensidade da } \\
\text { concorrência }\end{array}$ & & Alta & Alta \\
\hline \multirow[t]{3}{*}{ Estratégia } & $\begin{array}{l}\text { Posicionamento } \\
\text { de mercado }\end{array}$ & $\begin{array}{l}\text { Diferenciação ou liderança de } \\
\text { custos }\end{array}$ & Diferenciação \\
\hline & $\begin{array}{l}\text { Características } \\
\text { de mercado }\end{array}$ & $\begin{array}{l}\text { Prospectoras, analisadoras ou } \\
\text { defensoras }\end{array}$ & Defensora \\
\hline & Ciclo de vida & Construir, manter ou colher & Manter \\
\hline Porte & & Médio-grande ou grande & Grande \\
\hline Estrutura & & $\begin{array}{l}\text { Orgânica, descentralizada, } \\
\text { cultura participativa, do tipo } \\
\text { matricial, com formação de } \\
\text { equipes para desenvolvimento } \\
\text { de produtos }\end{array}$ & $\begin{array}{l}\text { Características de estrutura } \\
\text { orgânica, certo grau de } \\
\text { descentralização (em especial } \\
\text { no sentido horizontal), cultura } \\
\text { participativa, tipo matricial, } \\
\text { com formação de equipes } \\
\text { temporárias. }\end{array}$ \\
\hline $\begin{array}{l}\text { Tecnologia } \\
\text { informação }\end{array}$ & & A utilização pode favorecer & $\begin{array}{l}\text { Utilização de vários tipos de } \\
\text { tecnologia da informação, com } \\
\text { percepção de qualidade nos } \\
\text { sistemas avaliados. }\end{array}$ \\
\hline $\begin{array}{l}\text { Tecnologia } \text { da } \\
\text { produção }\end{array}$ & & $\begin{array}{l}\text { Produtos especializados, } \\
\text { diversificados, com baixo } \\
\text { volume e produção enxuta e } \\
\text { flexível. A utilização de } \\
\text { tecnologias contemporâneas } \\
\text { pode favorecer }\end{array}$ & $\begin{array}{l}\text { Produtos padronizados, } \\
\text { diversificados, com baixo } \\
\text { volume e características de } \\
\text { produção enxuta e flexível em } \\
\text { alguns aspectos. Existe o uso de } \\
\text { várias tecnologias } \\
\text { contemporâneas }\end{array}$ \\
\hline
\end{tabular}

Pelo exposto no Quadro 5, poucos dos fatores contingentes presentes na Alfa apresentaram diferença em relação à literatura e, conforme discutido nas análises, nenhum deles foi considerado inadequado ou com possibilidade de inibir a utilização do Custeio Alvo. Nenhuma inconsistência ou desalinhamento que prejudicasse a utilização dessa prática foi detectado. As respostas para a questão 1.1 (Dos fatores contingentes descritos na literatura como relacionados à adoção do Custeio Alvo, quais estavam presentes na empresa objeto do estudo de caso inibindo ou favorecendo sua utilização?) estão evidenciadas no Quadro 5, e todos os fatores foram considerados como favorecendo a utilização.

\subsubsection{Dimensão Uso do Custeio Alvo}

A investigação do tipo de uso que a alta gestão da Alfa faz do Custeio Alvo é importante para mostrar de que forma o mesmo está relacionado às estratégias, como pode influenciar as mesmas e auxiliar sua implementação; porém para facilitar o entendimento é necessário verificar onde essa prática está inserida nesse processo. Conforme abordado em item anterior 
a Alfa compete pela busca de inovação em seus modelos de produtos existentes através da diferenciação de forma defensora com objetivo de manter a participação de mercado e garantir retorno razoável sobre o investimento. Para tanto, a empresa busca eficiência através do controle dos custos para a obtenção do retorno desejado.

De acordo com os objetivos da empresa (refletidos pelas estratégias), as incertezas estratégicas do negócio estão relacionadas ao surgimento de novas tecnologias e aos atributos exigidos pelos clientes que têm potencial para modificar os modelos existentes e, por consequência, sua estrutura de custos, afetando o resultado. Essas incertezas estratégicas influenciam o desenvolvimento de produtos, a fabricação e a entrega dos produtos acabados, incluindo nessa fase as atividades e os gastos pós-vendas. Devido a isso, foi verificado que a alta gestão (especialmente o presidente) acompanha pessoalmente e periodicamente o sistema de controle que envolve esse processo, sendo o Custeio Alvo uma das práticas usadas no mesmo.

Para acompanhar esse processo são feitas reuniões em que são discutidos os projetos submetidos ao desenvolvimento de produtos bem como o acompanhamento do processo produtivo. Participam dessas reuniões os membros representantes dos setores envolvidos (como as engenharias, desenvolvimento e compras, vendas, controle de custos) e o presidente da organização. Segundo o funcionário A, "Nós temos uma reunião mensal checando o custo de todos os setores, checando resultado e também o custo que está sendo usado para o resultado financeiro. [...].", nessa reunião de acompanhamento de resultados o diretor financeiro também participa. Além dessa, o funcionário $\mathrm{C}$ mencionou que existem reuniões semanais para acompanhamento dos projetos e outra diária “[...] para ver como está a fábrica, atendeu ou não atendeu, porque na realidade a gente tem meta de entrega por dia sabe? Olha tem pedido tem que entregar. Então tudo isso aí é planejado. E se não entregou porque não entregou, qual o motivo.”.

Conforme os comentários, as reuniões são feitas para acompanhamento de resultados financeiros, acompanhamento dos projetos e acompanhamento das atividades da fábrica, todas com a participação do presidente, envolvendo a discussão das incertezas estratégicas e dos fatores críticos de sucesso relativos às estratégias estabelecidas. Nessas reuniões são discutidas as metas propostas para a empresa bem como as atividades e ações que estão sendo realizadas para sua obtenção. $\mathrm{O}$ funcionário $\mathrm{C}$ comentou sobre essas reuniões mencionando que as discussões são feitas “[...], não para procurar um culpado, mas para dar uma solução 
para o problema. [...].”. Isso indica que os problemas são tratados de um modo construtivo, proporcionando o aprendizado por toda a organização de maneira conjunta, pois participam membros de vários setores e vários níveis hierárquicos (diretores, gerentes, chefes).

O Custeio Alvo faz parte desse processo apoiando o processo decisório e o controle de custos para obtenção dos resultados esperados. De acordo com o funcionário A, a Alfa elabora um plano de negócios no início de cada ano de acordo com as diretrizes e metas estipuladas pela matriz, durante o ano são realizadas as atividades para atingir essas metas e o Custeio Alvo auxilia esse processo. O cálculo e a obtenção do custo alvo é o principal procedimento para tal. Tanto que somente são lançados os produtos que conseguem atingir o custo alvo e, por consequência, o retorno desejado. Posteriormente, quando da fabricação do produto, o custo alvo é transformado no padrão, sendo usado para o controle dos custos produtivos. Isso indica que o processo do Custeio Alvo está atrelado à atividade de desenvolvimento de produtos, mas também apoia o sistema de controle de custos na fase de produção e na avaliação de desempenho.

Com essas constatações foi possível verificar que esse processo bem como as informações geradas pelo Custeio Alvo são agendas importantes e permanentes dirigidas pelos níveis mais altos da gestão; os dados e informações são interpretados e discutidos em reuniões de superiores e subordinados e, ainda, o processo se apoia em desafios e debates contínuos de informações fundamentais para embasar os planos de ação necessários nesse processo. Todas essas características evidenciam o uso interativo de acordo com Simons (1991), em especial porque o acompanhamento das metas não é feito por exceção, mas de forma permanente. Ressalta-se que todas as alternativas da questão 64, referente ao uso interativo (letras f a i) no roteiro de entrevistas, foram consideradas como de utilização intensa pela Alfa de acordo com o funcionário $\mathrm{B}$, sendo confirmado também pelo conteúdo das demais entrevistas.

O funcionário A comentou que a utilização das informações do Custeio Alvo também auxilia na avaliação do lucro e no orçamento. Para o funcionário $\mathrm{B}$, o custo alvo também é usado para auxiliar no estabelecimento de metas e para alinhar medidas de desempenho com prioridades e metas estratégicas, modelando os incentivos de acordo com o desempenho. Embora esses comentários relacionem o uso da informação de maneira diagnóstica, monitorando o desempenho e corrigindo os desvios existentes, esse acompanhamento não é realizado de forma periódica nem por exceção. 
Desse modo, as informações são usadas também de forma diagnóstica, mas devido à forma de envolvimento da alta gestão nesse processo e a sua ligação com as estratégias estabelecidas, além da forma de acompanhamento envolvendo vários setores e níveis hierárquicos, o tipo de uso predominante do sistema de controle ao qual o Custeio Alvo está vinculado é o interativo. A literatura aponta que os sistemas de controle podem ser usados das duas formas, sempre havendo uma predominante. A opção por uma das formas de uso não significa que uma seja melhor que outra, mas sim que a depender do contexto e das incertezas estratégicas os gestores escolhem um sistema de controle para acompanhar de modo mais intensivo, no caso o interativo.

Em relação ao uso disfuncional todas as alternativas da questão 64 (letra $\mathrm{j}$ a 1) foram apontadas pelo funcionário B como tendo pouca utilização, indicando a ausência desse tipo de uso. Ressalta-se que, em relação ao uso da prática para medir variáveis não relacionadas às prioridades estratégicas e como fonte de poder político e influência, o funcionário B mencionou que as tarefas e a avaliação de desempenho são realizadas por equipes e não por funções, o que não dá margem para manipulações entre os setores. Mencionou ainda que o Custeio Alvo não pode ser usado para construção de folgas nas medidas uma vez que o custo padrão (base para avaliação de desempenho) é construído com base no custo alvo e depois é comparado com o custo real, por isso, qualquer tipo de folga seria detectada e cobrada dos gestores pela matriz.

Por essas constatações, a resposta da questão 1.6 (Que tipo de uso - diagnóstico, interativo ou disfuncional - a empresa objeto do estudo de caso vem fazendo em relação ao Custeio Alvo?) é que o sistema de controle em que o Custeio Alvo está atrelado é usado predominantemente de forma interativa, por consequência, suas informações também.

\subsubsection{Desempenho do Custeio Alvo}

Essa categoria foi avaliada tendo por base a satisfação do usuário e a utilidade percebida, que representa o impacto individual. $\mathrm{O}$ funcionário $\mathrm{B}$ afirmou estar muito satisfeito com o sistema gerencial e com os resultados do processo do Custeio Alvo. Em relação à utilidade percebida todas as alternativas foram consideradas como de alto impacto pelo funcionário $\mathrm{B}$, o que indica a percepção da utilidade do sistema em relação às tarefas e aos resultados esperados pela organização. O funcionário B também comentou que sem o processo de Custeio Alvo 
não dá para iniciar um projeto e afirmou "Eu não consigo ver a fábrica sem o custo objetivo.", pois é a base de tudo que é feito lá e disse ainda que "O custo padrão e o objetivo é tudo para a empresa.”. Destaca-se que o custo objetivo é o custo alvo.

Dado que o conteúdo das entrevistas, em especial do funcionário B, mostrou satisfação com o sistema e a percepção de sua utilidade, destacando-se a dependência das informações do Custeio Alvo nas atividades e na avaliação de desempenho, a resposta da questão 1.7 (O desempenho do Custeio Alvo quanto à satisfação dos usuários e ao impacto individual, na empresa objeto do estudo de caso, inibe ou favorece sua utilização?) é que o desempenho dessa prática favorece sua utilização.

\subsection{Análise das Categorias Investigadas à Luz da NSI}

As questões de pesquisa e as análises baseadas na NSI foram separadas em dois momentos, a adoção, englobando os fatores institucionais e econômicos que inibiram ou favoreceram a mesma, e a implementação, que avaliou o estágio do processo de institucionalização, os fatores institucionais e econômicos presentes nesse processo que podem ter influenciado o modo como o Custeio Alvo foi institucionalizado e a resposta estratégica da organização (coupling ou decoupling). Todas as categorias avaliadas estão relacionadas ao modelo teórico proposto (Figura 4.1) para as análises e o objetivo foi de responder as questões secundárias de pesquisa relativas à NSI.

Um fato que não era esperado nesta parte do trabalho acabou por não permitir que algumas das questões que buscavam respostas sobre os fatores institucionais e econômicos na fase de adoção pudessem ser feitas de forma direta, pois os funcionários entrevistados foram contratados após a adoção do Custeio Alvo. Por isso, indícios dessas categorias foram buscados nas entrevistas e na pesquisa documental com base nas possíveis causas que ainda hoje podem ser percebidas como responsáveis pela adoção.

Por um lado, a questão da época da adoção e a dificuldade em obter dados sobre esse período representaram uma limitação em relação aos objetivos iniciais da pesquisa. Por outro auxiliou nas análises sobre o processo de institucionalização e sobre a resposta estratégica, uma vez que o Custeio Alvo foi adotado há pelo menos vinte e cinco anos, o que pode indicar que esse processo esteja relativamente estabilizado, não estando em fases iniciais de mudança. Isso 
permite capturar num estudo transversal o efeito do processo, ou seja, a resposta estratégica como seu resultado. Isso não significa que não possa existir mudança, uma vez que estabilidade e mudança são elementos inerentes ao processo de institucionalização.

\subsubsection{Fatores Institucionais Relacionados à Adoção}

Os fatores institucionais foram usados para investigar a pressão por legitimidade. Essa análise foi realizada levando-se em consideração dois tipos de fatores institucionais, sendo os mecanismos de mudança isomórfica, em que se buscou captar a forma predominante de difusão do Custeio Alvo na Alfa; e a legitimidade, buscando verificar indícios de sua presença de modo a influenciar essa fase do processo de institucionalização.

\subsubsection{Mecanismo de Mudança Isomórfica}

Conforme abordado na fundamentação teórica (Capítulo 2 item 2.2.2.5) os mecanismos de mudança isomórfica podem ser três: o coercitivo, o normativo e o mimético. Pelas características da Alfa e de seu contexto e pelos dados das entrevistas os indícios apontaram que o mecanismo coercitivo tenha sido o responsável pela adoção do Custeio Alvo. Na sequência foram apresentados as evidências e os argumentos que sustentam essa conclusão.

O isomorfismo coercitivo é resultado de pressões formais e informais que as organizações experimentam exercidas por outras organizações das quais depende e pelas características culturais da sociedade em que atuam. Um exemplo disso, discutido na fundamentação teórica, é que as subsidiárias podem ser obrigadas a adotar práticas contábeis, avaliação de desempenho e planos orçamentários de acordo com as políticas da matriz (DIMAGGIO; POWELL, 1983). Esta foi uma evidência no caso da Alfa por ser uma subsidiária do tipo global e pelo fato de a literatura acadêmica mencionar a utilização do Custeio Alvo pela matriz, informação confirmada pelo funcionário $\mathrm{C}$ quando comentou que há muito tempo essa prática é usada na matriz.

O site da Alfa contém várias declarações de que são seguidas as mesmas diretrizes da matriz e que compartilham as mesmas filosofias, conforme já mencionado. O presidente e o diretor financeiro são oriundos do país de origem da matriz e nomeados por ela, o que caracteriza um 
tipo de dependência. Além disso, foi verificado que o método de custeio, o preço de transferência e o cálculo dos lucros consolidados são estipulados pela matriz e que as planilhas de custos e resultados são todas semelhantes às da matriz. A análise em relação aos custos fixos segue as diretrizes da matriz e o retorno estipulado para as subsidiárias é determinado pela matriz. Cerca de duas vezes por ano a empresa envia suas planilhas de custos para a matriz para prestação de contas. Algumas dessas informações possuem caráter estratégico e a partir delas a matriz controla os resultados do grupo. Toda decisão final sobre lançamento de produtos, que é uma atividade chave da organização, é de responsabilidade da matriz e baseada no custo alvo. Indicando que o processo de Custeio Alvo é exigido pela matriz.

Quando questionado se a matriz usa o mesmo processo de Custeio Alvo que a subsidiária o funcionário $\mathrm{C}$ responde que “[...] dentro do grupo em termos de desenvolvimento o procedimento é o mesmo. [...] eles fazem a mesma coisa também, tanto é que as planilhas que a gente usa são todas parecidas [...].”. Em outro comentário sobre um projeto que foi analisado entre várias subsidiárias sob o comando da matriz ficou claro que o processo do Custeio Alvo é igual tanto na matriz quanto nas subsidiárias, caso contrário esse tipo de análise conjunta seria difícil de ser praticado.

Foi verificado nas entrevistas se os funcionários têm conhecimento do uso do Custeio Alvo pelos concorrentes, que poderia ser uma fonte de imitação remetendo ao mimetismo. As respostas mostraram que a informação sobre a utilização ou não do Custeio Alvo pelas empresas concorrentes não tem importância para os entrevistados. O funcionário D mencionou: "Vou te dar uma resposta de ordem pessoal, eu não estou preocupado com o que a concorrência utiliza ou não, eu fico preocupado se eu vou conseguir atingir o meu custo, o meu target.". Essa visão foi corroborada pelo funcionário C que afirmou que "[...] a gente não se preocupa com isso, a gente se preocupa por conta de estar conseguindo colocar no mercado. Porque cada empresa tem a sua história [...].".

Por essas constatações foi possível verificar que a subsidiária está sob controle da matriz existindo dependência em relação a vários aspectos, em especial aos procedimentos e controles. A matriz impõe desde o retorno objetivado até o preço de transferência que deve ser usado, não restando muita autonomia para a subsidiária. Os estudos analisados na fundamentação teórica sobre subsidiárias confirmam que se uma prática é exigida pela matriz a subsidiária é obrigada a obedecer e esse parece ser o caso da Alfa. Dessa forma, a evidência 
mais provável foi de que o isomorfismo coercitivo, pressão da matriz em relação à subsidiária, tenha sido o mecanismo de difusão para a adoção do Custeio Alvo.

Investigar o mecanismo de isomorfismo é importante porque esse tipo de exigência para a adoção, no caso a coerção, pode gerar reações a tal imposição influenciando a resposta estratégica. Por isso, essa constatação também vai ser usada na análise referente ao tipo de resposta estratégica da Alfa (item 5.4.3.3).

\subsubsection{Legitimidade}

A busca de legitimidade pode ser um dos fatores que influenciam a adoção e a institucionalização de práticas como o Custeio Alvo. Nessa pesquisa dois tipos de legitimidade foram avaliados, um relacionado à matriz e outro ao ambiente externo em que a Alfa se situa (legitimidade interna e externa). Qualquer evidência (nos textos corporativos e nas entrevistas) relativa à busca de legitimidade nesses dois ambientes serviu como indicador de sua presença. Primeiro foi avaliada a legitimidade interna e externa de forma geral no grupo Alfa com o objetivo de contextualizar a preocupação com a mesma e, posteriormente, foi avaliada de forma específica a legitimidade da Alfa em relação ao Custeio Alvo.

De modo geral, os textos corporativos tanto da matriz quanto da subsidiária mostraram que os valores corporativos e as crenças são comuns à matriz e às subsidiárias, assim como existe um compromisso para o cumprimento das regras de conduta e dos procedimentos estabelecidos. Uma declaração institucional da matriz afirma que os códigos de conduta da organização são importantes princípios norteadores e indicam o que o grupo deveria ser. A Alfa menciona em um dos textos institucionais que "As diretrizes e estratégias da alta administração são pontualmente implantadas em todo o grupo Alfa para atingir os objetivos". Isso caracteriza indício de legitimidade interna, uma vez que assumir os mesmos valores e cumprir as determinações impostas nos códigos de conduta e nas normas coloca as atividades e os resultados da Alfa em conformidade com os procedimentos considerados adequados pela matriz, legitimando os mesmos.

Em relação à busca de legitimidade externa do grupo os textos mostram que o valor corporativo é a qualidade e confiabilidade e que isso representa a soma da confiança que a sociedade em geral e todas as partes interessadas depositam no grupo Alfa. Para a empresa a 
busca desse valor assegura que os produtos e serviços sejam altamente valorizados pelos clientes, o que é uma crença. Pode-se verificar por outros textos corporativos e pelas entrevistas que a busca desses valores é empreendida como forma de legitimar as ações do grupo, ou seja, os procedimentos, as rotinas, as práticas gerenciais e os resultados são fundamentados nessa busca.

De modo mais específico a Alfa busca legitimidade interna cumprindo os requisitos e exigências da matriz, tanto de procedimentos quanto de prestação de contas. Por exemplo, a atividade de desenvolvimento de produtos é feita sempre da mesma forma, atendendo todos os requisitos exigidos, sendo amparada pelas informações que auxiliam na decisão final sobre o lançamento dos mesmos. Essa decisão sempre é tomada com base na informação do custo alvo. Desse modo, o Custeio Alvo e, especificamente, o resultado de seu processo (atingiu ou não o custo alvo) é usado para legitimar essa decisão na Alfa e na matriz. Uma declaração do funcionário C ilustra essa questão: “[...] antes de começar o projeto é feito um estudo de custo alvo onde a diretoria aprova e só através disso a matriz também vai aprovar a produção desse novo produto.".

Declarações das entrevistas mostraram um caso em que foi verificada a necessidade de lançar um modelo de produto no mercado nacional, mas que o mesmo não havia atingido o custo alvo, não sendo lançado. Posteriormente, foi feita a análise de seu custo alvo em outros países até que esse fosse atingido e o produto lançado. $\mathrm{O}$ funcionário $\mathrm{C}$ mencionou que os projetos que não atingem o alvo são arquivados e que “[...] Tem máquina, por exemplo, que eu já estudei umas quatro ou cinco vezes [...].”. Isso mostra que a informação do custo alvo sempre embasa essas decisões conferindo legitimidade tanto para lançar quanto para não lançar um produto.

Uma vez que todos os procedimentos e normas determinados pela matriz são seguidos na atividade de desenvolvimento de produtos esta é legitimada, independente de atingir ou não o custo alvo. As entrevistas também evidenciaram que o valor corporativo da qualidade e confiabilidade e as estratégias seguidas são considerados essenciais de modo que a empresa não lança produtos apenas para atingir o retorno desejado, mas também para garantir os requisitos dos clientes, a inovação tecnológica e a qualidade, sendo que o processo do Custeio Alvo auxilia e legitima esse tipo de decisão. Percebe-se com isso estreita relação entre os discursos (quanto aos valores e objetivos organizacionais) e as ações implementadas para sua consecução. Esse entendimento é reforçado com uma declaração do funcionário $\mathrm{C}$ quando 
questionado se a Alfa em algum caso utiliza o custo mais margem (mark up) para precificar produtos, a resposta foi que "Nesse mercado não existe isso." E acrescentou sobre sempre usar o Custeio Alvo:

Isso é, sempre é priorizado, não adianta a gente querer tentar empurrar uma coisa, então na realidade, a primeira coisa, a coisa mais importante inclusive que a gente sempre discute é (pausa) conseguir captar bem realmente o que o mercado está precisando e montar essa especificação. [...] a gente tenta chegar no que o cliente quer e a gente tenta colocar nosso custo dentro também.

Nesse sentido, atender as especificações do cliente é uma fonte de legitimidade externa e o processo do Custeio Alvo é uma fonte de legitimidade interna para o processo de desenvolvimento de produtos e seu lançamento. A busca de legitimidade externa também pode ser verificada pelo esforço da Alfa para se adequar às demandas do mercado, sendo que as mudanças nos requisitos dos clientes têm reduzido consideravelmente o ciclo de vida dos produtos e o uso do Custeio Alvo pode auxiliar a obtenção dos resultados esperados com os novos produtos. Em relação à busca de legitimidade interna também pode ser considerada uma declaração do funcionário D sobre o fato de que as metas de redução de custos da Alfa são estipuladas pela alta gestão, mas têm como base as metas de retorno do plano de negócios, que é imposto pela matriz. Dessa forma, o processo do Custeio Alvo ajuda a legitimar o desempenho da Alfa, ou seja, a obtenção ou não do retorno desejado relativo ao lançamento de produtos.

Pelo exposto, podem ser observadas evidências de que a utilização do processo do Custeio Alvo legitima a atividade de desenvolvimento de produtos e as decisões sobre o lançamento dos mesmos, no Brasil e na matriz.

\subsubsection{Fatores Econômicos Relacionados à Adoção}

Os fatores econômicos foram analisados para investigar a pressão por eficiência, principalmente pelo fato de a Alfa ser uma empresa privada com fins lucrativos. A questão que consta no roteiro de entrevista sobre os problemas econômicos que poderiam ter levado à adoção do Custeio Alvo pela Alfa, como quedas acentuadas dos lucros, por exemplo, não pôde ser formulada uma vez que nessa época, como já mencionado, os entrevistados não trabalhavam na empresa. Por isso, no caso da Alfa não foi possível fazer qualquer consideração acerca dos aspectos econômicos que poderiam ter influenciado a adoção da prática. Ainda mais que, pelo fato de as evidências mostrarem que adoção foi imposição da 
matriz (coerção), os problemas econômicos que poderiam ter influência na adoção do Custeio Alvo estariam relacionados à matriz, por ser esta quem adotou e depois disseminou para o grupo. No entanto, essa análise não fez parte do escopo dessa pesquisa.

Por outro lado, quando essa investigação tem foco no presente e a busca não se baseia nos problemas econômicos e sim em outros fatores econômicos, os relatos das entrevistas mostraram claramente que a utilização do Custeio Alvo pela Alfa tem o objetivo de sinalizar áreas estratégicas chaves e auxiliar o alcance de metas de resultado previamente estipuladas e determinadas pela matriz. Isso reflete a importância do aspecto econômico para a utilização do mesmo uma vez que funciona como um dos meios usados para a obtenção desses resultados.

Além disso, pela discussão a respeito da legitimidade percebe-se que, em relação ao desenvolvimento e lançamento de produtos, a decisão está embasada em fatores econômicos como atingir o custo alvo, atingir o retorno desejado, garantir a meta de lucratividade estipulada pela matriz, dentre outros. $\mathrm{O}$ funcionário $\mathrm{C}$, por exemplo, mencionou que $\mathrm{o}$ objetivo de utilizar o Custeio Alvo é "Chegar ao custo alvo do projeto, ao lucro objetivado pelo grupo ou estipulado pela matriz.”. Devido a essas evidências e à sua importância na interpretação acerca da resposta estratégica da Alfa, os fatores econômicos também foram avaliados em relação ao processo de institucionalização do Custeio Alvo na fase de implementação, sendo feitas análises mais detalhadas a esse respeito no item 5.4.3.2.

Com as análises feitas sobre os fatores institucionais e econômicos é possível responder a questão 1.2 (Quais fatores institucionais, dentre os elencados na literatura, estavam presentes por ocasião da adoção do Custeio Alvo na empresa objeto do estudo de caso inibindo ou favorecendo sua adoção? Quais os fatores econômicos presentes nesse contexto?)

Os fatores institucionais avaliados foram o mecanismo de mudança isomórfica e a legitimidade e foi detectada a presença de ambos. O mecanismo coercitivo foi apontado como responsável pela adoção do Custeio Alvo e, juntamente com a busca de legitimidade interna e externa, favoreceu sua adoção. Destaca-se que pela sua característica de imposição, o mecanismo coercitivo pode influenciar de forma negativa (inibindo) a implementação da prática, mas quanto à adoção ele favoreceu, uma vez que a Alfa não teve outra alternativa. Os 
fatores econômicos detectados nesse contexto estão focados na obtenção das metas de retorno, englobando a busca de eficiência.

\subsubsection{Implementação do Custeio Alvo}

Nesta etapa foram investigados os aspectos relacionados ao processo de institucionalização do Custeio Alvo abrangendo o estágio em que se encontra esse processo, os fatores institucionais e econômicos que podem ter influenciado a resposta da Alfa em relação ao Custeio Alvo e o tipo de resposta da organização à sua implementação.

\subsubsection{Estágios do Processo de Institucionalização}

Investigar o estágio do processo de institucionalização do Custeio Alvo na Alfa permitiu o entendimento de diversos aspectos envolvidos no mesmo. Conforme apontado em outros mementos nessa pesquisa, vários tipos de pressões podem afetar o processo de institucionalização de uma prática e, por consequência, sua forma de uso e a percepção de sua utilidade. Para investigar esse processo e detectar esses aspectos foi usado o modelo conceitual de Hasselbladh e Kallinikos (2000) para verificar em qual estágio do processo de institucionalização (separado em objetificação e internalização) o Custeio Alvo se encontra na Alfa e como o mesmo está conectado à estrutura e às rotinas da empresa. Por isso, as discussões e análises que se seguem também vão auxiliar na investigação das outras categorias mencionadas, como a resposta estratégica.

Quanto ao estágio de objetificação a análise levou em conta dois aspectos propostos por Hasselbladh e Kallinikos (2000), os discursos e as técnicas de controle, que auxiliam na objetificação de uma instituição. Esses aspectos foram confrontados com os requisitos necessários para a implementação do Custeio Alvo proposto por Ansari et al. (2006) que são baseados em exigências técnicas, comportamentais, culturais, políticas e ainda alguns pontos que podem caracterizar a institucionalização do mesmo baseados em imperativos estratégicos, políticas e procedimentos formais, existência de um local oficial, medidas de desempenho, recompensas e compensação e cultura organizacional. 
O primeiro aspecto analisado foi o discurso. Nas análises foram usadas a linguagem escrita, referente aos textos corporativos, e a linguagem oral obtida pelas entrevistas. Um discurso promove uma objetificação sobre a ideia, ou seja, consegue expor uma ideia com maior exatidão e ainda consegue explicar suas conexões e formas de aplicação de modo a agir sobre a realidade. Nesse contexto, se algo como o processo do Custeio Alvo puder ser descrito e explicado de forma a delinear com detalhes consideráveis suas relações, seu papel social e suas regras de conduta, ele estará em nível de discurso, de acordo com o modelo usado.

Dessa forma, o que se buscou foram padrões na linguagem oral dos entrevistados e na linguagem escrita da pesquisa documental que conseguissem delimitar e descrever esse processo com um nível considerável de detalhes. Além disso, por essa lógica, não pode haver ambiguidades nem conflitos entre as descrições do processo extraídas dessas fontes, uma vez que isso pode indicar que a prática ainda não saiu do estado de abstração e não foi objetificada. Se for possível verificar que o Custeio Alvo foi explicado de forma clara, através de relações com sua utilização prática e sem contradições entre os conteúdos analisados podese concluir que o nível de discurso da prática foi atingido.

Na sequência foram feitas as discussões confrontando-se os requisitos para implementação do Custeio Alvo e o discurso. O primeiro item da análise se refere aos requisitos técnicos exigidos para a utilização do Custeio Alvo nos quais são incluídas as equipes funcionais cruzadas ou multifuncionais para realizar as tarefas, as relações de parcerias entre os membros da cadeia de suprimentos e os investimentos em informação, processos e ferramentas.

Quanto à existência de equipes, o conteúdo das entrevistas e dos textos corporativos mostrou que a atividade de desenvolvimento de produtos, onde é usado o processo do Custeio Alvo, é efetuada através de uma estrutura de equipes temporárias em que há envolvimento de vários setores da organização como vendas, planejamento e controle da produção, controle de custos, desenvolvimento e compras, produção, engenharia de produção, engenharia de processo, qualidade e administração. Segundo o funcionário C:

Olha, na realidade quando a gente lança um projeto a gente envolve praticamente toda a empresa, então vem desde uma área de vendas, uma área de PCP planejamento, área de custo, área de compras e as fábricas, na realidade nós estamos com três fábricas, nós temos a fábrica de máquinas, a fábrica de fundidos e a fábrica de calderados leves.

O funcionamento dessa equipe ocorre da seguinte forma segundo os relatos: o setor de vendas dispara o processo com as informações do mercado (requisitos do modelo e preço) e todos os 
demais setores envolvidos começam a fazer parte das discussões e das atividades relacionadas ao projeto, análises e tentativas de atingir o custo alvo.

Essa equipe tem funções tanto relacionadas ao produto, como as engenharias e compras, quanto de apoio, como vendas e controle de custos. Cada membro da equipe temporária pode ter uma equipe própria em seu setor para auxiliar nas tarefas, como foi o caso descrito pelo funcionário D, gerente do setor de desenvolvimento e compras, que conta com quatro pessoas atuando nesta atividade sendo composta por ele, um coordenador e dois técnicos. Tanto a equipe principal quanto a dos setores têm definição de responsabilidade e conhecem os objetivos das tarefas que são realizadas bem como conhecem seu funcionamento e suas rotinas. As atividades e os resultados das equipes de desenvolvimento de produtos são apresentados e discutidos em reuniões (cujos detalhes foram abordados no item 5.3.2) em que prestam contas, ampliando o fórum de discussão dos problemas e soluções encontrados nessa atividade. Isso indica a existência tanto de coordenação quanto de controle em relação às atividades desenvolvidas para a operacionalização dessa atividade e do Custeio Alvo.

Conforme mencionado o presidente e alguns diretores participam de todas as reuniões estando sempre integrados aos processos bem como sempre informados a respeito do que está acontecendo nessas atividades, evidenciando o comprometimento da alta gestão com o sistema de controle em que o Custeio Alvo está atrelado. A literatura menciona que um elemento chave de sucesso do Custeio Alvo é o apoio e a participação da alta gestão e que o mesmo deveria ser implementado na forma top down e não bottom up. Isto é importante especialmente pelo fato da Alfa ter uma combinação estratégica (defensora, manter e diferenciadora) em que as atividades de desenvolvimento de produtos e o controle de custos são considerados chaves, necessitando de acompanhamento efetivo da alta gestão.

Foi mencionado nas entrevistas que as características de cada presidente contribuem para esse tipo de comportamento podendo ter algumas diferenças como, por exemplo, o presidente anterior que não tinha por hábito fazer reuniões diárias, mas que eram feitas com periodicidade semanal e mensal. Porém, as discussões e informações eram disponibilizadas da mesma forma. Isso indica que esse processo sempre é conduzido da mesma forma, pelo menos desde que os entrevistados entraram na empresa, e que independente de características pessoais de cada membro o modo geral de condução permanece. 
Um ponto que merece destaque quanto às equipes temporárias é que o setor de contabilidade não participa do processo do Custeio Alvo em nenhuma etapa. $\mathrm{O}$ suporte em relação às informações de custos é dado pelo setor de controle de custos cujos funcionários bem como seu chefe não são contadores. Pesquisas apresentadas na fundamentação teórica mostraram que empiricamente não existe um consenso sobre a participação do setor de contabilidade, sendo que em algumas foi identificada pouca ou nenhuma participação desse departamento no processo dessa prática, e em outras foi considerado um setor chave no processo. De qualquer forma, isso não afeta a institucionalização.

De acordo com a literatura usada como base no Capítulo 3 as equipes multifuncionais são necessárias para realizar as tarefas inerentes ao desenvolvimento de produtos, que incluem o processo do Custeio Alvo, e este tipo de configuração assegura que as atividades sejam realizadas de forma a obter os resultados esperados, por isso, é um ponto crucial para a utilização dessa prática. Quanto à análise em relação à utilização de equipe multifuncional não foi captada nenhuma contradição, ambiguidade ou conflito nos discursos em relação à descrição de sua composição e de suas atividades, o que confirma sua utilização no processo de desenvolvimento de produtos e do Custeio Alvo na Alfa.

O próximo requerimento técnico analisado se refere às relações de parcerias entre os membros da cadeia de suprimentos. A literatura foca esta questão uma vez que, para que o processo seja efetivo, é necessária a participação dos fornecedores nas equipes multifuncionais desde os estágios iniciais do processo, pois os esforços de redução de custos não devem estar restritos internamente à empresa. Os fornecedores podem auxiliar nesta tarefa reduzindo custos de componentes e atuando como parceiros na cadeia de valor.

Foi relatado pelo funcionário $\mathrm{D}$ que quando o setor de vendas obtém as características do produto de acordo com a demanda dos clientes, o setor de desenvolvimento e compras fica responsável por verificar os custos dos itens integrantes do produto, os quais são separados em materiais adquiridos de fornecedores, componentes fabricados na própria empresa e componentes fabricados por fornecedores. Este setor prepara uma planilha com a estimativa de todos os custos dos materiais e componentes. Em alguns casos os componentes fabricados por fornecedores também são avaliados pelo processo do Custeio Alvo. Nos itens referentes aos materiais, são feitas três cotações para negociação de preço. 
Foi verificado que não é hábito da Alfa convidar os membros da cadeia de suprimentos para as reuniões das equipes multifuncionais. $\mathrm{O}$ envolvimento com fornecedores acontece apenas quando existe necessidade de algum tipo de entendimento ou discussão a respeito das características dos componentes, e geralmente isso é feito com o setor de desenvolvimento e compras e não com a equipe. Quando um produto novo está sendo desenvolvido o procedimento é ir até o fornecedor mostrar as características do produto, onde o componente é importante dentro do conjunto e o que vai ser inspecionado de forma mais rigorosa.

Uma declaração do funcionário D relata que "[...] quando a gente tem algum problema aí sim vamos chamar ele (o fornecedor) e dizer: você é o único fornecedor que faz isto e está caro, nós fizemos um custo e chegamos a isso, [...] eu tento dar um norte, mas o fornecedor não conhece nossa planilha.". Foi comentado também que quando o fornecedor alega não conseguir atingir o custo calculado pela Alfa, esta auxilia o mesmo no processo de redução de custos. Com isso, verificou-se a existência de compartilhamento de informações entre a Alfa e os fornecedores bem como de parcerias para empreender esforços de redução de custos de componentes, mas as planilhas de custos não são passadas para os fornecedores, ou seja, há o compartilhamento das informações, mas não das planilhas e das formas de cálculo. Além disso, a Alfa mantém, como política, encontros periódicos com os principais fornecedores que são tratados como parceiros, existindo até uma premiação para os melhores.

O envolvimento dos fornecedores foi um ponto interessante, uma vez que a literatura geralmente discute que os materiais e componentes são estudados em conjunto com os fornecedores e que, às vezes, a empresa usa o Custeio Alvo para as peças dos fornecedores para ajudar na redução de custos. Essas características foram observadas na Alfa, mas não foi constatada a participação dos mesmos nas equipes. No entanto, mesmo os fornecedores não participando das equipes, as informações necessárias para o desenvolvimento do processo são compartilhadas e a meta de redução de custos é buscada em conjunto. Os discursos em relação aos fornecedores foram claros, não sendo captada nenhuma contradição, ambiguidade ou conflito. As informações da pesquisa documental apontaram para o mesmo tipo de relação mencionada nas entrevistas.

De acordo com as entrevistas outros membros da cadeia de valor como os clientes também não participam das reuniões nem das equipes. Para a Alfa, segundo os relatos, o importante em relação aos clientes é que a organização consiga oferecer o produto que eles querem ao 
preço que estão dispostos a pagar. A literatura menciona a participação dos clientes nessa equipe, mas na Alfa isso não ocorre.

O terceiro requerimento avaliado se refere aos investimentos em informação, processos e ferramentas que auxiliam no desenvolvimento do Custeio Alvo. Existe a necessidade de métodos e práticas que capacitam o Custeio Alvo como a análise de exigência dos clientes, a decomposição do custo alvo, a estimativa de custos, a análise trade-off de custos, o monitoramento do status do custo alvo e, ainda, algumas ferramentas essenciais como a análise de valor e a engenharia de valor.

As respostas mostraram pouca divergência em relação às práticas usadas para auxiliar o processo do Custeio Alvo presentes no roteiro de entrevistas. $\mathrm{O}$ funcionário $\mathrm{C}$ não mencionou o trade-off de custos entre os componentes, talvez pelo fato de que esta atividade seja desenvolvida pelo setor de desenvolvimento e compras e pelas engenharias. Já o funcionário D não citou a análise de requisitos, exigências e necessidades dos clientes e dos consumidores de forma direta, mas quando questionado sobre a adoção da perspectiva do cliente pela empresa a resposta foi "Eu não consigo enxergar o que o consumidor quer no produto, mas essa informação vem da área de vendas [...].”. Em relação às outras práticas todas foram citadas como sendo usadas pelos funcionários $\mathrm{C}$ e D.

Quanto ao uso da engenharia de valor foi mencionado pelo funcionário $\mathrm{C}$ que para o desenvolvimento de produtos o setor de engenharia responsável por essa atividade estima o custo baseado na engenharia de valor, chamada na Alfa de VE0 (value engineering zero). $\mathrm{O}$ VE0 é a referência para negociação de preço com os fornecedores e o valor negociado passa a ser chamado de VT1(Value table 1) na fase de protótipo, sendo definido o preço final após a definição do desenho de produção e sendo negociado o novo valor de produção em função das mudanças que foram necessárias. Nesta, que é a fase final, já está sendo garantida a função e a qualidade do produto bem como a facilidade de produção.

Pelas entrevistas foi possível constatar que os processos e ferramentas que auxiliam o processo do Custeio Alvo são usados e são conhecidos pelos entrevistados uma vez que conseguem explicá-los e dizer em que e como são usados, não havendo ambiguidades ou conflitos nas descrições.

O segundo requerimento analisado se refere ao aspecto comportamental e sua relação com o discurso. Essas considerações incluem os comportamentos desejados em relação ao processo 
do Custeio Alvo como o respeito entre os membros da equipe, a adoção da perspectiva do cliente, eliminação de barreiras quando identificadas e a busca por oportunidades de melhoria através da cadeia de valor. Quanto à relação entre os membros das equipes foi investigada a existência de conflitos e a forma de resolvê-los. Isso é importante na medida em que um conflito não resolvido pode prejudicar o desenvolvimento de seu processo. Além disso, foram procurados indícios de conflitos relacionados ao descontentamento ou reação ao processo da prática.

Os funcionários B e C relataram a existência de conflitos nas equipes, mas ressaltaram que isso é um ponto importante no processo, pois são resultantes de ideias diferentes em que cada membro quer impor as suas. O funcionário $\mathrm{D}$ mencionou que "O bom é quando a equipe é participativa.”. Os conflitos encontrados estavam ligados às discussões sobre como as coisas devem ser feitas, as ideias são ouvidas e sempre se busca decidir pela mais plausível, a que é melhor para a empresa, segundo o funcionário D. Não houve relato sobre conflitos envolvendo descontentamentos em relação ao processo do Custeio Alvo ou reações à sua utilização. Os indícios apontam para a evidência de que o processo de desenvolvimento de produtos bem como do Custeio Alvo são rotinas para os funcionários e parece apresentar estabilidade, não sendo identificada qualquer menção a respeito de preocupações com a forma de realização das atividades dessas atividades, ou ainda, com possíveis alternativas que poderiam substituir as atividades atuais, o que poderia indicar a necessidade ou o início de mudança nesses processos.

A forma como esses processos são elaborados não é discutida ou questionada, o que existe é a preocupação de encontrar soluções que ajudem as equipes a atingir as metas determinadas. Pelo exposto os conflitos entre membros da equipe não atrapalham o processo de Custeio Alvo e as relações interpessoais são marcadas por respeito. Não foram encontradas ambiguidades ou conflitos entre os conteúdos dos discursos neste quesito.

O próximo item avaliado se refere à adoção da perspectiva do cliente, se a mesma foi adotada e acatada e se os discursos apontam para a percepção da importância em satisfazer os requisitos do cliente. Este é um ponto fundamental para o processo do Custeio Alvo uma vez que é através das exigências dos clientes que o processo é iniciado, sendo orientado pelo mercado. Na Alfa essas exigências envolvem tanto as características requeridas nos produtos quanto o preço que os clientes estão dispostos a pagar pelos mesmos. Num dos textos corporativos da matriz o cliente é tratado como o principal stakeholder, sendo considerado o 
mais importante para os negócios. No site da matriz é mencionado que a organização busca ouvir as percepções dos clientes e proporcionar as soluções mais adequadas. É interessante notar que a organização se refere aos mesmos como clientes e não como consumidores, conferindo o entendimento de que o cliente não é apenas o consumidor de seus produtos, existindo uma relação mais estreita entre os mesmos.

Outra informação disponibilizada pela matriz, e já comentada diversas vezes nesse trabalho, é que para alcançar os valores da organização (qualidade e confiabilidade) são disponibilizadas normas com o que deve ser feito por todos os funcionários das empresas do grupo no cumprimento das atividades do dia a dia. A primeira norma é: sempre pensar nas necessidades dos clientes. Pelo conteúdo dos discursos foi possível observar que a Alfa trata essa questão como ponto crucial no desenvolvimento de seus produtos.

Quando da visita na sede da Alfa foi possível observar que desde a entrada principal, onde se situa a recepção, até onde se estende a parte administrativa essa importância é enfatizada pela distribuição de cartazes e painéis com informações institucionais a respeito de seus valores, que declaram a importância de se respeitar e cumprir os requisitos dos clientes. O que se espera com isso é que os clientes tenham orgulho em possuir um produto da marca Alfa e a obtenção da qualidade e confiabilidade garante a valorização do produto junto ao cliente, o que é uma crença para a organização e pode ser verificada em vários textos corporativos, nas entrevistas e em comentários informais.

Um dos pontos mais recorrentes no conteúdo das entrevistas foi a questão da importância dos clientes no processo. O compromisso é trabalhar o custo alvo de forma a conseguir manter todos os requisitos especificados pelos clientes incluindo o preço levantado no mercado, ou seja, sem a hipótese de mudança nesses requisitos. Se isso não for obtido o produto não é lançado, o que indica que os requisitos dos clientes são respeitados. Foi questionado ao funcionário A se a Alfa prioriza os esforços para redução de custos ou o atendimento aos requisitos dos clientes e a resposta foi: "Os dois, primeiro a gente escolhe cortar custos, mas se está muito fora, por exemplo, o preço de venda está muito baixo e o custo muito alto a gente tenta reduzir, mas tem um limite, quando não tem como atingir nossa margem de lucro a gente não faz e para de estudar.”.

A questão do compromisso com os requisitos dos clientes é reforçada quando dos comentários dos funcionários $\mathrm{C}$ e D sobre as mudanças de características dos produtos nos 
projetos devido a algum problema para cumprir a especificação original. Segundo os funcionários, deve-se fazer um pedido de mudança formal primeiro para a engenharia de produção, que vai estudar os impactos relacionados à qualidade, custo, dentre outros e só depois vai responder formalmente se é possível ou não. Quando a engenharia de produção não está segura sobre a decisão de mudar alguma especificação o pedido é encaminhado para a matriz, levando cerca de dez a quinze dias para análise do impacto da mudança e o retorno da resposta. Isso mostra que para a Alfa o importante em relação aos clientes é que a organização consiga oferecer o produto com as características que eles definiram e ao preço que estão dispostos a pagar. Essas declarações mostram não somente que os discursos apontam para a adoção da perspectiva do cliente, mas que as ações também convergem para isso.

Quanto à adoção da perspectiva do cliente pela Alfa os discursos referentes às entrevistas e aos textos corporativos não apresentaram ambiguidades ou conflitos. Isso confirma que esse ponto fundamental é considerado pela Alfa e incluído nas atividades relativas ao desenvolvimento de produtos e ao processo do Custeio Alvo.

Quanto à eliminação de barreiras identificadas não foi encontrado qualquer indício de barreira relacionada ao processo do Custeio Alvo nem à sua utilização. No caso da busca por oportunidades de melhoria através da cadeia de valor foi referenciado o esforço para redução de custos entre a Alfa e seus fornecedores.

O próximo requisito se refere ao fator cultural. Neste tópico foram consideradas questões como o encorajamento de decisões baseadas em fatos e a confiança no compartilhamento das informações sobre os clientes com todos os membros da equipe. O encorajamento de decisões baseadas em fatos significa que alguma informação é usada para embasar a decisão, não sendo esta oriunda apenas da percepção do gestor. $\mathrm{O}$ funcionário $\mathrm{C}$ mencionou que $\mathrm{o}$ presidente da Alfa tem acesso a todas as informações e, em relação ao Custeio Alvo, é este quem aprova o relatório consolidado de desenvolvimento de produto e toma decisão com base no custo alvo. Isso evidencia que o Custeio Alvo gera informações imprescindíveis para a tomada de decisão, ou seja, decisão baseada em fatos. Além disso, caracteriza a utilização efetiva dessa prática pela Alfa, não sendo usada de forma esporádica ou por exceção, e sim em todos os projetos.

Quanto à confiança entre os membros do grupo foi mencionado que existe preocupação com o compartilhamento de informações relativas ao processo de Custeio Alvo entre os participantes 
das equipes e que existe confiança nessa relação. No entanto, o compartilhamento é restrito aos membros internos da empresa, os membros externos pertencentes à cadeia de valor não recebem nenhum tipo de informação. A não ser no caso dos fornecedores, conforme já mencionado. Sobre o compartilhamento de informações, o funcionário $\mathrm{C}$ comentou que a informação "[...] fica disponível para todos, dentro de um único diretório onde o pessoal tem acesso [...].". E sobre a confiança ele mencionou que é "Primordial, porque na realidade ali nós estamos trabalhando com dados confidenciais da empresa, custo, tecnologia.".

As informações extraídas do processo do Custeio Alvo são disseminadas para seus usuários, que são os participantes das equipes bem como outros interessados, como os gestores (presidente e diretores) e a matriz. Existe preocupação com o compartilhamento dessas informações e as mesmas são disponibilizadas através de relatórios ou através de apontamentos apresentados nas reuniões das equipes e nas reuniões de prestação de contas.

Quanto à decisão baseada em fatos percebe-se que o discurso aponta para isso sem ambiguidades ou conflitos. Em relação à confiança foi constatada uma diferença entre o que Ansari et al. (2006) apontam como sendo a necessidade de confiança entre membros da cadeia de valor e os comentários dos entrevistados sobre esse assunto. A Alfa não compartilha informações com membros da cadeia de valor, com exceção dos fornecedores no caso descrito anteriormente. Em relação aos membros internos o conteúdo dos discursos evidencia que existe confiança no compartilhamento das informações, não sendo registrada nenhuma ambiguidade sobre esse quesito.

Os requisitos políticos se referem à mudança de controle sobre o conhecimento e os recursos afetando os padrões de influência e poder da organização. Essa questão não pode ser investigada porque o Custeio Alvo já havia sido implantado há algum tempo na Alfa e os entrevistados não conheciam a estrutura de controle, de conhecimento e de recursos nem o modelo de poder antes da adoção e nem o que mudou. Ressalta-se que a ausência de avaliação desse ponto não afeta a verificação do estágio do processo de institucionalização da prática analisada.

Ansari et al. (2006) também mencionam a questão da institucionalização chamando a atenção para o fato de que mesmo quando um processo de Custeio Alvo é bem executado, o mesmo pode não ser sustentável, a menos que esteja institucionalizado nas rotinas diárias da organização. Embora nessa pesquisa esteja sendo avaliado o estágio do processo de 
institucionalização de acordo com o proposto por Hasselbladh e Kallinikos (2000), Ansari et al. (2006) também comentam sobre esse processo mencionando que o mesmo se torna imerso na organização e que frequentemente compartilha seis características sendo o imperativo estratégico, políticas e procedimentos formais, existência de um lugar oficial, medidas de desempenho, recompensas e compensação e cultura organizacional. Por isso, essas características de institucionalização, relativas à implementação do Custeio Alvo, também foram avaliadas nas entrevistas.

Imperativo estratégico significa que o Custeio Alvo deveria ser um processo padrão exigido sempre que novos produtos ou principais reprojetos sejam desenvolvidos, fazendo parte da rotina da organização, por apoiar a estratégia competitiva. De acordo com os entrevistados o processo de Custeio Alvo já se encontra totalmente implementado na organização não existindo fases ou procedimentos que ainda necessitem ser incorporados ao processo, funcionando de forma completa. Todos os projetos são elaborados e desenvolvidos de acordo com esse processo e nenhuma decisão a respeito do lançamento de produtos é tomada sem que as informações oriundas do Custeio Alvo sejam analisadas, sendo essa a rotina para essa atividade, conforme já mencionado exaustivamente no decorrer deste Capítulo.

A Alfa tem objetivos claros quanto ao que se quer com o uso dessa prática. Ela é usada para auxiliar na discussão e decisões envolvendo questões estratégicas e no cumprimento de metas estipuladas, funcionando como um dos dispositivos que atua entre o plano traçado para a Alfa e seu resultado. Desse modo, as informações do Custeio Alvo são usadas tanto para tomada de decisão quanto para controle. Isso indica que o processo do Custeio Alvo é entendido como um instrumento de apoio à gestão. Comparando o que a organização faz e o que a literatura menciona a respeito dessa prática, foi possível constatar que a Alfa o utiliza em conformidade com sua essência e sabe por que usar, em que usar, quando usar e como usar para atingir seus objetivos.

Além disso, as declarações mostraram que geralmente os projetos submetidos ao Custeio Alvo e que têm seus produtos lançados conseguem atingir o custo padrão (que é baseado no alvo) quando de sua fabricação, ou seja, são submetidos ao controle de custos e à avaliação de desempenho. Nesse sentido o funcionário $\mathrm{C}$ mencionou que "Até hoje todo projeto custo alvo que a gente colocou, a gente conseguiu atingir.[...].”. Dessa forma, quanto ao imperativo estratégico não houveram ambiguidades ou conflitos nos discursos mostrando que esse 
processo se trata de um imperativo estratégico na Alfa, fazendo parte das rotinas da organização.

Em relação às políticas e procedimentos formais, Ansari et al. (2006) mencionam que o Custeio Alvo deveria ser incorporado nos manuais de procedimentos e políticas da organização servindo para guiar o comportamento organizacional e codificar as rotinas organizacionais de modo a ser repassado de geração para geração. A Alfa possui manual de procedimento em relação às suas principais atividades, conforme mencionado na análise do fator estrutura, incluindo a de desenvolvimento de produtos ao qual o processo do Custeio Alvo está ligado.

A verificação da presença do Custeio Alvo nos manuais de procedimentos também é importante em relação ao discurso, pois retrata seu processo em linguagem escrita. Conforme mencionado por Hasselbladh e Kallinikos (2000), isso fornece uma estabilidade no processo de institucionalização. Uma vez incorporado nos procedimentos e atividades da organização ele é repassado a todas as gerações de funcionários, caracterizando sua repetição enquanto rotina. As informações da pesquisa documental também mostraram a preocupação do grupo com o repasse dos valores e procedimentos a todas as gerações de funcionários, reforçando esse aspecto. Nesse quesito não foram encontradas ambiguidades ou conflitos no conteúdo dos discursos.

A existência de um lugar oficial foi outra característica investigada. Nesse sentido, algum setor da empresa deve ser a sede do Custeio Alvo. Este lugar pode ser a engenharia, compras ou finanças, mas na prática isso varia muito (ANSARI et al., 2006). O processo de Custeio Alvo na Alfa é desenvolvido em sua sede na região sudeste do Brasil, onde fica situada a administração e algumas das fábricas. O setor responsável pela gestão do processo na data das entrevistas era o de desenvolvimento e compras. Segundo as entrevistas, esta responsabilidade é delegada de maneira ad hoc e como atualmente o setor de compras tem sido muito requisitado no processo a responsabilidade fica a cargo de seu membro, no caso o gerente. Não foram encontradas ambiguidades nas respostas.

Outra característica analisada considera que as mensurações extraídas do processo do Custeio Alvo deveriam estar atreladas a algum tipo de medida de desempenho. Em relação a este quesito, foi verificado que na Alfa os funcionários A e B mencionaram que as informações do processo de Custeio Alvo são usadas para avaliação do lucro e do orçamento, bem como para 
controle do custo do produto na fase de desenvolvimento e após o início de sua produção. O funcionário B também mencionou que o custo alvo é a referência para qualquer relatório de custo e para a avaliação de resultado e compensação na Alfa. Assim, a organização utiliza informações oriundas dessa prática para auxiliar o desenvolvimento de outras práticas, como o plano de negócios, o controle dos custos e o orçamento. Desse modo, essas informações não são usadas apenas nas decisões de lançamento de produtos, são também insumos de outras práticas gerenciais que auxiliam em outros tipos de decisão. Novamente não foram encontradas ambiguidades nos discursos.

Quanto às recompensas e compensações ligadas ao processo do Custeio Alvo na Alfa não foi encontrado qualquer indício das mesmas atreladas à participação no processo de Custeio Alvo, e sim aos seus resultados. De acordo com os comentários, na Alfa essa prática está imersa na rotina de tal forma que não existem planos para motivação em relação ao seu uso. Os participantes das equipes percebem que sua utilização é um dos meios para o cumprimento das metas organizacionais, de forma que os planos de remuneração relacionados à motivação dos funcionários se referem às atividades organizacionais de forma geral não tendo uma separação para envolvimento no processo do Custeio Alvo. O que existe, de acordo com o funcionário $\mathrm{B}$, é uma política de recompensa baseada nos resultados do processo, ou seja, no controle do custo padrão, que é baseado no alvo. Pelo conteúdo dos discursos foi possível verificar que o Custeio Alvo não é algo que ainda necessite de motivação para o envolvimento dos funcionários, estes já percebem sua importância e não contestam sua aplicação, embora seja um procedimento obrigatório.

É preciso salientar que os passos sugeridos por Ansari et al. (2006) se referem ao processo de implementação do Custeio Alvo, mas no caso da Alfa o mesmo já se encontra implementado há pelo menos vinte e cinco anos conforme os relatos. Por isso, no caso dessa organização é possível que algumas das características da institucionalização abordadas pelos autores, como a necessidade de compensação, possam não ser mais necessárias ou ainda podem ter um tipo de aplicação diferente. Dessa forma, o tempo de utilização dessa prática na Alfa pode ser uma das explicações, fazendo com que a mesma não seja uma novidade que precise de motivação para funcionar. Não foram detectadas ambiguidades ou conflitos entre os discursos.

Quanto à cultura organizacional, quando o processo de Custeio Alvo está incorporado na rotina organizacional, ele se torna um modo de vida e os líderes deveriam reforçar esta abordagem enfatizando seu sucesso. Pelos comentários dos entrevistados, os funcionários 
envolvidos na geração e no uso das informações estão acostumados com seu processo e as atividades relacionadas ao mesmo fazem parte da rotina organizacional, sendo seus resultados evidenciados nas reuniões. Também foi mencionado pelos funcionários $\mathrm{B}$ e C que o Custeio Alvo é a base de tudo que é feito na fábrica, a começar pelo desenvolvimento dos produtos e que não conseguem imaginar como seria o trabalho na empresa sem essa prática. Essa declaração reforça a sua importância para a Alfa. Não foram encontradas ambiguidades nos comentários relativos a esse aspecto.

As discussões e análises apresentadas até foram relativas à busca de evidências em relação ao discurso. O próximo aspecto do processo de institucionalização do modelo usado para análise (HASSELBLADH e KALLINIKOS, 2000) foram as técnicas de controle. As técnicas de controle são expressas geralmente na forma numérica ou outras formas de apresentação como os sistemas contábeis e os sistemas de medida, sendo geralmente comunicadas por linguagem oral ou escrita. O interessante nessa análise é que a construção desses sistemas de codificação torna possível a ação sobre as relações objeto-sujeito constituídas por um discurso e são usadas para controlar o resultado da ação. Dessa forma, compreendem relatórios e outros documentos que evidenciem o resultado do processo e permitem seu controle.

$\mathrm{Na}$ Alfa foram encontradas evidências de vários tipos de relatórios e apontamentos envolvendo o processo do Custeio Alvo. Nas fases iniciais do processo o funcionário D descreveu: “[...] a gente se utiliza de uma planilha que a gente criou e virou um padrão onde temos os custos de tudo que é componente, os custos de matéria prima, os custos de mão de obra, [...].”. O funcionário C relatou que as informações geradas no processo de Custeio Alvo são disponibilizadas através de relatórios ou de apontamentos que ficam disponíveis em um diretório único em que todo o pessoal envolvido tem acesso. $\mathrm{O}$ funcionário $\mathrm{B}$ mencionou que as informações são disponibilizadas no sistema gerencial (Hyperium) e que incluem gráficos para facilitar o entendimento.

Não foi encontrada evidência de que exista na organização um relatório específico do Custeio Alvo ou com algum nome ligado ao mesmo. $\mathrm{O}$ funcionário $\mathrm{C}$ comentou que "Na realidade, a gente simplesmente tem que comprovar que chegou na meta, então não tem nenhum nome assim, sabe. [...].”. O que foi verificado é que existem informações relacionadas a cada projeto analisado de acordo com o processo dessa prática que comprovam que se chegou ou não no custo alvo. Essas informações são disponibilizadas em números e gráficos, de forma detalhada (por componente, por produto, etc.). 
Mesmo não existindo um relatório específico do Custeio Alvo, informações geradas pelo seu processo são usadas e disseminadas nos relatórios dos projetos, evidenciando a existência de técnicas de controle e, por consequência, a codificação formal desse processo. Essa constatação é importante porque a existência desse tipo de controle através de relatórios pode ser um indicativo de que a prática investigada possa estar objetificada na Alfa.

Para auxiliar a análise, antes de apresentar a conclusão sobre a objetificação foi apresentado o Quadro 6 contendo um resumo das discussões e análises relativas ao estágio de objetificação do processo de institucionalização com os aspectos investigados (discurso e técnicas de controle) e os requisitos pra implementação do Custeio Alvo que foram os itens avaliados até este ponto. 
Quadro 6 - Resumo dos achados sobre o estágio de objetificação do processo de institucionalização

\begin{tabular}{|c|c|c|}
\hline \multirow{3}{*}{\begin{tabular}{|l|} 
Estágio \\
Requisitos Aspectos \\
\end{tabular}} & \multicolumn{2}{|l|}{ Objetificação } \\
\hline & Discurso & Técnicas de Controle \\
\hline & & \\
\hline Técnicas & $\begin{array}{l}\text { Equipes multifuncionais conduzindo o } \\
\text { desenvolvimento de produtos e usando o } \\
\text { Custeio Alvo; } \\
\text { - Participação não permanente de } \\
\text { fornecedores na equipe, mas } \\
\text { participação efetiva no processo; } \\
\text { - Utilização efetiva de ferramentas e } \\
\text { processos necessários para a condução } \\
\text { do Custeio Alvo. }\end{array}$ & 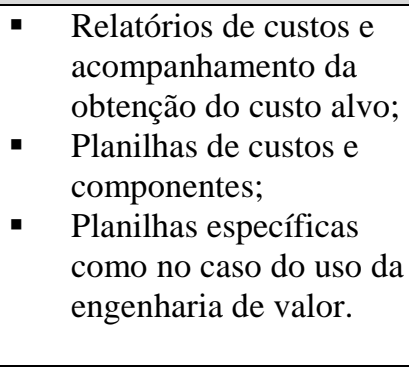 \\
\hline Comportamentais & $\begin{array}{l}\text { - Conflitos ligados à discussão de ideias e } \\
\text { não a reações ao processo; } \\
\text { Existe o respeito entre os membros das } \\
\text { equipes; } \\
\text { - O foco no cliente é questão } \\
\text { fundamental. }\end{array}$ & \\
\hline Culturais & $\begin{array}{l}\text { As decisões relativas ao lançamento de } \\
\text { produtos são sempre baseadas em fatos; } \\
\text { Existe confiança no compartilhamento } \\
\text { das informações sobre o Custeio Alvo } \\
\text { entre os membros internos; } \\
\text { Os membros externos não participam } \\
\text { do processo, com exceção dos } \\
\text { fornecedores. }\end{array}$ & $\begin{array}{l}\text { Informações referentes ao } \\
\text { processo de Custeio Alvo } \\
\text { são disponibilizadas no } \\
\text { sistema gerencial. }\end{array}$ \\
\hline Políticas & Não foram investigados & \\
\hline Imperativo Estratégico & $\begin{array}{l}\text { O Custeio Alvo é usado em todos os } \\
\text { projetos de produtos. }\end{array}$ & \\
\hline $\begin{array}{l}\text { Políticas e Processos } \\
\text { Formais }\end{array}$ & $\begin{array}{l}\text { Conhecimento dos procedimentos sobre } \\
\text { atividades e processos do Custeio Alvo. }\end{array}$ & \\
\hline Local Oficial & $\begin{array}{l}\text { - Na data das entrevistas, o setor de } \\
\text { desenvolvimento e compras era o } \\
\text { responsável pela gestão do Custeio } \\
\text { Alvo. }\end{array}$ & \\
\hline Medidas de Desempenho & $\begin{array}{l}\text { - Utilização de informações do Custeio } \\
\text { Alvo para avaliação do lucro, dos } \\
\text { custos e orçamento. }\end{array}$ & \\
\hline $\begin{array}{l}\text { Recompensa e } \\
\text { Compensação }\end{array}$ & $\begin{array}{l}\text { - Não foi encontrado esse tipo de } \\
\text { motivação específico para o Custeio } \\
\text { Alvo; } \\
\text { A motivação através de compensação se } \\
\text { dá de forma geral na organização. }\end{array}$ & \\
\hline Cultura Organizacional & $\begin{array}{l}\text { As atividades relacionadas ao Custeio } \\
\text { Alvo fazem parte das rotinas } \\
\text { organizacionais e seus resultados são } \\
\text { divulgados entre os membros da equipe. }\end{array}$ & \\
\hline
\end{tabular}

Pelo Quadro 6 é possível notar que na Alfa todos os requisitos avaliados puderam ser descritos e explicados pelos entrevistados e foram confrontados com os textos corporativos, com exceção dos aspectos políticos. A não inclusão desse aspecto não limita nem invalida a análise sobre a objetificação por não se tratar de item essencial para a utilização do Custeio Alvo. Destaca-se também que conforme as análises apresentadas nenhum dos aspectos 
avaliados apresentou ambiguidade ou conflito entre qualquer tipo de discurso, apresentando descrições semelhantes de seu processo não havendo constatação de contradições.

Conforme ressaltado na fundamentação teórica (item 2.2.3), o processo de objetificação ocorre através da imersão social de uma instituição e pode não ser linear. Então, a existência de uma técnica de controle (que foi o último aspecto avaliado) por si só não é suficiente para atestar a objetificação de uma prática, sendo necessária a existência de outras evidências para comprovar esse resultado. Nesse caso, a existência de técnica de controle que especificamente demonstra que o processo do Custeio Alvo na Alfa vem sendo empreendido indica uma relação entre ambos; ou seja, a informação que mostra se o custo alvo foi atingido ou não é uma das relações entre a prática e seu resultado. Esse fato, somado às análises e constatações desse tópico e resumidos no Quadro 6, evidenciam que o processo do Custeio Alvo está ligado às rotinas da Alfa (representando sua imersão social) indicando, por consequência, sua objetificação.

Desse modo, até aqui foi avaliado o nível de objetificação do processo de institucionalização. Entretanto, para que esse processo esteja completo é necessária a internalização da instituição, ou seja, do Custeio Alvo na Alfa. Dessa forma, a análise seguinte se concentrou na investigação dos vestígios que indiquem sua internalização. Este estágio, se alcançado, representa a institucionalização completa de uma instituição, conforme o modelo evidenciado na Figura 4, na fundamentação teórica.

Para investigar esse estágio foi verificada a facilidade com que as instituições são reproduzidas (reprodutibilidade), quão transitórias ou duráveis elas são (durabilidade) e como se dá sua imediata compreensibilidade (comunicabilidade), conforme indicado por Hasselbladh e Kallinikos (2000). Os dados obtidos pelas entrevistas mostraram que as informações oriundas do processo do Custeio Alvo sempre embasam as decisões finais sobre lançamentos de produtos e que todos os projetos de produtos passam por esse processo. Essas constatações evidenciaram que o mesmo não é usado de forma esporádica, por exceção ou em algum tipo de projeto em especial, mas em todos os projetos no decorrer do tempo, estando imerso nas rotinas, caracterizando sua reprodutibilidade.

O fato de ser usado de forma rotineira e como suporte à decisão e ao controle pode ser indício de que o mesmo é importante para a Alfa. O funcionário A comentou sobre a utilização do Custeio Alvo mencionando que: “[...] no começo do ano nós temos um business plan, uma 
meta comprometida com a matriz [...] e estamos fazendo atividades para atingir essa meta do ano." Nessas atividades está o desenvolvimento de produtos e o cálculo e a tentativa de obtenção do custo alvo. Isso implica dizer que a prática tem uma finalidade específica, atrelada às estratégias estabelecidas, à obtenção de resultado e à cobrança por parte da matriz.

Essas constatações evidenciam a percepção de que o Custeio Alvo é um dos mecanismos que auxiliam na implementação das estratégias e no gerenciamento dos custos para a obtenção das metas exigidas. Além disso, o significado do Custeio Alvo na organização pode ser ligado a uma das proposições extraídas do trabalho de Phillips et al. (2004), que se refere ao fato de que quando as ações têm um sentido organizacional elas são mais prováveis de produzirem a institucionalização. Nesse contexto, o Custeio Alvo apresenta um significado que possui sentido em relação à organização e seus objetivos, sendo entendido e compartilhado entre os membros e disseminado pela organização. Isso caracteriza a comunicabilidade, pois os envolvidos no processo sabem por que ele é usado e o que o mesmo significa para a organização.

Quanto à sua durabilidade, verificou-se pelos discursos que o mesmo é usado há pelo menos vinte e cinco anos nas atividades de desenvolvimento de produtos e não foi encontrado indício de que isso possa estar mudando. Essas constatações mostram que não se trata de rotina transitória, caracterizando sua durabilidade. De acordo com o funcionário $\mathrm{C}$ poucos projetos não atingem o custo alvo, normalmente o que a equipe se propõe a fazer tem conseguido atingir o resultado. Isso mostra que o processo é realizado e seu resultado é avaliado e cobrado, demonstrando seu uso efetivo. Além disso, com a constatação da existência das três características da internalização (reprodutibilidade, comunicabilidade e durabilidade), pode-se concluir que o mesmo encontra-se internalizado na Alfa.

Dessa forma, a questão 1.3 (De acordo com o modelo de estágios do processo de institucionalização de Hasselbladh e Kallinikos (2000), em qual estágio o Custeio Alvo encontra-se institucionalizado na empresa objeto do estudo de caso?) apresenta como resposta o estágio de internalização, ou seja, está completamente institucionalizado na Alfa. Ressalta-se que as triangulações entre as fontes de dados da investigação sobre as características de implementação do Custeio Alvo não apresentaram ambiguidades nem conflitos o que confere confiabilidade aos dados usados para a análise e indica que os entrevistados apresentaram um discurso coeso, evidenciando que conhecem o seu processo e funcionamento. Esse fato reforça o entendimento da institucionalização completa do Custeio 
Alvo na Alfa e apresenta concordância com uma das proposições de Phillips et al. (2004) de que discursos mais coerentes e estruturados são mais prováveis de produzir instituições.

Cabe destacar que a investigação desta etapa, na forma como foi elaborada, se mostrou imprescindível para essa pesquisa pelo fato de avaliar de modo mais profundo a forma e os detalhes de como a Alfa vem utilizando o Custeio Alvo. Devido ao envolvimento de vários aspectos (técnicos, comportamentais, culturais, dentre outros) o conteúdo extraído das respostas dos entrevistados foi minucioso em relação a esse processo, o que auxiliou sobremaneira na conclusão a respeito do estágio de institucionalização.

\subsubsection{Influência dos Fatores Institucionais e Econômicos sobre a Resposta Estratégica}

Os fatores institucionais e econômicos foram avaliados anteriormente em relação à adoção do Custeio Alvo na Alfa, no entanto, pelo fato de que indícios de sua presença foram verificados também na fase de implementação torna-se necessária sua análise também nesse estágio. Por isso, foram avaliados o fator institucional legitimidade e os fatores econômicos que podem indicar a busca por eficiência. Essa análise é importante para detectar qual o tipo de interpretação predominante que os atores fazem desses fatores em relação à utilização dessa prática, o que pode influenciar a resposta estratégica.

A literatura sobre a NSI apontou que quando uma prática é adotada apenas visando a busca de legitimidade a probabilidade é de que a mesma seja usada de forma desconectada (decoupling) da estrutura e das ações; e quando é adotada por motivos de eficiência a probabilidade é de que seja conectada à estrutura e às ações. Isso não significa que a legitimidade sempre conduz ao decoupling e que a busca por eficiência sempre conduz ao coupling, mas essas são as situações prováveis de acontecer. Com base nessas constatações da literatura é que a análise desses fatores foi realizada. Primeiramente foram procurados vestígios da presença de fatores econômicos ligados à utilização do Custeio Alvo; dessa forma, qualquer frase ou palavra que identifique a busca por eficiência ou a busca por resultados favoráveis (financeiros ou não como lucro, participação de mercado etc.) foram considerados indícios de sua presença, motivando a utilização da prática.

O fato, já amplamente mencionado nesse trabalho, de que o processo de desenvolvimento de produtos é orientado pelo mercado e que o preço considerado é o que o cliente está disposto a 
pagar, tem como implicação para a Alfa que, para obter o retorno desejado com o produto, a empresa tem que gerenciar os custos quando excedem o alvo. Essa orientação faz parte de suas estratégias, que englobam o desenvolvimento de produtos diferenciados com qualidade e confiabilidade que tragam o retorno desejado de modo a manter a participação no mercado e obter um retorno razoável sobre o investimento. Por isso, espera-se que uma prática como o Custeio Alvo, que auxilia na busca desses objetivos, seja significada de modo a refletir esse entendimento.

Nesse sentido, foi verificado que na Alfa um produto só é lançado se trouxer o retorno desejado. O funcionário $\mathrm{C}$ comentou que:

\footnotetext{
Na realidade a gente tem quer ter o mínimo de condição, por exemplo, de lançar. Então, por exemplo, existe um número mágico, vamos dizer assim, que não quer dizer que a gente tenha que ter sempre lucro, ela pode ter um mínimo de lucro, por exemplo, 2 ou 3\%, mas a gente pode lançar. O que importa realmente em termos de lucro não é o lucro da Alfa do Brasil, mas o lucro do grupo.
}

Esse comentário mostra a preocupação em atingir as metas estipuladas pela matriz para o grupo. Em outro momento o mesmo funcionário declarou que "Chegou naquele número mágico, está acima, está bom.”, o que enfatiza a preocupação com o desempenho e com a eficiência para atingir "o número mágico". As observações e análises evidenciaram a crença de que o Custeio Alvo é um dos meios de atingir essa meta ou esse número. O funcionário $\mathrm{A}$ comentou que a utilização do Custeio Alvo tem um propósito específico na Alfa, fazendo parte das atividades que são realizadas para atingir as metas estipuladas no plano de negócios.

O funcionário C comentou que "No ano passado deram um target altíssimo para o pessoal [...] essa máquina eu quero tantos por cento de redução [...]." e o funcionário D comentou que "[...] eu fico preocupado se eu vou conseguir atingir o meu custo, o meu target.". E acrescentou que a pressão para derrubar os custos é uma realidade da Alfa e que eles estão acostumados com isso. Por essas declarações percebe-se que a pressão por eficiência, no caso para redução de custos, se mostra um fator relevante para a utilização do Custeio Alvo uma vez que esta é uma das funções dessa prática. O funcionário A comentou que se o custo alvo não for atingido o projeto do produto não é implementado, pois é preciso garantir a margem determinada pela matriz. Assim, o custo alvo é o elemento chave para a decisão, uma vez que ele demonstra se é possível atingir os resultados esperados ou não.

Para justificar o uso do custo alvo para garantir a margem da Alfa o funcionário C comentou: 
É que na realidade tem alguns, por exemplo, essa margem de contribuição total consolidada, se ela for abaixo de um certo nível o risco começa a ficar grande. Então, fazendo isso, por mais que você tenha variações cambiais ou tenha algum aumento de matéria prima, ainda a gente consiga ficar dentro daquela margem de segurança. [...].

No decorrer doas entrevistas, palavras como lucro, meta, alvo, margem, custos foram usadas com frequência, evidenciando a preocupação da Alfa com fatores econômicos. Pelo exposto foi possível verificar que fatores econômicos estavam presentes nos discursos indicando uma motivação para a utilização do Custeio Alvo.

Na sequência foram procurados vestígios da busca por legitimidade ligada à utilização do Custeio Alvo, representando o fator institucional. Dessa forma, qualquer frase ou palavra que identifique a busca pela legitimidade das ações foram consideradas indícios de sua presença, motivando a utilização da prática. Primeiramente foi analisada a legitimidade interna. Foi verificado que o Custeio Alvo é usado na Alfa, dentre outras coisas, para embasar a tomada de decisão de lançamento do produto, evidenciando que o resultado alcançado com o uso dessa prática legitima a decisão. Independente de se atingir ou não o alvo, essa informação não é contestada, ou seja, a utilização do processo do Custeio Alvo, seguido conforme as especificações da matriz e sua tentativa de atingir o custo alvo, mostra o empenho da organização na busca das metas propostas. Não foi encontrado qualquer vestígio de contestação dos seus resultados pela matriz. Pelo fato de a Alfa seguir todos os procedimentos, regras e normas relacionadas à atividade de desenvolvimento de novos produtos, o que inclui a utilização do Custeio Alvo, seu resultado final em relação à informação de que conseguiu ou não atingir o alvo é legitimado, assim como a decisão de lançar ou não lançar o produto.

Quanto à legitimidade externa foi observado que a regra de atendimento às especificações dos clientes, incluindo preço, qualidade e inovação tecnológica, pode ser considerada uma fonte de legitimidade visto que o conteúdo dos discursos indica uma conformação com essas demandas. A redução do ciclo de vida dos produtos com mudanças estruturais em seus modelos e especificações para atendimento da demanda do mercado é outro exemplo que indica a busca de legitimidade com o mercado. De acordo com a NSI a conformação às demandas sociais não necessariamente desencadeia ações para seu efetivo cumprimento e a crença de que a empresa está conformada a essas demandas de forma simbólica já é suficiente para a obtenção de legitimidade. 
No entanto, na Alfa as evidências mostram que esse não foi o caso. A busca do cumprimento dos requisitos dos clientes é questão estratégica na empresa sendo empreendidos esforços para alcançar esse objetivo. Muitos exemplos e comentários dos entrevistados mostraram essa preocupação (discutida no item 5.4.3.1), e que o Custeio Alvo é usado para auxiliar no atendimento dos requisitos dos clientes e do retorno desejado pela empresa. Essas evidências apontam que a conformação às demandas está atrelada à obtenção do resultado e que a legitimidade, nesse processo, está embasada não apenas nas intenções, mas nas ações.

Foi observado também que existe um contentamento por parte dos entrevistados quando da obtenção dos resultados esperados. O funcionário $\mathrm{C}$ comentou sobre os projetos recentes que conseguiram atingir o custo alvo: “[...] esse [...] o híbrido, conseguimos, um outro que nós lançamos agora, conseguimos chegar no alvo [...] então, modéstia à parte até que eu sou razoavelmente (risos), eu e minha equipe, vamos dizer assim.”. Esse comentário evidencia que a utilização da prática é importante e que quando conseguem atingir o alvo (que é o resultado do processo) existe um contentamento, uma espécie de dever cumprido. Nesse caso, o cumprimento do dever se dá tanto com os clientes quanto com a matriz, pois, chegar ao alvo representa a obtenção dos objetivos de ambos e também o da Alfa.

Outra observação que permite concluir que a busca da legitimidade é envolvida por ações é o fato de que a prestação de contas da Alfa em relação à matriz se dá com a apresentação de informações que demonstram o resultado final e não de relatórios que comprovam que o Custeio Alvo foi realizado. A cobrança da matriz se dá em relação à obtenção dos resultados estipulados que está atrelado ao cumprimento dos processos e atividades exigidas para esse fim. Desse modo, as ações (uso do Custeio Alvo) não foram justificadas pela exigência da matriz ou por temerem alguma sanção, e sim para obter eficiência no lançamento de produtos e atingir os objetivos esperados.

Conforme mencionado na fundamentação teórica, a literatura institucional tem enfatizado que quando uma instituição está baseada na obtenção de legitimidade o discurso pode estar diferente da prática. Mas, na Alfa, as evidências mostraram que a busca de legitimidade interna e externa está respaldada pelas ações empreendidas para se conformar às demandas. Isso indica que a tentativa de obtenção dos resultados da forma como exigida pela matriz é que legitima as ações da Alfa, estando baseada nas ações e não nas intenções. Pelo exposto, foram encontradas evidências tanto da busca por eficiência quanto por legitimidade, e ambas estão respaldadas nas ações e não nas intenções ou nos discursos. Isso indica que esses dois 
fatores estão interconectados, afinal a busca por eficiência nos moldes estabelecidos pela matriz reflete os dois tipos de fatores.

Com essas análises a resposta para a questão 1.4 Considerando-se a influência dos fatores institucionais e econômicos encontrados nesse processo, qual é o tipo de motivação predominante (busca de eficiência ou de legitimidade) em relação à institucionalização do Custeio Alvo? é que as duas motivações foram encontradas e que atuam de forma interconectada, uma vez que os dois fatores estão baseados nas ações empreendidas para que sejam alcançados. Na Alfa o cumprimento dos requisitos e exigências da matriz e do mercado é pautado na busca de eficiência, resultando na legitimidade das ações. Em outras palavras, a busca para a obtenção das metas estipuladas (eficiência) gera legitimidade para a Alfa, pois mesmo quando a meta não é alcançada e todos os procedimentos exigidos foram empregados, a ação e os resultados são legitimados. Desse modo, os dois fatores influenciaram a interpretação do significado dessa prática na Alfa, mas a legitimidade está ligada aos meios e a eficiência aos fins. Por isso, entende-se que a motivação predominante foi a busca pela eficiência.

\subsubsection{Resposta Estratégica}

Foi verificado que o Custeio Alvo na Alfa está no estágio de internalização, ou seja, institucionalizado. Mas, isso não é garantia de que suas atividades, processos e informações influenciem as decisões, os controles bem como os resultados da organização. Foi discutido na fundamentação teórica que a adoção de práticas com objetivo de conformação às demandas institucionais pode não ser adequada ao contexto organizacional, causando inconsistências com a estrutura formal. Nesse caso, a prática pode não ser percebida como útil aos propósitos da organização, ou ainda pode apresentar conflitos com a busca de eficiência. Uma forma de obter legitimidade e proteger a estrutura quando da existência de conflitos é institucionalizar a prática de modo que a mesma não tenha interferência nos resultados da organização, fazendo com que os possíveis conflitos entre estrutura, estratégias e práticas sejam amortecidos. Isso é tratado como adoção cerimonial ou decoupling entre a estrutura e a ação, ou seja, embora esteja institucionalizada a prática não interfere na estrutura nem nas rotinas.

Por outro lado, quando uma organização é obrigada a adotar uma prática, mas sua utilidade é percebida ou a mesma não apresenta conflitos ou ambiguidades com a estrutura, as estratégias 
e a eficiência, como foi o caso da Alfa, sua aceitação de forma acoplada às rotinas e aos resultados (coupling) tem maior probabilidade de ocorrer. Os fatores institucionais e econômicos tanto na época da adoção quanto na fase de implementação da prática podem influenciar a resposta estratégica da organização, podendo levar a uma reação por parte da subsidiária em não aceitar a prática imposta ou pode ocorrer sua aceitação. Por isso, esses fatores foram avaliados tanto na adoção quanto na implementação e foram usados para auxiliar no entendimento da resposta da Alfa. Destaca-se que não foi considerada nessa pesquisa a possibilidade de resposta do tipo "não adotar a prática" uma vez que se trata de imposição da matriz, não havendo alternativa. O que foi considerado inicialmente é que a prática poderia não estar institucionalizada, mas pelas análises do estágio de institucionalização as evidências mostraram o contrário.

Em relação aos fatores institucionais na adoção, as análises indicaram que o mecanismo de isomorfismo coercitivo foi o responsável pela adoção do Custeio Alvo na Alfa, imposto pela matriz. Esse fato tende a aumentar as chances do decoupling como forma de resposta organizacional principalmente quando a organização entende e significa a imposição enquanto coerção. No entanto, outra forma de significar a imposição é através da percepção da importância da prática para obtenção dos objetivos organizacionais, ligada mais aos aspectos cognitivos do que aos impositivos ou regulatórios. Pelas evidências extraídas dos discursos foi possível perceber que a utilização do Custeio Alvo não representa o cumprimento de um ditame, mas é entendido como um processo que auxilia a obtenção de resultados e também legitima as ações e os resultados. Isso indica a presença do aspecto cognitivo influenciando o significado da prática para a Alfa e, desse modo, mesmo tendo sido imposto via coerção, o mesmo não é entendido ou percebido dessa forma pelos atores.

Isso levanta um ponto interessante para análise, em especial por se tratar de uma subsidiária, que envolve o tipo de relação que a Alfa mantém com a matriz, pois isso pode ter auxiliado esse tipo de entendimento. Na fundamentação teórica foi verificado que, para Kostova e Roth (2002), a dependência, a confiança e a identidade com a matriz pode influenciar o tipo de resposta da subsidiária. Essas características se mostraram oportunas para ilustrar o caso da Alfa em relação ao mecanismo coercitivo, por isso, na sequência essas três características foram analisadas.

A dependência da subsidiária em relação à matriz se refere aos recursos como tecnologia, capital e expertise, implicando tanto a subordinação quanto o controle. As subsidiárias que 
percebem essa dependência e a interpretam como algo coercitivo têm a tendência de acatar as imposições de modo cerimonial. A Alfa mostrou ter dependência da matriz em vários aspectos como o cumprimento dos códigos de conduta e das normas estabelecidas, os controles e relatórios que são iguais aos da matriz, os métodos de cálculo de custos, do lucro consolidado e do preço de transferência que são estipulados pela matriz.

Em relação ao planejamento do lucro, quem estipula o que a Alfa deve gerar de retorno é a matriz e não ela própria. A decisão final de lançar ou não um produto é da matriz, devido ao envolvimento de licenças e pagamento de royalties, acentuando uma dependência em relação à tecnologia. Também foi mencionado nas entrevistas que muitos componentes e partes dos produtos são fabricados em plantas no país de origem da matriz e a Alfa depende desses recursos. O presidente e o diretor financeiro da subsidiária vieram do país de origem da matriz nomeados pela mesma, evidenciando que a gestão da subsidiária fica a cargo de pessoas de confiança da matriz, cumprindo seus mandatos e amortecendo possíveis discordâncias entre as duas empresas. Esse fato pode ter contribuído para a perpetuação dos valores e da cultura da matriz na subsidiária, incluindo os procedimentos exigidos nas atividades, como o processo de desenvolvimento de novos produtos e o Custeio Alvo. De acordo com essas constatações existe dependência em relação à matriz, mas não foi encontrado indício de que isso seja algo negativo para a Alfa.

$\mathrm{O}$ outro aspecto se refere à confiança da subsidiária em relação à matriz, sendo que a percepção de confiança pode auxiliar o entendimento das exigências impostas. Um indício de confiança da Alfa em relação à matriz é o fato de que esta envia para as subsidiárias um relatório com informações de custos de todas as empresas do grupo para que possam ser comparadas e usadas para auxiliar as atividades. O acesso às informações de caráter estratégico pode levar à confiança, uma vez que a empresa acaba por conhecer a situação do grupo Alfa. Outra evidência pode ser verificada pelo comentário do funcionário $\mathrm{C}$ e sua tentativa de entender porque a matriz impõe determinada margem de contribuição para a Alfa: “[...] Isso é uma análise que eu mesmo fiz, a matriz não me disse nada, a gente vê o número começa a trabalhar e, ah! realmente! tem razão de ser aquele número. [...].”. Isso indica a tentativa de entender o funcionamento, reforçando o aspecto cognitivo, verificando que o que a matriz vem exigindo tem uma lógica. Entender a lógica pode aumentar a confiança em relação à matriz por perceber que não se trata de exploração ou outro aspecto negativo. 
A terceira característica é a identificação, ou seja, a ligação com a matriz e o sentimento de fazer parte do grupo Alfa. A esse respeito o funcionário $\mathrm{C}$ mencionou que: "[...] nosso presidente lá da matriz, ele não está preocupado quanto a Alfa do Brasil está tendo de lucro, ele quer saber: nós estamos tendo lucro ou não estamos tendo lucro como grupo." Isso evidencia a identificação da Alfa com o grupo e considera o presidente da matriz como "nosso presidente", indicando a identificação com a matriz. Foi comentado também que se espera que os clientes tenham orgulho em possuir um produto da marca Alfa. Além disso, o funcionário $\mathrm{C}$ comentou sobre muitas informações da matriz indicando que existe conhecimento de como as coisas são feitas por lá, o que pode promover a identificação.

Pelo exposto foi possível verificar que, mesmo existindo a coerção para a adoção e utilização do Custeio Alvo, as características que envolvem a relação entre subsidiária e matriz, em especial a confiança e a identificação, indicam uma percepção favorável em relação aos mandatos a serem cumpridos. Isso pode ter favorecido o entendimento da importância do processo do Custeio Alvo para a organização. O peso da coerção da matriz parece não existir ou não ter importância no processo de interpretação, sugerindo que o entendimento na Alfa é de que os mandatos servem como diretrizes necessárias para o andamento das operações da subsidiária e não como coerção. Além disso, pelo conteúdo das entrevistas e da pesquisa documental a semelhança com a matriz parece ser desejável e trazer legitimidade.

Foi observado também que o conteúdo dos discursos das entrevistas não apontou para descontentamentos ou qualquer problema em relação à matriz e suas exigências. Mesmo quando do estabelecimento de metas mais difíceis de serem atingidas, conforme comentário dos funcionários $\mathrm{C}$ e $\mathrm{D}$, os mesmos demonstraram que isso é entendido como algo natural e que serve para ajudar o grupo Alfa a atingir seus objetivos.

Em relação à legitimidade foi verificada a sua presença tanto na adoção quanto na implementação e utilização do processo do Custeio Alvo. Foi observado também que a Alfa não presta contas da utilização do Custeio Alvo para a matriz, o que existe é a utilização das informações desse processo para discutir questões estratégicas, embasar a tomada de decisão e para controle, auxiliando na obtenção do resultado esperado. Essas constatações indicam que o mesmo é usado e que tem um propósito específico que não é sua prestação de contas para a matriz, mas sim de seus resultados, atingir ou não as metas estipuladas. Com isso verifica-se a influência dos fatores econômicos além do institucional, uma vez que o objetivo de utilização da prática está atrelado à obtenção dos resultados desejados. Percebe-se com isso que existe 
uma conexão entre o significado da prática proposto pela matriz e o significado encontrado na Alfa, controlar ações e resultados.

Quando a estrutura está dissociada da ação (onde há decoupling) a avaliação de desempenho tende a ser minimizada e até evitada, ou ainda feita de forma cerimonial. No caso da Alfa as evidências mostraram que o processo de Custeio Alvo apresenta tanto coordenação quanto controle de forma a possibilitar a avaliação de desempenho, sendo a base para a construção das metas de desempenho. Não foram verificados conflitos ou ambiguidades entre as atividades do Custeio Alvo e a estrutura ou a rotina da organização de modo geral. As análises do processo de institucionalização evidenciaram que os requisitos necessários para a utilização dessa prática foram encontrados na Alfa. Além disso, não foram encontrados indícios do uso do Custeio Alvo de forma cerimonial em qualquer uma das etapas do seu processo, sendo que a coerção e a busca de legitimidade, que representam as possibilidades de reação nesse sentido, foram investigadas e não apresentaram esse tipo de resposta.

Pela análise do estágio do processo de institucionalização bem como de outros aspectos da pesquisa, foi possível verificar que na Alfa a estrutura (o processo do Custeio Alvo) está associada às ações uma vez que a prática é operacionalizada para a obtenção do custo alvo, usada para controle, tomada de decisão de lançamento do produto e avaliação de desempenho. Por essas análises verificou-se que a resposta da questão 1.5 (De que forma o Custeio Alvo encontra-se institucionalizado, coupled ou decoupled?) é que o mesmo foi institucionalizado da forma coupled, ou seja, sua estrutura está atrelada às rotinas e ações, que por sua vez, estão atrelados aos resultados.

\subsection{Discussões e Análises Gerais do Caso}

O objetivo deste item foi discutir os achados da pesquisa de modo a responder a questão geral levantada, que engloba as análises pelas duas teorias. Primeiro foram apresentados os assuntos relativos à Teoria da Contingência, depois os da Teoria Institucional. Ressalta-se que as duas teorias, por serem de paradigmas diferentes, foram usadas de forma separada, cada qual com seu foco sob o mesmo fenômeno, o Custeio Alvo. Por isso, é difícil fazer comparações entre os resultados. No entanto, para Crotty (1998) paradigmas diferentes não podem ser comparados, mas podem ser relacionados. Dessa forma, adicionalmente, procurouse nos achados pontos que pudessem ser relacionados entre as duas teorias. 
Em uma pesquisa do tipo estudo de caso interpretativo é importante não apenas descrever as características e a forma de uso da prática investigada, mas entender seu funcionamento naquele contexto particular. Isso porque permite que os aspectos gerais subjacentes a uma teoria sejam evidenciados em um nível mais específico, exemplificando uma realidade. Nesse sentido, a Teoria da Contingência foi usada nesta pesquisa para verificar a adequação das informações oriundas do processo do Custeio Alvo a alguns fatores contingentes. Pelo fato de a teoria apresentar aspectos gerais em suas proposições, foi necessário verificar quais tipos de informações o processo do Custeio Alvo disponibiliza para poder fazer as análises num contexto específico. Verificou-se que considerável parte de suas informações se encaixou no perfil daquelas descritas na literatura como sendo de escopo amplo e contemporâneas, apresentando também características estratégicas.

Antes de se proceder as análises, é importante mencionar que dessa necessidade decorreu uma das dificuldades da pesquisa, qual seja, "encaixar" as informações do Custeio Alvo nos modelos ou tipos de informação disponíveis na literatura de base. Em especial porque muitas pesquisas empíricas que usaram essa abordagem (analisadas na fundamentação teórica) englobavam várias práticas ou vários tipos de informações que compõe o SCG e acabavam por resumir as suas características principais. Dois pontos principais surgiram em decorrência disso, um foi a dificuldade para adaptar as medidas baseadas na literatura usadas nos estudos de levantamento (survey) por serem amplas, englobando muitas características amarradas a cada fator; outra por ser difícil na prática transportar os conhecimentos gerais da teoria para um contexto específico, ou seja, conforme Malmi e Granlund (2009), é difícil para uma organização trazer para sua realidade os resultados das pesquisas por serem muito genéricos.

O reflexo disso é que não se conhece de modo mais específico que tipos de SCG estão relacionados ao tipo de informação descrito nas pesquisas e se a forma como os sistemas são usados tem alguma implicação no seu resultado (conforme discutido por MALMI; GRANLUND, 2009). Por isso, entender como as informações do Custeio Alvo estão sendo utilizadas na Alfa foi importante para elucidar essa situação.

Outra questão que merece destaque é que esta pesquisa permitiu verificar na Alfa que a maioria das características e requisitos do Custeio Alvo, apresentados na literatura, estava incorporada no processo, e este estava gerando os resultados esperados e a percepção de sua utilidade. A forma como essas características emergiram no decorrer da pesquisa mostrou a complexidade que envolve a adoção, a implementação e o uso dessas práticas, em especial 
quando se considera as premissas da NSI relacionadas à agência estratégica, evidenciando que as interpretações em relação às mesmas podem ser diferentes em cada organização.

A implicação disso é que, em abordagens como a Teoria da Contingência, que não considera o voluntarismo em seus pressupostos, deve-se ter o cuidado nas pesquisas empíricas não apenas de especificar quais práticas as organizações estão adotando, mas como estão acopladas ao sistema de controle e como vem sendo utilizadas, pois pode acontecer de uma organização informar o uso de determinada prática, mas a mesma não interferir em suas rotinas (decoupling). Nesse sentido, a avaliação do uso apenas com referência ao modelo de Simons (1995), uso interativo ou diagnóstico, não consegue captar esse tipo de variação nas respostas estratégicas e isso pode causar vieses nos resultados e interpretações. Por isso, a necessidade de que as pesquisas desenvolvam formas de contornar essa questão preservando os pressupostos da teoria usada, de modo que os achados possam refletir de maneira mais aproximada a realidade das organizações. Além disso, o uso de teorias de forma complementar pode ajudar a captar essas nuances que envolvem as motivações e interesses por traz dos discursos, que foi o caso da presente pesquisa.

Quanto aos achados, foi verificado que o Custeio Alvo é usado no desenvolvimento de produtos, que é uma atividade chave para a Alfa, pois de acordo com suas estratégias (defensora, diferenciação e manter), os requisitos dos clientes, a inovação tecnológica, a qualidade dos produtos bem como a manutenção da participação do mercado são essenciais. Por isso, desenvolver produtos que refletem os requisitos do mercado e o retorno desejado foi um ponto recorrente nos discursos em todas as entrevistas e nos textos corporativos, enfatizando esses objetivos. Isso indica que informações relativas a esses enfoques auxiliam a Alfa a lidar com as incertezas estratégicas e tendem a ser utilizadas e consideradas como úteis desde que esse discurso esteja refletido nas ações organizacionais.

As análises acerca do processo do Custeio Alvo na Alfa mostraram que isso aconteceu, ou seja, as ações empreendidas no processo de desenvolvimento de produtos estavam consoantes com os objetivos propostos, evidenciados pelos discursos. Essa é uma constatação relevante no âmbito da Teoria da Contingência, uma vez que não faz parte de seu escopo verificar se as organizações estão, de fato, utilizando as práticas que dizem usar e como estão utilizando, por considerar o determinismo em sua abordagem. Isso não é uma crítica ao paradigma dessa teoria e sim uma contribuição no sentido de evidenciar a necessidade de aproximar os seus 
aspectos e proposições gerais do que acontece nas organizações, auxiliando suas explicações da realidade.

Foi verificado também que a Alfa utiliza informações relacionadas às características que os clientes querem nos produtos (externas e não financeiras), preço que o cliente está disposto a pagar (externas e financeira), margem desejada e custos estimados (internas), informação do custo alvo (caráter ex ante), dentre outras que são oriundas do processo do Custeio Alvo e usadas para auxiliar a implementação das estratégias estabelecidas. As análises mostraram que essas informações foram consideradas pelos entrevistados como essenciais para auxiliar o controle e a tomada de decisão em relação ao desenvolvimento e lançamento de produtos.

Além disso, quando o produto é lançado e começa a ser fabricado, o acompanhamento entre o esperado e o realizado (com rígido controle de custos via custo padrão, integrado com a avaliação de desempenho e o sistema de compensação) promove a percepção de que os esforços empreendidos na busca dos objetivos não se perdem no discurso organizacional. Ao contrário, fornece as evidências da integração e coordenação entre planos, ações e resultados.

Com base nessas características foram feitas as análises dos fatores contingentes e, na sequência, foram apresentadas as deduções e inferências acerca dos achados. Quanto aos fatores externos, foi verificada a existência de intensa concorrência (também encontrada nos trabalhos de DEKKER; SMIDT, 2003 e AX et al., 2008) e baixa incerteza ambiental, que não evidenciou adequação com a literatura, apresentando resultado contrário ao de Dekker e Smidt (2003). Ressalta-se que no caso da incerteza ambiental foi verificado que a experiência da empresa em realizar o processo dessa prática há vários anos pode estar auxiliando na obtenção dos dados e informações necessárias, o que pode ser uma das explicações sobre a percepção de baixa incerteza. Além disso, um ponto importante para auxiliar na explicação desse fator foi a investigação da tipologia estratégica de característica de mercado, no caso da Alfa descrita como defensora. Organizações que atuam com a estratégia defensora implementam ações que tornam seu ambiente mais previsível e estável, por isso, nesses casos a baixa incerteza percebida é esperada.

Para Miles e Snow (2003), empresas com estratégia defensora não estão preocupadas com concorrência, nem com incerteza ambiental, nem com outras informações vindas do ambiente externo, a não ser os requisitos que os clientes desejam nos produtos que fazem parte do escopo escolhido para sua atuação. Por isso, quando da análise da incerteza ambiental é 
importante considerar tanto o tempo de atuação das organizações investigadas quanto a estratégia seguida, para reduzir possíveis vieses nas análises.

O interessante é que mesmo apresentando baixa incerteza ambiental foi verificado que as informações do Custeio Alvo são importantes para a Alfa buscar seus objetivos. Desse modo, a organização utiliza informações de escopo amplo (ex ante, não financeiras, externas etc.), extraídas do processo do Custeio Alvo, mesmo apresentando incerteza ambiental baixa, o que de certa forma não condiz com a proposição lançada por Chenhall (2007), baseada nos resultados dos estudos da Contingência, de que quanto mais incerto é o ambiente, mais aberto e com foco externo é o SCG.

O que não foi encontrado na literatura pesquisada nessa abordagem é como as empresas geram essas informações descritas por Chenhall (2007) e em que partes do SCG as mesmas são mais abertas e com foco externo para lidar com este ambiente. Por exemplo, elas são geradas por uma prática ou por várias dentro do SCG? São extraídas do SCG como um todo, conforme a proposição leva a crer? São geradas pela Contabilidade? São relatórios específicos? São regulares ou esporádicos? Esse tipo de direcionamento não está claro na literatura, por isso, quando essas proposições são levadas para as organizações é difícil estabelecer qualquer relação mais direta entre o tipo de informação e como ela é obtida, dificultando o entendimento sobre sua aplicação prática e suas contribuições. Nessa pesquisa foram mostradas as informações extraídas do Custeio Alvo na Alfa, como é seu processo, bem como onde e de que forma elas são usadas e qual o resultado com sua utilização, auxiliando tanto a literatura quanto as organizações que pretendem adotar esse tipo de prática.

Pelas análises, foi verificado que mesmo apresentando baixa incerteza os fatores externos favorecem a utilização do Custeio Alvo na Alfa. Em relação aos fatores internos, as análises mostraram que os fatores contingentes avaliados e presentes na Alfa estão favorecendo a utilização do Custeio Alvo, em especial pelo fato de evidenciarem a ausência de conflitos e ambiguidades entre os aspectos técnicos da prática (apresentados no Capítulo 3) e os objetivos e características da organização (relacionados aos fatores contingentes internos).

Um achado interessante diz respeito à combinação de estratégias encontrada na Alfa, sendo, defensora (também encontrada nos resultados de CINQUINI; TENUCCI, 2010), diferenciação (também encontrada em HIBBETS et al., 2003) e manter (não foi encontrada em outros estudos sobre Custeio Alvo). Destaca-se que, empiricamente, apenas o estudo de 
Cinquini e Tenucci (2010) e a presente pesquisa usaram três tipologias de estratégia. As análises mostram que a combinação encontrada entre as três tipologias no caso da Alfa foi diferente tanto da encontrada no estudo de Cinquini e Tenucci (2010) (em que a relação se deu apenas entre defensoras e de liderança de custos) quanto das proposições sobre as possíveis combinações levantadas por Langfield-Smith (1997), Kald et al. (2000) e Chenhall (2007), que não foram testadas empiricamente.

As diferenças encontradas entre a presente pesquisa e as proposições desses últimos autores podem ser analisadas considerando-se as evidências encontradas na Alfa sobre a utilização do Custeio Alvo e sobre a forma rígida de controle dos custos na empresa. Analisando as características das informações requeridas em relação às estratégias, Langfield-Smith (1997) propõe que combinações viáveis seriam entre defensora, liderança de custos e colher, e a outra entre prospectoras, construir e diferenciação. Nenhuma dessas combinações foi encontrada na Alfa. A proposição de Kald et al. (2000) que mais se aproximou da encontrada na Alfa foi defensora, manter e diferenciação, porém, nesse caso os controles da organização seriam frouxos; o que não foi o caso da Alfa, visto que informações extraídas do Custeio Alvo e o próprio controle de custos são usados de forma rígida. Chenhall (2007) propõe que a combinação defensora, liderança de custos e colher, estaria ligada a sistemas de controles formais; na Alfa os controles ligados às incertezas estratégicas são formais, a diferença é que na Alfa a combinação foi diferente (defensora, diferenciação e manter). Embora a combinação encontrada foi diferente dos estudos analisados, foi verificado que o Custeio Alvo é adequado para a mesma, não sendo detectado qualquer conflito ou ambiguidade entre as estratégias e as informações da prática, bem como a forma como são usadas.

Os outros fatores internos encontrados foram o porte grande (também encontrado em CADEZ; GUILDING, 2008); a estrutura (com características do tipo orgânica, matricial, com cultura participativa e formação de equipes temporárias), a utilização de algumas tecnologias de informação e algumas características de tecnologia de produção (produção com baixo volume, características de produção enxuta e flexível em alguns aspectos e uso de tecnologias de produção contemporâneas). Destaca-se que os resultados dessa pesquisa foram comparados somente com os trabalhos dispostos no Capítulo 2 (item 2.1.3) que apresentaram semelhança nas medidas e objetivos; estrutura e tecnologia não tiveram base de comparação.

Finalmente, foi verificado que os fatores contingentes analisados, mesmo os que não apresentaram adequação em relação à literatura, foram considerados como favorecendo a 
adoção e a utilização do Custeio Alvo. Um dos pontos comuns encontrado para explicar essa questão (envolvendo a baixa incerteza, a padronização de produtos e a combinação de estratégias encontrada) foi a duração do ciclo de vida dos produtos. A constante mudança nos requisitos dos clientes e na inovação da tecnologia tem como consequência a mudança nas características dos produtos; se a organização não se adequar a essas demandas pode perder mercado e posição competitiva. Essa questão na Alfa é tratada como fundamental, sendo a frequência de mudanças nos produtos subjacente às suas estratégias, o que pode explicar em parte, a adequação do Custeio Alvo mesmo com produtos padronizados e com baixa incerteza acerca do ambiente. Assim, as constatações relativas à adequação entre a utilização do Custeio Alvo e os fatores contingentes evidenciaram o alinhamento entre o que se quer (objetivos e planos organizacionais), as ações para implementação dos objetivos e o controle dos resultados.

Em relação ao uso foi verificado que o sistema de controle da qual o Custeio Alvo faz parte se refere ao desenvolvimento e à fabricação dos produtos. Nesse sistema, a prática analisada apresentou características de uso diagnóstico e interativo, mas devido à forma como é discutido e implementado, seu uso predominante tem a forma interativa. Esse achado está de acordo com as discussões de Simons $(1990 ; 1995)$ de que o sistema de controle escolhido para uso interativo pela alta gestão é aquele relacionado às incertezas estratégicas, que foi o caso da Alfa, uma vez que estas se referem às demandas dos clientes e às inovações tecnológicas que podem modificar as características dos produtos e sua estrutura de custos, influenciando a busca pela eficiência.

Em relação ao desempenho da prática, a percepção da utilidade do Custeio Alvo na Alfa pôde ser verificada indiretamente em todas as entrevistas, sendo que o funcionário $\mathrm{B}$ foi questionado sobre a mesma de forma direta. Para ele o Custeio Alvo foi considerado como de alto impacto em todas as suas atividades sendo imprescindível para a Alfa e estando muito satisfeito com o mesmo. Foi verificado na fundamentação teórica que a adequação do SCG aos fatores contingentes pode resultar em aumento de desempenho. Em relação a isso, o que pode ser percebido na Alfa é que o alinhamento entre meios e fins, conforme comentado, pode favorecer a percepção da utilidade da prática, em especial quando esta interfere nas rotinas organizacionais, sendo um instrumento de gestão. Portanto, em relação ao desempenho foi verificada a satisfação com sua utilização e a percepção de sua utilidade. 
De forma geral, o que foi investigado com base na Teoria da Contingência trouxe entendimento sobre as informações do Custeio Alvo em relação aos fatores contingentes e sua forma de uso em um contexto específico. Porém, a consideração de outra perspectiva (NSI) sobre o mesmo fenômeno fez com que outras questões emergissem. O estudo da implementação dessa prática pela NSI mostrou que a mesma se assemelha em muito ao descrito na literatura sobre Custeio Alvo, apresentando a maioria das características apontadas por Ansari et al. (2006). Sua utilização nestes moldes levou à percepção de sua utilidade e os discursos evidenciaram que o desenvolvimento de produtos auxiliado pelas informações dessa prática tem conseguido atingir os resultados esperados (lançamento de produtos que atingiram o custo alvo).

Relacionando esses achados com o fato de a adoção pela Alfa ter sido de forma coercitiva, a exigência da matriz para o uso do custo alvo como informação essencial para a decisão de lançamento de produtos reforça a busca pela eficiência. A ausência de conflitos entre os requisitos técnicos dessa prática e os fatores contingentes analisados parece reforçar seus aspectos técnicos, uma vez que a não adequação poderia reduzir a eficiência. Ma e Tayles (2009) fundamentaram seus achados nas pressões econômicas para concluir que a lógica por trás da adoção de novas práticas é a existência de uma adequação entre a agenda estratégica da organização e a das práticas de Contabilidade Gerencial. Esse argumento evidencia que a presença de conflitos e ambiguidades pode ser contrária a essa lógica, uma vez que a falta de contradição entre a estrutura e a rotina pode facilitar sua adoção. Isso pode ter alguma influência na resposta da forma coupling.

Outro tipo de relação que pode ser extraída diz respeito a uma das proposições de Phillips et al. (2004), que os textos produzidos por atores que são entendidos como tendo um poder legitimado para falar, que tem poder sobre recursos ou autoridade formal, ou que sejam localizados de forma central num campo são mais prováveis de se tornarem imersos no discurso, ou seja, de serem institucionalizados. Por isso, o uso interativo do processo do Custeio Alvo contando com a participação e colaboração da alta gestão também pode ter influenciado a aceitação e a imersão do mesmo nas rotinas organizacionais.

Outro fato que pode ter reforçado o entendimento acerca da utilização do Custeio Alvo com base na eficiência é que os resultados acabam por espelhar os discursos, ou seja, o que se comenta sobre o uso do Custeio Alvo na Alfa aparece de alguma forma nas ações e nos 
resultados. Com isso parece haver uma circularidade em que os discursos sustentam o uso da prática e que os resultados obtidos com o seu uso sustentam os discursos.

Em relação à NSI as análises indicaram que o mecanismo coercitivo foi o responsável pela adoção do Custeio Alvo na Alfa. Esse fato tende a aumentar as chances de uma resposta do tipo decoupling dependendo do tipo de interpretação dos atores acerca da coerção. No entanto, todas as evidências levaram a uma associação entre a estrutura e as ações (coupling), ressaltando o perfil cognitivo, pois o teor das entrevistas evidenciou que os quatro funcionários sabem para que a prática é usada, como é usada e quais os resultados esperados e obtidos com sua utilização. Essa forma de entendimento indica uma estreita relação entre meios e fins e uma consistência da prática com os valores e crenças da organização. Essas constatações evidenciam que a coerção não foi entendida somente como restrição de comportamento, mas também enquanto habilitadora para as ações, num processo recursivo.

Foi verificado que os entrevistados mostraram que o Custeio Alvo foi entendido como sendo importante para a organização obter os resultados desejados, sendo usado sem exceção nos projetos de produtos a serem lançados, embasando o controle de custos e o processo decisório. Esse fato reforça o aspecto econômico como forma de interpretação e a crença na validade técnica do Custeio Alvo. Não foram verificados indícios nos discursos de que apenas seguir os mandatos da matriz é suficiente para obter legitimidade, o que ressaltaria a crença nas propriedades simbólicas da prática pela tradição institucional. A busca de legitimidade no ambiente e em relação à matriz foi encontrada, mas não apresentou preponderância em relação à forma de interpretação. Ao invés disso, foi detectado que esses mandatos (no caso o uso do Custeio Alvo) geram uma interferência nas rotinas da Alfa influenciando seu curso de ação, caracterizando que a construção do significado da prática se baseou em suas propriedades técnicas.

Com os achados desse caso foi possível verificar que um conjunto de fatores (institucionais e econômicos) auxiliou a interpretação e a construção do significado do Custeio Alvo de modo que a resposta estratégica foi sua internalização da forma coupled. Além disso, a adequação da prática com os fatores contingentes pode ter influenciado essa resposta pela ausência de ambiguidades e conflitos entre a estrutura e sua exigência. $\mathrm{O}$ entendimento compartilhado dos atores construiu o significado do Custeio Alvo na Alfa conformando a resposta tanto ao ambiente institucional (matriz, clientes etc.) quanto à situação interna, evidenciando a 
recursividade entre a limitação (coerção) e a habilitação para a ação na construção dos significados, sendo a matriz nesse caso, um condicionante estrutural.

Os achados na Alfa sugerem que a agência dos atores modelam as rotinas da organização (além da estrutura), caso contrário, todas as organizações que atuam em um mesmo ambiente e sofrem as mesmas pressões institucionais e econômicas deveriam apresentar estruturas e rotinas muito semelhantes. Por isso, o significado das instituições em contextos específicos depende da interpretação e da agência dos atores envolvendo os interesses e pressões sofridas. Isso também implica que organizações com características semelhantes às da Alfa que adotarem o Custeio Alvo podem não obter os mesmos resultados; ou ainda, descarta a ideia de que estas empresas "devam" usar essa prática como forma de obter resultados semelhantes, visto que os resultados vão depender da forma de interpretação e de significação que, por sua vez, vão influenciar a forma de utilização.

A difusão que ocorre no campo institucional é a difusão das práticas, das instituições, das regras e do seu significado nesse campo, mas não quer dizer que este vai ser o significado na organização. Scott (2001) explora o raciocínio de Max Weber, que auxiliou nos pressupostos da NSI, sobre o fato de que os indivíduos não respondem mecanicamente aos estímulos, primeiro eles interpretam e depois modelam suas respostas, por isso, segundo Scott, os pesquisadores não podem esperar entender o comportamento social sem considerar esses significados que mediam a ação social.

Uma das implicações desse raciocínio é que mesmo tendo suas bases fundamentadas na obtenção de eficiência, as práticas da Contabilidade podem não ser entendidas e significadas dessa forma em todas as organizações. Outros fatores como os institucionais e as características da organização podem influenciar essa interpretação. Práticas como o Custeio Alvo, o Custeio Baseado em Atividade, o Balanced Scorecard, dentre outras que são discutidas na literatura embasadas em pressupostos racionais de eficiência, podem não ser significadas dessa mesma forma na organização, e isso pode ajudar a explicar o "sucesso" ou o "fracasso" em sua adoção. Por isso, além dos pesquisadores, os contadores, consultores e outros que implantam práticas nas organizações devem atentar não apenas para as suas características técnicas, mas também para os aspectos que podem influenciar a interpretação dos atores em relação à mesma, bem como aos aspectos que podem causar conflitos e ambiguidades com as rotinas existentes. 
As análises pautadas nos discursos acerca do estágio do processo de institucionalização permitiram capturar nuances sobre a forma de interpretação e o tipo de resposta da Alfa à implementação do Custeio Alvo, o que auxiliou nas discussões e conclusões das demais questões secundárias e da questão principal. Essas análises abriram caminhos para o entendimento acerca das motivações que envolveram a implementação da prática de forma recursiva, ou seja, não considerando as mesmas como tendo uma relação direta e linear, mas sim como um processo complexo que envolve a interligação de fatores e suas combinações para se chegar ao resultado. A consideração das categorias analisadas sob as lentes da NSI de forma dicotômica, como ocorreu nos estudos analisados na fundamentação teórica, não permitiria o tipo de análise feita nesse trabalho nem as conclusões geradas (e apresentadas no Capítulo 6), o que evidencia a sua originalidade e suas contribuições para a teoria bem como para auxiliar em possíveis decisões de adoção de práticas como o Custeio Alvo.

As discussões apresentadas nesse tópico são as respostas da questão principal dessa pesquisa (Que (quais) deduções e inferências podem ser extraídas acerca da introdução do Custeio Alvo na empresa objeto do estudo de caso à luz da Teoria da Contingência e da NSI?) e para facilitar a exposição das mesmas foi elaborado o Quadro 7 que resume as principais deduções e inferências discutidas com base em cada teoria de modo separado e no que pôde ser relacionado entre as duas. 
Quadro 7 - Resumo dos Achados

\begin{tabular}{|c|c|c|}
\hline Teoria da Contingência & Relação entre achados & Teoria Institucional \\
\hline $\begin{array}{l}\text { As ações empreendidas no } \\
\text { processo de desenvolvimento de } \\
\text { produtos, incluindo o uso do } \\
\text { Custeio Alvo, estão consoantes } \\
\text { com os objetivos da Alfa. }\end{array}$ & $\begin{array}{l}\text { A adequação aos fatores } \\
\text { contingentes reforçam os } \\
\text { aspectos técnicos do Custeio } \\
\text { Alvo e o foco na busca pela } \\
\text { eficiência. }\end{array}$ & $\begin{array}{l}\text { A adoção se deu pelo mecanismo } \\
\text { coercitivo, mas foi constatada a } \\
\text { associação entre a estrutura e as } \\
\text { ações (coupling), ressaltando o } \\
\text { perfil cognitivo. }\end{array}$ \\
\hline $\begin{array}{l}\text { O Custeio Alvo é usado para } \\
\text { controlar ações e resultados } \\
\text { ligados ao desenvolvimento de } \\
\text { produtos e ao controle de custos, } \\
\text { estando, portanto, acoplado a esse } \\
\text { sistema de controle. }\end{array}$ & $\begin{array}{l}\text { O uso interativo pode ter } \\
\text { auxiliado no entendimento } \\
\text { da importância da prática } \\
\text { para a Alfa e de sua imersão } \\
\text { nas rotinas. }\end{array}$ & $\begin{array}{l}\text { A coerção não foi entendida } \\
\text { apenas como constrangendo as } \\
\text { ações, mas também habilitando as } \\
\text { mesmas, evidenciando a } \\
\text { recursividade do processo de } \\
\text { institucionalização. }\end{array}$ \\
\hline $\begin{array}{l}\text { Os fatores que apontaram } \\
\text { diferenças em relação à literatura } \\
\text { foram: incerteza ambiental } \\
\text { percebida, combinação de } \\
\text { estratégias e modelos de produtos } \\
\text { padronizados. }\end{array}$ & $\begin{array}{l}\text { As ações decorrentes do uso } \\
\text { da prática refletem os } \\
\text { discursos, indicando a } \\
\text { existência de rama } \\
\text { circularidade em que os } \\
\text { discursos sustentam o uso do } \\
\text { Custeio Alvo e os resultados } \\
\text { obtidos com seu uso } \\
\text { sustentam os discursos. }\end{array}$ & $\begin{array}{l}\text { Crença de que o uso do Custeio } \\
\text { Alvo auxilia na busca dos } \\
\text { resultados esperados. } \\
\text { Significado: o Custeio Alvo é um } \\
\text { dos meios usados para obter os } \\
\text { resultados esperados, controlando } \\
\text { as ações e resultados. }\end{array}$ \\
\hline $\begin{array}{l}\text { Mesmo apresentando algumas } \\
\text { diferenças com a literatura, foi } \\
\text { verificada a adequação entre os } \\
\text { fatores contingentes avaliados e a } \\
\text { utilização do Custeio Alvo. }\end{array}$ & & $\begin{array}{l}\text { Consistência entre as } \\
\text { características técnicas do Custeio } \\
\text { Alvo e os valores e crenças da } \\
\text { Alfa. }\end{array}$ \\
\hline $\begin{array}{l}\text { O sistema de controle em que o } \\
\text { Custeio Alvo faz parte é usado de } \\
\text { forma interativa, permitindo a } \\
\text { discussão colegiada e a cultura } \\
\text { participativa em relação aos } \\
\text { assuntos estratégicos, enfatizando } \\
\text { o aprendizado através da } \\
\text { organização. }\end{array}$ & & $\begin{array}{l}\text { A legitimidade é obtida com a } \\
\text { conformação aos mandatos. Mas, } \\
\text { não foi detectado o entendimento } \\
\text { de que apenas seguir esses } \\
\text { mandatos é suficiente para obter } \\
\text { legitimidade, ou seja, a crença não } \\
\text { está nas propriedades simbólicas } \\
\text { do Custeio Alvo. }\end{array}$ \\
\hline $\begin{array}{l}\text { As ações de acompanhamento } \\
\text { entre o esperado e o realizado } \\
\text { (após o lançamento dos produtos), } \\
\text { bem como a integração com } \\
\text { avaliação de desempenho e } \\
\text { sistema de compensação (baseados } \\
\text { no custo padrão que é construído } \\
\text { com base no custo alvo), promove } \\
\text { a percepção de que os esforços } \\
\text { empreendidos na busca pelos } \\
\text { objetivos não estão apenas no } \\
\text { nível de discurso e sim nas ações. }\end{array}$ & & $\begin{array}{l}\text { O Custeio Alvo foi entendido } \\
\text { como sendo importante para a } \\
\text { organização obter os resultados } \\
\text { desejados, sendo usado sem } \\
\text { exceção nos projetos de produtos, } \\
\text { evidenciando sua interpretação } \\
\text { com base na busca pela eficiência } \\
\text { e a crença em sua validade técnica, } \\
\text { o que contribuiu para a resposta do } \\
\text { tipo coupling. }\end{array}$ \\
\hline $\begin{array}{l}\text { A maioria das características do } \\
\text { Custeio Alvo usado na Alfa é } \\
\text { semelhante ao descrito na } \\
\text { literatura. }\end{array}$ & & \\
\hline $\begin{array}{l}\text { A forma com que a prática vem } \\
\text { sendo usada está trazendo os } \\
\text { resultados esperados, levando à } \\
\text { percepção de sua utilidade. } \\
\text { As informações do Custeio Alvo } \\
\text { foram consideradas pelos } \\
\text { entrevistados como essenciais para } \\
\text { auxiliar o controle e a tomada de } \\
\text { decisão. }\end{array}$ & & \\
\hline
\end{tabular}


Com base nas análises e nos achados deste Capítulo, na sequência foram extraídas as conclusões que evidenciam as contribuições da pesquisa e as recomendações para futuros trabalhos. 


\section{CONCLUSÕES}

A constatação da necessidade de proporcionar entendimentos adicionais acerca dos aspectos ligados à adoção de práticas de controle gerencial pelas organizações e como isso se reflete em seu funcionamento foi a motivação para a realização desta pesquisa. Para tanto, através de um estudo de caso foi investigada a adoção, a implementação e o uso de uma dessas práticas, o Custeio Alvo. Duas teorias foram usadas de forma separada para nortear a investigação.

Pelas lentes da Teoria da Contingência foi verificado se os fatores contingentes presentes na organização estavam favorecendo a adoção e a utilização do Custeio Alvo em relação ao tipo de informação que este disponibiliza em seu processo. Ainda, foi verificado como a prática vem sendo usada na Alfa e seu desempenho, baseado na utilidade percebida. Pela NSI foi analisado de que forma o Custeio Alvo está institucionalizado, bem como os motivos que podem ter influenciado a interpretação e a resposta estratégica sobre o mesmo na organização. A utilização das duas abordagens permitiu então, não apenas descrever o funcionamento do Custeio Alvo na Alfa, mas verificar alguns dos processos e condições (pressões) que conduziram a essa forma de utilização.

Tão importante quanto responder as questões que embasaram a problemática da pesquisa é verificar as implicações daí decorrentes. Por isso, as conclusões apresentadas na sequência foram focadas nas reflexões acerca dos achados da pesquisa (discutidos no Capítulo 5) que podem contribuir tanto com as teorias usadas quanto com a prática da Contabilidade Gerencial e do SCG nas organizações. Posteriormente, foram apresentadas algumas recomendações para futuros trabalhos. É importante ressaltar que, por se tratar de estudo de caso, as conclusões se referem aos achados e sua relação com as teorias e a literatura de base, ou seja, sua generalização é analítica.

\subsection{Conclusões Referentes aos Achados Baseados na Teoria da Contingência}

Foi verificado que os fatores contingentes analisados e presentes na Alfa favorecem a utilização do Custeio Alvo, mesmo nos casos em que foram detectadas diferenças entre o que 
a literatura aponta como sendo adequado. Devido a esse resultado algumas conclusões podem ser extraídas.

Quanto à combinação de estratégias encontrada na Alfa pode-se concluir que o Custeio Alvo é uma prática gerencial compatível com posturas estratégicas conservadoras, como defensora e mantenedora, e que essa opção não conflita com a postura de diferenciação. Pelas análises é possível concluir também que é difícil senão impossível estabelecer, a priori, correlações, biunívocas ou não, entre o uso de determinadas práticas de Controle Gerencial e determinadas posturas estratégicas, especialmente sem considerar a forma de utilização das informações.

A combinação de estratégias encontrada na Alfa e estas conclusões reforçam o argumento de Langfield-Smith (2007) de que o conhecimento sobre a relação entre estratégias e SCG é ainda limitado, mas ao mesmo tempo lança uma luz sobre o assunto ao mostrar que as organizações adotam combinações não esperadas (em relação à literatura), mas que fazem sentido quando se analisa a forma como são empregadas. Desse modo, as estratégias parecem estar relacionadas ao tipo de informação de uma prática do SCG (escopo amplo ou estreito ou ambos) e a forma como é utilizada pela organização (de forma rígida ou frouxa, para gestão ou para controle etc.), e não que o tipo de estratégia é que vai modelar o SCG, conforme apresentado na literatura analisada. Isso porque, conforme discutido (Capítulos 2 e 5), foi verificado que uma mesma prática é capaz de apoiar diferentes abordagens estratégicas (CINQUINI; TENUCCI, 2010).

Ressalta-se que a investigação do fator estratégia usando três tipologias permitiu uma análise mais abrangente sobre a adequação das informações do Custeio Alvo por focarem aspectos distintos em relação aos objetivos organizacionais (características de mercado, ciclo de vida e posicionamento de mercado), gerando uma contribuição ao evidenciar que suas combinações nas organizações podem ser as mais diversas.

Outra conclusão diz respeito à constatação da necessidade de analisar o fator incerteza ambiental juntamente com outros fatores; uma vez que a baixa incerteza ambiental, quando analisada de forma isolada, não pareceu apresentar adequação com o uso do Custeio Alvo, mas que sua análise em conjunto com a estratégia defensora e a consideração do tempo de atuação da empresa auxiliou sobremaneira no entendimento de sua adequação naquele contexto. 
As contribuições extraídas das descrições e análises do funcionamento do Custeio Alvo com base na Teoria da Contingência estão relacionadas ao mapeamento dos fatores que estão contribuindo para a utilização dessa prática, bem como sua forma de uso e seu resultado, percebido pelos seus usuários. Essas informações podem ser usadas tanto na formulação de hipóteses a serem testadas em outros estudos que pretendem investigar o Custeio Alvo quanto para a prática nas organizações, por mostrar como a Alfa está alinhando os planos e as ações de modo a gerar os resultados esperados, o que pode servir de referência para outras empresas que pretendem adotar esse tipo de prática. Os fatores estrutura, tecnologia da informação e tecnologia da produção não foram analisados empiricamente nos estudos sobre Custeio Alvo referenciados nessa pesquisa, por isso, a descrição dessas características, conforme encontradas na Alfa, é uma contribuição para a literatura sobre essa prática.

\subsection{Conclusões Referentes aos Achados Baseados na NSI}

Os achados com base na NSI evidenciaram que a Alfa adotou o Custeio Alvo pela coerção da matriz, que o mesmo foi interpretado não apenas para buscar legitimidade, mas como um meio de obter os resultados desejados (foco na eficiência); e que o alinhamento entre os objetivos organizacionais, as características organizacionais e os aspectos técnicos dessa prática revelaram a ausência de conflitos e ambiguidades em relação à sua implementação e utilização. Todos esses aspectos favoreceram a utilização da prática interferindo no curso de ação e nas rotinas da Alfa, ou seja, uma resposta estratégica do tipo coupling. Essas constatações foram extraídas através da consideração da agência estratégica dos atores e da recursividade no processo de institucionalização (diferente das formas usadas nos estudos da NIS abordados na fundamentação teórica), com isso, algumas conclusões e implicações emergiram.

Uma conclusão relacionada à investigação do processo de institucionalização foi que os resultados obtidos nessa pesquisa sugerem que a interpretação dos atores sobre as instituições não estão relacionadas apenas à sua internalização ou institucionalização completa (visto que na Alfa esta foi coercitiva e obrigatória), mas principalmente à forma como as mesmas interferem nas rotinas, de acordo com a resposta estratégica. Em outras palavras, dado que uma organização está inserida em um ambiente institucional (como a Alfa) e precisa se conformar às suas demandas institucionais (até porque não é aceito outro comportamento, em 
especial na sua relação com a matriz), a tendência é de que as mesmas sejam institucionalizadas (provocando a mudança em sua estrutura), independente da interpretação que se faça das mesmas. No entanto, a forma de resposta atribuída a essas demandas, ou seja, permitir ou não sua interferência no curso de ação da organização (mudança na rotina), é que sofre a influência das interpretações dos atores acerca do ambiente, podendo ser influenciadas pelas pressões institucionais e econômicas e pela presença de conflitos e ambiguidades entre a instituição e as rotinas.

Embora essa conclusão tenha sido extraída do estudo de caso e que esta constatação não tenha sido levantada em outros estudos, pelo menos naqueles referenciados nessa tese, os resultados de outras pesquisas como as de Siti-Nabiha e Scapens (2005), Kholeif et al. (2007), NorAziah e Scapens (2007) e Järvinen (2006) (esta última no caso da adoção do Custeio Baseado em Atividades em uma das organizações estudadas) corroboram a mesma, pois também evidenciaram que as empresas analisadas institucionalizaram as práticas investigadas visto serem obrigatórias (coercitiva), mas que sua internalização não garantiu a mudança nas rotinas. Nesses casos, as rotinas continuaram estáveis, enquanto o que mudou foi apenas a estrutura. Dessa forma, quando a difusão se apresenta eminentemente da forma coercitiva, os mitos, as regras e as normas institucionais podem determinar a estrutura, mas não necessariamente as rotinas. As evidências apontaram que a mudança nas rotinas depende da interpretação que os atores fazem das mesmas, construindo as respostas de modo a acomodar as conveniências e interesses tanto do ambiente externo quanto interno.

Com base nesta conclusão a explicação acerca da resposta estratégica da Alfa, em relação à internalização da forma coupling, se mostrou diferente daquela apresentada por Nor-Aziah e Scapens (2007) e por Siti-Nabiha e Scapens (2005); que argumentaram que o decoupling encontrado em seus estudos (Nor-Aziah e Scapens chamaram de loose coupling) não foi uma resposta e sim um processo. Comparando essa forma de interpretar o achado com a proposta da presente pesquisa percebe-se que o decoupling (ou loose coupling) bem como o coupling são respostas extraídas de um processo, e que esses comportamentos não são o processo em si, mas sim seu resultado. Por isso, não se trata de um processo de conexão ou não conexão da instituição com as rotinas, mas sim de um processo de interpretação e construção do significado da instituição que gera esses comportamentos como respostas.

O caso da Alfa (analisado com base na agência estratégica) ainda evidenciou outra conclusão que pode complementar as discussões de alguns dos trabalhos referenciados quando da 
análise da interação entre fatores institucionais e econômicos no caso de resposta do tipo coupling. Nesse sentido, os resultados na Alfa sugerem que a rotina (e não a estrutura) parece ser alvo de mudança quando a interpretação da instituição levar ao entendimento e à significação com base em sua validade técnica e não em sua validade simbólica. No entanto, essa forma de entendimento vem acompanhada das condições que permitem sua utilização com interferência nas rotinas sem causar conflitos e ambiguidades que possam reduzir a eficiência (conforme apontado por MEYER e ROWAN, 1977).

Nos trabalhos de Järvinen (2006), James (2009) e Tsamenyi et al. (2006) foi usado o argumento de que as forças institucionais e econômicas podem interagir e até serem complementares, de forma que a organização utiliza instituições de forma coupling para obter tanto eficiência quanto legitimidade. Essas evidências também foram encontradas na Alfa. No entanto, em nenhum desses trabalhos foi discutido o que poderia ser uma explicação para a escolha desse tipo de resposta, ou seja, a busca de conformação às duas demandas. $\mathrm{Na}$ presente pesquisa, a explicação e a conclusão recaem sobre a interpretação de forma predominante com base na crença acerca dos aspectos técnicos da prática (busca de eficiência) além da crença em seu aspecto simbólico (busca de legitimidade).

Outro ponto interessante que emergiu foi a coerção, que embora tenha uma carga de conotação negativa, não foi entendida pelos atores como algo negativo ou como uma dominação sobre a organização. Ao contrário, as evidências apontaram que, para a Alfa, a matriz é um modelo e que se assemelhar a esse modelo é visto como algo bom. Por isso, outra conclusão que se apresenta é que a coerção não necessariamente implica em resistência a algo.

Essa questão enfatiza um ponto discutido de forma recorrente nesta pesquisa, a recursividade; podendo ser verificado que a exigência da matriz para a subsidiária seguir os procedimentos e regras tanto limitou as escolhas por formas alternativas de controle quanto capacitou ou habilitou a ação naquela direção. Vista por esse ângulo, a interpretação da instituição atua na construção e na reconstrução (entre o ambiente institucional e o organizacional) de seu significado. A implicação disso é que a forma como uma organização entende e significa seu ambiente (aqui foi tratado principalmente o ambiente relativo à matriz, mas o mesmo raciocínio pode ser usado para o ambiente mais amplo de atuação) também pode influenciar a interpretação sobre a instituição e, por consequência, a resposta estratégica. 
Em relação aos achados com base na NSI, destaca-se a originalidade do uso da abordagem recursiva nos estudos sobre os SCG, e mais especificamente da Contabilidade Gerencial e do Custeio Alvo. Embora os estudos analisados na fundamentação teórica explorassem diversas vertentes e abordagens da Teoria Institucional, não foi encontrado nas buscas para esta pesquisa qualquer trabalho, no Brasil ou no exterior, que utilizasse essa forma de análise nessa área. Essa abordagem trouxe para as análises a importância de considerar a agência estratégica e de não considerar os aspectos institucionais de forma dicotômica, o que abriu espaço para novos insights em relação à literatura existente e como forma de auxiliar as organizações nos processos de institucionalização de práticas do SCG.

\subsection{Recomendações para Futuras Pesquisas e para as Organizações}

Durante o desenvolvimento dessa pesquisa várias reflexões surgiram e não puderam ser contempladas devido a algumas limitações como escopo, tempo etc. Por isso, as mesmas foram evidenciadas na sequência como temas que podem ser investigados em trabalhos futuros, ou ainda, como problemas que devem ser repensados quando da sua aplicação empírica.

Dada a dificuldade em mapear os fatores contingentes em uma organização com base no que a literatura oferece, conforme apontado anteriormente, é interessante que os pesquisadores que utilizam a Teoria da Contingência repensem as formas de medidas dos fatores e das características avaliadas (como no caso das informações), de modo que as proposições não sejam tão genéricas e tenham mais aplicação na prática das organizações.

Uma das limitações desta pesquisa foi o fato de não ter investigado o significado da eficiência para a organização com base na NSI. A própria definição de eficiência é um fenômeno institucional, podendo ter significados diferentes para os atores e, por isso, também pode ter influência na interpretação da instituição e na resposta estratégica. A recomendação é a investigação desse significado para o processo de institucionalização envolvendo a resposta estratégica.

Foi verificada na pesquisa a importância de conhecer o significado que os atores atribuem ao ambiente em que a organização atua. Por isso, outra recomendação é que os estudos sobre a adoção e utilização de práticas de controle gerencial com base na NSI considerem o 
entendimento dos atores a respeito do ambiente de atuação das organizações, considerando inclusive os mecanismos de difusão que motivaram a institucionalização (coercitivo, mimético ou normativo).

A consideração dos fatores econômicos e institucionais nas análises gerou uma curiosidade que não estava no escopo dessa pesquisa. Será que quando a busca pela eficiência e pela legitimidade atuam na mesma direção a tendência ou a probabilidade é de que a internalização da instituição seja do tipo coupling? Isso parece ser reforçado pelo fato de que o discurso, nesse caso, vai estar amparado nas ações, de modo que um reflete e, ao mesmo tempo, dá condições ao outro. Por isso, é uma questão interessante a ser investigada.

Foi identificado que o setor de contabilidade na Alfa é responsável pelas informações de custos que já ocorreram (os custos reais) e que as informações para o Custeio Alvo e para o custo padrão é feito pelo setor de controle de custos (em geral por pessoas com formação em engenharia). Uma questão que surge desse panorama é: qual o papel da Contabilidade e dos contadores na modelagem do SCG nas organizações? Conforme visto no trabalho, o alinhamento entre as estratégias, a estrutura (e as características organizacionais) e as ações é fundamental para a obtenção dos resultados desejados. Nesse sentido, qual o envolvimento da Contabilidade e dos contadores nesse processo?

A empresa Alfa é de origem asiática e seu presidente e o diretor financeiro são também oriundos do mesmo país da matriz e nomeados por ela. Mesmo a empresa tendo origem e influência de uma cultura tão diferente da brasileira, o Custeio Alvo foi implantado e vem sendo usado com características muito parecidas com as descritas na literatura, em especial aquelas oriundas de estudos da utilização dessa prática em empresas japonesas, como Ansari et al. (1997) e Cooper e Slagmulder (1997). Esse fato levanta a questão da influência da cultura nacional no modelo de SCG. Que fatores facilitam ou dificultam a implementação desse tipo de prática ou de outras em relação à cultura? O fato de a prática ter sido implementada na Alfa mesmo havendo diferenças culturais em relação à matriz pode ser indício de que esse tipo de cultura (nacional) exerce pouca ou nenhuma influência na adoção de práticas?

Enfim, esses pontos levantados são assuntos interessantes que emergiram no decorrer da pesquisa e que podem indicar caminhos àqueles que pesquisam práticas de controles gerenciais. 
Em relação às recomendações para as organizações ressalta-se a importância de verificar o alinhamento da prática a ser adotada com os fatores contingentes presentes bem como analisar os fatores institucionais e econômicos envolvidos de modo a tentar reduzir os conflitos e ambiguidades que podem prejudicar a utilização da prática para o fim a que se destina. 


\section{REFERÊNCIAS}

ABBAGNANO, Nicola. Dicionário de filosofia. 5 ed. São Paulo: Martins Fontes, 2007.

ABDEL-KADER, Magdy; LUTHER, Robert. The impact of firm characteristics on management accounting practices: a UK-based empirical analysis. The British Accounting Review, vol. 40, p. 2-27, 2008.

ABRAHAMSON, Eric. Managerial fads and fashions: the diffusion and rejection of innovations. Academy of Management Review, vol. 16, n. 3, p. 586-612, 1991.

ABRAHAMSON, Gun. GERDIN, Jonas. Exploiting institutional contradictions: the role of management accounting in continuous improvement implementation. Qualitative Research in Accounting \& Management, vol. 3, n. 2, p. 126-144, 2006.

ABERNETHY, Margaret A.; et al. Product diversity and costing system design choice: field study evidence. Management Accounting Research, vol. 12, p. 261-279, 2001.

ABERNETHY, Margaret A.; LILLIS, Anne, M. The impact of manufacturing flexibility on management control system design. Accounting, Organizations and Society, vol. 20, n. 4, p. 241-258, 1995.

AGUIAR, Andson B.; FREZATTI, Fábio. Escolha da estrutura apropriada de sistema um de controle gerencial: uma proposta de análise. Revista de Educação e Pesquisa em Contabilidade, vol. 1, n. 3, p. 21-44, 2007.

ALVESSON, Mats; KARREMAN, Dan. Varieties of discourse: on the studies of organization through discourse analysis. Human Relations, vol. 53, n. 9, p. 1125-1149, 2000.

ANDERSON, Shannon W. YOUNG, Mark S. The impact of contextual and process factors on the evaluation of activity-based costing systems. Accounting, Organizations and Society, vol. 24, p. 525-559, 1999.

ANSARI, Shahid; et al. Target costing: the next frontier in strategic cost management. La Vergne: LLC, 1997.

ANSARI, Shahid; et al. A template for implementing target costing. Cost Management, Sep/Oct, Vol. 20 (5), p. 20-27, 2006.

ANSARI, Shahid; et al. Target costing: uncharted research territory. In: CHAPMAN, Christopher S. et al. (Org.). Handbook of Management Accounting. Vol. 2. Elsevier: Netherlands, 2007.

ANTHONY, Robert N.; GOVINDARAJAN, Vijay. Sistemas de controle gerencial. São Paulo: McGraw-Hill, 2008.

ASTLEY, W. Graham; VAN de VEN, Andrew H. Debates e perspectivas centrais na teoria das organizações. Revista de Administração de Empresas, vol. 45, n. 2, p. 52-73, 2005. 
ATKINSON, Anthony A.; et al. New directions in management accounting research. Journal of Management Accounting Research, vol. 9, p. 79-108, 1997.

AX, Christian et al. The impact of competition and uncertainty on the adoption of target costing. International Journal of Production Economics, vol. 115, p. 92-103, 2008.

BACIC, Miguel Juan. Gestão de custos: uma abordagem sob o enfoque de processo competitivo e da estratégia empresarial. Curitiba: Juruá Editora, 2008.

BAKER, William M. The missing element in cost management: competitive target costing. Industrial Management, vol. 37, n. 2, p. 29-32, 1995.

BAINES, Annette; LANGFIELD-SMITH, Kim. Antecedents to management accounting change: a structural equation approach. Accounting, Organizations and Society, vol. 28, n. 7-8, p. 675-698, 2003.

BALDRIDGE, Victor J.; BURNHAM, Robert A. Organizational innovation: individual, organizational, and environmental impacts. Administrative Science Quarterly, vol. 20, p. 165-176, 1975.

BAKER, Richard C.; BETTNER, Mark S. Interpretive and critical research in accounting: a commentary on its absence from mainstream accounting research. Critical Perspectives on Accounting, vol. 8, p. 293-310, 1997.

BARDIN, Laurence. Análise de conteúdo. São Paulo: Persona, 1977.

BAXTER, Jane; CHUA, Way F. Alternative management accounting research: whence and whither. Accounting, Organizations and Society, vol. 28, p. 97-126, 2003.

BEARD, Donald W; DESS, Gregory G. Corporate-level strategy, Business-level strategy, and firm performance. Academy of Management Journal, vol. 24, n. 4, p. 663-688, 1981.

BECKERT, Jens. Agency, entrepreneurs, and institutional change. The role of strategic choice and institutionalized practices in organizations. Organizations Studies, vol. 20, p. 777-799, 1999.

BERGER, Peter L.; LUCKMANN, Thomas. The social construction of reality: a treatise in the sociology of knowledge. New York: Doubleday, 1967.

BERRY, Anthony J.; et al. Emerging themes in management control: a review of a recent literature. The British Accounting Review, vol. 41, p. 2-20, 2009.

BERTUCCI, Carlos Eduardo. Custeio alvo na indústria brasileira de autopeças. São Paulo, 2008. Dissertação (Mestrado em Controladoria e Contabilidade) - Faculdade de Economia, Administração e Contabilidade da Universidade de São Paulo.

BHIMANI, Alnoor; OKANO, Hiroshi. Target excellence: target cost management at Toyota in the UK. Management Accounting, vol. 73, n. 6, p. 42-44, 1995.

BIAZEBETE, Célia M.; et al. Análise da aplicação do custeio alvo e do custeio pleno em indústria de confecções: um estudo de caso. Revista de Contabilidade e Organizações, vol. 3, n. 5, p. 44-61, 2009. 
BISBE, Josep et al. Defining management accounting constructs: a methodological note on the risks of conceptual misspecification. Accounting, Organizations and Society, vol. 32, n. 7-8, p. 789-820, 2007.

BISBE, Josep; OTLEY, David. The effects of the interactive use of management control system on product innovation. Accounting, Organizations and Society, vol. 29, p. 709-737, 2004.

BLAU, Peter, M. A formal theory of differentiation in organizations. American Sociological Review, vol. 35, n. 2, p. 201-218, 1970.

BNDES. Banco Nacional do desenvolvimento. Disponível em: http://www.bndes.gov.br/SiteBNDES/bndes/bndes_pt/Navegacao_Suplementar/Perfil/Grande Empresa/porte.html. Acesso em: 30/01/2012.

BOMFIM, Gabriel M. Gerenciamento de resultados em cursos de pós graduação latu senso através da metodologia do custeio alvo. São Paulo, 2006. Dissertação (Mestrado em Controladoria e Contabilidade) - Faculdade de Economia, Administração e Contabilidade da Universidade de São Paulo.

BOXENBAUM, Eva; JONSSON, Stefan. Isomorphism, diffusion and decoupling. In: GREENWOOD, Royston et al. (Orgs.). The Sage handbook of organizational institutionalism. Wiltshire: Sage Publications, 2008.

BRAUSCH, John M. Beyond ABC: Target costing for profit enhancement. Management Accounting, vol. 76, n. 5, p. 45-49, 1994.

BRITO, Rigel S.; et al. Custeio alvo: utilização do sistema de gerenciamento de lucro pelos fabricantes de veículos automotores com indústria no Brasil. Revista de Contabilidade e Organizações, vol. 2, n. 2, p. 71-86, 2008.

BRYNJOLFSSON, Erik; HITT, Lorin M. Beyond computation: information technology, organizational transformation and business performance. Journal of Economic Perspectives, vol. 4, n. 4, p. 23-48, 2000.

BUCHKO, Aaron A. Conceptualization and measurement of environmental uncertainty: an assessment of the Miles and Snow perceived environmental uncertainty scale. Academy of Management Journal, vol. 37, n. 2, p. 410-425, 1994.

BURNS, John; SCAPENS, Robert W. Conceptualizing management accounting change: an institutional framework. Management Accounting Research, vol. 11, p.3-25, 2000.

BURNS, John; VAIVIO, Juhani. Management accounting change. Management Accounting Research, vol. 12, n. 4, p.389-402, 2001.

BURNS, Tom; STALKER, G. M. The management of innovation. London: Tavistock, 1961.

BURRELL, Gibson; MORGAN, Gareth. Sociological paradigms and organizational analysis: elements of the sociology of corporate life . Londres: Heinemann, 1979. 
BUSCO, Cristiano; et al. Globalizations and the international convergence of management accounting. In: HOPPER, Trevor; et al. (Org.). Issues in management accounting. Harlow: England Prentice Hall, 2007.

CADEZ, Simon; GUILDING, Chris. An exploratory investigation of an integrated contingency model of strategic management accounting. Accounting, Organizations and Society, vol. 33, n. 7-8, p. 836-863, 2008.

CALDAS, Miguel P.; FACHIN, Roberto. Paradigma funcionalista: desenvolvimento de teorias e institucionalismo nos anos 1980 e 1990. Revista de Administração de Empresas, vol. 45, n. $2,2005$.

CALDAS, Miguel P.; VERGARA, Sylvia Constant. Paradigma interpretacionista: a busca da superação do objetivismo funcionalista nos anos 1980 e 1990. Revista de Administração de Empresas, vol. 45, n. 4, 2005.

CAMACHO, Reinaldo R. Custeio alvo em serviços hospitalares: Um estudo sob o enfoque da gestão estratégica de custos. São Paulo, 2004. Dissertação (Mestrado em Controladoria e Contabilidade) - Faculdade de Economia, Administração e Contabilidade da Universidade de São Paulo.

CAMACHO, Reinaldo R.; ROCHA, Welington. Custeio-alvo em serviços hospitalares: um estudo de caso sob o enfoque da gestão estratégica de custos. Revista de Contabilidade \& Finanças USP, vol. 19, n. 47, p. 19-30, mai/ago, 2008.

CARDOSO, Rodrigo S.; BEUREN, Ilse M. O custo meta no desenvolvimento de novos produtos: um caso em indústria de conserva de pescado. Revista Brasileira de Gestão de Negócios, vol. 8, n. 22, p. 13-22, 2006.

CARRUTHERS, Bruce G. Accounting, ambiguity, and the new institutionalism. Accounting, Organizations and Society, vol. 20, n. 4, p. 313-328, 1995.

CHANDLER, Alfred Du Pont Jr. Strategy and structure: chapters in the history of the industrial enterprise. Cambridge: MIT Press, 1962.

CHAPMAN, Christopher S. Reflections on a contingent view of accounting. Accounting, Organizations and Society, vol. 22, n.2, p.189-205, 1997.

CHENHALL, Robert. Management control systems design within its organizational context: findings from contingency-based research and directions for the future. Accounting, Organizations and Society, vol. 28, n. 2-3, p. 127-168, 2003.

CHENHALL, Robert. Theorizing contingencies in management control systems research. In: CHAPMAN, Christopher S. et al. (Org.). Handbook of Management Accounting. Vol. 2. Elsevier, 2007.

CHENHALL, Robert. Accounting for the horizontal organization: a review essay. Accounting, Organizations and Society, vol. 33, n. 4-5, p.517-550, 2008.

CHENHALL, Robert; LANGFIELD-SMITH, Kim. The relationship between strategic priorities, management techniques and management accounting: an empirical investigation 
using a systems approach. Accounting, Organizations and Society, vol. 23, n. 3, p.243-264, 1998a.

CHENHALL, Robert; LANGFIELD-SMITH, Kim. Adoption and benefits of management accounting practices: an Australian study. Management Accounting Research, vol. 9, n. 1, p.1-19, $1998 b$.

CHENHALL, Robert; MORRIS, Deigan. The impact of structure, environment, and interdependence on the perceived usefulness of management accounting systems. The Accounting Review, vol. LXL, n. 1, p. 16-35, 1986.

CHENHALL, Robert. CHAPMAN, Christopher S. Theorizing and testing fit in contingency research on management control systems. In: HOQUE Zahirul (Org.). Methodological Issues in Accounting Research. Spiramus: London, 2006.

CHIAVENATO, Idalberto. Introdução à teoria geral da administração. 6 ed. Rio de Janeiro, Campus, 2000.

CHILD, John. Predicting and understanding organization structure. Administrative Science Quarterly, vol. 18, n. 2, p. 168-185, 1973.

CHONG, Vincent, K.; CHONG, Kar Ming. Strategic choices, environmental uncertainty and SBU performance: a note on the intervening role of management accounting systems. Accounting and Business Research, vol. 27, n. 4, p. 268-276, 1997.

CINQUINI, Lino; TENUCCI, Andrea. Strategic management accounting techniques: exploring distinctive features and adoption influencing variables. 5th Conference on New Directions in Management Accounting: Innovations in Practice and Research. Brussels, Belgium, December 14-16, 2006.

CINQUINI, Lino; TENUCCI, Andrea. Strategic management accounting and business strategy: a loose coupling? Journal of Accounting \& Organizational Change, vol. 6, n. 2, p.228-259, 2010.

CINTRA, Yara C. A integração da sustentabilidade às práticas de controle gerencial das empresas no Brasil. São Paulo, 2011. Tese (Doutorado em Controladoria e Contabilidade) Faculdade de Economia, Administração e Contabilidade da Universidade de São Paulo.

CLEGG, Stewart R.; HARDY, Cynthia. Introdução: organização e estudos organizacionais. In: CLEGG, Stewart R. et al. (Org.). Handbook de Estudos Organizacionais: modelos de análise e novas questões em estudos organizacionais. Vol.1, São Paulo: Atlas, 2007.

COLAUTO, Romualdo D.; et al. O custeio variável e o custeio-alvo como suportes às decisões de investimentos no desenvolvimento de novos produtos. BASE - Revista de Administração e Contanilidade da Unissinos, vol. 1, n. 2, p. 33-42, 2004.

COOPER, Robin. Costing techniques to support corporate strategy: evidence from Japan. Management Accounting Research, vol. 7, p. 219-246, 1996.

COOPER, David J; MORGAN, Wayne. Case study research in accounting. Accounting Horizons, vol. 22, n. 2, p. 159-178, 2008. 
COOPER, Robin; SLAGMULDER, Regine. Target costing and value engineering. Portland: Productivity Press, 1997.

COOPER, Robin; SLAGMULDER, Regine. Develop Profitable New Products with Target Costing. Sloan Management Review, vol. 40, n. 4, p. 23-33, 1999.

COOPER, Robin; SLAGMULDER, Regine. Achieving full-cycle cost management. Sloan Management Review, Fall, vol. 46, n. 1, p. 45-52, 2004.

COOPER, Donald R.; SCHINDLER, Pamela S. Métodos de pesquisa em administração. 7. ed. Porto Alegre: Bookman, 2003.

CROTTY, Michael. The foundations of social research: meaning and perspective in the research process. Allen Unwin: Crows Nest, 1998.

COVALESKI, Mark A. et al. Managerial accounting research: the contributions of organizational and sociological theories. Journal of Management Accounting Research, vol. 8, p. 1-35, 1996.

CRESWELL, John W. Qualitative inquiry \& research design: choosing among five approaches. 2 ed. Thousand Oaks: Sage Publications, 2007.

CRUBELLATE, João M. Parâmetros de qualidade de ensino superior: análise institucional em IES privadas do estado de São Paulo. São Paulo, 2004. Tese (Doutorado em Administração de Empresas) - Escola de Administração de Empresas de São Paulo da Fundação Getúlio Vargas.

CRUBELLATE, João M. Três contribuições conceituais neofuncionalistas à teoria institucional em organizações. Revista de Administração Contemporânea, edição especial, p. 199-222, 2007.

CRUBELLATE, João M. et al. A questão institucional e suas implicações para o pensamento estratégico. Revista de Administração Contemporânea, edição especial, p. 37-60, 2004.

CRUBELLATE, João M. et al. Resposta estratégicas de programas e professores paranaenses de mestrado/doutorado em administração à avaliação da capes: configurando proposições institucionais a partir de redes de cooperação acadêmica. Revista de Negócios, vol. 13, n. 2, p. 77-92, 2008.

CRUZ, Cássia V. O. A.; ROCHA, Welington. Custeio-alvo: reflexões sobre definições, finalidades e procedimentos. Revista Contemporânea de Contabilidade, vol. 1, n. 10, p. 31$51,2008$.

DAMBRIN Claire et al. Control and change: Analyzing the process of institutionalization. Management Accounting Research, vol. 18, n. 2, p. 172-208, 2007.

DEEPHOUSE, David L; SUCHMAN, Mark. Legitimacy in organizational institutionalism. In: GREENWOOD, Royston et al. (Orgs.). The Sage handbook of organizational institutionalism. Wiltshire: Sage Publications, 2008.

DEKKER, Henry; SMIDT, Peter. A survey of the adoption and use of target costing in Dutch firms. International Journal of Production Economics, vol. 84, n. 3, p. 293-305, 2003. 
DELONE, W. H.; MCLEAN, E. R. Information systems success: the quest for dependent variable. Information Systems Research, vol. 3, n. 1, p. 60-95, 1992.

DENT, Jeremy F. Strategy, organization and control: some possibilities for accounting research. Accounting, Organizations and Society, vol. 15, n. 1-2, p. 3-25, 1990.

DENT, Jeremy F. Global competition: challenges for management accounting and control. Management Accounting Research, vol. 7, p. 247-269, 1996.

DILLARD, Jesse F. et al. The making and remaking of organization context: duality and the institutionalization process. Accounting, Auditing \& Accountability Journal, vol. 17, n. 4, p. 506-542, 2004.

DIMAGGIO, Paul J.; POWELL, Walter W. The iron cage revisited: institutional isomorphism and collective rationality in organizational fields. American Sociological Review, vol. 48, n. 2, p. 147-160, 1983.

DONALDSON, Lex. The contingency theory of organizations. Thousand Oaks: Sage, 2001.

DONALDSON, Lex. Teoria da contingência estrutural. In: CLEGG, Stewart. R. et al. (Org.). Handbook de Estudos Organizacionais: modelos de análise e novas questões em estudos organizacionais. Vol.1, São Paulo: Atlas, 2007.

DUNCAN, Robert B. Characteristics of organizational environments and perceived environmental uncertainty. Administrative Science Quarterly, vol. 17, p. 313-327, 1972.

EISENHARDT, Kathleen M. Building theories from case study research. The Academy of Management Review, vol. 14, n. 4, p. 532-550, 1989.

ELLRAM, Lisa M. Supply management's involvement in the target costing process. European Journal of Purchasing e Supply Management, Winter, Vol. 8, p 235-244, 2002.

ELLRAM, Lisa M. The implementation of target costing in the United States: theory versus practice. The Journal of Supply Management, Winter, p 13-26, 2006.

ESPEJO, Márcia, M. S. B. Perfil dos atributos do sistema orçamentário sob a perspectiva contingencial: uma abordagem multivariada. São Paulo, 2008. Tese (Doutorado em Controladoria e Contabilidade) - Faculdade de Economia, Administração e Contabilidade da Universidade de São Paulo.

EVERAERT, Patricia et al. Characteristics of target costing: theoretical and field study perspectives. Qualitative Research in Accounting and Management, vol. 3, n. 3, p. 236263, 2006.

EWERT, Ralf; ERNST, Christian. Target costing, co-ordination and strategic cost management. European Accounting Review, vol. 8, n. 1, p. 23 - 49, 1999.

FARIA, Ana C.; et al. O empreendedor e a aplicação do sistema de custeio-alvo em pequena empresa do segmento de plástico: uma pesquisa-ação. Revista de Negócios, vol. 14, n. 1, p. 63-81, 2009. 
FEIL, Patrick et al. Japanese target costing: a historical perspective. International Journal of Strategic Cost Management, Spring, 2004.

FERREIRA, Aldonio; OTLEY, David. The design and use of management control systems: an extended framework for analysis. Working paper, SSRN, 2005.

FERREIRA, Aldonio; OTLEY, David. Exploring inter and intra-relationships between design and use of management control systems. Working paper, SSRN, 2006.

FERREIRA, Aldonio; OTLEY, David. Design and use of management control systems: an analysis of the interaction between design misfit and intensity of use. Working paper, $28^{\text {th }}$ annual congress of EAA, 2009.

FILOMENA, Tiago P.; et al. Target costing operationalization during product development: model and application. International Journal of Production Economics, vol. 118, p. 398409, 2009.

FISHER, Joseph. Contingency-based research on management control systems: categorization by level of complexity. Journal of Accounting Literature, vol. 14, p. 24-48, 1995.

FONSECA, Valéria S.; MACHADO-DA-SILVA, Clóvis L. Conversação entre abordagens da estratégia em organizações: escolha estratégica, cognição e instituição. Revista Organizações \& Sociedade, vol. 9, n. 25, p. 93-110, 2002.

FREEMAN, Tom. Transforming cost management into a strategic weapon. CAM-I, Originally presented on April 23, 1998 at the Hong Kong Industrial Technology Center Corporation in Conjunction with Hong Kong Polytechnic University, p.1-21, 1998.

FREZATTI, Fábio; et al. Controle gerencial: uma abordagem da contabilidade gerencial no contexto econômico, comportamental e sociológico. São Paulo: Atlas, 2009.

GERDIN, Jonas. Management accounting system design in manufacturing departments: an empirical investigation using a multiple contingencies approach. Accounting, Organizations and Society, vol. 30, n. 2, p. 99-126, 2005.

GERDIN, Jonas; GREVE, Jan. Form of contingency fit in management accounting research a critical review. Accounting, Organizations and Society, vol. 29, n. 3-4, p. 303-326, 2004.

GIDDENS, Anthony. The constitution of society. Berkeley: University of California Press, 1984.

GODOY, A. S. Estudo de caso qualitativo. In: MELLO, Rodrigo B. et al. (Orgs.). Pesquisa qualitativa em estudos organizacionais: paradigmas, estratégias e métodos. São Paulo: Saraiva, 2006.

GORDON, Lawrence A.; NARAYANAN, V. K. Management accounting systems, perceived environmental uncertainty and organization structure: an empirical investigation. Accounting, Organizations and Society, vol. 9, n. 1, p. 33-47, 1984.

GRANLUND, Markus. Towards explaining stability in and around management accounting systems. Management Accounting Research, vol. 12, p. 141-166, 2001. 
GREENWOOD, Royston et al. Introduction. In: GREENWOOD, Royston et al. (Orgs.). The Sage handbook of organizational institutionalism. Wiltshire: Sage Publications, 2008.

GUERRA, Almir, R. Arranjos entre fatores situacionais e sistemas de contabilidade gerencial sob a ótica da teoria da contingência. São Paulo, 2007. Dissertação (Mestrado em Controladoria e Contabilidade) - Faculdade de Economia, Administração e Contabilidade da Universidade de São Paulo.

GUILDING, Chris. Competitor-focused accounting: an exploratory note. Accounting, Organizations and Society, vol. 24, n. 7, p. 583-595, 1999.

GUILDING, Chris; et al. An international comparison of strategic management accounting practices. Management Accounting Research, vol. 11, n. 1, p. 113- 135, 2000.

GUL, Ferdinand A.; CHIA, Yew M. The effects of management accounting systems, perceived environmental uncertainty and decentralization on managerial performance: a test of three-way interaction, Accounting Organizations and Society, vol. 19, n. 4-5, p. 413-426, 1994.

GUPTA, Anil, K.; GOVINDARAJAN, Vijay. Business unit strategy, managerial characteristics, and business unit effectiveness at strategy implementation. Academy of Management Journal, vol. 27, n. 1, p. 25-41, 1984.

HALDMA, Toomas; LÄ̈̈TS, Kertu. Contingencies influencing the management accounting practices of Estonian manufacturing companies. Management Accounting Research, vol. 13, n. 4, p.379-400, 2002.

HALL, Richard H. Organizações: estrutura e processos. 3 ed. Rio de Janeiro: Prentice Hall do Brasil, 1984.

HANSEN, Allan; MOURITSEN, Jan. Management accounting and operations management: understanding the challenges from integrated manufacturing. In: CHAPMAN, Christopher S. et al. (Org.). Handbook of Management Accounting. Vol. 2. Elsevier: Netherlands, 2007.

HANSEN, J. E. Aplicação de custeio alvo em cursos de pós graduação latu sensu: um estudo sob o enfoque da gestão estratégica de custos. São Paulo, 2002. Dissertação (Mestrado em Controladoria e Contabilidade) - Faculdade de Economia, Administração e Contabilidade da Universidade de São Paulo.

HANSEN, Stephen. C. Cost analysis, cost reduction and competition. Journal of Management Accounting Research, vol.10, p. 181-203, 1998.

HANSEN, Stephen C.; VAN DER STEDE, Win, A. Multiple facets of budgeting: an exploratory analysis. Management Accounting Research, vol. 15, p. 415-439, 2004.

HASSELBLADH, Hans; KALLINIKOS, Jannis. The project of rationalization: a critique and reappraisal of neo-institutionalism in organization studies. Organization Studies, vol. 21, n. 4, p. 697-720, 2000.

HERATH, Siriyama, K. A framework for management control research. Journal of Management Development, vol. 26, n. 9, p. 895-915, 2007. 
HIBBETS, Aleecia R. et al. The competitive environment and strategy of target costing implementers: evidence from the field. Journal of Managerial Issues, vol. 15, n. 1, p. 65-81, 2003.

HOFER, Charles, W. Toward a contingency theory of business strategy. Academy of Management Journal, vol. 18, n. 4, p. 784-810, 1975.

HOFER, Charles, W.; SCHENDEL, D. E. Strategy formulation: analytical concepts. St Paul: Minnesota, 1978.

HUSSAIN, Md Mostaque; HOQUE, Zahirul. Understanding non-financial performance measurement practices in Japanese banks: a new institutional sociology perspective. Accounting, Auditing \& Accountability Journal, vol. 15, n. 2, p. 162-183, 2002.

HYVÖNEN, Johanna. Strategy, performance measurement techniques and information technology of the firm and their links to organizational performance. Management Accounting Research, vol. 18, n. 4, p.343-366, 2007.

ITTNER, Christopher D.; LARCKER, David F. Assessing empirical research in managerial accounting: a value-based management perspective. Journal of Accounting and Economics, vol. 32, p. 349-410, 2001.

JAMES, Wendy. Rationality, institutionalism and accounting change: understanding a performance management system within an Australian public sector entity. Journal of Accounting \& Organizational Change, vol. 5, n. 3, p. 362-389, 2009.

JÄRVINEN, Janne. Institutional pressures for adopting new cost accounting systems in Finnish hospitals: two longitudinal case studies. Financial Accountability and Management, vol. 22, n. 1, p. 21-46, 2006.

JEPPERSON, Ronald L. Institutions, institutional effects, and institutionalization. In: POWELL, Walter W.; DIMAGGIO, Paul J. (Orgs.). The new institutionalism in organizational analysis. Chicago: The University of Chicago Press, 1991.

JOHNSON, H.; KAPLAN, Robert S. Relevance Lost: the rise and fall of management accounting. Boston: Harvard Business School Press, 1987.

JOHNSON, Phil; et al. Evaluating qualitative management research: towards a contingent criteriology. International Journal of Management Reviews, vol. 8, n. 3, 2006.

JUNQUEIRA, Emanuel, R. Perfil do sistema de controle gerencial sob a perspectiva da teoria da contingência. São Paulo, 2010. Tese (Doutorado em Controladoria e Contabilidade) Faculdade de Economia, Administração e Contabilidade da Universidade de São Paulo.

KALD, Magnus, et al. On strategy and management control: the importance of classifying the strategy of the business. British Journal of Management, vol. 11, p. 197-212, 2000.

KAPLAN, Robert S. The evolution of management accounting. The Accounting Review, vol. LIX, n. 3, 1984.

KATO, Yutaka. Target costing support systems: lessons from leading Japanese companies. Management Accounting Research, vol. 4, p. 33-47, p. 131-156, 1993. 
KEATING, Patrick, J. A framework for classifying and evaluating the theoretical contributions of case research in management accounting. Journal of Management Accounting Research, vol. 7, Fall, 1995.

KHANDWALLA, Pradip N. The effect of different types of competition on the use of management controls. Journal of Accounting Research, Autum, p. 275-285, 1972.

KHOLEIF, Ahmed O. R. et al. ERP customization failure: institutionalized accounting practices, power relations and market forces. Journal of Accounting \& Organizational Change, vol. 3, n. 3, p. 250-269, 2007.

KIM, Il-Woon; et al. Target costing: lessons from Japan. International Journal of Strategic Cost Management, vol. 2, n. 2, autumn, 1999.

KOSTOVA, Tatiana; ROTH, Kendall. Adoption of an organizational practice by subsidiaries of multinational corporations: institutional and relational effects. Academy of Management Journal, vol. 45, n. 1, p. 215-233, 2002.

KOSTOVA Tatiana; ZAHEER, Srilata. Organizational legitimacy under conditions of complexity: the case of the multinational enterprise. Academy of Management Review, vol. 24, n. 1, p. 64-81, 1999.

KRUMWIEDE, Kip, R. The implementation stages of activity-based costing and the impacto of contextual and organizational factors. Journal of Management Accounting Research, vol. 10, p. 239-277, 1998.

LANGFIELD-SMITH, Kim. Management control systems and strategy: a critical review. Accounting, Organizations and Society, vol. 22, n. 2, p. 207-232, 1997.

LANGFIELD-SMITH, Kim. A review of quantitative research in management control systems and strategy. In: CHAPMAN, Christopher S. et al. (Org.). Handbook of Management Accounting. Vol. 2. Elsevier: Netherlands, 2007.

LANGFIELD-SMITH, Kim. Strategic Management Accounting: how far have we come in 25 years. Accounting, Auditing \& Accountability Journal, vol. 21, n. 2, p. 204-228, 2008.

LAPSLEY, Irvine. Making sense of interactions in an investigation of organizational practice and processes. In: Humphrey, C. e Lee, B. The real life guide to accounting research: a behind-the-scenes view of using qualitative research methods. Oxford: Elsevier, 2004.

LAWRENCE Paul R.; LORSH, Jay. Organization and environment. Boston, Harvard Business School, 1967.

LIMA JUNIOR, Edson. Métodos de custeio e o custeio alvo: uma contribuição ao estudo de custos em organizações hospitalares. São Paulo, 2006. Dissertação (Mestrado em Controladoria e Contabilidade) - Faculdade de Economia, Administração e Contabilidade da Universidade de São Paulo.

LLEWELLYN, Sue. Working in hermeneutic circles in management accounting research: some implications and applications. Management Accounting Research, vol. 4, p. 231-249, 1993. 
LLEWELLYN, Sue. Case studies and differentiated realities. Qualitative Research in Accounting \& Management, vol. 4, n. 1, p. 53-68, 2007.

LUKKA, Kari. Management accounting change and stability: Loosely coupled rules and routines in action. Management Accounting Research, vol. 18, n. 1, p. 76-101, 2007.

LUKKA, Kari. The roles and effects of paradigms in accounting research. Management Accounting Research, vol. 21, n. 2, p. 110-115, 2010.

LUKKA, Kari; KASANEN, Eero. The problem of generalizability: anecdotes and evidences in accounting research. Accounting, Auditing \& Accountability Journal, vol. 8, n. 5, p. 7190, 1995.

MA, Yi; TAYLES, Mike. On the emergence of strategic management accounting: an institutional perspective. Accounting and Business Research, vol. 39, n. 5, p. 473-495, 2009.

MACHADO-DA-SILVA, Clóvis L. et al. Estrutura, agência e interpretação: elementos para uma abordagem recursiva do processo de institucionalização. Revista de Administração Contemporânea, edição especial, p. 9-39, 2005.

MACHADO, Débora G; SOUZA, Antônio M. Análise das relações entre a gestão de custos e a gestão do preço de venda: um estudo das práticas adotadas por empresas industriais conserveiras estabelecidas no RS. Revista Universo Contábil, vol. 2, n.1, p. 42-60, 2006.

MALMI Teemu. Reflections on paradigms in action in accounting research. Management Accounting Research, vol. 21, p. 121-123, 2010.

MALMI Teemu; BROWN David A. Management control systems as a package opportunities, challenges, and research directions. Management Accounting Research, vol. 19, p. 287-300, 2008.

MALMI Teemu; GRANLUND, Markus. In search of management accounting theory. European Accounting Review, vol. 18, n. 3, p. 597-620, 2009.

MARTINS, Gilberto A.; TEÓPHILO, Carlos R. Metodologia da investigação científica para ciências sociais aplicadas. São Paulo: Atlas, 2007.

MARTINS, Gilberto A. Estudo de caso: uma estratégia de pesquisa. São Paulo: Atlas, 2008.

MAXIMIANO, Antonio Cesar Amaru. Teoria geral da administração: da revolução urbana à revolução digital. São Paulo: Atlas, 2004.

MAXIMIANO, Antonio Cesar Amaru. Teoria geral da administração. São Paulo: Atlas, 2008 .

MERCHANT, Kenneth A. Influences on departmental budgeting: an empirical examination of a contingency model. Accounting, Organizations and Society, vol. 9, n. 3-4, p. 291-307, 1984. 
MERCHANT, Kenneth A.; OTLEY, David. A review of the literature on control and accountability. In: CHAPMAN, Christopher S. et al. (Org.). Handbook of Management Accounting. Vol. 2. Elsevier, 2007.

MERCHANT; Kenneth A.; VAN DER STEDE, Wim A. Management control systems: performance measurement, evaluation and incentives. 2 ed. Pearson Education: Harlow, 2007.

MERTON, Robert King. Social theory and social structure. 3 ed. New York: The Free Press, 1968.

MEYER, John W. Reflections on institutional Theories of organizations. In: GREENWOOD, Royston et al. (Orgs.). The Sage handbook of organizational institutionalism. Wiltshire: Sage Publications, 2008.

MEYER, John. W.; ROWAN, Brian. Institutionalized organizations: formal structure as myth and ceremony. The American Journal of Sociology, vol. 83, n. 2, p. 340-363, 1977.

MICHAELLIS. Moderno dicionário da língua portuguesa. Disponível em: michaelis.uol.com.br/moderno/portugues/index.php.

MILES Raymond E.; SNOW, Charles C. Organizational strategy, structure and process. Stanford: Stanford Business Classics, 2003.

MILGROM, Paul; ROBERTS, John. Complementarities and fit strategy, structure, and organizational change in manufacturing. Journal of Accounting and Economics, vol. 19, p. 179-208, 1995.

MILLIKEN, Frances J. Three types of perceived uncertainty about the environment: state, effect, and response uncertainty. Academy of Management Review, vol. 12, n. 1, p. 133$143,1987$.

MISES, Ludwig von. Ação humana: um tratado de economia. 2. ed. Rio de Janeiro: Instituto Liberal, 1995.

MODELL, Sven. Bridging the paradigm divide in management accounting research: the role of mixed methods approaches. Management Accounting Research, vol. 21, n. 2, p. 124-129, 2010.

MONDEN, Yasuhiro. Cost Reduction System: Target Costing and Kaizen Costing. Portland: Productivity Press, 1995.

MONDEN, Yasuhiro; HAMADA, Kazuki. Target costing and kaizen costing in japanese automobile companies. Journal of Management Accounting Research, Fall, p. 16-34, 1991.

MORGAN, Gareth. Accounting as reality construction: towards a new epistemology for accounting practice. Accounting, Organizations and Society, vol. 13, n. 5, p. 477-485, 1988.

NASCIMENTO, Artur, R. Controle gerencial como prática social e organizacional: análise crítica a partir dos paradigmas neofuncionalista, interpretativista e pós-estruturalista. São Paulo, 2011. Tese (Doutorado em Controladoria e Contabilidade) - Faculdade de Economia, Administração e Contabilidade da Universidade de São Paulo. 
NASCIMENTO, Artur, R. et al. Pesquisa acadêmica em contabilidade gerencial no Brasil: análise e reflexões sobre teorias, metodologias e paradigmas. Revista de Administração Contemporânea, vol. 14, n. 6, p. 1113-1133, 2010.

NEILSEN, Eric H.; RAO, M. V. H. The strategy-legitimacy nexus: a thick description. Academy of Management Review, vol. 12, n. 3, p. 523-533, 1987.

NOR-AZIAH, Abu Kasim; SCAPENS, Robert W. Corporisation and accounting change: the role of accounting and accountants in a Malaysian public utility. Management Accounting Research, vol. 18, n. 2, p. 209-247, 2007.

OLIVER, Christine. Strategic responses to institutional processes. Academy of Management Review, vol. 15, n. 1, p. 145-179, 1991.

ONO, Koki; ROBLES JUNIOR, Antônio. Utilização do target costing e de outras técnicas de custeio: um estudo exploratório em municípios de Santa Catarina. Revista de Contabilidade e Finanças, edição especial, p. 65-78, 2004.

OTLEY, David. Budgetary use and managerial performance. Journal of Accounting Research, vol. 16, n. 1, p. 122-149, 1978.

OTLEY, David. The contingency theory of management accounting: achievement and prognosis. Accounting, Organizations and Society, vol. 5, n. 4, p. 413-428, 1980.

OTLEY, David. Performance management: a framework for management control systems research. Management Accounting Research, vol. 10, n. 4, p. 363-382, 1999.

OTLEY, David. Extending the boundaries of management accounting research: developing systems for performance management. British Accounting Review, vol. 33, p. 243-261, 2001.

OTLEY, David. Did Kaplan and Johnson get it right? Accounting, Auditing \& Accountability Journal, vol. 21, n. 2, p. 229-239, 2008.

PALMER, Donald et al. Is the new institutionalism a theory? In: GREENWOOD, Royston et al. (Orgs.). The Sage handbook of organizational institutionalism. Wiltshire: Sage Publications, 2008.

PHILLIPS, Nelson et al. Discourse and institutions. Academy of Management Review, vol. 29, n. 4, p. 635-652, 2004.

PORTER, Michael. Vantagem competitiva: Criando e sustentando um desempenho superior. Rio de Janeiro: Campus, 1992.

POWELL, Walter W. Expanding the scope of institutional analysis. In: POWELL, Walter W.; DIMAGGIO, Paul J. (Orgs.). The new institutionalism in organizational analysis. Chicago: The University of Chicago Press, 1991.

PUGH, D. S. et al. A conceptual scheme for organizational analysis. Administrative Science Quarterly, vol. 8, n. 3, p. 289-315, 1963. 
PUGH, D. S. et al. The context of organization structures. Administrative Science Quarterly, vol. 14, n. 1, p. 91-114, 1969a.

QUATTRONE, Paolo; HOPER, Trevor. What does organizational change means: speculations on a taken for granted category. Management Accounting Research, vol. 12, n. 4, p. 403-435, 2001.

RAI, Arun; et al. Assessing the validity of IS success model: an empirical test and theoretical analysis. Information Systems Research, vol. 13, n. 1, p. 50-69, 2002.

RECKZIEGEL, Valmor.; et al. Práticas de gestão de custos adotadas por empresas estabelecidas nas regiões noroeste e oeste do estado do Paraná. Revista Brasileira de Gestão de Negócios, vol. 9, n. 23, p. 14-27, 2007.

RIBEIRO, João A.; SCAPENS, Robert W. Institutional theories in management accounting change: contributions, issues and paths for developments. Qualitative Research in Accounting \& Management, vol. 3, n. 2, p. 94-111, 2006.

RICHARDSON, Allan J. Accounting as a legitimating institution. Accounting, Organizations and Society, vol. 12, n.4, p. 341-355, 1987.

ROCHA, Wellington. Contribuição ao estudo de um modelo conceitual de sistema de informação de gestão estratégica. São Paulo, 1999. Tese (Doutorado em Controladoria e Contabilidade) - Faculdade de Economia, Administração e Contabilidade da Universidade de São Paulo.

RUEF, Martin.; SCOTT, Richard W. A multidimensional model of organizational legitimacy: hospital survival in changing institutional environments. Administrative Science Quarterly, vol. 43, n. 4, p. 877-904, 1998.

SAKURAI, Michiharu. Gerenciamento integrado de custos. São Paulo: Atlas, 1997.

SCAPENS, Robert W. Never mind the gap. Towards an institutional perspective on management accounting practice. Management Accounting Research, vol. 5, p. 301-321, 1994.

SCAPENS, Robert W. Doing case study research. In: Humphrey, C. e Lee, B. The real life guide to accounting research: a behind-the-scenes view of using qualitative research methods. Oxford: Elsevier, 2004.

SCAPENS, Robert W. Understanding management accounting practices: a personal journey. The British Accounting Review, vol. 38, p. 1-30, 2006.

SCAPENS, Robert W. Management accounting research: 20 years on. Management Accounting Research, vol. 21, n. 4, p. 278-284, 2010.

SCAPENS, Robert W.; ROBERTS, John. Accounting and control: a case study of resistance to accounting change. Management Accounting Research, vol. 4, n. 1, p. 1-32, 1993.

SCARPIN, J. E. Target costing e sua utilização como mecanismo de formação de preço para novos produtos. Londrina, 2000. Dissertação (Mestrado em Controladoria e Contabilidade) UNOPAR. 
SCOTT, W. Richard. Institutions and organizations. 2 ed. Thousand Oaks: Sage Publications, 2001.

SCOTT, W. Richard. Approaching Adulthood: the maturing of institutional theory. American Journal Sociology, vol. 37, p. 427-442, 2008.

SCOTT, W. Richard; MEYER, John W. The organization of societal sectors:propositions and early evidence. In: POWELL, Walter W.; DIMAGGIO, Paul J. (Orgs.). The new institutionalism in organizational analysis. Chicago: The University of Chicago Press, 1991.

SELTO, Frank H.; et al. Assessing the organizational fit of a just-in-time manufacturing system: testing selection, interaction and systems models of contingency theory. Accounting, Organizations and Society, vol. 20, n. 7-8, p. 665-684, 1995.

SELZNICK, Philip. Institutionalism "old" and "new". Administrative Science Quarterly, vol. 41, p. 270-277, 1996.

SHANK, John; FISHER, Joseph. Case study: target costing as a strategic tool. Sloan Management Review, Fall, vol. 41, n. 1, p. 73-82, 1999.

SHANK John; GOVINDARAJAN, Vijay. Strategic cost management: tailoring controls to strategies. Journal of Cost Management, autumn, p. 14-24, 1992.

SIMON, Herbert A. Administrative behavior: a study of decision-making process in administrative organization. New York: Free Press, 1976.

SIMONS, Robert. Accounting control systems and business strategy: an empirical analysis. Accounting, Organizations and Society, vol. 12, n. 4, p. 357-374, 1987.

SIMONS, Robert. The role of management control systems in creating competitive advantage: new perspectives. Accounting, Organizations and Society, vol. 15, n. 1-2, p. 127-143, 1990.

SIMONS, Robert. Strategic orientation and top management attention to control systems. Strategic Management Journal, vol. 12, n. 1, p. 49-63, 1991.

SIMONS, Robert. How new top managers use control systems as levers of strategic renewal. Strategic Management Journal, vol. 15, n. 3, p. 169-189, 1994.

SIMONS, Robert. Levers of control: how managers use innovative control systems to drive strategic renewal. Boston: Harvard Business School Press, 1995.

SITI-NABIHA, A. K.; SCAPENS, Robert W. Stability and change: an institutionalist study of management accounting change. Accounting, Auditing \& Accountability Journal, vol. 18, n. 1, p. 44-73, 2005.

SNOW, Charles, C.; HAMBRICK, Donald, C. Measuring organizational strategies: some theoretical and methodological problems. Academy of Management Review, vol. 5, n. 4, p. 527-538, 1980. 
SNOW, Charles, C.; HREBINIAK, Lawrence G. Strategy, distinctive competence and organizational performance. Administrative Science Quarterly, vol. 25, p. 317-336, 1980.

SOIN, Kim et al. ABC and organizational change: an institutional perspective. Management Accounting Research, vol. 13, n. 2, p. 249-271, 2002.

SOUTES, Dione O. Uma investigação do uso de artefatos da Contabilidade Gerencial por empresas brasileiras. 2006. 108 p. Dissertação (Mestrado em Controladoria e Contabilidade)- Faculdade de Economia, Administração e Contabilidade da Universidade de São Paulo.

SOUZA, Antônio M.; et al. Prática de contabilidade gerencial adotadas por subsidiárias brasileiras de empresas multinacionais. Revista de Contabilidade e Finanças, vol. 32, p. 4057, 2003.

SOUZA, Antônio M. et al. Práticas de gestão estratégica de custos: um estudo em uma empresa multinacional brasileira. Revista de Contabilidade e Organizações, vol. 4, n. 9, p. 145-167, 2010a.

SOUZA, Antônio M. et al. Planejamento e controle de custos: um estudo sobre as práticas adotadas por empresas industriais de Caxias do Sul - RS. Revista Contabilidade Vista e Revista, vol. 21, n. 2, p. 121-151, 2010b.

SOUZA, Marcos Antônio; et al. Utilização do custeio-meta por empresas brasileiras como estratégia de gestão: alguns estudos setoriais utilizando o método de causalidade de Granger. Revista de Contabilidade \& Finanças USP, São Paulo: Fipecafi, n. 39, p. 33-46, set/dez, 2005.

STONER, James A. F.; FREEMAN, R. Edward. Administração. Rio de Janeiro: Prentice Hall do Brasil, 1985.

SUCHMAN, Mark. Managing legitimacy: strategic and institutional approaches. The Academy of Management Review, vol. 20, p. 571-610, 1995.

SWENSON, Dan; et al. Best practices in target costing. Management Accounting Quarterly, vol. 4, n. 2, p. 12-22, 2003.

SWENSON, D.; et al. Using the CAM-I diagnostic to evaluate readiness for target costing. Cost Management, vol. 19, n. 3, p. 41-48, 2005.

TANI, Takeyuki; et al. Target cost management in Japanese companies: current state of the art. Management Accounting Research, vol. 5, n. 1, p. 67-81, 1994.

TANI, Takeyuki. Interactive control in target cost management. Management Accounting Research, vol. 6, n. 4, p. 399-414, 1995.

TILLEMA, Sandra. Towards an integrated contingency framework for MAS sophistication: case studies on the scopes of accounting instruments in Dutch power and gas companies. Management Accounting Research, vol. 16, n. 1, p. 101-129, 2005. 
TOLBERT, Pamela S.; ZUCKER, Lynne G. A institucionalização da teoria institucional. In: CLEGG, Stewart. R et al. (Org.). Handbook de Estudos Organizacionais: modelos de análise e novas questões em estudos organizacionais. Vol.1, São Paulo: Atlas, 2007.

TRIVIÑOS, Augusto N. Silva. Introdução à pesquisa em ciências sociais: a pesquisa qualitativa em educação. 1 ed. São Paulo: Atlas, 2008.

TSAMENYI, Mathew et al. Changes in accounting and financial information system in a Spanish electricity company: a new institutional theory analysis. Management Accounting Research, vol. 17, n. 4, p. 409-432, 2006.

VOLLMER, Hendrik. Management accounting as normal social science. Accounting, Organizations and Society, vol. 34, n. 1, p. 141-150, 2009.

WICKRAMASINGHE, Danture; ALAWATTAGE, Chandana. Management accounting change: approaches and perspectives. New York: Routledge, 2007.

WIJEWARDENA, Hema; DE ZOYSA, Anura. A comparative analysis of management accounting practices in Australia and Japan: an empirical investigation. The International Journal of Accounting, vol. 34, n. 1, p. 49-70, 1999.

WOODWARD, Joan. Industrial organization: theory and practice. Oxford: Oxford University Press, 1965.

YIN, Robert K. The case study crisis: some answers. Administrative Science Quarterly, vol. 26, n. 1, p. 58-65, 1981.

YIN, Robert K. Estudo de caso: planejamento e métodos. 4 ed. Porto Alegre: Bookman, 2010.

YOUNG, S. M.; SELTO, F. H. new manufacturing practices and cost management: a review of the literature and directions for research. Journal of Accounting Literature, vol. 10, p. 265-297, 1991.

ZUCKER, Lynne G. The role of institutionalization in cultural persistence. American Sociological Review, vol. 42, n. 5, p.726-743, 1977.

ZUCKER, Lynne G. The role of institutionalization in cultural persistence. . In: POWELL, Walter W.; DIMAGGIO, Paul J. (Orgs.). The new institutionalism in organizational analysis. Chicago: The University of Chicago Press, 1991. 


\section{APÊNDICE 1 - Roteiro de Entrevista}

\section{IDENTIFICAÇÃO}

1. Empresa:

2. Ramo de atuação (Tani et al., 1994, Dekker e Smidt, 2003):

4. Receita Operacional Bruta de 2010 (BNDES 2012, on line):

5. Nome do respondente:

6. Cargo ocupado:

\section{$\underline{\text { Primeira rodada de entrevistas }}$}

\section{Bloco 1 - Adoção e implementação do Custeio Alvo}

7. Adoção do Custeio Alvo:

(Objetivo: verificar se há indícios de adoção do Custeio Alvo pela empresa.)

7.1. A empresa possui processo de planejamento (antes do lançamento) e controle de custos, individualizado produto por produto, um a um, ainda que não seja para todos os produtos existentes?

( ) Sim.

( ) Não.

7.2. O processo de planejamento e controle de custos de cada produto começa com informações trazidas de fora da empresa, relativas ao preço máximo que pode ser praticado (pesquisa de preço dos concorrentes, de clientes, consumidores etc.)?

( ) Sim.

( ) Não.

7.3. A empresa estabelece uma meta individualizada para a margem a ser obtida com cada produto?

( ) Sim.

( ) Não.

7.4. A empresa apura o valor do custo máximo admissível para cada produto considerando o preço máximo que pode ser praticado e a margem objetivada?

( ) Sim.

( ) Não.

7.5. Se o custo estimado do produto for maior que o custo máximo admissível a empresa:

( ) Inicia um trabalho de gerenciamento de custos, ainda na etapa de pré-produção, para eliminar o custo excedente, mantendo suspenso o lançamento do produto até que o custo excedente seja equacionado.

( ) Inicia um trabalho de gerenciamento de custos para eliminar o custo excedente mas não suspende o lançamento do produto e entra no processo de produção.

( ) Lança o produto mas não inicia de imediato o trabalho de redução.

( ) Aborta o lançamento do produto. 
8. Em que ano foi adotado o Custeio Alvo?

(Objetivo: verificar há quanto tempo o mesmo foi adotado para poder relacioná-lo à questões históricas envolvidas no processo, por exemplo, época em que houve aumento de concorrência ou entrada de novos concorrentes, entrada em novos mercados ou outros)

9. Por que a empresa resolveu adotar o Custeio Alvo?

(Objetivo: auxiliar no levantamento de fatores que ainda não estejam relacionados na literatura, como os fatores das questões $10,11,12,13,48,49,50,51$ )

10. Na ocasião da adoção: (Ansari et al., 2006)

(Objetivo: verificar antecedentes relacionados à lucratividade que podem ter influenciado a adoção)

( ) Havia histórico de prejuízo ou de queda nos lucros.

( ) Havia histórico de queda na receita.

( ) Havia histórico de aumento de custos.

( ) Havia histórico de redução do market share.

( ) Havia pressão para aumentar a eficiência em relação aos custos.

( ) Havia pressão para aumentar o prestígio da empresa no mercado.

11. Na ocasião da adoção: (DiMaggio e Powell, 1983)

(Objetivo: verificar presença de antecedentes relacionados a isomorfismo mimético)

( ) Havia informação da adoção do Custeio Alvo pelos concorrentes.

( ) Havia informação da adoção por outras empresas da cadeia de valor.

( ) Houve algum tipo de consultoria que desencadeou o processo de adoção.

( ) Outros

12. Na ocasião da adoção: (DiMaggio e Powell, 1983)

(Objetivo: verificar presença de isomorfismo coercitivo)

( ) Havia pressão de outras empresas do grupo ou de outras unidades de negócio para a adoção do Custeio Alvo.

( ) Havia pressão para seguir ações de empresas líderes para propiciar redução de incertezas.

( ) Outros

13. Na ocasião da adoção houve um mandato oficial da alta gestão para iniciar o processo de adoção e implementação do Custeio Alvo? (Ansari et al., 2006)

(Objetivo: verificar o envolvimento da alta gestão com o processo de adoção)

( ) Sim.

( ) Não.

14. Na ocasião da adoção: (Ansari et al., 2006)

(Objetivo: verificar qual estratégia de implementação a empresa usou)

( ) Houve um plano piloto.

( ) Houve implementação parcial.

( ) outros 
15. Em relação à alta gestão: (Ansari et al., 2006)

(Objetivo: verificar o comprometimento e a participação da alta gestão na adoção e no processo do Custeio Alvo e confirmar se o mesmo é usado de forma interativa ou diagnóstica [Simons, 1990])

( ) Existiu comprometimento e envolvimento na adoção do Custeio Alvo.

Qual o tipo de participação da alta gestão na adoção?

( ) Ainda existe comprometimento e envolvimento com o processo do Custeio Alvo.

Qual o tipo de participação da alta gestão hoje?

16. Foram criados incentivos ligados ao processo do Custeio Alvo? Que tipo? (Ansari et al., 2006)

(Objetivo: verificar se houve algum tipo de compensação para o envolvimento dos funcionários no processo do Custeio Alvo como forma de torná-lo relevante para os funcionários, ou seja, tentar minimizar os efeitos negativos da mudança)

17. Que áreas da empresa estão envolvidas no processo do Custeio Alvo? (Ansari et al., 2006) (Objetivo: verificar quais áreas estão envolvidas atualmente na elaboração e condução do Custeio Alvo)

18. O Custeio Alvo já está totalmente implementado? (Ansari et al., 2006)

(Objetivo: verificar se alguma etapa da implementação ainda não foi efetivada para auxiliar na caracterização da institucionalização do Custeio Alvo)

( ) Sim.

( ) Não.

Em caso negativo o que falta?

19. Em relação ao processo de adoção e implementação:

(Objetivo: verificar se houve ou não resistência à mudança, principalmente nos casos em que se apresentar algum tipo de isomorfismo)

( ) Não houve resistência.

( ) Houve resistência mas não afetou o processo.

( ) Houve resistência e afetou o processo.

Em caso afirmativo de qual área:

20. Como essa questão foi resolvida?

(Objetivo: verificar as medidas tomadas pela empresa para contornar ou eliminar os problemas relativos à resistência)

21. Em relação aos objetivos e às metas estipuladas quanto ao que se quer atingir com o uso do Custeio Alvo: (Ansari et al., 2006)

(Objetivo: verificar se o processo do Custeio Alvo está atrelado a algum tipo de planejamento e aos objetivos e às metas da empresa. Isto pode caracterizar indícios de que o Custeio Alvo é considerado importante dentro do processo de planejamento)

( ) Não existem metas nem objetivos.

( ) Existem metas e objetivos.

Por exemplo: 
(Estudo dos elementos necessários à implementação do Custeio Alvo; Ansari et al., 2006)

\section{Técnico:}

22. Em relação à formação de equipes multifuncionais que participam do processo do Custeio Alvo: (Ansari et al., 2006 e Swenson et al., 2005)

(Objetivo: verificar como ocorre a formação das equipes necessárias no processo do Custeio Alvo como forma de caracterizar que o mesmo faz parte das atividades rotineiras da empresa)

( ) Existe a formação de equipes por projeto.

( ) Existe uma equipe permanente.

( ) Não existe formação de equipe.

Neste caso, quem participa do processo do Custeio Alvo:

23. Quem é o responsável pela gestão do processo do Custeio Alvo?

(Objetivo: verificar qual gestor está envolvido e é responsável pelo processo)

24. Em relação à participação de outras empresas no processo do Custeio Alvo: (Ansari et al., 2006)

(Objetivo: verificar se existe a participação de membros da cadeia de suprimentos e da cadeia de valor no processo e quem são eles)

( ) Existe participação de membros da cadeia de suprimentos de forma esporádica.

( ) Existe participação de membros da cadeia de suprimentos de forma constante em cada projeto.

( ) Existe participação de membros da cadeia de suprimentos de forma permanente.

Quem participa:

( ) Existe participação de outros membros da cadeia de valor.

Por exemplo:

25. Quem foram os responsáveis por padronizar os processos, as ferramentas utilizadas e pela divulgação dos resultados da implementação? (Ansari et al., 2006)

(Objetivo: verificar de quem é a responsabilidade pelo processo de implementação bem como auxiliar na caracterização da institucionalização)

26. Como são formadas e quem compõe as equipes (de produtos, de apoio, outras)? Quais são as tarefas? (Ansari et al., 2006)

(Objetivo: verificar aspectos da formação das equipes bem como auxiliar na caracterização da institucionalização)

( ) Existe equipe de produto.

Quem participa:

( ) Existe equipe de apoio.

Quem participa:

27. Em relação às equipes: (Ansari et al., 2006)

(Objetivo: verificar aspectos relacionados às equipes bem como auxiliar na caracterização da institucionalização) (tentar mapear os níveis na entrevista)

( ) Existe definição de responsabilidades entre as equipes e seus membros.

( ) Existe definição de accountability entre as equipes e seus membros.

( ) Existe definição de autoridade entre as equipes e seus membros.

( ) As equipes têm objetivos definidos em relação ao processo de Custeio alvo.

28. Existe comunicação entre as equipes e a alta gestão? Qual é o mecanismo usado para divulgação e disseminação das informações? (Ansari et al., 2006) 
(Objetivo: verificar aspectos da comunicação entre as equipes e a alta gestão bem como auxiliar na caracterização da institucionalização)

( ) Existe comunicação entre as equipes e a alta gestão.

As informações são divulgadas/disseminadas de que forma:

( ) Não existe comunicação entre as equipes e a alta gestão.

29. São usados no processo do Custeio Alvo: (Ansari et al., 2006 e Swenson et al., 2005)

(Objetivo: verificar quais ferramentas são usadas no processo de forma a averiguar o esforço para tentar atingir o custo alvo)

( ) Análise de requisitos, exigências e necessidades dos consumidores e dos clientes.

( ) Decomposição do custo dos componentes dos produtos, em tabelas.

( ) Estimativa de custos dos componentes dos produtos.

( ) Trade-off de custos entre os componentes.

( ) Monitoramento do status do Custeio Alvo.

( ) Engenharia de valor.

( ) Análise de valor.

Outros:

\section{Comportamental:}

30. Quanto à relação entre os membros das equipes: (Ansari et al., 2006)

(Objetivo: verificar existência de conflitos e a forma de resolvê-los bem como auxiliar na caracterização da institucionalização)

( ) Não existem conflitos.

( ) Existem conflitos.

De que forma são resolvidos:

31. A perspectiva do cliente foi acatada e adotada? Existe importância nos requisitos do cliente? (Ansari et al., 2006)

(Objetivo: verificar a importância do cliente no processo e auxiliar na caracterização da institucionalização)

( ) A perspectiva do cliente foi adotada pois seus requisitos são importantes para o processo.

(...) A perspectiva do cliente foi adotada parcialmente.

( ) A perspectiva do cliente não foi adotada.

\section{Cultural:}

32. Em relação aos aspectos culturais: (Ansari et al., 2006)

(Objetivo: verificar aspectos culturais envolvidos no processo bem como auxiliar na caracterização da institucionalização)

( ) Existe preocupação com o compartilhamento de informações entre os participantes (por exemplo, informações sobre os clientes).

( ) Existe confiança na relação entre os participantes das equipes multifuncionais (internos e externos à empresa).

( ) Existe o encorajamento para que a tomada de decisão seja baseada em fatos.

\section{Político:}

33. Em relação aos aspectos políticos: (Ansari et al., 2006)

(Objetivo: verificar aspectos políticos envolvidos no processo bem como auxiliar na caracterização da institucionalização)

( ) A implementação do Custeio Alvo provocou algum tipo de mudança no controle sobre recursos e conhecimento (aumentou ou diminuiu o controle, por exemplo). 
( ) O processo afetou o poder e os padrões de influência na empresa (houve deslocamento de poder entre os cargos e/ou entre as pessoas na empresa, por exemplo).

Como foram resolvidos os problemas decorrentes dessas mudanças políticas:

\section{Comunicação:}

34. Em relação à comunicação envolvida no processo: (Ansari et al., 2006)

(Objetivo: verificar aspectos relacionados à comunicação no processo e auxiliar na caracterização da institucionalização)

( ) Existiu um plano de comunicação para informar sobre o processo do Custeio Alvo na sua adoção.

( ) Ainda existe plano de comunicação para informar os resultados do processo do Custeio Alvo quando de sua utilização.

( ) O plano é formalizado.

( ) Existe manual de procedimentos.

35. Na adoção do Custeio Alvo houve algum dos seguintes tipos de comunicação para esclarecimento dos participantes: (Ansari et al., 2006)

(Objetivo: verificar que tipo de planos de comunicação foi usado bem como auxiliar na caracterização da institucionalização)

( ) Fóruns ou formas de análise de feedback sobre melhorias no processo do Custeio Alvo.

( ) Palestras.

( ) Cursos.

( ) Treinamentos.

( ) Outros:

36. Em relação à utilização do Custeio Alvo ainda existe alguns dos seguintes tipos de comunicação para esclarecimento dos participantes: (Ansari et al., 2006)

(Objetivo: verificar que tipo de planos de comunicação ainda é usado bem como auxiliar na caracterização da institucionalização)

( ) Fóruns ou formas de análise de feedback sobre melhorias no processo do Custeio Alvo.

( ) Palestras.

( ) Cursos.

( ) Treinamentos.

( ) Outros:

\section{Institucionalização:}

37. Quem são os principais usuários das informações e do aprendizado extraídas do processo do Custeio Alvo?

(Objetivo: verificar quem é (são) o (s) usuário (s) da informação bem como auxiliar na caracterização da institucionalização)

38. Em que tipos de decisões as informações extraídas do processo do Custeio Alvo são usadas?

(Objetivo: verificar em que decisões a informação é usada e auxiliar na caracterização da institucionalização) 
39. Em relação ao processo do Custeio Alvo: (Ansari et al., 2006)

(Objetivo: verificar se o processo de Custeio Alvo está associado às atividades rotineiras da empresa, auxiliando na caracterização da internalização do processo de institucionalização)

( ) Os funcionários envolvidos na geração de informações estão acostumados com o processo.

( ) As atividades relacionadas ao processo do Custeio Alvo fazem parte das rotinas do dia a dia.

( ) O processo do Custeio Alvo está incorporado nas atividades rotineiras da empresa.

40. Quanto à utilização das informações relativas ao Custeio Alvo: (Ansari et al., 2006)

(Objetivo: verificar a frequência de utilização das informações do Custeio Alvo bem como auxiliar na caracterização da institucionalização)

( ) É usada em cada novo projeto.

( ) É usada em cada novo re-projeto.

( ) É usada apenas em determinados projetos.

Quais e quando:

41. Com que frequência novos produtos são lançados ou remodelados? (Ansari et al., 2006) (Objetivo: verificar a relação entre a frequência de utilização do Custeio Alvo e a frequência de lançamento de novos produtos e auxiliar na caracterização da institucionalização)

42. Qual é o tempo do ciclo de vida médio desses produtos? (Ansari et al., 2006)

(Objetivo: verificar a relação entre a frequência de utilização do Custeio Alvo e o ciclo de vida médio dos produtos bem como auxiliar na caracterização da institucionalização)

43. Em qual unidade da empresa e em qual setor está situada formalmente a estrutura necessária para o desenvolvimento do processo relativo ao Custeio Alvo? (Ansari et al., 2006) (Objetivo: verificar onde está situada a estrutura física/humana bem como auxiliar na caracterização da institucionalização)

44. Em relação às medidas de desempenho: (Ansari et al., 2006)

(Objetivo: verificar se o processo do Custeio Alvo está, de alguma forma, atrelado a algum tipo de medida de desempenho bem como se existe recompensa para o pessoal envolvido no processo)

( ) Existem medidas de desempenho para avaliar o processo do Custeio Alvo.

( ) O processo do Custeio Alvo fornece algum tipo de medida que pode ser incorporada a alguma medida de desempenho (por exemplo, no Balanced Scorecard).

( ) Existe recompensa ou compensação do pessoal envolvido no processo do Custeio Alvo.

\section{Bloco 2 - Fatores Contingentes}

\section{Variável Ambiente}

(adaptado de Gordon e Narayanan, 1984; baseado em Ax et al. 2008)

45. Escolha a opção que mais se aproxima com as características de concorrência e de incerteza ambiental em que a empresa está inserida, considerando: 
1. De intensidade insignificante (muito estável)

2. Extremamente intenso (muito dinâmico)

\begin{tabular}{|l|l|}
\hline Intensidade da Concorrência & \\
\hline a. Nível de intensidade da concorrência que a empresa enfrenta & \\
\hline b. Frequência de lançamento de novos produtos ou serviços & \\
\hline c. Nível de estabilidade ou de dinamismo do ambiente externo & \\
\hline d. Frequência de novas descobertas científicas na área & \\
\hline e. Grau de restrições regulatórias (legais, políticas ou econômicas) & \\
\hline
\end{tabular}

1. Baixa previsibilidade (muito dinâmico)

2. Alta previsibilidade (muito estável)

Incerteza Ambiental Percebida (PEU)

a. Previsibilidade das atitudes da concorrência

b. Previsibilidade das preferências dos cliente

\section{Variável Estratégia}

(Adaptado de Cinquini e Tenucci, 2010; baseado em Miles e Snow, 1978, Snow e Hrebiniak, 1980)

46. Qual dos modelos abaixo mais se aproxima das características estratégicas da empresa:

\begin{tabular}{|l|l|}
\hline Características de Mercado & \\
\hline A empresa tenta localizar e manter um nicho seguro em uma área relativamente \\
estável de produto ou serviço. Tende a oferecer uma gama mais limitada de \\
produtos ou serviços que seus concorrentes e tenta proteger seu domínio \\
oferecendo qualidade superior, serviço superior, preços mais baixos, e assim por \\
diante. Frequentemente não está na vanguarda dos desenvolvimentos do setor e \\
tende a ignorar as mudanças que não têm influência direta sobre as atuais áreas de \\
operação, ao invés disso, se concentra em fazer o melhor trabalho possível em uma \\
área limitada. (defenders) \\
\hline Opera dentro de um amplo domínio de produto/mercado que passa por redefinição \\
periódica. A empresa tem como valor ser a "primeira" em novos produtos e áreas \\
de mercado, mesmo que nem todos estes esforços se revelem altamente rentáveis. \\
A empresa responde rapidamente a sinais iniciais relativos às áreas de \\
oportunidade essas respostas frequentemente conduzem a uma nova rodada de \\
ações competitivas. Entretanto, este tipo de empresa pode não manter força de \\
mercado em todas as áreas em que entra. (prospectors) \\
\hline A empresa tenta manter uma linha estável, limitada de produtos ou serviços, \\
enquanto ao mesmo tempo move-se rapidamente para seguir um conjunto \\
cuidadosamente selecionado dos novos desenvolvimentos mais promissores do \\
setor. Raramente é a "primeira" em novos produtos ou serviços. No entanto, \\
através do monitoramento cuidadoso das ações dos principais concorrentes em \\
áreas compatíveis com a sua base estável de produto/mercado, a empresa pode \\
frequentemente estar em "segundo" com um produto ou serviço com maior \\
eficiência em custos. (analysers) \\
\hline A empresa parece não ter uma orientação de produto/mercado consistente. \\
Geralmente não é tão agressiva na manutenção de produtos e mercados \\
estabelecidos quanto alguns dos seus concorrentes, nem está disposta a assumir \\
tantos riscos como os outros concorrentes. Em vez disso, responde naquelas áreas \\
em que é forçada por pressões ambientais. (reactors)
\end{tabular}


(adaptado de Guilding, 1999; baseado em Gupta e Govindarajan, 1984)

47. Qual dos modelos abaixo mais se aproxima da estratégia em relação ao ciclo de vida:

\begin{tabular}{|l|l|}
\hline Ciclo de Vida & \\
\hline $\begin{array}{l}\text { a. Aumentar vendas e market share e estar dispostos a aceitar baixos retornos } \\
\text { sobre o investimento a curto e médio prazos, se necessário. (build) }\end{array}$ & \\
\hline b. Manter market share e obter um retorno razoável sobre o investimento.(hold) & \\
\hline $\begin{array}{l}\text { c. Maximizar a rentabilidade e fluxo de caixa no curto e médio prazo, estar } \\
\text { dispostos a sacrificar market share se necessário. (harvest) }\end{array}$ & \\
\hline
\end{tabular}

(Adaptado de Hibbets et al., 2003; baseado em Porter, 1989)

48. Qual dos modelos abaixo mais se aproxima da estratégia em relação ao posicionamento de mercado da empresa:

\begin{tabular}{|l|l|}
\hline Posicionamento de Mercado & \\
\hline a. Objetiva fornecer um produto de baixo custo e competir com base no preço de & \\
venda. (baixo custo) & \\
\hline $\begin{array}{l}\text { b. Objetiva fornecer um produto de alta qualidade e diferenciar o produto em } \\
\text { relação aos concorrentes. (diferenciação) }\end{array}$ & \\
\hline
\end{tabular}

Bloco 3 - Estágios do Processo de Institucionalização

49. Existiu algum tipo de disseminação de novas idéias ou ideais em relação ao modo de fazer as coisas quando da adoção do Custeio Alvo? (Hasselbladh e Kallinikos, 2000)

(por exemplo, voltar o foco para o cliente, usar custos orientado pelo mercado, outros).

(Objetivo: verificar aspectos relativos ao primeiro estágio do processo de institucionalização conjuntamente com a questão 33)

50. Houve mudança de discurso em decorrência disso? O Custeio Alvo e seus princípios foram incorporados no discurso da organização? (Hasselbladh e Kallinikos, 2000)

(Objetivo: verificar aspectos relacionados ao segundo estágio do processo de institucionalização conjuntamente com as questões $27,29,30,36,37,38$ e 39)

51. Que tipos de relatórios são emitidos regularmente utilizando-se as informações do Custeio Alvo? Houve mudança nos relatórios contábeis gerenciais formais ou informais com a adoção do Custeio Alvo? (Hasselbladh e Kallinikos, 2000)

(Objetivo: verificar aspectos relacionados ao terceiro estágio do processo de institucionalização conjuntamente com as questões 40, 41, 43, 44, 45)

\section{$\underline{\text { Segunda rodada de entrevistas }}$}

\section{Bloco 1 - Fatores Contingentes}

\section{Variável Estrutura}

(adaptado de Gordon e Narayanan, 1984)

52. Escolha a opção que mais se aproxima do nível de delegação de autoridade para os gestores, considerando: 
1. Sem delegação (decisão totalmente centralizada)

2. Completa delegação (decisão totalmente descentralizada)

\begin{tabular}{|l|l|}
\hline Classes de Decisão & \\
\hline a. Lançamento de novos produtos & \\
\hline b. Contratação e demissão de pessoal da gestão & \\
\hline c. Seleção de investimentos relevantes & \\
\hline d. Alocação de verba orçamentária & \\
\hline e. Formação de preços & \\
\hline
\end{tabular}

53. Escolha a opção que mais se aproxima da empresa considerando:

1. É uma função claramente especificada, com critérios de desempenho bem estabelecidos (função centralizada)

2. Não há descrição ou especificação formal (função descentralizada)

\section{Formalização}

a. Especificação de cargos e funções

54. Escolha a opção que mais se aproxima da empresa considerando:

1. Descrição detalhada das tarefas e direitos dos funcionários (centralização)

2. Somente questões básicas são delineadas (descentralização)

\begin{tabular}{|l|l|}
\hline Formalização & \\
\hline a. Manual de procedimentos & \\
\hline
\end{tabular}

55. Escolha a opção que mais se aproxima da empresa em relação às principais decisões operacionais, considerando:

1. Nível de executivo sênior (centralização)

2. Níveis gerenciais mais baixos (descentralização)

\begin{tabular}{|l|l|}
\hline Nível de decisões operacionais & \\
\hline a. Decisões operacionais & \\
\hline
\end{tabular}

56. Escolha a opção que mais se aproxima do estilo de gestão, considerando:

1. Espera-se conformidade com um estilo uniforme (centralização)

2. Pode variar do muito formal para o informal (descentralização)

\section{Estilo gerencial}

a. Estilo de gestão

(adaptado de Hansen e Van der Stede, 2004, com base em Junqueira, 2010 e Abernethy e Lillis, 1995)

57. Escolha a opção que mais se aproxima da estrutura organizacional, considerando:

1. Pouca utilização

2. Utilização intensa

\begin{tabular}{|l|l|}
\hline Estrutura & \\
\hline a. Estrutura funcional (funções definidas pela especialização das atividades) & \\
\hline $\begin{array}{l}\text { b. Estrutura divisional (certas atividades sendo executadas em diferentes } \\
\text { divisões ou em diferentes departamentos) }\end{array}$ & \\
\hline $\begin{array}{l}\text { c. Estrutura é matricial (departamentalização híbrida com formação de equipes } \\
\text { funcionais cruzadas com característica temporária) }\end{array}$ & \\
\hline d. Estrutura é flexível e permite uma rápida adaptação às mudanças ambientais & \\
\hline
\end{tabular}


(baseado em Baines e Langfield-Smith, 2003; Abernethy e Lillis, 1995 e Junqueira, 2010)

58. Escolha a opção que mais se aproxima da forma de trabalho, considerando:

1. Pouca utilização

2. Utilização intensa

\begin{tabular}{|l|l|}
\hline Forma de Trabalho & \\
\hline a. Utilização de equipes & \\
\hline b. Equipes multifuncionais constituídas para cada projeto e produto & \\
\hline c. Várias equipes multifuncionais trabalhando permanentemente & \\
\hline $\begin{array}{l}\text { d. Uma equipe multifuncional permanente, com membros de vários } \\
\text { departamentos }\end{array}$ & \\
\hline e. Estimulo à cultura participativa & \\
\hline
\end{tabular}

Variável Tecnologia

Tecnologia da Informação (adaptado de Krumwiede, 1998)

59. Escolha a opção que mais se aproxima da tecnologia da informação usada, considerando:

1. Baixa intensidade

2. Alta intensidade

\begin{tabular}{|l|l|}
\hline Tecnologia da Informação - Qualidade & \\
\hline $\begin{array}{l}\text { a. Integração do sistema de informação entre os setores (informações e } \\
\text { acessibilidade) }\end{array}$ & \\
\hline b. O sistema é amigável considerando vários tipos de usuários & \\
\hline $\begin{array}{l}\text { c. Uma ampla variedade de dados de custos e desempenho é disponibilizada no } \\
\text { sistema }\end{array}$ & \\
\hline $\begin{array}{l}\text { d. Dados da produção e outros operacionais são atualizados em tempo real (em } \\
\text { oposição à atualização periódica) }\end{array}$ & \\
\hline
\end{tabular}

Tecnologia da Informação (adaptado de Hyvönen, 2007, com base em Junqueira, 2010 e Espejo, 2008)

60. Escolha a opção que mais se aproxima da tecnologia de informação usada, considerando:

1. Pouca utilização

2. Utilização intensa

\begin{tabular}{|l|l|}
\hline Tecnologia da Informação & \\
\hline a. Comércio eletrônico (venda de produtos pela internet) & \\
\hline b. Gerenciamento de relação com cliente (CRM) & \\
\hline c. Gerenciamento da cadeia de suprimentos (SCM) & \\
\hline d. Armazenamento de dados (data warehouse) & \\
\hline e. Troca de dados de forma eletrônica (EDI) & \\
\hline f. Sistema integrado de gestão (ERP) & \\
\hline
\end{tabular}

Tecnologia da Produção

Complexidade (adaptado de Krumwiede, 1998)

61. Escolha a opção que mais se aproxima da tecnologia de produção usada, considerando:

1. Pouca utilização

2. Utilização intensa

\begin{tabular}{|l|l|}
\hline Diversidade de Produtos e sistema de Produção & \\
\hline a. Produtos padronizados & \\
\hline b. Produtos especializados fabricados em pequenos lotes & \\
\hline
\end{tabular}




\begin{tabular}{|l|l|}
\hline $\begin{array}{l}\text { c. Diversificação da linha de produtos (apontar aproximadamente o número de } \\
\text { modelos fabricados) }\end{array}$ & \\
\hline d. Produtos por encomenda (únicos ou em baixos volumes) & \\
\hline e. Produção em massa (volume alto) & \\
\hline f. Fluxo contínuo de produção (pouca flexibilidade) & \\
\hline g. Fluxo de produção em série (com maior grau de flexibilidade) & \\
\hline h. Repetitividade das atividades fabris & \\
\hline i. Produção empurrada (controlado pelo PCP) & \\
\hline j. Produção puxada (demanda do cliente) & \\
\hline
\end{tabular}

62. Escolha a opção que mais se aproxima do ambiente de produção, considerando:

1. Pouca utilização (não utilização da produção enxuta)

2. Utilização intensa (utilização de produção enxuta)

\begin{tabular}{|l|l|}
\hline Complexidade do ambiente de produção & \\
\hline a. O tempo de setup vem sendo reduzido significativamente & \\
\hline $\begin{array}{l}\text { b. As matérias primas, componentes, partes e peças são recebidas de acordo com } \\
\text { a necessidade, sem formação de estoques }\end{array}$ & \\
\hline c. As matérias primas e componentes são recebidos em grandes lotes & \\
\hline d. O layout é organizado em forma de células de produção flexíveis & \\
\hline e. As práticas de produção são orientadas para a eliminação de estoques & \\
\hline $\begin{array}{l}\text { f. A produção é interrompida automaticamente sempre que é detectada uma } \\
\text { falha no processo }\end{array}$ & \\
\hline g. São exigidos treinamento em várias funções & \\
\hline h. É exigida rotatividade de funções & \\
\hline
\end{tabular}

Tecnologias contemporâneas (adaptado de Baines e Langfield-Smith, 2003, baseado em Guerra, 2007)

63. Escolha a opção que mais se aproximadas tecnologias usadas, considerando:

1. Pouca utilização

2. Utilização intensa

\begin{tabular}{|l|l|}
\hline Uso de tecnologias contemporâneas & \\
\hline a. Gestão da qualidade total (TQM) & \\
\hline b. Produção Just in time & \\
\hline c. Seis sigma & \\
\hline d. Projeto auxiliado por computador (CAD) & \\
\hline e. Manufatura integrada por computador (CIM) & \\
\hline f. Manufatura auxiliada por computador (CAM) & \\
\hline g. Sistemas de produção flexíveis & \\
\hline h. Planejamento de requisições de materiais & \\
\hline i. Planejamento dos recursos da produção & \\
\hline j. Produção lean & \\
\hline k. ISO & \\
\hline l. Kanban & \\
\hline m. Kaizen & \\
\hline
\end{tabular}




\section{Bloco 2 - Uso do Sistema}

(Adaptado de Simons, 1995, baseado em Ferreira e Otley (2006)

64. Escolha a opção que mais se aproxima da forma de uso do Custeio Alvo, considerando:

1. Pouca utilização

2. Utilização intensa

\begin{tabular}{|l|l|}
\hline Uso do Custeio Alvo para & \\
\hline a. Estabelecer metas & \\
\hline b. Alinhar medidas de desempenho com prioridades e metas estratégicas & \\
\hline c. Modelar incentivos de acordo com o desempenho & \\
\hline d. Revisar regularmente relatórios de exceção & \\
\hline e. Acompanhar desvios e exceções significantes & \\
\hline f. Sinalizar áreas estratégicas chaves & \\
\hline g. Melhoria contínua (aprendizado pela experiência) & \\
\hline h. Discussão de dados com gestores responsáveis de modo construtivo & \\
\hline i. Desafio e debate contínuo dos dados, suposições e planos de ação & \\
\hline j. Construir folgas nas metas & \\
\hline k. Medir variáveis não relacionadas às prioridades e metas estratégicas & \\
\hline l. Uso como fonte de poder político e influência & \\
\hline
\end{tabular}

\section{Bloco 3 - Desempenho do Sistema}

(Aguiar e Frezatti, 2007; baseado em Rai et al., 2002)

65. Escolha a opção que mais se aproxima da sua opinião, considerando:

1. Baixo (pouco satisfeito)

2. Alto (muito satisfeito)

\section{Satisfação do usuário}

a. Grau de satisfação em relação aos resultados do Custeio Alvo

66. Escolha a opção que mais se aproxima da sua opinião, considerando o nível de impacto:

1. Baixo (baixo impacto)

2. Alto (alto impacto)

\begin{tabular}{|l|l|}
\hline Utilidade percebida (Impacto individual) & \\
\hline $\begin{array}{l}\text { a. O uso do Custeio Alvo capacita as pessoas para desempenhar suas atividades } \\
\text { de modo mais eficiente }\end{array}$ & \\
\hline b. O uso do Custeio Alvo melhora meu desempenho no trabalho & \\
\hline c. O uso do Custeio Alvo aumenta a capacidade de tomar decisões & \\
\hline d. O uso do Custeio Alvo aumenta minha eficácia no trabalho & \\
\hline e. O uso do Custeio Alvo torna mais fácil meu trabalho & \\
\hline f. O uso do Custeio Alvo é útil em meu trabalho & \\
\hline
\end{tabular}

(baseado em Aguiar e Frezatti, 2007; DeLone e McLean, 1992)

67. Escolha a opção que mais se aproxima da sua opinião, considerando o nível de impacto:

1. Baixo (baixo impacto)

7. Alto (alto impacto) 


\begin{tabular}{|l|l|}
\hline Utilidade percebida (Impacto individual) & \\
\hline a. Grau de dependência do Custeio Alvo em minhas atividades & \\
\hline $\begin{array}{l}\text { b. O uso do Custeio Alvo oferece melhor entendimento do contexto da tomada } \\
\text { de decisão }\end{array}$ & \\
\hline c. O uso do Custeio Alvo produz mudança nas minhas atividades & \\
\hline $\begin{array}{l}\text { d. O uso do Custeio Alvo mudou minha percepção sobre a utilidade de um } \\
\text { sistema }\end{array}$ & \\
\hline $\begin{array}{l}\text { e. O uso do Custeio Alvo tem possibilitado atingir as metas estabelecidas pela } \\
\text { empresa }\end{array}$ & \\
\hline $\begin{array}{l}\text { f. As decisões tomadas com base nas informações do Custeio Alvo têm impacto } \\
\text { nas atividades dos funcionários }\end{array}$ & \\
\hline
\end{tabular}

68. Por que o uso do Custeio Alvo é importante? 
APÊNDICE 2 - Matriz de Avaliação

Caso:Alfa

Documento: Entrevista - presidente da Alfa do Brasil (A)

\begin{tabular}{|c|c|c|c|c|}
\hline Tema & Frequência & Ocorrência (nos textos) & Co-ocorrência & Análise em relação às categorias e à teoria \\
\hline \multicolumn{5}{|c|}{$\begin{array}{l}\text { Processo CA e } \\
\text { institucionaliza } \\
\text { ção }\end{array}$} \\
\hline Uso do CA & & usa & & \\
\hline $\begin{array}{l}\text { Por que usa } \\
\text { (objetivo) }\end{array}$ & $\begin{array}{l}\text { Lucro } \\
2 \text { vezes } \\
\text { Resultado } \\
3 \text { vezes }\end{array}$ & $\begin{array}{l}\text { "Para avaliar nosso lucro e nosso orçamento." } \\
\text { "normalmente a gente utiliza isso no } \\
\text { lançamento de novos produtos." (B) }\end{array}$ & $\begin{array}{l}\text { Fator } \\
\text { econômico e } \\
\text { Utilização das } \\
\text { informações } \\
\text { Uso } \\
\text { diagnóstico } \\
\text { coupling } \\
\text { Utilização }\end{array}$ & $\begin{array}{l}\text { O CA está amarrado ao orçamento e ao lucro e } \\
\text { é usado para avaliação, o que pode indicar que } \\
\text { é usado para controle. Usado para } \\
\text { acompanhamento e avaliação de resultados. } \\
\text { O uso para avaliar orçamento e lucro indica o } \\
\text { tipo de uso diagnóstico. } \\
\text { Indica que o CA não é elaborado apenas para } \\
\text { prestação de contas para a matriz, mas sim que } \\
\text { é utilizado pela Alfa. Isso remete à resposta do } \\
\text { tipo aceitação (coupling). Uso para } \\
\text { lançamento de produtos. }\end{array}$ \\
\hline $\begin{array}{l}\text { Envolvimento } \\
\text { com o processo } \\
\text { do CA }\end{array}$ & & $\begin{array}{l}\text { "nós temos uma reunião mensal checando o } \\
\text { custo de todos os setores, checando resultado } \\
\text { e também o custo que está sendo usado para o } \\
\text { resultado financeiro. Que diretamente está } \\
\text { ligado e mensalmente nós checamos o } \\
\text { resultado financeiro e sempre tem informação } \\
\text { periódica." }\end{array}$ & $\begin{array}{l}\text { Fator } \\
\text { econômico } \\
\text { Uso } \\
\text { diagnóstico } \\
\text { Uso interativo } \\
\text { Fator } \\
\text { econômico }\end{array}$ & $\begin{array}{l}\text { Acompanhamento pessoal do processo de } \\
\text { avaliação de resultado e de acompanhamento } \\
\text { dos custos, indicando que é usado para } \\
\text { controle. (não parece ser usado o } \\
\text { gerenciamento por exceção). } \\
\text { Envolvimento no processo, indicando o uso } \\
\text { interativo. } \\
\text { Resultado financeiro } \\
\text { Custo }\end{array}$ \\
\hline
\end{tabular}

